Axel Hennighausen

Wegekostenfinanzierung

und Lenkung im

deregulierten

europäischen

Verkehrsmarkt 


\section{Wegekostenfinanzierung und Lenkung im deregulierten europäischen Verkehrsmarkt}

Der Europäische Binnenmarkt hat im Zusammenhang mit der Liberalisierung der Verkehrsmärkte zu einem intensiveren innereuropäischen Warenaustausch geführt. Neben die positiven Aspekte dieser Entwicklung treten insbesondere für Transitländer umwelt- und verkehrspolitische Probleme. Diese Arbeit untersucht allokationstheoretisch und mit Modellen aus der Theorie des Steuerwettbewerbs, welche Optionen der Europäischen Union und ihren Mitgliedsländern zur Verfügung stehen, um das Dilemma aus Handelsgewinnen einerseits und steigenden Verkehrsproblemen andererseits aufzulösen. Von besonderer Bedeutung ist dabei die Frage, welche Instrumente den Ländern der EU einen möglichst weiten verkehrspolitischen Handlungsspielraum zulassen, ohne dabei unnötige Handelshemmnisse aufzubauen.

Axel Hennighausen wurde am 25.10.1970 in Bad Hersfeld geboren. Ab 1990 studierte er Volkswirtschaftlehre an der Universität Göttingen. Nach Abschluß des Examens 1995 war der Autor wissenschaftlicher Mitarbeiter am Volkswirtschaftlichen Seminar der Universität Göttingen. Seit 2001 ist er Referent bei der Deutschen Bahn. 
Wegekostenfinanzierung und Lenkung im deregulierten europäischen Verkehrsmarkt 


\section{Cege-Schriften}

Center for Globalization and Europeanization of the Economy Zentrum für Globalisierung und Europäisierung der Wirtschaft Goorg-August-Universitüt Göttingon

\section{Band 3}

Herausgegeben von Wolfgang Benner, Günter Gabisch, Jörg GüBefeldr, Andreas Haufler, Helmut Hesse, Hans-Joachim Jarchow, Renate Ohr, Helga Pollak, Peter Rühmann, Hermann Sautter, Stefan Tangermann und Wilholm H. Wacker

Verantworlliche Herousgeberin für diesen Band:

Holga Pollak

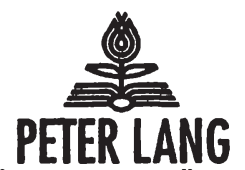

Frankfurt am Main - Berlin - Bern - Bruxelles - Now York - Oxford - Wien 


\section{Axel Hennighausen}

\section{Wegekostenfinanzierung und Lenkung im deregulierten europäischen Verkehrsmarkt}

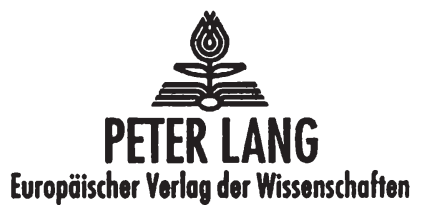


Die Deutsche Bibliothek - CIP-Einheitsaufnahme

Hennighausen Axel:

Wegekostenfinanzierung und Lenkung im deregulierten europäischen Verkehrsmarkt / Axel Hennighausen. - Frankfurt am Main ; Berlin ; Bern ; Bruxelles ; New York ; Oxford ; Wien : Lang, 2002

(CeGe-Schriften; Bd. 3)

Open Access: The online version of this publication is published on www.peterlang.com and www.econstor.eu under the international Creative Commons License CC-BY 4.0. Learn more on how you can use and share this work: http://creativecommons.org/ licenses/by/4.0.

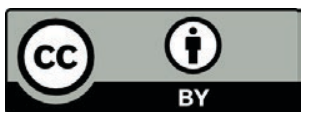

This book is available Open Access thanks to the kind support of ZBW - Leibniz-Informationszentrum Wirtschaft.

Zugl.: Gottingen, Univ., Diss., 2001

ISBN 3-631-39805-0

Gedruckt auf alterungsbestăndigem, săurefreiem Papier.

D7

ISSN 1617-741X

ISBN3-631-39805-0

ISBN 978-3-631-75701-7 (eBook)

C Peter Lang GmbH

Europäischer Verlag der Wissenschaften

Frankfurt am Main 2002

Alle Rechte vorbehalten.

Das Werk einschließlich aller seiner Teile ist urheberrechtlich geschutzt. Jede Verwertung außerhalb der engen Grenzen des Urheberrechtsgesetzes ist ohne Zustimmung des Verlages unzulässig und strafbar. Das gilt insbesondere fur Vervielfaltigungen, Ubersetzungen, Mikroverfilmungen und die Einspeicherung und Verarbeitung in elektronischen Systemen.

Printed in Germany 123457

www.peterlang.de 


\section{Vorwort der verantwortlichen Herausgeberin}

In den neunziger Jahren des letzten Jahrhunderts sind im Zusammenhang mit der Vollendung des Europäischen Binnenmarktes auch die zuvor stark regulierten und abgeschotteten Verkehrsmärkte liberalisiert worden. Eine erhebliche Zunahme des grenzüberschreitenden Warenverkehrs und insbesondere des Straßengüterverkehrs war die Folge. Auf Grund ihrer zentralen Lage im Herzen Europas ist die Bundesrepublik Deutschland von solchen Prozessen besonders betroffen.

Die genannte Entwicklung unterstreicht die Notwendigkeit, die Gestaltung der Verkehrsordnungspolitik und die am Straßenverkehr anknüpfende Steuerpolitik auch wissenschaftlich immer wieder auf den Prüfstand zu stellen. Aus der komplexen Problematik greift die vorliegende Studie zwei bedeutsame verkehrspolitische Aufgaben heraus: Erstens geht es um die allokationseffiziente Finanzierung der Straßeninfrastruktur, also vor allem um die fiskalische Seite der Verkehrsbesteuerung, zweitens um die von einer optimalen Gestaltung noch weit entfernte Integration der vielschichtigen Umweltbelastungen in die Verkehrspolitik und die Verkehrsbesteuerung.

Der Ist-Zustand der Verkehrspolitik in der Europäischen Union erweist sich für diese Aufgabe als unbefriedigend im Vergleich zu den staatlichen Instrumenten, die die Allokationstheorie angesichts des typischen „Marktversagens“ im Verkehrsbereich empfiehlt. Dies gilt, wie die Studie mit Hilfe theoretischer Modellansätze und empirisch-institutioneller Aufbereitungen nachweist, schon für national abgeschottete Verkehrsmärkte, erst recht aber für die Situation nach der Marktöffnung. Die theoretisch gestützten, aber auch die Praktikabilität berücksichtigenden Verbesserungsvorschlage, die dem Gesetzgeber schließlich unterbreitet werden, richten sich zum Teil an die Institution der Europäischen Union selbst, zum Teil an die Mitgliedsstaaten: Sie umfassen einerseits eine EUeinheitliche mehrgliedrige Schwerverkehrsabgabe und die Bewirtschaftung von Durchfahrtsrechten durch die EU, andererseits verschiedene differenzierte ordnungspolitische Maßnahmen und Abgaben auf Mineralöl, LKW-Erwerb und Schwerverkehr auf nationaler Ebene.

Die Publikation der Studie in der Schriftenreihe des Centrums für Globalisierung und Europäisierung (CeGe) soll dem Nachweis europäisch orientierter finanzwissenschaftlicher Forschung an der Universität Göttingen dienen. Sie soll darüber hinaus das Augenmerk politischer Entscheidungsträger darauf lenken, daß Wissenschaft auch Beiträge zur Lösung konkreter Problemstellungen zu erbringen vermag.

Helga Pollak 
Axel Hennighausen - 978-3-631-75701-7

Downloaded from PubFactory at 01/11/2019 02:45:58AM

via free access 
Obwohl ich als einzelner den Inhalt dieser Arbeit zu verantworten habe, ist sie in gewisser Weise auch das Werk vieler Kollegen und Freunde. Und was am Ende bleibt ist weniger die Promotion selbst als die gemeinsame Zeit, die ich mit diesen in Göttingen verbracht habe.

Deswegen bis hierher vielen Dank an: Vor allem Johannes für gute Ratschläge, Axel T., Holger, Kai und Klaus, die Unabsteigbaren, Sara, Kerstin, Ann Katrin, Ute, Tim, Frank, Alexandra, Diedrich Mann, Axel G., Matthias W. und viele andere. Und last, but not least Anke.

Bedanken möchte ich mich auch bei Prof. Dr. Haufler für seine Unterstützung und Frau Paschke, die mir einen großen Teil der täglich anfallenden Arbeit abgenommen hat.

Widmen möchte ich diese Arbeit meinen Eltern, die sicher während meiner Promotionsphase ein gerutteltes $\mathrm{Maß}$ an Geduld und Verständnis aufzubringen hatten. Ich kann aber nicht garantieren, daß es danach besser wird.

Axel Hennighausen 
Axel Hennighausen - 978-3-631-75701-7

Downloaded from PubFactory at 01/11/2019 02:45:58AM

via free access 


\section{Inhaltsverzeichnis}

1 EINLEITUNG ................................................................................................. 15

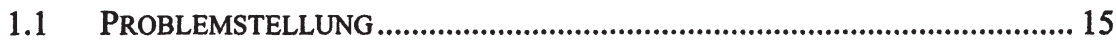

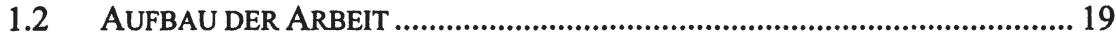

\section{2 ÖKONOMISCHE BESONDERHEITEN DES} GÜTERVERKEHRSSEKTORS.

2.1 DIE NACHFRAGE NACH GÜTERVERKEHRSLEISTUNGEN ........................ 21

2.2 MARKTVERSAGEN IM VERKEHRSSEKTOR.............................................. 24

2.2.1 Defizite des Verkehrsinfrastrukturmarktes ....................................... 29

2.2.2 Defizite der Beförderermärkte................................................................ 35

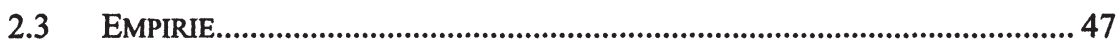

2.3.1 Die Kosten der Infrastruktur................................................................ 47

2.3.2 Die Quantifizierung der Externalitäten des Straßentransports ........... 50

3 DIE GESTALTUNG DER VERKEHRSPOLITIK IN DEUTSCHLAND UND DER EU

3.1 DIE REGULIERUNG DES STRABENGÜTERVERKEHRS IN DEUTSCHLAND VOR 1998 ....................................................................... 61

3.1.1 Staatliche Interventionspolitik im Verkehrssektor ............................. 61

3.1.2 Die Folgen der Marktregulierung.....................................................64 64

3.2 HARMONISIERUNGSMABNAHMEN DER EUROPÄISCHEN UNION................. 66

3.2.1 Harmonisierung der technischen und sozialen Wettbewerbsbedingungen ..................................................................... 67

3.2.2 Harmonisierung der Verkehrsbesteuerung........................................ 68 
4 INFRASTRUKTURFINANZIERUNG UND

VERKEHRSLENKUNG IN EINEM GESCHLOSSENEN

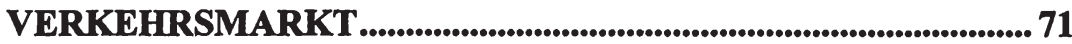

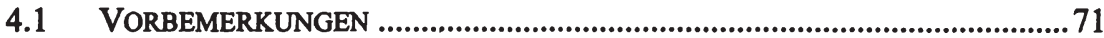

4.2 ZIELE UND INSTRUMENTE NATIONALER VERKEHRSPOLITIK ......................71

4.2.1 Die Abgeltung der Wegekosten.............................................................71

4.2.2 Die Internalisierung der Externalitäten des Straßengüterverkehrs ..... 79

4.3 DIE AUSGESTALTUNG DER INSTRUMENTE NATIONALER

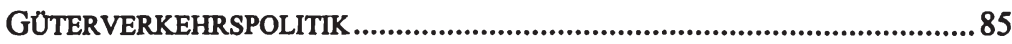

4.3.1 Abgaben zur Finanzierung der Straßenverkehrsinfrastruktur..............86

4.3.2 Instrumente zur Internalisierung externer Effekte des

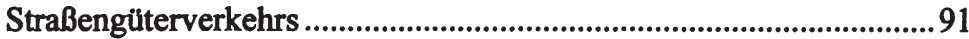

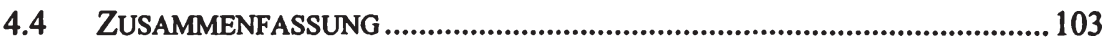

5 DIE FOLGEN EINZELSTAATLICHER

VERKEHRSPOLITIK IM BINNENMARKT ............................... 107

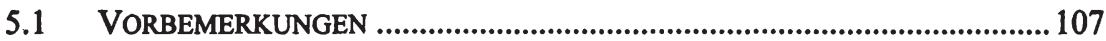

5.2 MODELLTHEORETISCHE GRUNDLAGEN ..............................................107

5.2.1 Das Verhalten der Staaten .................................................................. 108

5.2.2 Das Verhältnis der Staaten zueinander ............................................... 109

5.3 DIE FOLGEN FUR DIE BESTEUERUNGSINSTRUMENTE ..............................110

5.3.1 Abgaben auf die Benutzung der Verkehrsinfrastruktur......................111

5.3.2 Abgaben auf den Fahrzeugbesitz......................................................... 115

5.3.3 Zusammenfassung der Ergebnisse................................................118

5.4 DIE QUANTITATIVE ENTWICKLUNG DER VERKEHRSBESTEUERUNG .........119

5.4.1 Steuern auf stationäre Anlagen.......................................................119

5.4.2 Steuern auf mobile Anlagen ............................................................... 122 
6 INFRASTRUKTURFINANZIERUNG UND

VERKEHRSLENKUNG IN EINEM STAATENBUND

6.1 GRUNDLAGEN FÜR DIE NEUGESTALTUNG ........................................ 125

6.1.1 Die bisherigen Ergebnisse ........................................................... 125

6.1.2 Möglichkeiten zur Begrenzung des Steuerwettbewerbs ................. 126

6.2 DIE FINANZIERUNG DER INFRASTRUKTUR IN DER EU .......................... 131

6.3 DIE REDUKTION DER UMWELTSCHÄDEN DURCH DEN STRAßENGÜTERVERKEHR INNERHALB DER EU ..................................... 139

6.3.1 Probleme innerhalb der Europäischen Union................................... 139

6.3.2 Eine alternative Lösung................................................................ 144

6.4 ZUSAMMENFASSUNG DER VORSCHLÄGE............................................ 157

7 ERWEITERUNG UND SCHLUBBETRACHTUNG................... 161

7.1 EINE ERWEITERUNG: DiE VERTEILUNG DER AUFGABENKOMPETENZ..... 161

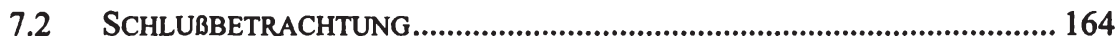




\section{Verzeichnis der Abbildungen}

Abb. 1: Entwicklung des Güterverkehrs in Tonnen ............................................. 17

Abb. 2: Entwicklung des Guterverkehrs in Tonnenkilometern............................. 18

Abb. 3: Wohlfahrtseffekte des Güterverkehrs..................................................22

Abb. 4: Das System der Kollektivguter......................................................... 26

Abb. 5: Das Defizitproblem bei sinkenden Durchschnittskosten........................... 30

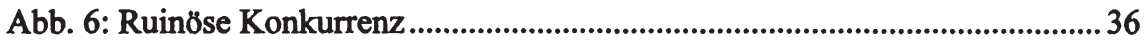

Abb. 7: Die Konsumentenrente ............................................................................ 38

Abb. 8: Kompensatorische Einkommensvariation .................................................. 39

Abb. 9: Äquivalente Einkommensvariation ......................................................40

Abb. 10: Möglichkeiten zur Bewertung von Externalităten..................................... 41

Abb. 11: Der Nutzen der Lärmreduktion............................................................ 43

Abb. 12: Darstellung des Verkehrsflußverhaltens.............................................. 44

Abb. 13: Relation zwischen Geschwindigkeit und Verkehrsfluß.......................... 45

Abb. 14: Relation zwischen Fahrtkosten und Verkehrsfluß................................... 46

Abb. 15: Wegekostenrechnung fur die Bundesautobahnen (Mill. DM)................ 49

Abb. 16: Mittlere Nutzungsdauer von Brutto-Anlageinvestitionen ...................... 49

Abb. 17: Lärmbelästigte durch Straßenverkehr 1986 bis 1994 (Angaben in \%) .. 54

Abb. 18: Externe Kosten des Klimawandels (1994 ECU pro Tonne $\mathrm{CO}_{2}$ )........... 56

Abb. 19: Externe Effekte des Straßengüterverkehrs (ECU/ 1000 tkm) ................. 58

Abb. 20: Die externen Effekte des Straßenverkehrs............................................59

Abb. 21: Ramsey-Preise .......................................................................................... 75

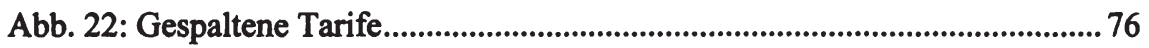

Abb. 23: Optimale Preise bei gegebener Kapazität................................................... 78

Abb. 24: Abgasgrenzwerte für LKW und Busse.................................................. 80

Abb. 25: Pigou-Steuer und Standard-Preis-Ansatz .................................................. 81

Abb. 26: Ökonomische Effizienz von Abgaben- und Auflagenlösungen .............. 82

Abb. 27: Die Funktionsweise von Umweltlizenzen ................................................ 84

Abb. 28: Optimale Achslast........................................................................... 90 
Abb. 29: Optimaler Straßenausbaugrad ................................................................... 91

Abb. 30: Relation zwischen Fahrtkosten und Verkehrsfluß ................................ 92

Abb. 31: EU-Grenzwerte für Geräuschemissionen neuzugelassener LKW ......... 97

Abb. 32: Relative Toxiditätsfaktoren der Kfz-Emissionen.................................. 100

Abb. 33: Zusammenfassung der Vorschläge......................................................... 105

Abb. 34: Die Erosion mobiler Steuerbemessungsgrundlagen.............................. 118

Abb. 35: Die Entwicklung der Mineralölbesteuerung in Europa......................... 120

Abb. 36: Die Entwicklung der Kfz-Besteuerung in Europa................................ 123

Abb. 37: Wohlfahrtsgewinne durch Dezentralisierung....................................... 128

Abb. 38:Verteilungsschlüssel für das gemeinsame Gebührenaufkommen aus

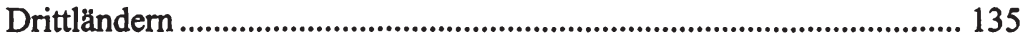

Abb. 39: Räumliche Verteilung von Kosten und Nutzen einer Fernstraße......... 145

Abb 40: Die wichtigsten Straßenverbindungen in Europa.................................... 153

Abb. 41: Versteigerung mehrerer Objekte ................................................... 155

Abb. 42: Finanzierung und Lenkung des Straßengüterverkehrs .......................... 158

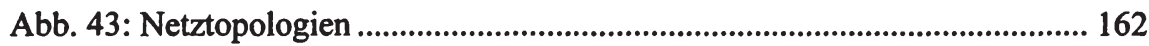


Axel Hennighausen - 978-3-631-75701-7

Downloaded from PubFactory at 01/11/2019 02:45:58AM

via free access 


\section{Einleitung}

\subsection{Problemstellung}

Mit der Schaffung des Europäischen Binnenmarktes 1992 war die Verwirklichung der sogenannten „vier Freiheiten“ - freiem Verkehr von Waren, Dienstleistungen, Personen und Kapital - zumindest formal erreicht. Von der Aufhebung der innereuropäischen Schranken versprachen sich alle beteiligten Länder Preissenkungen, zusätzliches Wachstum und damit verbunden neue Arbeitsplätze in beträchtlicher Größenordnung.'

Tatsächlich hat der Binnenmarkt zu einem intensiveren Warenaustausch zwischen den EU-Staaten gefuhrt. Dies bleibt nicht ohne Auswirkungen auf Menge und Zusammensetzung des Güterverkehrs. Mit der Europäisierung von Produktion und Verbrauch geht eine stetige Erhöhung der Transportweiten einher. Zudem haben die neuen Anforderungen an die Verkehrsträger bezliglich Geschwindigkeit und Flexibilität zur Folge, daß das Wachstum des Güterverkehrs zum großen Teil auf der Straße stattfindet. An den Diagrammen in Abb. 1 und Abb. 2 läßt sich diese Entwicklung für grenzüberschreitenden Verkehr und Durchgangsverkehr am Beispiel Deutschlands klar ablesen. Vor allem der Durchgangsverkehr, also Verkehr vom Ausland ins Ausland, weist große Wachstumsraten auf und belastet damit die nationale Infrastruktur und die Umwelt des Transitlandes. Wie die Diskrepanz zwischen der Entwicklung des Verkehrsaufkommens (in Tonnen) und der seit Einführung des Binnenmarktes weit stärker wachsenden Verkehrsleistung (in Tonnenkilometern) zeigt, ist dieses Wachstum nicht nur auf vermehrten Transport, sondern zum großen Teil auf größere Transportweiten zurückzuführen.

Dies jedoch bedeutet gleichzeitig, daß den Wohlfahrtsgewinnen des Binnenmarktes gesellschaftliche Kosten in beträchtlicher Höhe gegenuberstehen. Stau, Lärm, Luftverschmutzung und Unfallgefahren werden in zunehmendem Maße in den vom Straßengüterverkehr betroffenen Regionen als untragbare Belastungen empfunden und fuhren zu Initiativen gegen den Guterverkehr. Ein Beispiel hierfür ist der langanhaltende und teilweise energische Protest gegen den Transitverkehr auf der österreichischen Brennerautobahn, dem „Auspuff Europas“"2

Der einheitliche Verkehrsmarkt läßt diese Ambivalenz der Güterverkehrs deutlicher hervortreten. Die beschriebenen Vorteile des gemeinsamen Marktes kommen nicht notwendigerweise den gleichen Regionen zugute, die mit den Nachteilen aus dem daraus resultierenden Güterverkehr zu leben haben, wie sich aus der Entwicklung des Durchgangsverkehrs ablesen läßt. Dies birgt zwei Gefahren: Zum

Vgl. Cecchini, P. (1988).

Vgl. Sickinger, H. und R. Hussl (1993). 
einen kann die Akzeptanz des Binnenmarktes bei den Betroffenen leiden, was im Extremfall die politische Stabilität der Union gefährdet. ${ }^{3}$ Zum anderen ist nicht von vornherein auszuschließen, daß eine einseitig binnenmarktorientierte Verkehrspolitik die Nachteile des intensivierten Warenaustausches nicht ausreichend beachtet und damit Wohlfahrtseinbußen induziert.

Eine Zentralisierung der verkehrspolitischen Kompetenzen durch EU-weite Harmonisierungsmaßnahmen als Reaktion auf die Deregulierung der Verkehrsmärkte muß daher nicht zwangsläufig der Königsweg in der Verkehrspolitik sein. In dieser Arbeit soll daher überprüft werden, welche Möglichkeiten innerhalb der Europäischen Union zur Verfugung stehen, um den einzelnen Ländern eine eigene Verkehrspolitik innerhalb des gemeinsamen Verkehrsmarktes zu ermöglichen.

In dieser Arbeit wird auf eine Untersuchung des gesamten Güterverkehrssektors verzichtet und lediglich der Straßengüterverkehr als deren bedeutenster Teil analysiert. Eine weitere Einschränkung dieser Arbeit ist, daß sie nur die verkehrspolitischen Aspekte der Finanzierung gegebener Infrastruktur und der Internalisierung externer Effekte betrachtet. Ein anderer, eng mit der Finanzierung verbundener Aspekt der Verkehrsmarkteingriffe, die effiziente Bereitstellung der Verkehrsinfrastruktur, ist ein eigenständiges Problemfeld und kann nur in relevanten Einzelfällen kurz angerissen werden.

3 Die Schweiz hat den Beitritt zur Europăischen Union nicht zuletzt deswegen abgelehnt, weil eine Abkehr von ihrer bahnorientierten Verkehrspolitik keine Unterstutzung bei der Bevolkerung fand. 
Abb. 1: Entwicklung des Güterverkehrs in Tonnen

Entwicklung des grenzuberschreitenden Guterverkehrs

- Mio. $t$ -

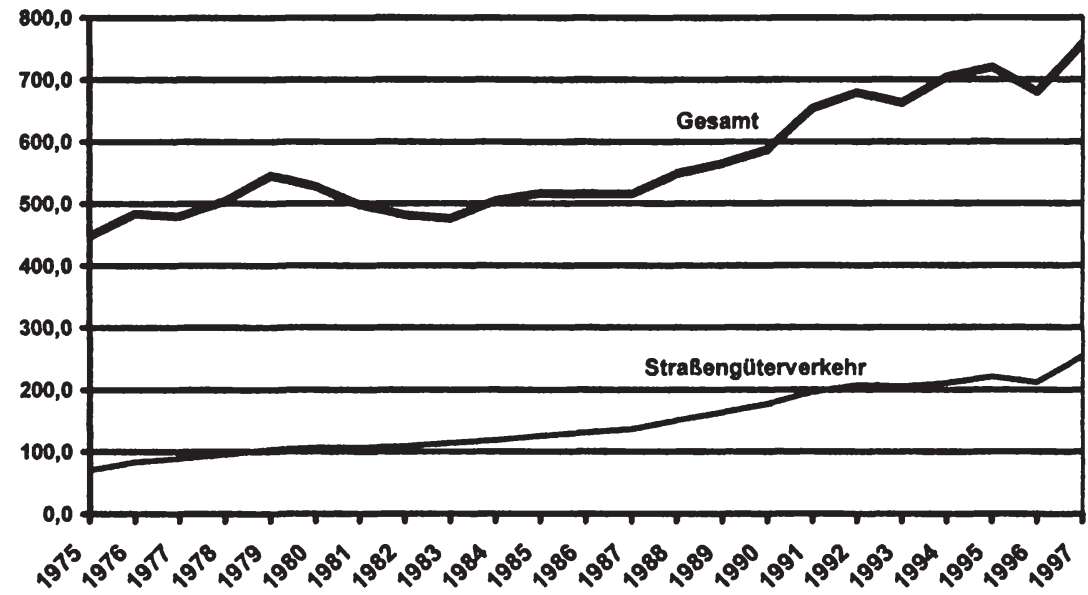

Entwicklung des Durchgangsverkehrs

- Mio. t -

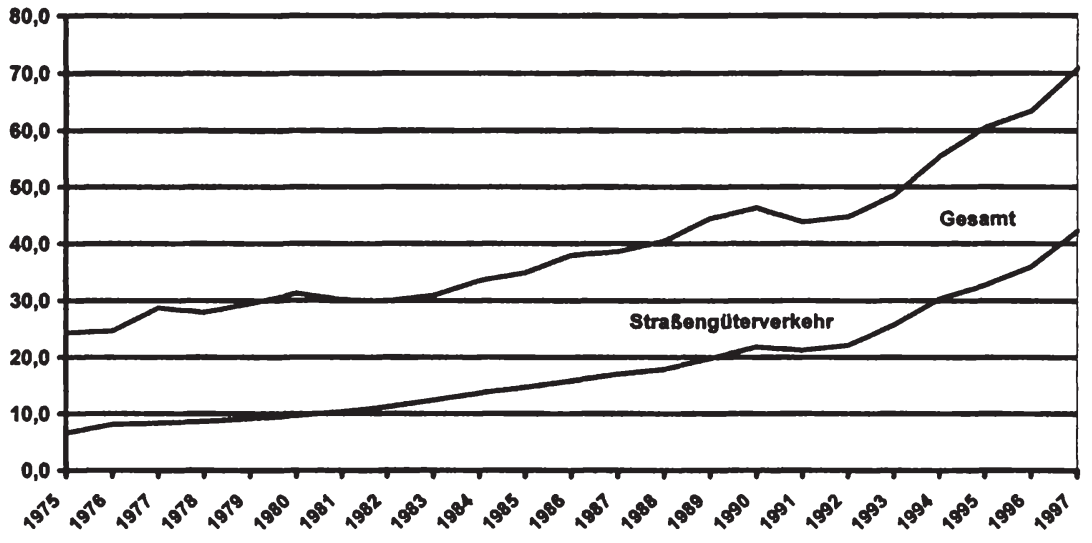

Quelle: Verkehr in Zahlen 1999. 
Abb. 2: Entwicklung des Guterverkehrs in Tonnenkilometern

Entwicklung des grenzaberschreitenden Gaterverkehrs - Mrd. tkm -

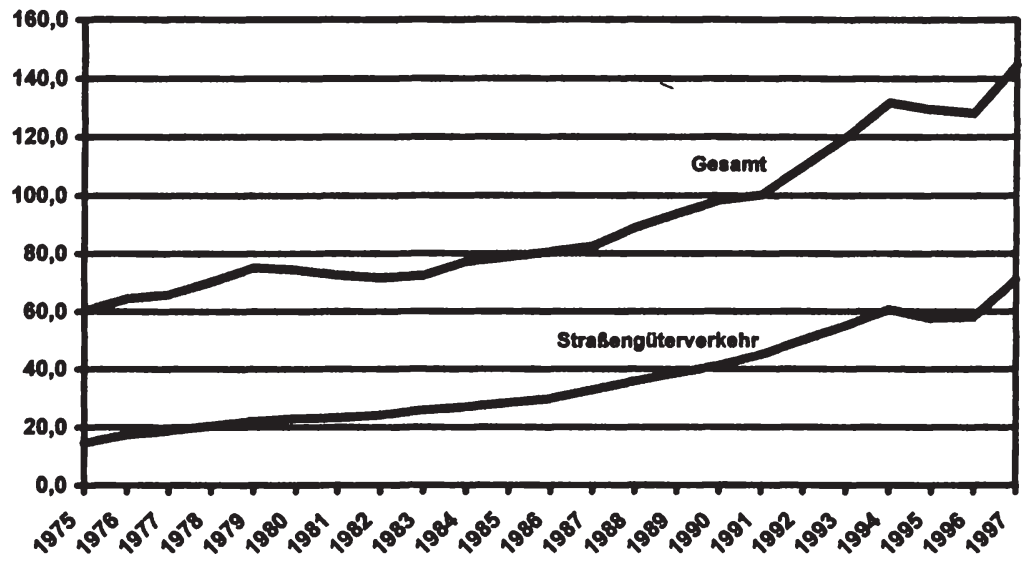

\section{Entwicklung des Durchgangsverkehrs}

- Mrd. tkm -

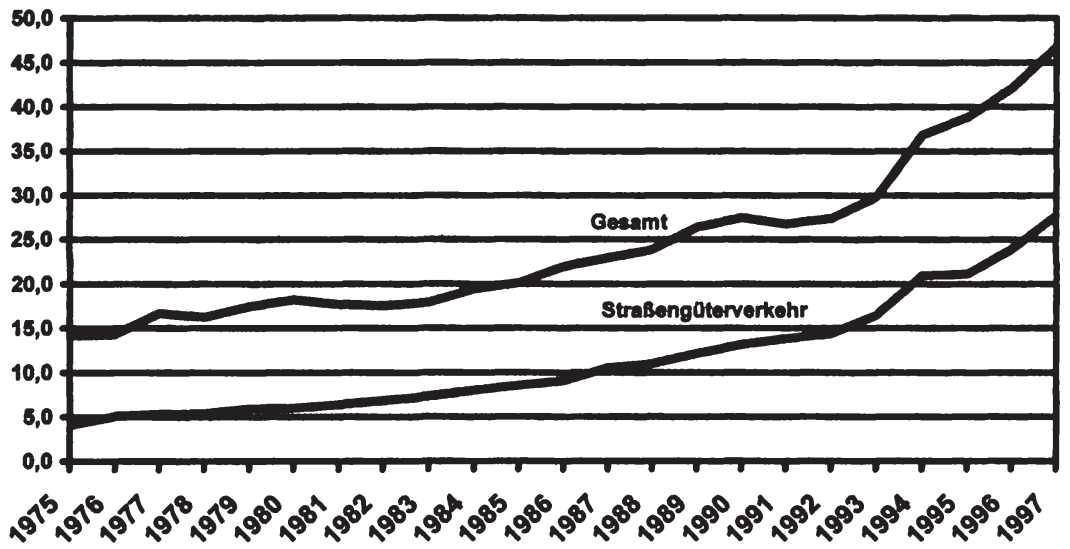

Quelle: Verkehr in Zahlen 1999. 


\subsection{Aufbau der Arbeit}

Die Arbeit ist in sieben Kapitel gegliedert. Nach der Einfuhrung werden im zweiten Kapitel die ökonomischen Eigenschaften der Verkehrsmärkte, die die normative Rechtfertigung furr staatliche Eingriffe liefern, dargestellt. In der Diskussion über die Besonderheiten der Verkehrsmärkte wird eine Trennung zwischen dem Verkehrsinfrastrukturmarkt und den Beförderermärkten vorgenommen. Beide weisen unterschiedliche Arten von Marktunvollkommenheiten auf, die eine von Anfang an getrennte Betrachtung - auch vor dem Hintergrund der späteren Politikempfehlungen - sinnvoll erscheinen lassen. Nach Darstellung der theoretischen Grundlagen werden die dort diskutierten Formen des Marktversagens mittels entsprechender Studien quantitativ untermauert.

Die Defizite der Verkehrsmärkte haben in den meisten europäischen Ländern zu einer Regulierung dieses Sektors geführt, welche erst im Zusammenhang mit der Einfuhrung des Binnenmarktes abgeschafft wurde. Diese Marktregulierung wird im dritten Kapitel am Beispiel Deutschlands dargestellt. Parallel und nachfolgend zur Deregulierung folgten Harmonisierungsmaßnahmen auf europåischer Ebene, welche im zweiten Abschnitt dieses Kapitels beschrieben werden. Es wird zu zeigen sein, daß beide nicht geeignet waren bzw. sind, um den Rahmen für einen effizient funktionierenden Verkehrssektor zu bieten.

Aufbauend auf dieser Feststellung wird im vierten Kapitel ein System ordnungsund steuerpolitischer Maßnahmen dargestellt, welches geeignet ist, einen Straßengüterverkehrsmarkt mit den diskutierten Marktunvollkommenheiten effizienter zu gestalten. Ausgehend von den hier betrachteten Ziele der Verkehrspolitik, der Infrastrukturfinanzierung und der Verkehrslenkung, werden allgemein Methoden zu deren effizienter Umsetzung diskutiert und auf den Gegenstand angepaßt. In diesem Kapitel wird noch von einer abgeschlossenen Volkswirtschaft ausgegangen, d. h. alle Nutzen und Kosten des Straßenguterverkehrs treffen diejenigen, welche auch die Entscheidungen über dessen Finanzierung oder über Lenkungsmaßnahmen zu treffen haben.

Diese Annahme stellt die Situation in Europa vor 1992 zum großen Teil richtig dar. Die Verkehrsmärkte waren weitgehend staatlich reguliert und gegenüber ausländischen Anbietern abgeschottet. Sie dient im vierten Kapitel aber in erster Linie dazu, von Problemen, die mit der Konkurrenz der Staaten untereinander auftreten, zu abstrahieren.

Entsprechend der beschriebenen Entwicklung wird die Annahme einer geschlossenen Volkswirtschaft im 4. Kapitel aufgegeben. Mit Modellen, die aus der Optimalsteuertheorie und der Literatur zum Steuerwettbewerb entnommen sind, läßt sich aufzeigen, daß das optimale Verhalten von Staaten mit nach außen offenen 
Verkehrsmärkten sich von Lăndern mit abgeschotteten Güterverkehrsmärkten unterscheidet.

Das sechste Kapitel zeigt aufbauend auf den Erkenntnissen der Kapitel vier und fünf Möglichkeiten auf, wie trotz Wegfall der meisten Regulierungsinstrumente durch die Einführung des Binnenmarktes und die geänderte Interessenlage der einzelnen Staaten eine sinnvolle Steuerung des Straßenguterverkehrs weiterhin möglich sein kann. Dabei werden neue Instrumente zur Finanzierung und Lenkung des Verkehrs eingeführt, mit deren Hilfe die in Kapitel vier ausgearbeiteten Lösungen trotz geänderter Interessenlage der einzelnen Staaten beibehalten werden können.

Im siebten Kapitel wird kurz auf die bis dahin vernachlässigte Bereitstellung der Infrastruktur innerhalb einer Föderation eingegangen und abschließend ein Resulmee der vorliegenden Arbeit gezogen. 


\section{2 Ökonomische Besonderheiten des Güterverkehrssektors}

\subsection{Die Nachfrage nach Güterverkehrsleistungen}

Nach Voigt ist unter der Güterverkehrswirtschaft die Erstellung und Bereitstellung von Einrichtungen zu verstehen, die die Raumüberwindung von Gütern bezwecken. Damit ist dieser Wirtschaftszweig dem Dienstleistungssektor zuzurechnen. ${ }^{4}$

Die Nachfrage nach Güterverkehr zeichnet sich dadurch aus, daß sie nicht originärer Natur, sondern abgeleitet ist. Sie resultiert nicht aus „Verkehrsbedürfnissen“, sondern aus dem Wunsch, ein andernorts vorhandenes Gut zu konsumieren. Da sowohl Produktions- und Konsumort als auch die verschiedenen Produktionsstandorte innerhalb eine Produktionskette in der modernen arbeitsteiligen Gesellschaft in der Regel voneinander abweichen, besteht die Notwendigkeit, den Raum zwischen beiden mittels Transport zu überwinden. Guterverkehr kann also als Teil des Produktionsprozesses einer räumlich arbeitsteilig organisierten Ökonomie angesehen werden. Aus der abgeleiteten Natur der Verkehrsnachfrage ergibt sich, daß Wohlfahrtseffekte des Verkehrs nicht an den Preisen für Verkehrsleistungen selbst, sondern in anderen Märkten beobachtbar sind. ${ }^{5}$

Diese Aussage sei kurz graphisch erläutert. Dazu kann auf ein einfaches Außenhandelsmodell mit zwei Ländern zurückgegriffen werden, in welchem die Wohlfahrtseffekte des Handels unter Berücksichtigung von Transaktionskosten - in unserem Fall die Kosten des Transports - aufgezeigt werden. ${ }^{6}$

In der Darstellung in Abb. 3 existieren zwei Märkte, der in der Autarkiesituation niedrigpreisige potentielle Exportmarkt rechts und der hochpreisige potentielle Importmarkt links. Besteht die Möglichkeit, durch Güterverkehr die beiden Märkte zu verbinden, entsteht aus den vormals isolierten Märkten ein gemeinsamer Markt in Form des in der Mitte abgebildeten Diagramms. Die Nachfrage $\mathrm{N}$ dieses Marktes entspricht der Differenz zwischen $\mathrm{N}_{\mathrm{i}}$ und $\mathrm{A}_{\mathrm{i}}$, also der Überschußnachfrage bei Preisen unterhalb des Autarkiegleichgewichts im Importmarkt. Das Angebot $A$ entspricht symmetrisch dazu der Differenz zwischen $A_{A}$ und $N_{A}$, also dem Überschußangebot bei Preisen oberhalb des Autarkiepreises im Exportmarkt. Da diese Angebotspreise um die Transportkosten ergänzt werden müssen, sieht sich der Nachfrager der Angebotskurve $A^{\prime}$ gegenüber, dargestellt durch die um die Transportkosten $\mathbf{z}$ nach oben verschobene Gerade $\mathrm{A}$.

\footnotetext{
4 Vgl. Voigt, F. (1973), S. 7.

3 Vgl. Koberlein, C. (1997), S. 49 f.

6 Die Argumentation ist angelehnt an: Verhoef, E. T., P. Nijkamp, et al. (1997), S. 3 ff.
} 
Durch die Zusammenlegung der Märkte steigt die Wohlfahrt sowohl der Export-, als auch der Importregion um die senkrecht schraffierte Fläche. ${ }^{7}$ Dieser Wohlfahrtsgewinn ist umso größer, je geringer die Transportkosten $\mathrm{z}$, dargestellt als Differenz zwischen den Exportsangebotsfunktionen, ist. Hier wird deutlich, daß ein zusätzlicher Wohlfahrtsgewinn aus einem verbesserten Verkehrssystem nicht aus Preis-/Mengenänderungen des Verkehrsmarktes selbst abzulesen ist, sondern sich durch Veränderungen auf anderen Gütermärkten abzeichnet.

\section{Abb. 3: Wohlfahrtseffekte des Guterverkehrs}

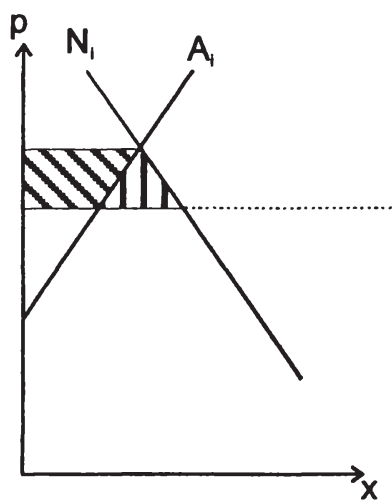

Importmarkt

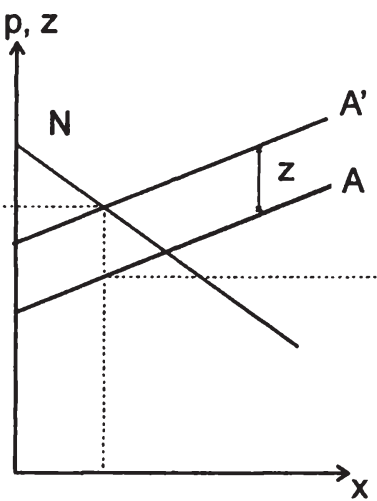

Gemeinsamer Markt

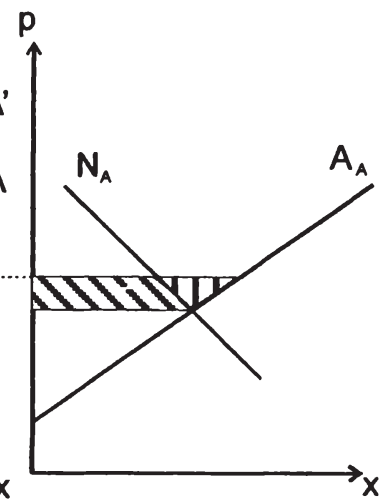

Exportmarkt

Quelle: Birnstiel, E. (1982), S. 104, eigene Darstellung.

Aus dieser einfachen Darstellung läßt sich außerdem ablesen, daß dieser Wohlfahrtsgewinn nicht allen Beteiligten zugute kommt. Wăhrend in der Exportregion die Konsumenten die schräg schraffierte Rente verlieren und der Nettozuwachs an Wohlfahrt produzentenseitig anfällt, ist es im Importland genau umgekehrt. Nach dem Kaldor-Hicks Kriterium stellt die Senkung der Transportkosten eine ParetoVerbesserung da, da die Nutznießer eines verbesserten Verkehrssystems die Verlierer kompensieren können. Allerdings darf bei der praktischen Umsetzung verkehrsverbessernder Maßnahmen nicht ignoriert werden, daß deren politische Akzeptanz in großem Maße von den tatsăchlichen Verteilungswirkungen des Verkehrssystems abhängt.

7 Die dunkelgraue Flache ergibt sich als Differenz zwischen zusătzlicher Konsumentenrente und dem Wegfall von Produzentenrente (hellgraue Fläche) im Importmarkt und zusătzlicher Produzentenrente und Wegfall von Konsumentenrente im Exportmarkt. 
Neben dieser beschriebenen Eigenschaft der Verkehrsnachfrage weist der Markt für Güterverkehr weitere Besonderheiten auf. Typisch für einen Dienstleistungsmarkt ist das Phănomen der periodischen Überlastung. Da Dienstleistungen definitionsgemäß nicht auf Vorrat produziert werden können, führen Nachfragespitzen regelmäßig zu Angebotsengpässen. Dies äußert sich beim Transport in Zeitverlusten durch Verkehrsengpässe. Typische Nachfragespitzen sind der tägliche Berufsverkehr, der wöchentlich auftretende Wochenendverkehr und der saisonale Urlaubsverkehr. Diese Spitzen entstehen zwar zum größeren Teil im Personenverkehr, wirken über die gemeinsam genutzte Infrastruktur aber in der beschriebenen Weise auf den Straßengüterverkehr.

Eine weitere Besonderheit ist die nahezu unendliche rä̀umliche Ausdehnungsfähigkeit des Verkehrs. Die Nachfrage nach Verkehr unterliegt nicht den bei anderen Gütern üblichen Sättigungstendenzen. Während bei den meisten Gütern selbst bei einem Preis $^{8}$ von Null nur eine begrenzte Menge nachgefragt wird, schneidet die Nachfrage nach Mobilităt die Abszisse grundsătzlich nicht. Die Konsequenzen einer Senkung der Benutzerkosten auf Null wäre somit die unbegrenzte Mobilität, die nur durch den Transportzweck selbst limitiert wird. Je weniger Zeit und Geld für eine bestimmte Strecke aufgebracht werden müssen, umso größer werden die Reiseweiten sein. Entfernungen sind bei fehlenden Transportkosten kein Hemmnis für die Ausnutzung komparativer und größenbedingter Vorteile. ${ }^{9}$

Allein im Verkehrssektor anzutreffen ist die Aufteilung der Kapitalausstattung in mobile und stationäre Anlagen, d. h. Fahrzeuge und Verkehrsinfrastruktur, die sich in ihren ökonomischen Eigenschaften wesentlich unterscheiden.

Unter die unbeweglichen Anlagen, die Verkehrsinfrastruktur ${ }^{10}$, werden Bauten und Einrichtungen des Verkehrssektors (materielle Infrastruktur) subsumiert, zum Teil aber auch Verkehrspolizei, die Straßenverkehrsordnung usw. (institutionelle Infrastruktur). Im Verlauf dieser Arbeit ist mit dem Begriff Verkehrsinfrastruktur nur die materielle Infrastruktur gemeint, wenn nicht ausdrücklich anderes gesagt wird. Ihre Bereitstellung zeichnet sich durch drei Besonderheiten aus:

8 Unter dem Preis eines Gutes seien nicht nur die monetăren Kosten verstanden, sondern alle Opportunitătskosten der Nutzung, beim Transport insbesondere die hierfür benötigte Zeit. Ein Preis von Null wlirde also unendlich schnellen Verkehr voraussetzen.

9 Vgl. Thomson, J. M. (1978), S. 37 ff. Man kann sich diesen Aspekt an einem Beispiel verdeutlichen: Bei sehr niedrigen Transportkosten könnten minimale Geschmacksunterschiede ausreichen, um das zumindest in Europa prinzipiell uberall quantitativ und qualitativ ausreichend vorhandene Gut „Wasser" uber große Distanzen zum Verbrauchsort zu transportieren.

10 Im deutschsprachigen Raum hat sich furr Infrastruktur die Definition von Jochimsen durchgesetzt, die diese definiert als ,... die Gesamtheit der materiellen, institutionellen und personellen Anlagen und Gegebenheiten, die den Wirtschaftseinheiten im Rahmen einer arbeitsteiligen Wirtschaft zur Verfugung gestellt werden“ (Jochimsen, R. (1966), S. 145). 
Hohe Fixkosten: Fur Unternehmen oder gar Privatpersonen ist die Finanzierung von Verkehrsinfrastruktur nahezu unmöglich, da ihnen in den seltensten Făllen die Aufbringung des nötigen Kapitals gelingen dürte.

$>$ Wenig alternative Nutzungsmöglichkeiten: In Verkehrsinfrastruktur investiertes Kapital ist in der Regel fur andere Verwendungen verloren. So werden z. B. stillgelegte Gleiskörper oder alte Straßen einfach belassen, da eine Umwandlung fur alternative Nutzung Kosten verursachen würde, die die potentiellen Nutzen weit ubersteigt. Die Opportunitătskosten von Verkehrsinfrastrukturnutzung sind daher sehr gering.

$>$ Möglichkeiten für Größenvorteile: Im Bereich der Verkehrsinfrastruktur ergeben sich erhebliche Möglichkeiten, Kostendegressionseffekte zu nutzen. So zeichnet sich die Bereitstellung durch Unteilbarkeiten, $d$. h. Sprünge zwischen den Graden an Kapazitătsauslegung, aus. Die wichtigste Unteilbarkeit ist die ublicherweise recht hohe Minimalkapazität. Liegt die Verkehrsnachfrage allerdings erheblich unter dieser Untergrenze, was beim Großteil der Infrastruktur der Fall ist (zweispurige Landstraße, einspuriges Gleis im Hinterland), sind die Kostendegressionseffekte allerdings irrelevant. Eine Begrenzung ist die ökonomische Obergrenze einer einzelnen Anlage. Straßen, Flughäfen, Parkplătze etc. lassen sich nicht beliebig vergrößern, ohne daß die Transaktionskosten (z. B. durch Spurwechsel) die Größenvorteile wieder verringern oder sogar überkompensieren.

Die mobilen Anlagen, also die Fahrzeuge, haben im wesentlichen genau die entgegengesetzten Eigenschaften der Infrastruktur: Keine sehr lange Lebensdauer (außer evtl. Schiffe), kaum Kostendegressionseffekte, die Größenbeschränkung ist weniger technisch als wirtschaftich und durch die Infrastruktur, z. B. die Breite der Fahrspuren, bedingt. Aufgrund vielfältiger Einsatzmöglichkeiten und im Verhăltnis zum Kapitalaufwand relativ hoher Betriebskosten ergeben sich bei den Fahrzeugen echte Opportunitätskosten der Nutzung.

\subsection{Marktversagen im Verkehrssektor}

In einem bestimmten institutionellen Rahmen, der sogenannten Arrow-DebreuÖkonomie, fuhrt eigennutzmaximierendes Verhalten rationaler Akteure zu gleichgewichtigen Marktlösungen. Diese kompetitiven Gleichgewichte sind unter den getroffenen Annahmen alle pareto-effizient (erster Hauptsatz der Wohlfahrtsökonomie). ${ }^{11}$ Als pareto-effizient werden hierbei alle diejenigen Zustände bezeichnet, in denen kein Wirtschaftssubjekt besser gestellt werden kann, ohne gleichzeitig mindestens ein anderes zu verschlechtern. Gibt man bestimmte Annahmen dieses Modells der vollkommenen Konkurrenz auf, verlieren die Markt-

$"$ Vgl. Myles, G. D. (1995), S. 39. 
gleichgewichte ihre Effizienzeigenschaften. Im folgenden sollen die für den Verkehr relevanten Formen dieses Marktversagens diskutiert werden.

Untersucht man einen in vielfältiger Weise staatlichem Einfluß unterworfenen „Gegenstand“ wie Straßengüterverkehr mit dem Ziel, ein geeignetes Instrumentarium zur Bereitstellung und Finanzierung dieses Gutes zu finden, bietet sich als Analysewerkzeug zunächst das Konzept öffentlicher Güter.

Reine öffentliche Güter sind durch Nichtrivalität im Konsum und Nichtausschließbarkeit potentieller Nutzer gekennzeichnet. ${ }^{12}$ Nichtrivalität im Konsum liegt vor, wenn ein zusätzlicher Nutzer eines Gutes keine zusätzlichen Kosten verursacht. In diesem Fall wäre es ineffizient, eventuelle Interessenten durch Erhebung von Preisen von der Inanspruchnahme des Gutes abzuhalten. Zur Maximierung der sozialen Wohlfahrt sollte der Preis vielmehr - entsprechend der Grenzkostenpreisregel - Null sein. Musgrave nennt folgendes Beispiel für Nichtrivalität aus dem Bereich der Verkehrsinfrastruktur: Ist eine Brücke nicht ausgelastet, bewirkt ein weiterer Nutzer keine Störung des Verkehrsflusses. Daher wäre es ökonomisch ineffizient - obwohl fraglos technisch möglich - Fahrer von der Benutzung der Brucke durch Erhebung einer Mautgebühr abzuhalten.

Nichtausschließbarkeit bedeutet, daß der Ausschluß von Nutzern entweder technisch nicht möglich oder wirtschaftlich unrentabel ist, d. h. die Kosten des Ausschlusses dessen Nutzen übertreffen. Liegt Nichtausschließbarkeit vor, bietet sich für potentielle Nutzer der Anreiz, sich als Schwarzfahrer zu verhalten: Sie offenbaren ihre tatsächlichen Präferenzen für die Nutzung des Gutes nicht und nutzen es unentgeltlich. Ein privater Anbieter wird durch dieses Verhalten vom Angebot nichtausschließbarer Güter abgehalten. Als Beispiel nennt Musgrave wiederum einen Teil der Verkehrsinfrastruktur, eine überlastete innerstädtische Straße. Obwohl hier fraglos Rivalität im Konsum vorliegt, ist ein Ausschluß einzelner Nutzer technisch kaum zu realisieren bzw. würde den Verkehrsfluß noch weiter stören und damit ökonomisch ineffizient sein.

Für das Angebot öffentlicher Güter im Markt lassen sich also zwei Ergebnisse festhalten: Entweder sollte kein Preis verlangt werden (bei Nichtrivalität) oder kann kein Preis verlangt werden (bei Nichtausschließbarkeit). Im ersten Fall ist ein privates Angebot aus volkswirtschaftlichen Erwägungen abzulehnen, im zweiten Fall wird es aus betriebswirtschaftlichen Gründen nicht zustande kommen.

Der Fall reiner öffentlicher Güter - gekennzeichnet durch Nichtrivalität und Nichtausschließbarkeit - tritt jedoch nur höchst selten auf. Zur Klassifizierung soll deshalb ein gegenüber der groben Einteilung in öffentliche und private Guter differenzierteres Schema vorgestellt werden. ${ }^{13}$

12 Musgrave, R. A. and P. B. Musgrave (1984), S. 49 ff.

$13 \mathrm{Vgl}$. dazu auch Grossekettler, H. (1985), S. $212 \mathrm{ff}$. 
Die Polarisierung zwischen offentlichen Gütern einerseits und privaten Gütern andererseits ist für die finanzpolitische Diskussion nicht ausreichend. In dieser Darstellung wird daher versucht, eine Einordnung als Kontinuum zwischen dem Extremfall der rein privaten Güter p, bei denen Ausschließbarkeit und Rivalität im Konsum gegeben ist, und der weltweiten öffentlichen Güter $\delta$ vorzunehmen. Dabei ist ein zusätzliches drittes Kriterium, die Gruppengröße, einzuführen.

Abb. 4: Das System der Kollektivgüter

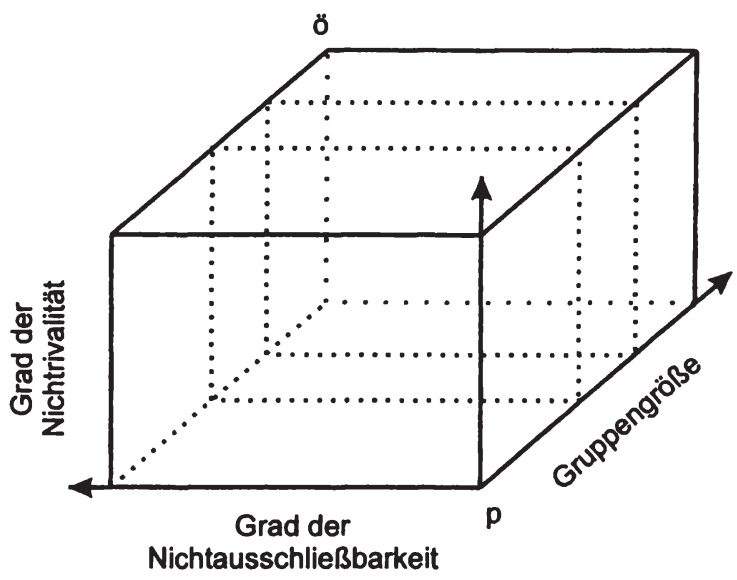

Quelle: Loehr, W. und T. Sandler (1978), S. 17.

Der Grad der Nichtausschließbarkeit wird durch die Exklusionskosten bestimmt. Je höher diese sind, desto größer ist die Wahrscheinlichkeit, daß das entsprechende Gut durch private Unternehmen im Markt nicht bereitgestellt werden kann, da die Ausschlußkosten - die ja zu den eigentlichen Produktionskosten hinzugezählt werden müssen - die Wertschätzung der Nachfrager ubertreffen. Allerdings kann der Exklusionsgrad stark davon abhängen, wie groß die jeweilige Nachfragergruppe gewählt wird. Nimmt man Landesverteidigung als Beispiel, läßt sich leicht nachvollziehen, daß innerhalb einer Gruppe, die die Bewohner eines einzelnen Landes umfaßt, ein Ausschluß einzelner Nachfrager von der Nutzung kaum möglich ist. In einem supranationalen Bündnis dagegen ist ein Ausschluß von der gemeinsamen Verteidigung durchaus möglich, wenn man als handelnden Akteur nicht mehr das einzelne Individuum betrachtet, sondern Staaten, letztlich also die Gruppengröße reduziert. Kommen einzelne Mitgliedsländer ihren Bündnispflichten nicht nach, ist es - im Gegensatz zum Bürger eines Landes - möglich, ihnen den Beistand zu verwehren. 
Der Grad der Nichtrivalität wird von zwei Größen bestimmt: Überfullung und Zugangsmőglichkeiten. ${ }^{14}$ Überfüllung meint, daß ein zusătzlicher Nutzer allen anderen Konsumenten Kosten aufbürdet. Es existieren also im Gegensatz zu reinen öffentlichen Gütern Opportunitätskosten der Nutzung. Diese haben zur Folge, daß es nicht mehr optimal ist, eine unbegrenzte Nutzung zum Preis von Null zuzulassen. Vielmehr sollte die Nutzung nur bis zu dem Punkt ausgedehnt werden, an dem die privaten Vorteile der Summe der Benachteiligungen aller anderen Konsumenten entsprechen. ${ }^{15}$

Für die Zugangsmöglichkeiten gilt, daß aufgrund der räumlichen Verteilung der Konsumenten das Gut nicht fur alle Personen in gleichem Maße zugänglich ist. Ein öffentliches Gut $\mathrm{X}$ wird dann nicht mehr von jedem Nutzer vollständig konsumiert. Formal ausgedruckt entspricht der Verbrauch des Konsumenten $i$ also nur noch einem Anteil $A_{i}$ des gesamten öffentlichen Gutes:

$$
X_{i}=A_{i} X \text {, wobei } A_{i} \leq 1 \text {. }
$$

Die Anwendung der Theorie öffentlicher Güter zur Analyse des Verkehrswesens ist allerdings mit einer Reihe von Problemen verbunden. Erstens tritt der Fall reiner öffentlicher Güter - gekennzeichnet durch Nichtrivalität und Nichtausschließbarkeit - nur bei einem Teil des Straßennetzes auf. Dies sind hauptsächlich nachrangige Straßen außerhalb von Ballungszentren, die nicht viel befahren werden und aufgrund ihrer großen Anzahl an Ab- und Zufahrten keinen ökonomisch sinnvollen Ausschluß erlauben. Bei einem aus internationaler Sicht interessanteren Fernstraßennetz gestaltet sich die Analyse jedoch deutlich schwieriger.

Der Grad an Nichtrivalităt einer Straße wird vor allem durch die in 1.1 kurz erwähnten Unteilbarkeiten und die Überfullungskosten beeinflußt. Aufgrund der hohen Minimalkapazität einer Straße und des notwendigen Netzaufbaus erfolgt die Produktion der Straßenverkehrsinfrastruktur mit relativ hohen Skalenerträgen. Die Höhe der Stauungskosten ist weniger eindeutig bestimmbar. Sie ist großenteils zeitabhängig: Je nach Tages-, Wochen- oder Jahreszeit beeinträchtigen sich die Autofahrer in unterschiedlichem Maße. Beispielhaft sei eine innerstädtische Straße im Berufsverkehr und außerhalb des Berufsverkehrs genannt. Aussagen über den Grad an Nichtrivalităt der materiellen Verkehrsinfrastruktur sind also nicht eindeutig zu treffen. Während die Unteilbarkeiten, also die hohe Minimalkapazität, eher für einen hohen Wert sprechen, ist der Einfluß der Überfüllungskosten nur in Zusammenhang mit Zeitangaben zu bestimmen. Als einziges Ergebnis läßt sich vielleicht festhalten, daß der Grad an Nichtrivalität aufgrund der steigenden Skalenerträge eher mittel bis hoch sein dürfte und das Straßennetz

14 Vgl. hierzu Loehr, W. und T. Sandler (1978), S. 19 f.

15 Vgl. Myles, G. D. (1995), S. 269 f. 
- nicht notwendig einzelne Straßenabschnitte - sich daher nicht generell für die private Bereitstellung eignet.

Die Ausschließbarkeit von der Nutzung ist vorrangig vom Straßentyp abhăngig. Einige wenige Typen - insbesondere Sonderbauten wie Brücken, Tunnel und $\mathrm{PaB}$ straßen - erlauben den Ausschluß potentieller Nutzer ohne relevante Exklusionskosten. Je mehr die Straße jedoch in ein Netz eingebunden ist, desto größer ist der technische und finanzielle Aufwand, um den Zutritt von Nutzern zu reglementieren. Damit wird die oben erwähnte Restriktion - die gerade noch wirtschaftliche Ausschlußtechnik - wirksam. Die Kontrolle der Nutzungszulassung kann bei vielen in ein enges Netz eingebundenen Straßen so hohe Kosten verursachen, das diese den Nutzen des Ausschlusses überkompensieren.

Wir kőnnen also feststellen, daß die Einordnung von Straßen zwischen die Pole Individual- und Kollektivgut einerseits zeit-, andererseits straßentypabhăngig ist. Die Einordnung ist fließend. Mit zunehmender Verkehrsdichte nimmt die Rivalität der Nutzer um das knapper werdende Gut Straße zu, mit zunehmender Anzahl von Auf- und Abfahrten wird die Erhebung von nutzungsabhängigen Gebuhren erschwert. Eine Aussage über Grad der Nichtrivalităt und Nichtausschließbarkeit läßt sich also nur bei einem bestimmten Straßentyp mit einem bestimmten Auslastungsgrad treffen. Um Klassen mit homogenen Gütern bilden zu können, müßte das Gut Straße also beispielsweise als „Autobahn A7 zwischen Kassel und Hannover wăhrend normaler Wetterbedingungen, 9.00-11.00 Uhr" definiert werden. Damit wăre jedoch im Hinblick auf den Zweck der Untersuchung wenig erreicht. Die Einordnung zwischen die Pole Individual- und Kollektivgut wird vorgenommen, um einen geeigneten Finanzierungsmechanismus für das jeweilige Gut $\mathrm{zu}$ finden. Wechselt die untersuchte Straße aber den Grad an Rivalităt und Ausschließbarkeit schon nach kurzen Streckenabschnitten bzw. innerhalb desselben Streckenabschnitts nach kurzer Zeit, kann ein sinnvolles Instrumentarium aus der Theorie $8 f f e n t l i c h e r$ Güter kaum abgeleitet werden. ${ }^{16}$

Das Problem der unzureichenden Klassifizierungsmöglichkeiten läßt sich vermeiden, wenn man den Verkehrssektor in die zu Beginn genannten mobilen und stationären Anlagen unterteilt und diese einzeln auf Marktversagen untersucht. Dies soll Ziel der nächsten beiden Teilkapitel sein.

${ }^{16} \mathrm{Zu}$ einem ahnlichen Ergebnis bezuglich der Anwendbarkeit des Konzepts offentlicher Guter kommt v. Suntum. Vgl. Suntum, U. v. (1986), S. 89 ff. 


\subsubsection{Defizite des Verkehrsinfrastrukturmarktes}

Für den Bereich der stationären Anlagen kommt als Marktversagen vor allem die Problematik der Subadditivität ${ }^{17}$ in Betracht. Allgemeines Kennzeichen von Subaddivităten ${ }^{18}$ ist

$$
\mathrm{K}\left(\mathrm{X}^{\mathrm{M}}\right)<\mathrm{K}\left(\mathrm{X}^{1}\right)+\mathrm{K}\left(\mathrm{X}^{2}\right)+\mathrm{K}\left(\mathrm{X}^{3}\right)+\ldots+\mathrm{K}\left(\mathrm{X}^{\mathrm{Z}}\right) \text {, wobei } \mathrm{X}^{\mathrm{M}}=\sum_{\mathrm{i}=1}^{\mathrm{Z}} \mathrm{X}^{\mathrm{i}}
$$

d. h. die Gesamtkosten für die Produktion von Teilmengen $\mathrm{X}^{\mathrm{i}}$ sind zusammen höher als für die Produktion der Gesamtmenge $\mathrm{X}^{\mathrm{M}}{ }^{19}$

Diese Marktunvollkommenheit soll im nun folgenden Teil dargestellt werden. Darauffolgend wird untersucht, ob dieses Problem für die stationären Anlagen im Verkehrssektor relevant ist.

Eine Annahme des Modells der vollkommenen Konkurrenz ist die beliebige Teilbarkeit aller Güter und Produktionsfaktoren. In vielen Fällen ist diese jedoch nicht gegeben. Vor allem im Bereich der Infrastruktur kann aufgrund technischer Gegebenheiten die Kapazität nur in großen Sprüngen variiert werden, der Fixkostenanteil ist somit sehr hoch. Es liegt eine Produktion mit sinkenden Durchschnittskosten vor. ${ }^{20}$ Dies hat eine Konzentration auf der Anbieterseite zur Folge, die im Extremfall zum sogenannten "natürlichen Monopol" führt.

Ebenfalls durch das Konzept der Subadditivitäten erklärt wird das Phänomen der "economies of scope". Formal läßt es sich wie folgt darstellen ${ }^{21}$ :

$$
\mathrm{K}(\mathrm{X}, \mathrm{Y})<\mathrm{K}(\mathrm{X}, 0)+\mathrm{K}(0, \mathrm{Y})
$$

17 Zum Teil werden Subadditivitäten nicht unter Marktversagen eingeordnet, sondern als Wettbewerbsversagen bezeichnet, da der Allokationsmechanismus bei Subadditivităten prinzipiell funktionsfähig ist und nur aufgrund mangelnden Wettbewerbs im jeweiligen Markt seine Aufgaben nicht erfullt. Vgl. Eickhof, N. (1986), S. 474 und Wink, R. (1995), S. 81.

In dieser Arbeit sollen der Einfachheit halber allerdings Formen des Wettbewerbsversagen unter Marktversagen subsumiert werden. Der Allokationsmechanismus wird demnach als nicht funktionsfăhig definiert, wenn er aufgrund marktinterner Faktoren (natüliche Monopole in Verbindung mit verfestigten Mărkten und ruinöser Konkurrenz) zu einem Monopolmarkt fuhrt.

18 Die hier angegebene Formel umschreibt ganz allgemein die Eigenschaft von Subadditivităten. Sinkende Durchschnittskosten sind eine Teilmenge der subadditiven Kostenfunktionen, da letztere auch mit sprungfixen Kosten vorstellbar sind. Sie stellen demgegenuber eine Obermenge zu steigenden Skalenertrăgen dar, welche an eine proportionale Veränderung der Produktionsfaktoren gebunden sind. Siehe dazu Fritsch, M., T. Wein, et al. (1996), S. 147 ff. 
Es ist im hier dargestellten Falls also günstiger, beide Güter gemeinsam anstatt in getrennter Produktion herzustellen. Gründe dafür können Kuppelprodukte sein, z. B. die bei der Raffinerie von Erdöl entstehenden Endprodukte schweres und leichtes Heizöl, Benzin und Teer, aber auch unausgelastete Kapazităten oder Portfolioeffekte bei Forschung und Entwicklung. Ersteres bedeutet, daß bei der Produktion eines Gutes zwangslăufig ein anderes anfallt. Im zweiten Fall können freie Kapazitäten für die Herstellung anderer Güter verwendet werden ${ }^{22}$.

Die Bereitstellung durch den Markt wirft dann folgende Probleme auf:

Wird - entsprechend dem Allokationsoptimum in der vollkommenen Konkurrenz - die Preis = Grenzkosten - Regel angewandt, realisiert der Anbieter in Abb. 5 Verluste in Höhe der Fläche $\mathrm{ABCp}^{0 \mathrm{~K}}$. Ist allerdings ein natürliches Monopol entstanden, d. h. ist nur ein Anbieter im Markt verblieben, sind solche Preise unwahrscheinlich. Der Monopolist hat in einem solchen Fall die Möglichkeit, Gewinnmaximierung gemäß der Grenzkosten $=$ Grenzerlös - Regel zu betreiben. Er bewirkt damit einen gesamtwirtschaftlichen Wohlfahrtsverlust gegenuber der Ausgangslage.

Abb. 5: Das Defixitproblem bei sinkenden Durchschnittskosten

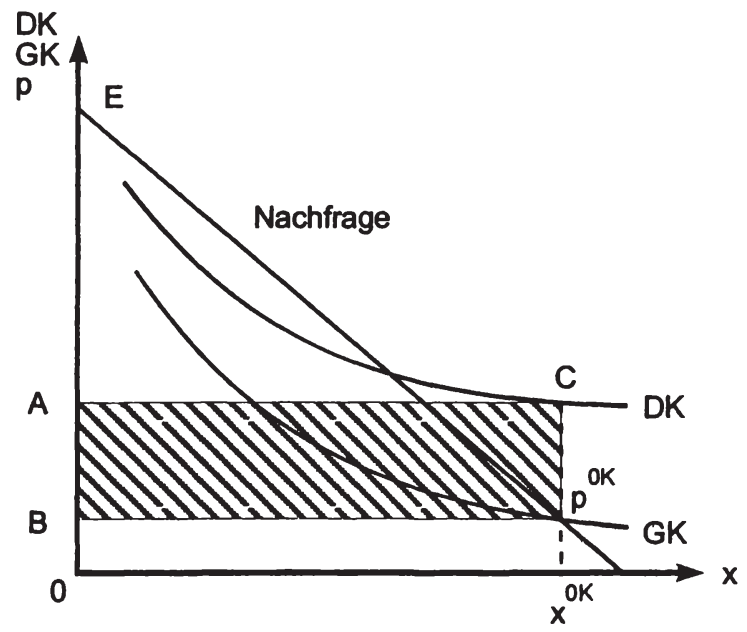

Quelle: Fritsch, M., T. Wein, et al. (1996), S. 155

22 Fritsch, M., T. Wein, et al. (1996), S. 151. 
Die letzte Preissetzungsregel wird jedoch von der Theorie bestreitbarer Märkte (contestable markets) in Frage gestellt ${ }^{23}$. Nach ihr ist der Wohlfahrtsverlust in einem Monopol umso geringer, je eher der Anbieter mit weiteren Markteintritten rechnen muß. Um diese im Vorfeld zu unterbinden, wird er auf Monopol-Preise verzichten und zu kostendeckenden Preisen tendieren. Bestreitbare Märkte können in bestimmten Fällen also auch ohne staatliche Eingriffe zweitbeste Lösungen herbeifuhren.

Die Wahrscheinlichkeit zusätzlicher Markteintritte, mit anderen Worten das Ausmaß an potentieller Konkurrenz, ist durch die Marktzutrittsschranken bestimmt. Für letztere sind insbesondere die sogenannten sunk costs ausschlaggebend. Damit sind solche Kosten gemeint, die "für den Markteintritt erforderlich sind und bei einem Marktaustritt unwiederbringlich abgeschrieben werden [müssen] ${ }^{624}$. Fallen solche irreversiblen Aufwendungen in hohem Maße beim Marktzutritt an, hat dies einen Abschreckungseffekt fur potentielle Neuanbieter, die im Falle eines Scheiterns ihre Anfangsinvestitionen nicht wieder kapitalisieren können.

Wendet man das Konzept der Subadditivităten auf die Straßenverkehrsinfrastruktur an, lassen sich folgende Argumente für Größenvorteile finden. ${ }^{25}$ Zum einen liegen bis zu einem gewissen Grad Economies of density, sogenannte Dichtevorteile vor. Zum anderen sinken bei steigender Auslastung des Netzes die Grenzkosten der Bereitstellung von Straßenkapazität ${ }^{26}$ durch den hohen Fixkostenanteil. Weiterhin können Economies of scope (Verbundvorteile) angenommen werden. Dies sind Vorteile des gemeinsamen Angebots, d. h. zusătzliche Kapazitäten innerhalb des Netzes können auch die Auslastung der anderen Strecken erhöhen und damit die Grenzkosten einer zusätzlichen Nutzung (in Form zuätzlicher Verkehrsleistung) senken.

Ebenfalls denkbar sind Verbundvorteile durch gemeinsame Streckennutzung fur Personen- und Guterverkehr. Ob diese tatsăchlich existieren, ist allerdings umstritten, da die Ansprliche an die Infrastruktur höchst unterschiedlich sind. Der Schwerlastverkehr beansprucht die Infrastruktur stärker, der Personenverkehr hat demgegenüber höhere Anforderungen an Qualităt und Geschwindigkeit ${ }^{27}$. Es

23 Siehe dazu Fritsch, M., T. Wein, et al. (1996), $161 \mathrm{ff}$.

24 Fritsch, M., T. Wein, et al. (1996), S. 162.

$25 \mathrm{Vgl}$. zu den folgenden Ausfuhrungen Wink, R. (1995), S. $127 \mathrm{ff}$.

26 Als Maß furr die Kapazităt einer Straße kann bspw. der maximale Verkehrsfluß genommen werden, d. h. die maximale Anzahl von Fahrzeugen, die in einem bestimmten Zeitraum einen Straßenabschnitt uberqueren.

27 Die Produktion verschiedener Transportleistungen auf einem Verkehrsweg muß nicht zwangslăufig economies of scope zur Folge haben. Ein Gegenbeispiel aus jüngerer Zeit ist die Trassierung des ICE. Um die Neubaustrecken gleichzeitig fur Guterverkehr nutzen zu können, mußten maßgebliche Anpassungen im Streckenverlauf vorgenommen werden. Der ICE wäre durchaus in der Lage, großere Steigungen zu uberwinden, kann aufgrund seiner Geschwindigkeit jedoch 
könnte also durchaus sein, daß diese Verbundvorteile gar nicht existieren, zumindest nicht durchgängig.

Die materielle Verkehrsinfrastruktur ist in hohem Maße verwendungsspezifisch und immobil. Einmal getătigte Investitionen in das Straßennetz sind daher kaum einer alternativen Verwendung zuzufuhren, so daß hohe Markteintritts- bzw. Marktaustrittsschranken vermutet werden können.

Größenvorteile und Irreversibilităten lassen vermuten, daß die betroffenen Mărkte zum natürlichen Monopol tendieren und damit ein gesamtwirtschaftlich ineffizientes Ergebnis - zu geringe Mengen bei zu hohen Preisen - verglichen mit der Referenzsituation Grenzkostenpreisbildung herausbilden.

Daraus kann jedoch noch nicht zwingend die Rechtfertigung staatlicher Eingriffe abgeleitet werden. Vor dieser Schlußfolgerung ist zu prüfen, ob der Wettbewerb zwischen den Verkehrsträgern (= intermodaler Wettbewerb) potentielle Konkurrenz schafft und somit eine gesamtgesellschaftlich unerwlinschte Situation vermeidet. Ob diese Konkurrenz vorliegt, ist von der Substitutionselastizität zwischen den einzelnen Verkehrsträgern abhăngig. Diese wiederum hăngt von der Affinităt der einzelnen Güter zu bestimmten Verkehrsträgern ab. Je nachdem wie hoch diese ist, hat ein Verkehrsträger geschützte Bereiche, in die ein anderer nicht ohne weiteres eindringen kann. So macht Schnelligkeit, Zuverlässigkeit und Netzbildungsfähigkeit den LKW für viele hochwertige Güter in einem so starken Maße zum geeigneten Verkehrsmittel, daß weder Bahn noch Schiff konkurrieren können. Im Gegensatz dazu besitzt beispielsweise die Bahn kaum geschützte Bereiche, sondern wird auf der Qualitătsseite vom LKW, auf der Kostenseite vom Binnenschiff bedrängt.

Weiterhin wăre es im Hinblick auf den Transitverkehr denkbar, daß regionale Anbieter beim Wettbewerb um überregionale Verkehrsachsen konkurrieren und so Marktmacht verhindern.

Außer unvollkommenen Märkten führt die Literatur im Bereich der Straßenverkehrsnetze Externalitäten als Ursache für Marktversagen an. Bei Externalităten handelt es sich um Beziehungen zwischen Wirtschaftssubjekten, die nicht innerhalb des Preissystems liegen. Formal ausgedruckt sind in den Nutzen- bzw. Gewinnfunktionen der Wirtschaftssubjekte reale Variablen enthalten, deren

keine engen Kurvenradien fahren. Guterzilge hingegen benotigen, bedingt durch ihr hohes Gewicht, eine ebene Streckenfuhrung. Im Ergebnis ist eine flache, gerade Trasse entstanden - mit den dadurch notwendig gewordenen Tunnel- und Bruckenbauten - die um ein vielfaches teurer ist als die Trassierung des franzősischen Schnellzuges TGV, die nur von diesem genutzt wird. Dennoch können kaum Güterzlige auf der ICE-Strecke fahren. Die Kräfe, die eine Begegnungsfahrt im Tunnel auslost, wurden im Vorfeld unterschătzt. Sie wurden die Waggons und die Ladung der Guterzlge erheblich gefahrden, wenn nicht zerstören, weshalb der Guterverkehr im wesentlichen auf die Nachtstunden beschrănkt ist. 
quantitative Ausprägung von Dritten ohne Berücksichtigung der damit verbundenen Wohlfahrtswirkungen bestimmt wird. Verändert die Externalität den Nutzen eines Individuums, spricht man von einer Konsumexternalităt, verăndert sie den Gewinn von einer Produktionsexternalität. ${ }^{28}$ Verringert der Effekt Nutzen bzw. Gewinn des betroffenen Individuums, bezeichnet man ihn als negative Externalităt, vergrößert er Gewinn oder Nutzen als positive.

Als Grund für die Existenz externer Effekte wird die mangelnde Definition oder Durchsetzbarkeit von Verfügungsrechten genannt. Beide haben zur Folge, daß die Nutzung entsprechender Güter keine Übertragung von Eigentumsrechten voraussetzt. Die mangelnde Definition der Rechte kann einerseits durch die physischen Charakteristika der Güter (Nichtausschließbarkeit), andererseits durch institutionelle Gegebenheiten, die gesellschaftliche Übereinkunft, bestimmte Güter aus der marktlichen Allokation auszuschließen, bedingt sein. ${ }^{29}$

Externalitäten bewirken, daß die gleichgewichtige Marktlösung nicht paretoeffizient ist, da die privaten Wertschätzungen der betroffenen Güter oder Faktoren von den sozialen Wertschätzungen abweichen.

Negative externe Effekte sind im Bereich der Netze von geringer Bedeutung. Sie beschränken sich im wesentlichen auf die Trennwirkung von Straßen. ${ }^{30}$ Daher sollen im folgenden vor allem die positiven externen Effekte der Infrastruktur diskutiert werden.

Relativ unstrittig ist der sogenannte Options- oder Basisnutzen der Netze. Vom Optionsnutzen spricht man, wenn nicht die Nutzung an sich, sondern schon deren Möglichkeit für Individuen einen Wert besitzt. Als Beispiel wird häufig genannt, daß auch ein Fußgänger einen positiven Nutzen aus der Tatsache zieht, daß er im Notfall mit einem Krankenwagen in die Klinik gebracht wird oder die Feuerwehr innerhalb kurzer Zeit verfügbar ist. ${ }^{31}$

In der verkehrswissenschaftlichen Literatur hat sich allerdings noch ein weiterer Argumentationsstrang herausgebildet. Dieser ist vor allem aus der Kritik an später darzustellenden Studien entstanden, welche aus negativen Externalităten des Verkehrs die Forderung nach dessen Verteuerung ableiten. ${ }^{32}$ Die Argumente sind im wesentlichen dynamischer Natur und verlassen somit den Modellrahmen, inner-

28 Myles, G. D. (1995), S 312 f.

29 Vgl. Bőssmann, E. (1979), S. 147.

30 Die Kosten der Zergliederung von Landschaften und bewohnten Gebieten ăußern sich in Umwegen und Wartezeiten, optischen Wirkungen, verringertem Erholungswert, evtl. verminderte Marktwerte landwirtschaftlicher Grundstucke, falls diese durch Straßen geteilt werden sowie eingeschrănkte Bewegungsmőglichkeiten von Tierarten.

Willeke, R. (1996), S. 108.

32 Vgl. Willeke, R. (1996). 
halb dessen Externalităten üblicherweise diskutiert werden: Über die evolutorischen und strukturverändernden Wirkungen des Verkehrs werden Wachstumseffekte induziert und zusätzlicher Konsum und Gelegenheiten zur Freizeitgestaltung ermöglicht. ${ }^{33} \mathrm{Da}$ sich diese dynamischen Effekte in der üblicherweise verwendeten statischen Modellwelt nicht abbilden, besteht nach Meinung einiger Autoren die Gefahr, daß sie in der Diskussion um Nutzen und Kosten des Verkehrs nicht beachtet werden. Sie erheben daher die Forderung, diese positiven dynamischen Effekte mit den später zu diskutierenden Externalitäten, die großteils negativer Art sind, aufzurechnen.

Würde man jedoch alle diese Sekundäreffekte und Nutzendiffusionen, die eine Transaktion mit sich bringt, einbeziehen, wäre eine Abwägung von Nutzen und Kosten einer Maßnahme von vorneherein zum Scheitern verurteilt. Andere Branchen wecken ebenfalls Innovationspotentiale und haben strukturverändernde Wirkungen, beispielhaft sei die Mikroelektronik genannt. Dennoch wirde niemand die Forderung erheben, Computer seien aufgrund von positiven Externalităten zu subventionieren. Der Vorteil eines marktwirtschaftlichen Systems besteht gerade darin, daß außer den zu entgeltenden Opportunitätskosten noch zusätzliche Nutzen beim Nachfrager und Anbieter in Form von Renten und bei anderen in Form von Entwicklungspotentialen anfallen und damit die Gesamtwohlfahrt gesteigert wird.

Die Frage nach der Existenz externer Nutzen scheint also ein Problem des jeweiligen Blickwinkels. In statischen Modellen werden hier als „externe“ Nutzen bezeichnete Effekte zu Renten und pekuniären Externalitäten. In der dynamischen Sichtweise, die von den Befurwortern der Existenz positiver externer Nutzen eingenommen wird, mag dies nicht mehr gelten. Allerdings wirft diese Dynamisierung bei năherem Hinsehen Probleme auf. Eine individualistische Wirtschaftstheorie wird sich mit der Beurteilung einer Sachlage schwer tun, wenn sie nicht in irgendeiner Weise auf geäußerte Präferenzen zurückgreifen kann. Im normalen Marktgeschehen ist dies kein Problem: Präferenzen äußern sich in nachgefragten Mengen und Preisen und sind so erfaßbar. Existieren externe Effekte, sind solche Marktdaten logischerweise nicht mehr vorhanden. Sie müssen indirekt durch abgeleitetes Verhalten oder direkt mittels Befragungen ermittelt werden. Aber auch diese Verfahren sind nur bei der Beurteilung heute vorliegender Externalităten, nicht aber bei der Bewertung volkswirtschaftlicher Entwicklungspotentiale anwendbar. Bei der Ermittlung eines optimalen Entwicklungspfades müßten billigerweise die Präferenzen der zukünttigen Generationen in die Betrachtung mit eingehen. Diese jedoch existieren naturgemäß noch nicht. Zudem könnten sie die Lage auch nicht angemessen beurteilen, weil ihnen die Alternativen nicht bewußt sein können. Man kann sich vielleicht in diese Lage versetzen, indem man sich

33 Willeke, R. (1996), S. 103 ff. 
die Frage stellt, ob man die beginnende Motorisierung vor ca. 100 Jahren gutheißt oder sie lieber untersagt hätte. Da sich niemand anmaßen kann, die Entwicklung der Gesellschaft, die sich ohne Motorisierung ergeben hätte, vorauszusagen, ist eine vernünftige Antwort kaum zu erwarten.

So bleibt letztendlich nur, die Ergebnisse der statischen Modelle zu akzeptieren und anzunehmen, daß eine optimale Allokation der Ressourcen in der Gegenwart auch in einen sinnvollen Entwicklungspfad mündet.

\subsubsection{Defizite der Beforderermärkte}

Bei der Analyse der Beförderermärkte werden grundsätzlich dieselben Formen des Marktversagens untersucht wie bei den Infrastrukturmärkten. Während bei letzteren jedoch der Schwerpunkt eindeutig bei der Problematik sinkender Durchschnittskosten zu suchen ist, ist das hervorstechende Merkmal der Transporteure vor allem der hohe Anteil externer Kosten an den Gesamtkosten.

Dennoch soll zunächst eine Form des Marktversagens im Beförderermarkt folgen, die ursächlich auf die Existenz sinkender Durchschnittskosten zurückzuführen ist. Es handelt sich hierbei um die Problematik der sogenannten ruinösen Konkurrenz, die vor allem im Zusammenhang mit dem Verkehrssektor intensiv diskutiert wurde. Obwohl seine empirischen Relevanz stark umstritten, eventuell sogar das Konzept als solches uberholt ist, ${ }^{34}$ soll es aufgrund seiner langen Dominanz in der verkehrspolitischen Diskussion dennoch kurz dargestellt werden.

In der Wettbewerbstheorie wird die Verdrängung ineffizienter Anbieter zu den Aufgaben des Wettbewerbs gezählt. Es ist damit besonders erklärungsbedürtig, wenn ein Wettbewerb als ruinös bezeichnet wird. ${ }^{35}$ Ruinös ist ein Wettbewerb dann, wenn er zum Ausscheiden effizienter Anbieter fuhrt oder wenn Besonderheiten der Mărkte ein Ausscheiden von Anbietern verhindern und dadurch dauerhafte, gesamtwirtschaftlich ineffiziente Preiskämpfe stattfinden.

Dies sei kurz graphisch erlăutert:

34 Vgl. Koberlein, C. (1997), S. 129.

$35 \mathrm{Zu}$ den folgenden Ausfuhrungen vgl. Suntum, U. van (1986), S. $61 \mathrm{ff}$. 
Abb. 6: Ruinőse Konkurrenz

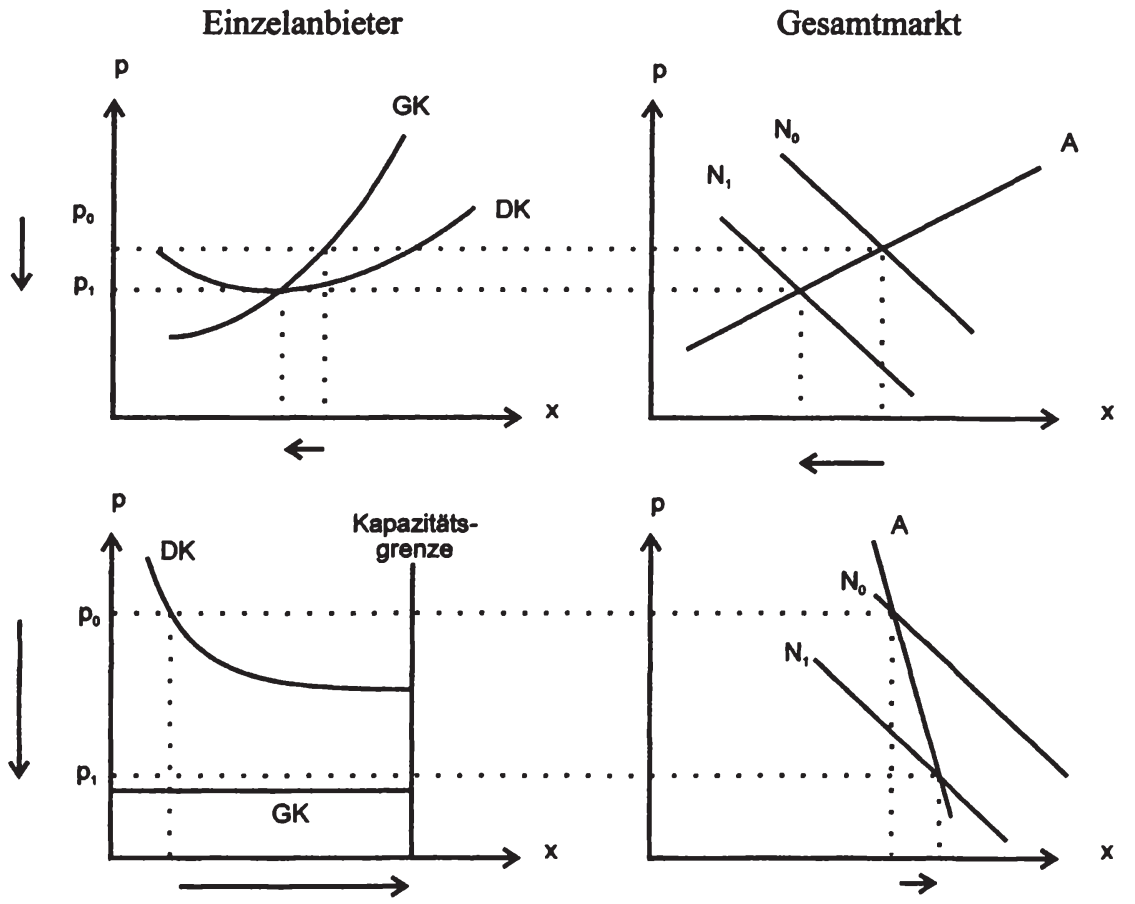

Quelle: Suntum, U. v. (1986), S. 62.

Im oben dargestellten Normalfall eines U-formigen Durchschnittskostenverlaufs führt ein Nachfragerückgang zu einer „weichen“ Anpassung des Angebots: Da der Anbieter nach der Regel Preis = Grenzkosten handelt, wird er sein Angebot einschränken, indem er z. B. Überstunden abbaut, unrentable Betriebsteile stillegt usw. Kurzfristig wird er auch zu Preisen unterhalb der Durchschnittskosten, also im Verlustbereich, anbieten, langfristig muß er jedoch aus dem Markt ausscheiden. Liegt jedoch eine Kostenstruktur wie im unten dargestellten Fall vor, ist eine Reduktion des Angebots als Folge sinkender Nachfrage nicht zu erwarten: Die fortwăhrende Durchschnittskostendegression (im Beispiel aufgrund hoher Fixkosten) fuhrt $\mathrm{zu}$ inversen Angebotsreaktionen: Die Produzenten versuchen, die Preisrückgånge dadurch zu kompensieren, daß sie ihre Kapazităten in noch höherem Maße auslasten. Durch dieses unelastische Angebot fuhren - wie aus obiger Darstellung abzulesen ist - gleiche Nachfragerückgånge zu weit größeren Preisänderungen, als im daruber abgebildeten Normalfall. Naturlich müssen auch hier verlustbringende Überkapazităten langfristig abgebaut werden. Sind diese Kapazi- 
täten jedoch sehr langlebig, verläuft die Anpassung also schleppend, können in Folge des andauernden Preiskampfes auch solche Unternehmen gefährdet werden, die in einem normalen Anpassungsprozeß uberlebt hätten. Es kann also möglich sein, daß nicht die Unternehmen mit den höchsten Durchschnittskosten aus dem Markt ausscheiden, sondern effiziente Anbieter.

Das Argument ruinöser Konkurrenz hat seit dem Zweiten Weltkrieg eine tragende Rolle für die Regulierung der Verkehrsmärkte ${ }^{36}$ gespielt. ${ }^{37}$ Bei den mobilen Anlagen des Straßengliterverkehrs sind hohe Fixkosten allerdings kaum feststellbar: Eine weiche Anpassung ist z. B. durch die Einstellung von Nacht- und Sonntagsfahrten möglich, zudem ist die Ladekapazität wohl ausreichend teilbar, so daß eine Reduktion durch Aussonderung abgeschriebener Transportmittel möglich ist. Als Besonderheit wird oft angesehen, daß die Kosten für leere Rückfahrten zu tragen sind und Transporteure daher um jeden Preis Ruckfracht annehmen, damit aber die Preise der Hinfahrer verderben. Das Argument kann näherer Betrachtung jedoch kaum standhalten. Ein vernünftig wirtschaftender Transportunternehmer wird eine Mischkalkulation aus Hin- und Rückfracht vornehmen und sich damit am Markt behaupten, wenn er dabei geschickt genug ist.

Ruinöse Konkurrenz erfordert zudem auf Seiten der Nachfrager plötzliche, unvorhersehbare Nachfragesenkungen. Ist eine Abnahme der Nachfrage absehbar, können Kapazitäten rechtzeitig abgebaut werden, ohne daß es zu den befürchteten Anpassungsproblemen kommt. Ebenfalls unzureichend für die Entstehung von ruinöser Konkurrenz sind die in der Einleitung beschriebenen Nachfrageschwankungen. Werden in Nachfragetälern nicht die gesamten Kosten gedeckt, ist dies im allgemeinen kein Grund zur Marktregulierung, sondern kann durch entsprechende Aufschläge zu Spitzenlastzeiten ausgeglichen werden. ${ }^{38}$

Insgesamt hat das Argument ruinöser Konkurrenz stark an Anziehungskraft verloren und wird im allgemeinen nicht mehr zur Rechtfertigung einer marktregulierender Maßnahmen herangezogen.

Das im Zusammenhang mit dem Verkehrssektor am intensivsten diskutierte Marktversagen ist das Vorliegen externer Effekte. Aufgrund seiner besonderen Eigenschaften weichen bei der Straßennutzung private und soziale Kosten ungleich stärker als in anderen Sektoren voneinander ab. Die Quantifizierung dieser Differenz, also der externen Effekte, spielt in der wissenschaftlichen und politischen Diskussion eine wichtige Rolle. Im folgenden Abschnitt werden daher die Ansätze zur Bestimmung dieser Externalităten kurz diskutiert.

36 Stărker als beim Straßengaterverkehr hat das Argument bei der Regulierung der Binnenschiffahrt durchgeschlagen und in mehreren staatlich subventionierten Abwrackaktionen gemündet. 
Externe Effekte unterliegen definitionsgemäß keiner marktlichen Bewertung. Um das Ausmaß des Marktversagens trotz fehlender Marktpreise dennoch bestimmen zu können, müssen die entsprechenden Wohlfahrtswirkungen - aus Gründen der Vergleichbarkeit ausgedrückt in Preisen - mit anderen Meßmethoden bestimmt werden. Diesen Meßmethoden können unterschiedliche theoretische Konzepte zugrunde liegen, die Konsumentenrente, die kompensierende Einkommensvariation und die äquivalente Einkommensvariation. Diese sollen zunächst kurz vorgestellt werden, da die Auswahl des grundsätzlichen Bewertungsansatzes und der darauf aufbauenden Instrumente in der Praxis nicht unwesentliche Auswirkungen auf das Ergebnis bei der Bewertung von Externalitäten hat.

Die Konsumentenrente KR entspricht der Differenz zwischen maximaler Zahlungsbereitschaft und Preis. Eine Maßnahme, in Abb. 5 dargestellt als Preissenkung, führt zu einer Erhöhung dieser Konsumentenrente um $\triangle K R$, welche das $\mathrm{Maß}$ fur die Wohlfahrtsänderung des betroffenen Individuums darstellt.

Abb. 7: Die Konsumentenrente

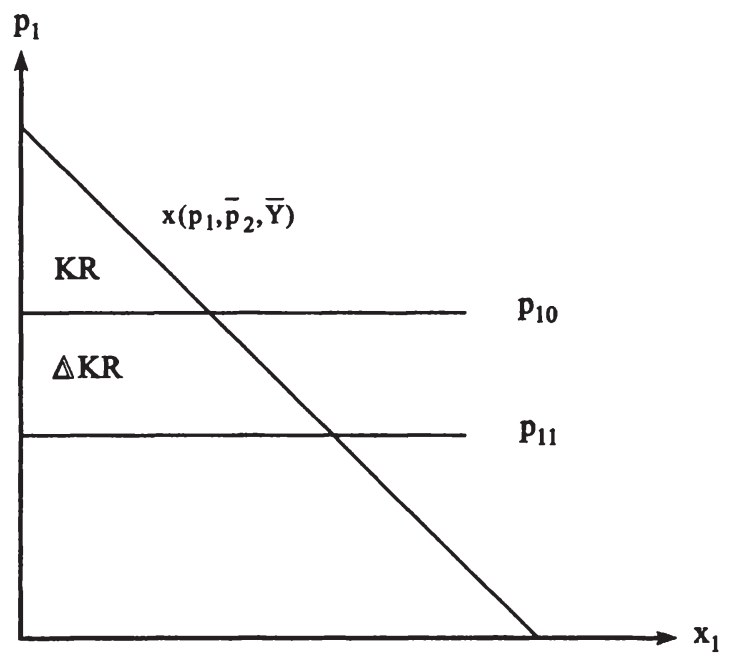

Der theoretische Nachteil bei der Benutzung der Konsumentenrente als Wohlfahrtsma $\beta$ ist, daß die beobachtete Nachfrage als Indikator individueller Wertschătzung herangezogen wird. Die Nachfragefunktion zeigt an, welche Menge der Konsument bei jedem Preis nachfragt. Bei der dargestellten Preissenkung resultiert ein Teil der zusätzlichen Nachfrage und damit der Änderung der Konsumentenrente allerdings nicht aus der Preissenkung selbst - mithin der Verbilligung der letzten Einheit - sondern aus der Einkommenserhöhung, die aus 
der Verbilligung aller Einheiten herrührt. Die Konsumentenrente ist daher nicht allein aus der zugrundeliegenden Nutzenfunktion zu erklären, sondern wird auch durch die Einkommensrestriktionen des jeweiligen Individuums bestimmt. Anders gesagt entspricht die Marshallsche Konsumentenrente der Nutzenänderung des jeweiligen Individuums, welche mittels eines Gewichtungsfaktors, dem Grenznutzen des Einkommens, in monetăre Größen transformiert wurde. Sie ist damit nur dann ein exaktes $\mathrm{Ma} ß$ individueller Wertschätzung, wenn der Grenznutzen des Einkommens bei beliebigen Preisänderungen konstant ist, was als äußerst restriktive Annahme gelten muß. ${ }^{39}$

Das Problem der induzierten Einkommensänderungen wird gelöst, indem man statt der Konsumentenrente die kompensatorische oder die äquivalente Einkommensvariation als Maße für Nutzenänderungen verwendet.40 Beide seien am Beispiel der schon oben diskutierten Preissenkung kurz skizziert.

Abb. 8: Kompensatorische Einkommensvariation

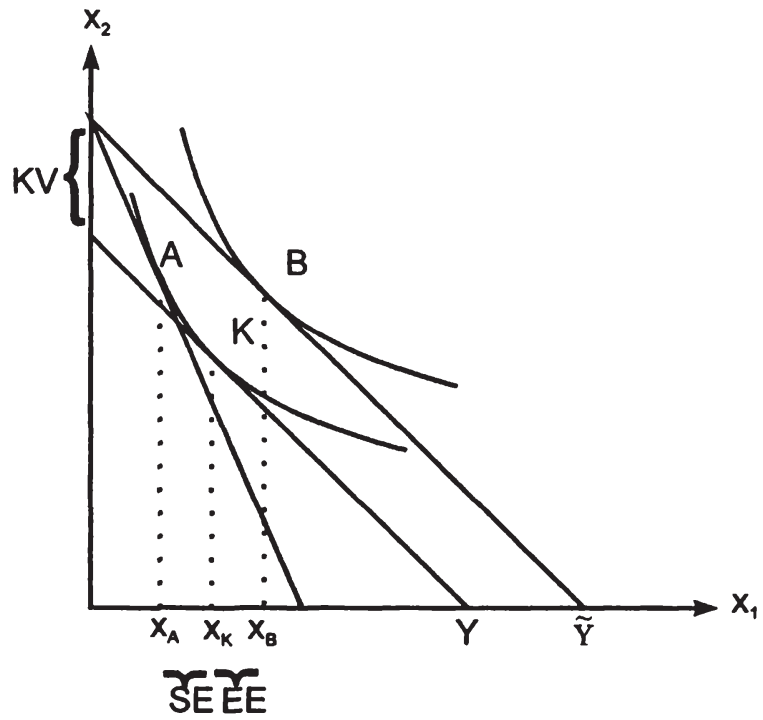

Die sogenannte kompensatorische Einkommensvariation fragt, welche Änderung seines Einkommens ein Konsument erfahren müßte, um zwischen der Ausgangssituation und den neuen Preisen indifferent zu sein. Sie kann im Beispiel gemes-

39 Vgl. Freeman III, A. M. (1993), S. $50 \mathrm{f}$.

$40 \mathrm{Vgl}$. zu den folgenden Ausfuhrungen Freeman III, A. M. (1993), S. 52ff. 
sen werden, indem man den Geldbetrag bestimmt, den ein Konsument maximal für eine Preissenkung zahlen würde.

In Abb. 8 entspricht die kompensatorische Einkommensvariation eines Übergangs von A nach B der Differenz zwischen $\tilde{Y}$ und $Y$. Technisch gesehen wird die Einkommensgerade um die alte Indifferenzkurve gedreht, bis das Preisverhältnis demjenigen nach Preisănderung entspricht. Der entsprechende Tangentialpunkt $\mathrm{K}$ stellt diejenige Guterkombination dar, in der der Preis furr $\mathrm{x}_{1}$ dem neuen Preis entspricht und das Individuum dasselbe Nutzenniveau wie in der Ausgangslage hat.

Die åquivalente Einkommensvariation fragt, welche Einkommensănderung bei gegebenen Preisen dieselbe Auswirkung auf die Wohlfahrt des Konsumenten hat wie die zu analysierende Preisänderung. Sie wird gemessen, indem man den Betroffenen fragt, wieviel zusătzliches Einkommen man ihm bieten müßte, damit er auf eine Preissenkung verzichtet. Als Referenz dient also im Gegensatz zur KV das Nutzenniveau nach Durchfuhrung der Maßnahme. Um es festzustellen, wird die Einkommensgerade um die neue Indifferenzkurve gedreht, bis ihre Steigung derjenigen vor der Preisänderung entspricht.

Abb. 9: Äquivalente Einkommensvariation

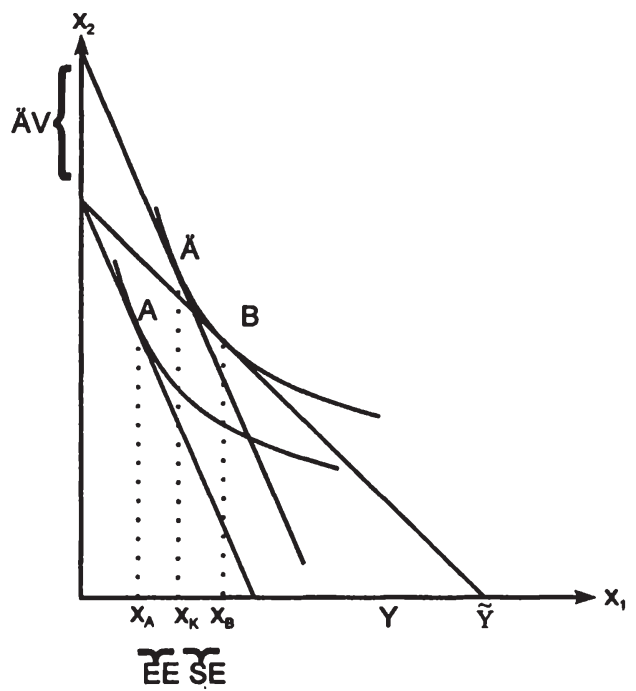

Die beiden Maße führen nur dann zum selben Ergebnis, wenn die Einkommenselastizităt der Nachfrage von $\mathrm{x}_{1}$ gleich Null ist. ${ }^{41}$ Ist sie größer Null, ubertrifft im hier dargestellten Fall einer Preissenkung die äquivalente Einkommensvariation

41 Dies setzt quasilineare Praferenzen voraus. Vgl. Varian, H. (1989), S. 239 ff. 
die kompensatorische. Bei Preissteigerungen dagegen ist es genau umgekehrt. Anders gesagt ist die Zahlungsbereitschaft (willingness to pay) regelmäßig niedriger als die notwendige Kompensation (willingness to accept). Welches Maß letztlich zur Bestimmung von Nutzenänderungen verwendet wird, ist eine Werturteilsentscheidung. ${ }^{42}$

Nach Darstellung der theoretischen Konzepte sollen die daraus abgeleiteten konkreten Meßverfahren skizziert werden. Den Zahlungsbereitschaftsansätzen liegt die äquivalente oder kompensatorische Einkommensvariation zugrunde, den Schadensbewertungs- und Vermeidungsansătzen das Konzept der Konsumentenrente.

Abb. 10: Mogglichkeiten zur Bewertung von Externalităten

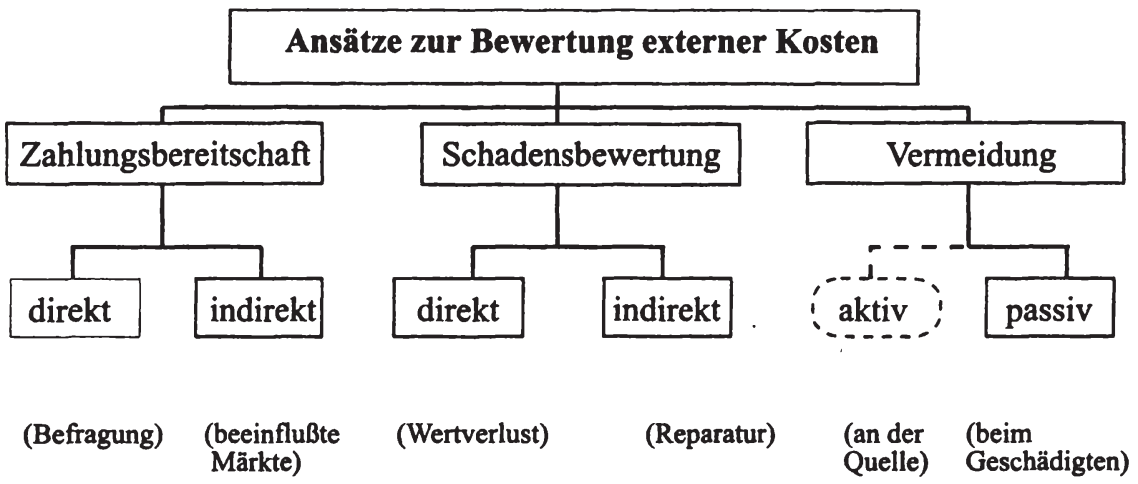

Quelle: Neuenschwander, R., H. Sommer, et al. (1992), S. 440.

Der direkte Ansatz zur Ermittlung der Zahlungsbereitschaft ist die Befragung. ${ }^{43}$ Hierbei wird unter kontrollierten Bedingungen ermittelt, wieviel man den Betroffenen für den entstandenen Schaden zahlen müßte, um sie zu kompensieren (willingness to accept) oder wieviel diese für die Nichtentstehung des Schadens zahlen (willingness to pay) würden. Als Kritik an diesem Ansatz werden in der Literatur das Trittbrettfahrerproblem und das Souveränitätsproblem angegeben. Ersteres meint die systematische Falschangabe von Präferenzen, sogenanntes strategisches Verhalten. Ist z. B. unwahrscheinlich, daß die Angabe einer Zahlungsbereitschaft tatsächlich zu Zahlungen in der Zukunft fuhrt, haben die Betroffenen einen Anreiz, ihre Präferenzen zu übertreiben. Unter dem Souveränitätsproblem versteht man, daß die Annahme vollinformierter, rational handelnder Individuen in der Realität kaum aufrecht erhalten werden kann. Eine Entscheidung wird also

42 Freeman III, A. M. (1993), S. 58.

$43 \mathrm{Zu}$ den folgenden Ausfuhrungen vgl. UIC (1995), S. $34 \mathrm{ff}$. 
in manchen Fällen nicht aufgrund der eigenen Präferenzen, sondern aus Unkenntnis der wahren Lage getroffen.

Unter dem indirekten Ansatz versteht man die Ableitung von Zahlungsbereitschaften durch Beobachtung von Märkten, welche vom jeweiligen externen Effekt beeinflußt werden (hedonic regression) ${ }^{44}$. Ein typisches Beispiel ist die Immobilienwertmethode. Da der Preis einer Immobilie neben vielem anderen auch z. B. vom Vèrkehrslärm abhängt, versucht man diesen Faktor zu isolieren und damit die Kosten des Lärms zu ermitteln. Voraussetzung ist natürlich, daß der Preis auf dem jeweiligen Markt tatsächlich die Knappheitsverhältnisse korrekt wiedergibt.

Beide Ansätze versuchen, die individuelle Bewertung der Externalitäten zu ermitteln. Oftmals sind direkte Befragungen aber zu kostspielig oder aus anderen Gründen nicht möglich und die indirekte Methode ist nicht anwendbar, weil beeinflußte Märkte nicht existieren. In diesem Fall muß auf Ersatzverfahren zurlickgegriffen werden.

Die Schadensbewertung zur Ermittlung externer Effekte (auch als Ressourcenansatz bezeichnet) ist eine direkt mit dem monetären Schaden verknüpfte Methode. Dabei werden alle Ressourcenschädigungen erfaßt und mit dem Wert entgangener Erträge (direkte Schadensbewertung) oder den Kosten des Ersatzes (indirekte Schadensbewertung) erfaßt. Ein Problem der Kostenwertansätze ist aber, daß sie implizit die Ersetzbarkeit der geschädigten Ressourcen annehmen.

Der Vermeidungsansatz bestimmt die Kosten der Vermeidung eines Schadens. Typisches Beispiel dafür sind Lärmschutzmaßnahmen an Straßen. Auch dieser Ansatz ist nicht ohne Probleme anwendbar. Jede Maßnahme kann außer dem gewünschten Effekt noch andere Wirkungen auf die Wohlfahrt des Individuums haben, beispielsweise dient ein Fenster nicht nur dem Lärmschutz, hat also zusätzliche positive Nutzen, während z. B. eine Lärmschutzwand in bezug auf die Gerăuschreduktion effizient sein mag, jedoch kein optischer Gewinn ist und die Sicht behindert und somit auch negativ auf die Wohlfahrt der Anwohner wirkt. Eine Reparatur kann zudem Kosten verursachen, die in keinem erkennbaren Verhältnis zum entstandenen Schaden stehen. Dazu sei ein Beispiel aus jüngerer Zeit genannt: „Der Schutz von 32 Großtrappen vor den Oberleitungen des ICE Hannover - Berlin im Havelländer Luch wird auf eine Million DM pro Vogel geschătzt “45.

Je nach Bewertungsverfahren können sich große Unterschiede in den Ergebnissen ergeben. Einen entsprechenden Vergleich stellt GLƠCK an, der die verschiedenen Bewertungsverfahren hinsichtlich ihrer Bewertung des Nutzens der Lärmreduktion vergleicht. Insbesondere bei großen Schädigungen - also hohem Gerăuschpe-

44 Neuenschwander, R., H. Sommer, et al. (1992), S. 439.

45 Tegner, H. (1997), S. 37. 
gel, in Abb. 11 an der Abszisse abgetragen - weichen die Verfahren deutlich voneinander ab, die Auswahl der Meßmethode ist also von wesentlicher Bedeutung für das resultierende Ergebnis.

Abb. 11: Der Nutzen der Lărmreduktion

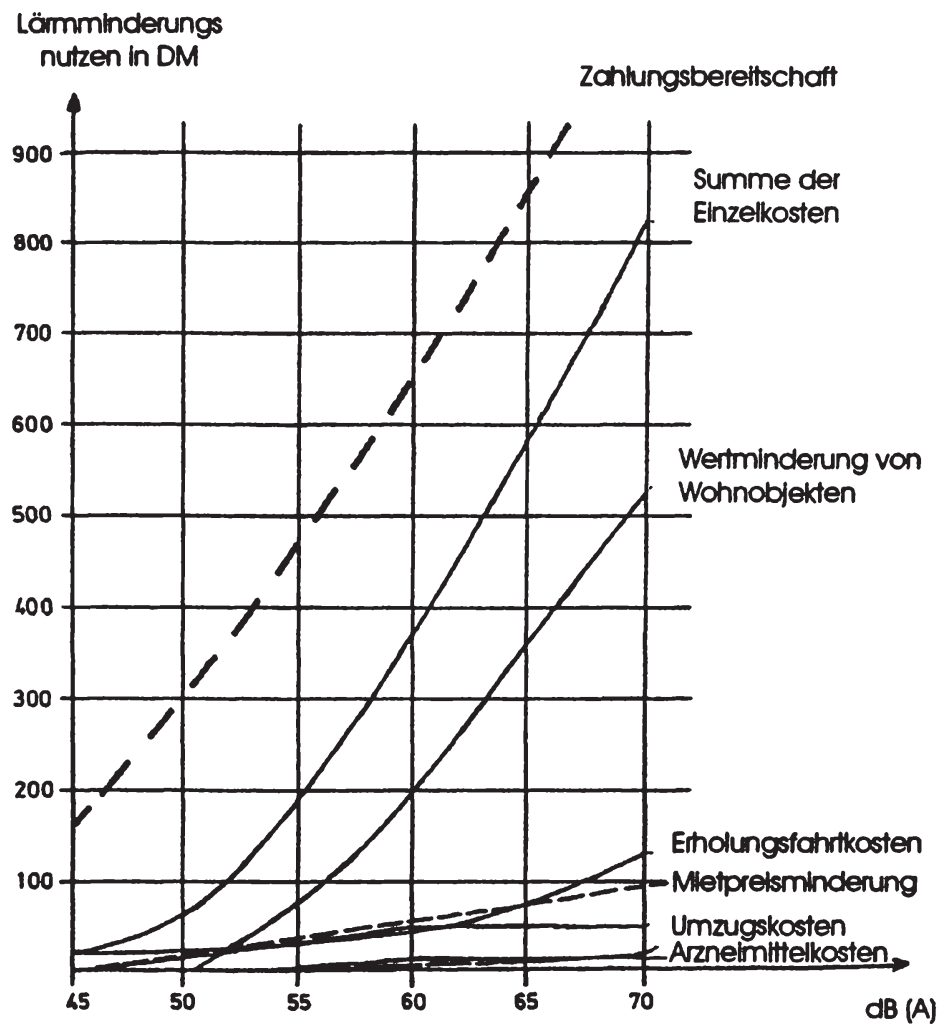

Quelle: Glück, K. (1986), S. 191.

Bevor die Externalităten im nächsten Abschnitt quantifiziert werden, soll ein einzelner Effekt, der Stau, noch einer genaueren Untersuchung unterzogen werden. Ziel unserer Analyse soll sein, eine Beziehung zwischen den Fahrtkosten der einzelnen Verkehrsteilnehmer und dem gesamten Verkehrsaufkommen auf einem Streckenabschnitt darzustellen.

Die Art des Zusammenhanges zwischen den Kosten einer Fahrt und dem Verkehrsaufkommen hăngt von der zugrunde liegenden Theorie des Verkehrsflusses ab. Definitionsgemäß gilt zunächst folgender Zusammenhang: 
Der Verkehrsfluß, d.h. die Anzahl der Fahrzeuge, die in einem bestimmten Zeitraum einen Streckenabschnitt durchqueren, also Fahrzeuge pro Stunde, ist das Produkt aus der Verkehrsdichte (Anzahl von Fahrzeugen auf einem bestimmten Streckenabschnitt, gemessen in Fahrzeuge pro Kilometer) und der Geschwindigkeit.

$\frac{\text { Fahrzeuge }}{\text { Stunde }}=\frac{\text { Fahrzeuge }}{\text { Kilometer }} \times \frac{\text { Kilometer }}{\text { Stunde }}$
Verkehrsfluß $=$ Verkehrsdichte

Entsprechend der sogenannten hydrodynamischen Theorie des Verkehrs, welche Verkehr als eine verdichtbare Flüssigkeit ohne Masse abbildet, wird eine bestimmte Beziehung zwischen Verkehrsfluß und Verkehrsdichte modelliert ${ }^{46}$ : Ein Verkehrsfluß von Null liegt bei einer Dichte von Null und der sogenannten Staudichte vor, bei der die Geschwindigkeit des Verkehrs Null wird. Dazwischen existiert eine Verkehrsdichte und eine dazugehörige Verkehrsgeschwindigkeit, bei der der Verkehrsfluß ein Maximum erreicht.

Abb. 12: Darstellung des VerkehrsfluBverhaltens

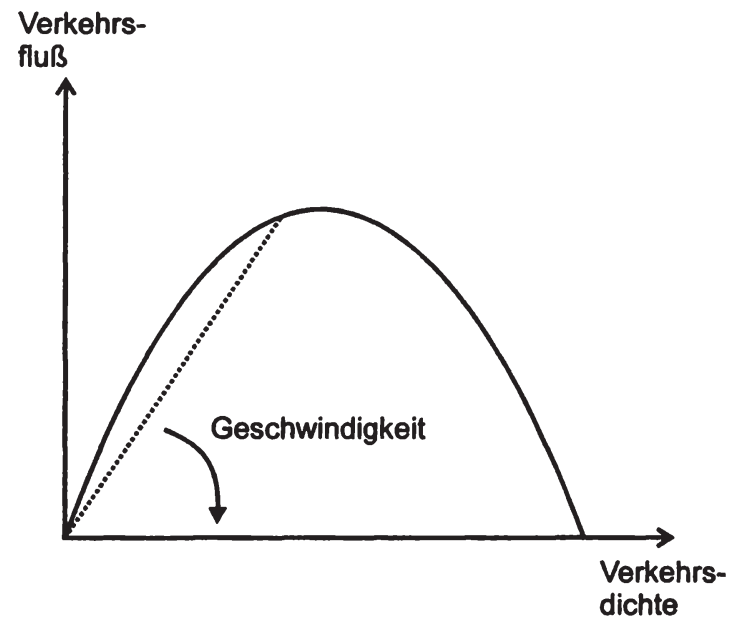

Quelle: Bell, M. G. H. und Y. Lida (1997).

Der hier abgebildete Zusammenhang laßßt sich wie folgt erklären: Zusătzliche Fahrzeuge bedeuten eine erhơten Verkehrsdichte, welche innerhalb dieses Modells gleichzeitig eine sinkende Geschwindigkeit zur Folge hat. Da Geschwindigkeit der Quotient aus Verkehrsfluß und Verkehrsdichte ist, kann sie in obigem

46 Vgl. Bell, M. G. H. and Y. Iida (1997), S. 6 f. 
Diagramm als Fahrstrahl aus dem Ursprung abgelesen werden. Die sinkende Geschwindigkeit führt durch die im Modell steigende Verkehrsdichte zunächst zu steigendem Verkehrsfluß. Ab der optimalen Verkehrsdichte überkompensiert sie jedoch den Dichteeffekt und der Verkehrsfluß nimmt ab.

Übertragen in ein Geschwindigkeits-/Verkehrsfluß-Diagramm ergibt sich aus der Grunddarstellung in Abb. 12 folgende Darstellung:

Abb. 13: Relation zwischen Geschwindigkeit und Verkehrsfluß

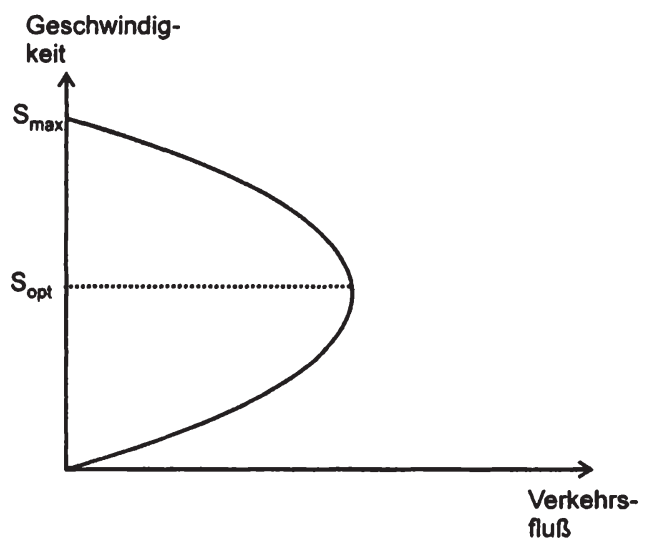

Quelle: Hau, T. D. (1998).

Die Reisegeschwindigkeit und damit die Zeit, die man furr eine bestimmte Strecke benötigt, determiniert zum großen Teil die Kosten einer Fahrt. ${ }^{47} \mathrm{Da}$ diese positive Abhängigkeit existiert, können die Kosten auch in Abhängigkeit vom Verkehrsfluß dargestellt werden:

Die durchschnittlichen Fahrtkosten sind diejenigen Kosten, die der jeweilige Verkehrsteilnehmer selbst zu tragen hat. Sie erhöhen sich leicht bis zum maximalen Verkehrsfluß (vgl. Abb. 13), da bis zu diesem Punkt schon signifikante gegenseitige Störungen der Verkehrsteilnehmer stattfinden. Ab dem maximalen Verkehrsfluß steigen die durchschnittlichen Fahrtkosten bzw. Verzögerungen exponentiell an und der gesamte Verkehrsfluß geht zurlick. Dadurch erhält diese Kostenkurve ihre charakteristische rückwärtsgebogene Form, die aus der Beziehung zwischen Geschwindigkeit und Verkehrsfluß entstanden ist.

47 Naturlich existieren noch viele andere variable private Kosten, z. B. Treibstoffverbrauch oder Fahrzeugabnutzung. Diese hăngen jedoch nach allgemeiner Auffassung nicht vom Verkehrsfluß ab, sind also in obiger Darstellung Lageparameter. 
Abb. 14: Relation zwischen Fahrtkosten und Verkehrsflub

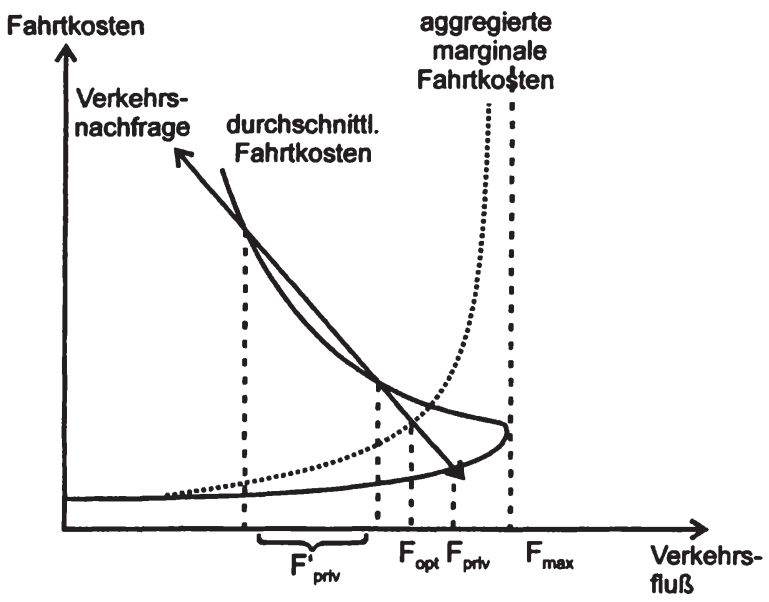

Quelle: Hau, T. D. (1998).

Die aggregierten marginalen Fahrtkosten sind die kumulierten Kosten, die die Gesamtheit der Verkehrsteilnehmer durch einen zusätzlichen Straßennutzer zu tragen hat, sie entsprechen somit den marginalen sozialen Kosten der Straßennutzung. Diese steigen logischerweise weit stärker an und năhern sich beim maximalen Verkehrsfluß $F_{\max }$ asymptotisch einer Senkrechten. Führt man eine Verkehrsnachfragekurve ein, lassen sich die Implikationen der externen Staukosten erkennen: Bei $F_{\text {priv, }}$, dem Punkt, ab dem der Nutzen einer zusätzlichen Fahrt gerade den individuellen Kosten in Form von Zeitverlusten entspricht, liegt die Geschwindigkeit, abzulesen als Fahrtkosten an der Ordinate, niedriger als im Optimum $F_{\text {opt, }}$ bei dem die Nachfrage den aggregierten marginalen Fahrtkosten, also den gesellschaftlichen Kosten einer zusätzlichen Fahrt, entspricht. Eine Ausrichtung der Fahrtentscheidung an den privaten Kosten fuhrt also zu einer höheren Verkehrsdichte und in deren Folge zu längeren Fahrtzeiten, als gesamtwirtschaftlich optimal wäre.

Die Punkte $F_{\text {priv }}$ sind furr unsere Betrachtung weniger relevant, da sie keine effizienten Gleichgewichte darsstellen. Sie sind dennoch von hoher mpirischer Relevanz. Sie kennzeichnen Situationen, in denen Gleichgewichte bei geringer Geschwindigkeit und geringem Verkehrsfluß existieren. Obwohl 8konomisch hoch ineffizient, sind sie doch jedem als Urlaubsstau oder aus überlasteten Innenstådten bekannt. Wir haben also nicht nur das Problem externer Staukosten, sondern auch eine Situation mit multiplen Gleichgewichten. 


\subsection{Empirie}

\subsubsection{Die Kosten der Infrastruktur}

In diesem Abschnitt sollen die in 2.2.1 dargelegten Probleme, die auf ein Marktversagen im Infrastrukturbereich hindeuten, mit einigen Daten untermauert werden.

Bei der Ermittlung der Infrastrukturkosten werden in der Literatur verschiedene Berechnungsmethoden diskutiert. Am weitesten verbreitet sind die betriebswirtschaftliche Vollkostenrechnung und die kameralistisch-fiskalische Methode, welche im folgenden kurz skizziert werden sollen. ${ }^{48}$

Die betriebswirtschaftliche Vollkostenrechnung interpretiert die Straßennutzung als Verbrauch des in den Verkehrswegen gebundenen Potentials an Wegenutzung. $\mathrm{Da}$ das Ziel die Substanzerhaltung der Verkehrswege ist, ist die Berechnung als Vollkostenrechnung konzipiert. In der Bundesrepublik wird diese Berechnung regelmäßig vom Deutschen Institut fur Wirtschaftsforschung (DIW) im Auftrag des Bundesverkehrsministeriums durchgefuhrt. ${ }^{49}$ Dazu wird zunächst das Bruttoanlagevermögen als Summe der kumulierten Investitionen abzïglich Desinvestitionen berechnet und dann mittels spezifischer Preisindizes der Wiederbeschaffungswert ermittelt. Die jährlichen Kapitalkosten setzen sich dann aus den Abschreibungen des Bruttoanlagevermögens und einer kalkulatorischen Verzinsung des nach Abschreibung verbleibenden Nettovermögens zusammen. $\mathrm{Zu}$ diesen Kapitalkosten werden die laufenden Kosten für Unterhaltung, Betrieb und Verwaltung addiert und die nicht dem Verkehr zuzurechnenden Kosten der Verkehrsinfrastruktur, also der Teil, der z. B. verteidigungs- oder regionalpolitisch motiviert ist, abgezogen.

Daneben existiert die kameralistisch-fiskalische Methode. Sie ermittelt kein betriebswirtschaftliches Ergebnis im Sinne eines Gewinnes oder Verlustes, sondern einen Einnahmenüberschuß oder -verlust. Es wird also lediglich gefragt, ob die im jeweiligen Jahr angefallenen Ausgaben fur Bau und Erhalt der Verkehrswege durch die dem Verkehr zugerechneten Steuereinnahmen (Kfz-Steuer, Mineralölsteuer, Parkgebühren und Mehrwertsteuer auf Mineralölprodukte) gedeckt sind. Dazu werden die Wegeausgaben eines Jahres ermittelt und um einen sogenannten „Staatsanteil" korrigiert. Dieser soll, wie im betriebswirtschaftlichen Ansatz auch, berlicksichtigen, daß ein Teil der Verkehrswege aus strategischen oder regionalpolitischen, also verkehrsfremden, Gründen errichtet und betrieben wird.

$48 \mathrm{Zu}$ den folgenden Ausfuhrungen vgl. Koberlein, C. (1997), S. $176 \mathrm{ff}$.

$49 \mathrm{Vgl}$. Enderlein, H. und U. Kunert (1992). 
Vergleicht man die Kosten des gesamten Straßennetzes in 1987 mit den Ausgaben, ergeben sich dem Verkehr zuzurechnende Kosten in Höhe von 33.336 Mill. DM und Ausgaben in Höhe von 23.425 Mill. DM. ${ }^{50}$ Die Differenz zwischen der kosten- und der ausgabenorientierten Methode ist in erster Linie durch die Mitberücksichtigung der kalkulatorischen Zinsen beim Kostenansatz zu erklăren. Deren Einbeziehung, die auch von der Europäischen Kommission präferiert wird, ist ein Streitpunkt in der wissenschaftlichen Diskussion. Gegner argumentieren, daß unternehmenszielbezogene Kostenabgrenzungen wie kalkulatorische Zinsen in gesamtwirtschaftlichen Analysen fehl am Platze wären. Begründet wird dies mit dem fehlenden Zusammenhang zwischen den wirtschaftlichen Erfordernissen und den tatsächlichen Infrastrukturinvestitionen, die oftmals aus rein politischem Kalkul getătigt wurden ${ }^{51}$. Das gesamte kostenorientierte Verfahren habe zudem mit kaum lösbaren Bewertungsproblemen zu kämpfen, so müssen die Wiederbeschaffungskosten, die Art der Abschreibung sowie die Höhe des kalkulatorischen Zinssatzes ermittelt werden. Die Befurworter dagegen führen an, daß erst die Miteinbeziehung der Zinsen den zeitlichen Aspekt des Verzichts auf alternative Verwendungen angemessen bericksichtige. ${ }^{52}$ Gleiches gilt natülich fur den Abzug des Staatsanteiles beim Ausgabenansatz, welcher ebenfalls dem Vorwurf der Beliebigkeit ausgesetzt ist.

Die Diskussion um den richtigen Ansatz kann in dieser Arbeit nicht weitergefuhrt werden. Das kostenorientierte Verfahren ist das theoretisch korrekte, aber mit großen Bewertungsunsicherheiten behaftet, das ausgabenorientierte Verfahren dagegen kann zwar auf leicht verfügbare Daten der Finanzstatistik zurückgreifen, ignoriert jedoch die Opportunitätskosten der Kapitalverwendung.

Ein weiterer Ansatz, die volkswirtschaftliche Methode der sozialen Grenzkosten, berucksichtigt im Gegensatz zu den beiden genannten Methoden keine tatsächlich angefallenen Kosten, sondern entgangene Erträge alternativer Verwendungen, d. h. Opportunitătskosten. Daraus folgt, daß einmal getătigte Investitionen in Verkehrsinfrastruktur, für die keine alternative Verwendung existiert (sunk costs), nicht berücksichtigt werden. Dafür werden die im Abschnitt 2.2.2 diskutierten sozialen Grenzkosten mit in die Wegekosten aufgenommen. Diese Berechnungsmethode spielt allerdings praktisch keine Rolle in der Wegekostendiskussion, umfassende Berechnungen existieren nicht.

Nach kurzer Darstellung der Verfahren sollen die tatsächlichen Kosten der StraBenverkehrsinfrastruktur fur Deutschland, bewertet nach der Methodik des DIW, kurz skizziert werden. Die Kosten des Anlagevermögens setzen sich aus der Verzinsung und der Abschreibung des eingesetzten Kapitals zusammen. Unten darge-

so Vgl. Enderlein, H. und U. Kunert (1990), S. 71 und 98.

51

Vgl. dazu Aberle, G. (1984), S. 181 f.

32 Vgl. Enderlein, H. und U. Kunert (1990), S. 14 ff. 
stellte Tabelle (Abb. 15) gibt in der ersten Zeile das Bruttoanlagevermögen zu Wiederbeschaffungswerten wieder. Vermindert man die Größe um die kalkulatorischen Abschreibungen, erhält man das Netto-Anlagevermögen, mithin den Zeitwert der Bundesfernstraßen. Die Abschreibung erfolgt linear uber eine geschätzte mittlere Nutzungsdauer (vgl. Abb. 16). Das Netto-Anlagevermögen bildet die Bezugsgröße fur die kalkulatorischen Zinsen, die vom DIW mit einem realen Zinssatz von $2,5 \%$ angesetzt werden. ${ }^{53}$

Die laufenden Kosten umfassen zum einen die Unterhaltung der Straßen, d. h. alle nicht investiven Aufwendungen im Straßenbau, zum anderen den Betrieb, der im wesentlichen aus den Kosten für die Verkehrspolizei besteht. Wie aus Abb. 15 erkennbar ist, ubertreffen die jährlichen Fixkosten die laufenden Kosten in etwa um ein Vierfaches.

Die Abschreibung als $\mathrm{Maß}$ für die Entwertung der Anlagen spiegelt den grundsätzlichen Investitionsbedarf einer Periode wieder. $\mathrm{Da}$ das BruttoAnlagevermögen $\mathrm{zu}$ Wiederbeschaffungswerten angesetzt wurde, sind dies neben reinen Ersatz- auch Modernisierungsinvestitionen.

Abb. 15: Wegekostenrechnung fur die Bundesautobahnen (Mill. DM)

\begin{tabular}{|l|l|l|l|}
\hline & 1981 & 1984 & 1987 \\
\hline Brutto-Anlagevermögen & 89.772 & 96.852 & 107.901 \\
\hline Netto-Anlagevermögen & 79.565 & 83.799 & 90.567 \\
\hline Kapitalkosten & 3.289 & 3.679 & 4.149 \\
\hline Abschreibungen & 1.300 & 1.584 & 1.885 \\
\hline Zinsen (2,5\%) & 1.989 & 2.095 & 2.264 \\
\hline Laufende Kosten & 794 & 984 & 1.276 \\
\hline Unterhaltung & 311 & 389 & 449 \\
\hline Betrieb & 172 & 206 & 378 \\
\hline Gesamtkosten & 4.083 & 4.663 & 5.425 \\
\hline
\end{tabular}

Quelle: Enderlein, H. und U. Kunert (1990), S. 87.

Abb. 16: Mittlere Nutzungsdauer von Brutto-Anlageinvestitionen

\begin{tabular}{|l|c|}
\hline Investitionsaggregat & Mittlere Nutzungsdauer \\
\hline Erdbau & 116 \\
\hline Fahrbahn & 35 \\
\hline Kunstbauten & 70 \\
\hline
\end{tabular}

Quelle: Enderlein, H. und U. Kunert (1992).

33 Enderlein, H. und U. Kunert (1990), S. 15. 


\subsubsection{Die Quantifizierung der Externalităten des Straßentransports}

Studien über Externalităten im Bereich der Beforderer existieren in großer Zahl. Aufgrund der diskutierten methodischen Probleme sind sie in ihren Ergebnissen uneinheitlich. Das folgende Kapitel kann daher nur versuchen, einen Überblick uber die Bandbreite der wissenschaftlichen Studien zu geben. Vor der eigentlichen Quantifizierung soll zunächst ein Überblick uber die Art der Schäden gegeben werden.

Für diese Arbeit erscheint die Einteilung der Externalităten nach dem Kriterium der răumlichen Ausbreitung geeignet. Dieses unterteilt Schäden in die drei Kategorien global, regional und lokal. Eine solche Aufteilung wird uns später erlauben, die geeigneten Politikmaßnahmen verschiedenen staatlichen Entscheidungsebenen zuzuweisen.

Auf globaler Ebene ist die meistdiskutierte Umweltwirkung der sogenannte Treibhauseffekt. Dieser besagt grob gesprochen, daß Treibhausgase die Rückstrahlung von Wärme ins All verhindern und sich dadurch die durchschnittliche Temperatur auf der Erde erhöht.

Diese Klimaveränderung wird zum nicht geringen Teil dem Treibhausgas Kohlendioxid $\left(\mathrm{CO}_{2}\right)$ angelastet ${ }^{54}$. Von Seiten der Bundesregierung liegt daher eine Absichtserklärung vor, nach der die $\mathrm{CO}_{2}$ Emissionen bis 2005 um $25 \%-30 \%$, bezogen auf das Jahr 1987, sinken sollen. Damit soll die Erfullung der UN Framework Convention on Climate Change (FCCC) ${ }^{55}$ gewährleistet werden. Dieses Reduktionsziel wird jedoch vor allem durch den ansteigenden Primärenergieverbrauch des Transportsektors gefährdet ${ }^{56}$. Das DIW gibt fur 1991 den Anteil des Verkehrs am gesamten antropogenen $\mathrm{CO}_{2}$-Aussto $B$ in der europäischen OECDLăndern mit $24 \%$ an $^{57}$. Der Anteil des Guterverkehrs am verkehrsbedingten

54 Der Beitrag von $\mathrm{CO}_{2}$ zur Erderwărmung wird auf ca. $50 \%$ geschătzt. Genaue Daten und Wirkungszusammenhănge sind aufgrund des komplexen Sachverhaltes allerdings noch nicht bekannt: ,Neither the physical extent nor the economic effects of the greenhouse effect are yet very well understood" (Quinet, É. (1994), S. 47). Einen Überblick uber verschiedene Studien zum Klimaproblem gibt Quinet, E. (1994), S. $48 \mathrm{ff}$.

Bleijenberg, A. N., J. M. W. Dings, et al. (1997). S. 11.

$\mathrm{CO}_{2}$ entsteht als Ergebnis jedes Verbrennungsprozesses und ist damit direkt mit dem Verbrauch fossiler Brennstoffe korreliert. Wăhrend der industrielle Endenergieverbrauch der OECD - Lander sich in den letzten 20 Jahren praktisch nicht verăndert hat, ist der der Haushalte um $30 \%$, der des Verkehrs aber um $80 \%$ gestiegen. Vgl. o.V. (1995).

57 Vgl. o.V. (1995), S. 26.

Aufgrund unterschiedlicher Meßverfahren variieren die Angaben von $18 \%$ (vgl. Rutkowsky, S.(1997)) und $40 \%$. Vgl. dazu Linster, M.(1990), S. 26. Grund dafur ist, daB in einigen Studien nur der direkte Treibstoffverbrauch des Verkehrs gemessen wird, in anderen die Fahrzeugherstellung usw. mit eingeht. Vgl. dazu Teufel, D., P. Bauer, et al. (1994), S. 38. 
$\mathrm{CO}_{2}$-Ausstoß betrăgt ca. ein Viertel. Gerade dieser Anteil wird jedoch - ausgehend von 1988 - bis 2010 am stärksten wachsen. Angenommen wird eine Steigerung um ca. zwei Drittel. Allein diese Entwicklung stellt die Erreichung des angestrebten Vermeidungsziels in Frage.

Der Rahmen dieser Arbeit, die sich mit der innereuropäischen Verkehrsproblematik befaßt, erfordert nicht unbedingt eine Quantifizierung der Kosten des Treibhauseffekts. Sie soll dennoch der Vollständigkeit halber am Ende dieses Abschnitts erfolgen, wird dann aber fur den Rest der Arbeit aus der Betrachtung ausgeblendet, ohne daß damit Ruckschlüsse auf seine Bedeutung gezogen werden sollen.

Auf regionaler Ebene sind die Auswirkungen der Luftverschmutzung leichter meßbar als bei der globalen Klimaveränderung. Gerade diese regionalen Schäden sind in hohem und weiter ansteigendem Maße dem Güterverkehr zuzurechnen. ${ }^{58}$ Die Stoffe, die wesentlich zu dieser Form der Luftverschmutzung beitragen, sind Kohlenmonoxid $(\mathrm{CO})$, Kohlenwasserstoffe $(\mathrm{HC})$, Stickoxide $\left(\mathrm{NO}_{\mathrm{X}}\right)$ und Schwefeloxide $\left(\mathrm{SO}_{\mathrm{X}}\right)$. Aufgrund der niedrigeren Verbrennungstemperatur und der vollständigeren Verbrennung beim Dieselmotor ist die Emission eigentlich geringer als bei entsprechenden Benzinmotoren. Da beim Diesel jedoch eine Ruckhaltetechnik entsprechend dem Katalysator fehlt ${ }^{59}$, nimmt sein Anteil an den verkehrsbedingten Emissionen überdurchschnittlich zu. Während z. B. der LKW-Anteil an den $\mathrm{NO}_{\mathrm{X}}$-Emissionen 1991 in den alten Bundesländern knapp $40 \%$ betrug, wird bis 2010 ein Anteil von $70 \%$ erwartet. Die emittierten Komponenten sind direkt nur etwa $200 \mathrm{~m}$ rechts und links der Straßen (hier Autobahnen und BundesstraBen) feststellbar. Von größerer Bedeutung sind daher die aus den Abgasen auf photochemischem Wege gebildeten Produkte, insbesondere Photooxidantien, z. B. Ozon, und Salpetersäure. Der Bildungsprozeß des Ozons verläuft relativ langsam und der Abbau außerhalb von Belastungsgebieten ist durch die fehlende reduzierende Wirkung anderer Abgase (wie NO) geringer.

Spitzenkonzentrationen sind daher oft erst in ländlichen Gebieten mit erheblicher Entfernung zur Emissionsquelle feststellbar. Eine weitere Belastungskomponente

58 Bleijenberg, A. N., J. M. W. Dings, et al. (1997). S. 4.

59 Zur Ruckhaltung der Stickoxide ist das Verfahren der ,selektiven katalytischen Reduktion“ in der Erprobung. Es hat wahrscheinlich ein Reduktionspotential von ca. 60 - $70 \%$, ohne sich nachteilig auf Treibstoffverbrauch und Partikelemissionen auszuwirken. Die Technologie erfordert jedoch extrem schwefelarmes Diesel und ein zusătzliches Reduktionsmittel, welches extra nachgefullt und deswegen an Tankstellen verkauft werden mußte. Es dürfte allerdings schwer zu kontrollieren sein, ob der Fahrer des LKW die Flüsigkeit tatsăchlich nachfullt oder nicht. Die Kosten fur die Raffinerien bei der Herstellung schwefelarmen Diesels sind ebenfalls nicht unerheblich und mit höherem Primärenergieverbrauch verbunden.

Vgl. Bleijenberg, A. N., J. M. W. Dings, et al. (1997). S. 4 f. 
der Stickoxide sind Ablagerungen von Stickstoffverbindungen im Boden, entweder als trockene Deposition von $\mathrm{NO}_{2}$ oder als nasse Emission der Oxidationsprodukte Salpetersăure und Nitrate.

Die Anreicherung von Nitraten im Boden fuhrt zur Überversorgung der Pflanzen mit Stickstoff und so zur Störung der Năhrstoffversorgung. Der Kontakt mit Salpetersăure schädigt die betroffenen Pflanzen direkt. Die Folge der Bodenversauerung ist Wuchsminderung und erhöhte Anfalligkeit. Năhrstoffuberversorgung fuhrt zudem zu einer Änderung der Pflanzenstruktur, indem auf năhrstoffarme Verhältnisse eingestellte Arten zurückgedrängt werden ${ }^{60}$ Schreitet die Bodenversauerung fort, kann sich die Säureablagerung bis in das Grundwasser auswirken. Die niedrigen pH-Werte des Wassers erhöhen die Löslichkeit von Schwermetallen und Aluminium. Deren Auswaschung ins Grundwasser kann die Aufbereitung als Trinkwasser erschweren.

Ozon als Folgeprodukt der Stickoxide beeintrăchtigt als aggressives Reizgas die Atemmechanik und den Gasaustausch der Lunge. Er ist wesentlicher Bestandteil des seit den neunziger Jahren auftretenden sogenannten Sommersmogs. Auch unterhalb der von der Umweltministerkonferenz festgelegten Warngrenze können bei empfindlichen Personen Gesundheitsbeeinträchtigungen festgestellt werden, so daß eine Absenkung der Belastung schon aus diesem Grund geboten scheint.

Die Vegetation wird durch direkte Einwirkung des Ozons geschädigt. Ozon beeinträchtigt die Photosyntheseleistung und stört den Wasserhaushalt, wodurch sich ein vermindertes Wurzelwachstum, verminderter Wuchs und höhere Anfälligkeit gegenüber anderen Streßfaktoren ergibt. ${ }^{61}$

Über die externen Wirkung des Landverbrauchs besteht in der Literatur keine Einigkeit. ${ }^{62}$ Unbebaute Flăchen erfullen Funktionen als Wasserspeicher und -filter, als Lebensraum für Tiere und Pflanzen und als Klimaregulator. Werden diese Flächen versiegelt, können sie diese Funktion nicht mehr wahrnehmen. Die Kosten für diese Bodenversiegelung sind allerdings isoliert kaum erfaßbar.

Ähnlich schwierig zu quantifizieren sind die Mobilitătsverluste nichtmotorisierter Verkehrsteilnehmer. Leicht nachvollziehbar ist allerdings, daß eine „Entwertung der Nähe ${ }^{\text {“63 }}$ durch die automobilbezogene Verkehrspolitik diejenigen gesellschaftlichen Gruppen benachteiligt, die am motorisierten Individualverkehr nicht oder nur eingeschrănkt teilhaben können. Der autogerechte Ausbau der Städte hat für diese Gruppen zur Folge, daß sie ihre Mobilitätsbedürfnisse in ihrer Umgebung nicht mehr befriedigen können, da dies aufgrund des Verkehrs teils zu ge-

\footnotetext{
60 Vgl. Ahrens, G.-A. (1991), S. $110 \mathrm{ff}$.

61 Vgl. Ahrens, G.-A. (1991), S. 101 und $112 \mathrm{f}$.

62 Vgl. dazu und im folgenden Dogs, E. und H. Platz (1991), S. 8-7 f.

63 Holzapfel, H., K. Traube, et al. (1992), S. 30.
} 
fährlich wäre, teils die dazu nötige Infrastruktur - Parks, Geschäfte usw. - dem Verkehr geopfert wurde. Einkauf, Freizeit und Naherholung wurden in großem Maßstab aus den Wohnumgebungen verdrängt und sind somit für nichtmotorisierte Personen außer Reichweite. Die Gruppe der Betroffenen sind vor allem Kinder und ältere Menschen, für die ein Aufenthalt in der Nähe vielbefahrener Straßen zu gefăhrlich wäre und immer noch in großem Maße Frauen, die gegenuber den Männern weit untermotorisiert sind. ${ }^{64}$ Diese Gruppen erfahren durch den Verkehr eine Einschränkung in ihren Konsummöglichkeiten. Diese müssen der zusätzlichen Handlungsfreiheit, die der Ausbau des Straßenverkehrs den Autobesitzern ermöglicht, gegengerechnet werden.

Das Gros der negativen externen Effekte des Straßengüterverkehrs spielt sich auf lokaler Ebene ab.

Im Bereich der Luftverschmutzung sind vor allem Stickoxide und feste Partikel durch den Gütertransport verursacht. $\mathrm{NO}_{\mathrm{X}}$ schädigt bei direktem Kontakt den Atemtrakt, kann die Anfälligkeit für Infektionen erhöhen und die Lungenfunktion beeinträchtigen. Das Einatmen von Schwefelstaub und Rußpartikeln trägt zur Entwicklung chronischer Erkrankungen bei und wirkt krebserregend. ${ }^{65}$

$\mathrm{NO}_{\mathrm{X}}$ wirkt über sein Folgeprodukt Salpetersäure schädigend auf Materialien. Genaue Dosis - Wirkungsbeziehungen lassen sich nicht ableiten, aufgrund der fehlenden Selbstheilungsmechanismen können jedoch bereits geringste Belastungen Schäden verursachen.

Bei dem von der Mehrzahl der Bevölkerung am deutlichsten empfundenen externen Effekt, dem Lärm ${ }^{66}$, ist der Verkehr unbestritten der Hauptverursacher ${ }^{67}$, da ein Ausweichverhalten aufgrund des dichten Straßennetzes nahezu unmöglich ist. Untersuchungen des Umweltbundesamtes haben gezeigt, daß 1985

$>$ mehr als 16 Millionen Bürger sich erst bei geschlossenen Schallschutzfenstern ungestört von Straßenverkehrslärm unterhalten konnten,

64 Vgl. Holzapfel, H., K. Traube, et al. (1992), S. 30 f. und $136 \mathrm{ff}$.

65 Vgl. Ahrens, G.-A. (1991), S. 96 f.

66 Lautstărke wird in Dezibel (dB) gemessen, welcher den Schalldruck in Beziehung zur Hörschwelle setzt. Da das menschliche Gehör nicht für alle Tonhöhen gleichermaßen empfindlich ist, wird das Schallsignal durch den sogenannten A-Filter der empfundenen Lautstarke angepaßt. Die so korrigierten Pegel werden mit dB(A) bezeichnet. Die Bandbreite des Pegels reicht von 0 (Hörschwelle) bis 130 (Unzumutbarkeitswert). Zu beachten ist, daß Lautstärke auf einem logarithmischen Maßstab abgebildet ist. Eine Erhöhung von $10 \mathrm{~dB}$ auf $20 \mathrm{~dB}$ entspricht daher etwa einer Verdoppelung der Lautstărke! Fur detailliertere Informationen siehe Eggenschwiler, K. (1994), S. 1 - 6. 
8,5 Millionen Bürgern erst bei geschlossenen Schallschutzfenstern ungestört von Straßenverkehrslärm schlafen konnten und

$>$ ca. 8 Millionen Bürger einem erhöhten Gesundheitsrisiko, vor allem Beeintrăchtigungen des Herz-Kreislauf-Systems, durch Straßenverkehrslärm ausgesetzt waren.

Nach medizinischen Untersuchungen bestehen bei Belastungspegeln über 65 $\mathrm{dB}(\mathrm{A})$ erhöhte Gesundheitsrisiken für das Herz-Kreislauf-System. Tags sind 15,5 $\%$ der Bevölkerung (alte Bundesländer, 1990) mit Pegeln über $65 \mathrm{~dB}(\mathrm{~A})$ durch Straßenverkehrslärm und über $1 \%$ noch mit Pegeln über 75d B(A) belastet. Nachts sind noch immer $2 \%$ der Bevölkerung von Pegeln uber $65 \mathrm{~dB}(\mathrm{~A})$ betroffen.

Abb. 17: Lårmbelastigte durch Straßenverkehr 1986 bis 1994 (Angaben in \%)

\begin{tabular}{|l|l|l|l|l|l|l|l|l|l|}
\hline & & 1984 & 1986 & 1987 & 1989 & 1991 & 1992 & 1993 & 1994 \\
\hline $\begin{array}{l}\text { Anteil Belasstigter durch } \\
\text { Straßenverkehr }\end{array}$ & D & & & & & - & 70 & 75 & 69 \\
\cline { 2 - 9 } & AL/NL & $61 /-$ & $65 /-$ & $54 /-$ & $69 /-$ & $69 / 85$ & $66 / 84$ & $72 / 85$ & $66 / 79$ \\
\hline \multirow{2}{*}{ davon stark belästigt } & D & & & & & - & 24 & 24 & 22 \\
\cline { 2 - 10 } & AL/NL & $21 /-$ & $25 /-$ & $19 /-$ & $23 /-$ & $21 / 35$ & $20 / 40$ & $21 / 36$ & $18 / 37$ \\
\hline
\end{tabular}

AL: Alte Bundesländer, NL: Neue Bundesländer

Quelle: http://www.umweltbundesamt.de/uba-info-daten/index.htm

Die Bedeutung des Lärms für die menschliche Gesundheit wurde in der Wissenschaft lange unterschătzt. Der einzige direkt zuzuordnende pathologische Effekt des Lärms, die Taubheit, tritt auch erst auf, wenn der Betroffene längere Zeit Lärm über $75-80 \mathrm{~dB}(\mathrm{~A})$ ausgesetzt ist. Dies entspricht in etwa dem Lärm direkt neben einer Autobahn oder an einer vielbefahrenen Kreuzung. Schon innerhalb von Wohnungen ist der Lärm - selbst bei geöffnetem Fenster - in der Regel geringer ${ }^{68}$. Neuere Studien haben jedoch ergeben, daß die möglichen Schäden durch Lärmbelastung uber die Taubheit hinausgehen. In lauten Gegenden ist der Konsum von Beruhigungs- und Schlaftabletten meßbar höher als in leisen, ebenso verhält es sich mit der Anzahl psychatrischer und psychotherapeutischer Behandlungen. $\mathrm{Ab} 60 \mathrm{~dB}(\mathrm{~A})$ stört Lärm die Verständigung, was insbesondere bei Kindern die geistige Entwicklung beeinträchtigt. Lärm beeinträchtigt den Schlaf, indem er die Tiefschlafphasen reduziert. Dies wird vom Schläfer zwar nicht wahrgenommen, fuhrt jedoch dazu, daß der Erholungswert des Schlafes geringer ist. Die OECD schlägt daher vor, den Außenlärm in Wohngebieten unter 65 $\mathrm{dB}(\mathrm{A})$ zu halten, in neu zu erbauenden Vierteln unter $55 \mathrm{~dB}(\mathrm{~A})$.

Ein externer Effekt innerhalb der Gruppe der Verkehrsteilnehmer ist der durch Verkehrsüberlastungen induzierte Zeitverlust. Auf den ersten Blick scheinen Stau-

68 Vgl. Linster, M. (1990), S. $21 \mathrm{ff}$. 
folgen, die ja zu denjenigen Kosten gehören, die von den Verkehrsteilnehmern selbst getragen werden müssen, nicht zu den Externalităten zu zählen. Diese Meinung findet sich teilweise auch in Studien zur Abschätzung externen Effekte des Verkehrs wieder. So argumentiert z. B. PLANCO, daß es sich „bei den genannten Staukosten nicht um externe Kosten [handelt], da sie nur den Kreis der Straßenverkehrsteilnehmer treffen. Ein zusătzlicher Internalisierungsbedarf ist nicht gegeben. ${ }^{699}$ Ähnlich argumentiert die Europåische Verkehrsministerkonferenz. ${ }^{70}$ Diese Auffassung kann jedoch nicht geteilt werden. Staukosten sind zwar innerhalb des Verkehrssektors interne Kosten, müssen also letztlich von den Vekehrsteilnehmern getragen werden, dies bedeutet jedoch lediglich, daß sie keine intersektoralen Verteilungswirkungen hervorrufen. Die allokative Beurteilung ist klar: Wie schon im vorigen Kapitel dargelegt, berücksichtigt der einzelne Straßennutzer bei seiner Fahrentscheidung nicht, daß er damit den Zeitbedarf der anderen Nutzer erhöht. Ein Teil der Gesamtkosten einer Fahrt taucht also in den Kostenfunktionen Dritter auf und ist damit internalisierungsbedürftig. Für den Teilbereich des Güterverkehr gilt, daß im Gegensatz zum Personenverkehr weniger der Zeitverlust an sich, insbesondere in Form zusätzlicher Personalkosten, als vielmehr die mit dem Zeitverlust einhergehenden Folgen, wie Produktionsausfälle oder Lieferengpåsse, den eigentlichen Schaden darstellen.

Nach Darstellung der Wirkungsketten sollen monetäre Bewertungen der Schäden dargestellt werden. Sie entstammen einer entsprechenden Veröffentlichung der Europäischen Verkehrsministerkonferenz, welche die entscheidenden Studien zu diesem Thema zusammengefaßt hat. ${ }^{71}$ Die Bewertung soll jeweils in Kosten pro gefahrenen Kilometer erfolgen.

Die Folgen des Klimawandels wurden von verschiedenen Autoren untersucht. Da fur die Verwendung von Zahlungsbereitschaften die entsprechenden Informationen bei den Betroffenen allgemein als zu gering eingeschätzt wurden, sind alle Studien in Form von Schadensbewertungen vorgenommen worden.

Aufgrund der Unsicherheit, die hinsichtlich der Wirkungszusammenhänge und der Folgen der Erderwärmung herrscht, weichen die Ergebnisse relativ stark voneinander $\mathrm{ab}$.

Alle Studien sind bezulglich der Beurteilung des potentiellen Schadens als eher konservativ einzuordnen, da sie nur die wahrscheinlichsten Klimafolgen berulcksichtigen und zudem mit hohen Diskontraten arbeiten. Als Alternative wurden daher die marginalen Kosten zur Erreichung des in der EU angestrebten Vermeidungsziels (vgl. S. 50) von INFRAS/IWW geschătzt und auf $50 \mathrm{ECU}$ pro Tonne

\footnotetext{
69 Dogs, E., Platz H. (1991), S. 7-2.

70 ECMT (1998), S. 213.

71 Vgl. ECMT (1998), Annex B.
} 
$\mathrm{CO}_{2}$ beziffert. Erkennt man an, daß eine genaue Ermittlung der Kosten nicht möglich ist und das Emissionsniveau daher politisch zu bestimmen ist, ist es angemessen, diese Größe als Ausgangslage der Berechnung anzunehmen. Wird diese Größe auf Fahrzeugkilometer umgerechnet, erhält man für den Güterverkehr externe Kosten des Klimawandels von durchschnittlich 0,028 ECU pro gefahrenem Kilometer.

Abb. 18: Externe Kosten des Klimawandels (1994 ECU pro Tonne CO2)

\begin{tabular}{|l|l|}
\hline Studie & Externer Schaden pro Tonne $\mathrm{CO}_{2}$ \\
\hline Nordhaus (1991) & 2,0 \\
\hline Cline (1992, 1993) & $11,2(1,6-35)$ \\
\hline Fankhauser (1994) & $5,7(1,7-12,5)$ \\
\hline Maddison (1994) & 1,6 \\
\hline
\end{tabular}

Quelle: ECMT (1998).

Bei der Bewertung der externen Kosten der Luftverschmutzung existiert eine gröBere Bandbreite methodischer Ansătze. Sowohl Zahlungsbereitschaftsanalysen als auch Schadensbewertungen in direkter (Vermeidung) oder indirekter (Reparatur) Form liegen vor. Schadensbewertungen neigen bei diese Gruppe externer Kosten zur Unterschätzung der wahren Werte, da nur die bekannten Kosten geschätzt werden können. Zahlungsbereitschaftsanalysen sind aufgrund der mangelnden Information der Betroffenen, wie bei der Beurteilung des Klimawandels auch, allerdings nur von begrenztem Informationsgehalt. Sie liegen mit ihren Werten in der Regel uber den anderen Untersuchungen.

Um den Gesamtschaden auf gefahrene Kilometer umrechnen zu können, sind bei den komplexeren Beziehungen zwischen Emissionen und tatsăchlichem Schaden einige Annahmen nötig. Der gesamte Schadstoffausstoß (hier $\mathrm{NO}_{\mathbf{x}}, \mathrm{VOC}^{72}$ und feste Partikel) muß auf die verschiedenen Verkehrsmittel umgerechnet werden, zudem ist eine Differenzierung nach dem Emissionsort (inner-, außerörtlich) vorzunehmen, um auf die tatsächlichen Schäden schließen zu können.

Die Schătzungen ergeben für den Straßengüterverkehr externe Kosten von durchschnittlich 23 ECU pro $1000 \mathrm{tkm}$ insgesamt und $20 \mathrm{ECU}$ furr den Schwerverkehr.

Als bedeutender lokaler Effekt gilt der Verkehrslärm. Für seine Bewertung existieren eine Anzahl von Studien, die sich verschiedener methodischer Ansätze bedienen. Am hăufigsten werden Zahlungsbereitschaften direkt uber Befragungen oder indirekt über beeinflußte Märkte (meist Immobilienwertansätze) ermittelt. Ebenfalls hăufig anzutreffen sind Studien zur Ermittlung von Vermeidungskosten.

72 Fluchtige organische Verbindungen wie aromatisierte Kohlenwasserstoffe, Aldehyde, Alkohole. 
Eher selten werden Schadensbewertungen vorgenommen, da die Auswirkungen des Lärms auf die Gesundheit nur sehr schwer zu messen sind. Die Studien weichen in ihren Ergebnissen in etwa um den Faktor 100 voneinander ab. Vermeidungskostenansätze sind dabei am unteren Ende anzutreffen, Abschătzungen anhand von Immobilienwerten am oberen. Ein zusätzliches Problem ist die Aufteilung des Lärms auf die verschiedenen Verursacher. Da erst die Summe der Lärmquellen die letztliche Belastung ergibt, ist die Zuordnung auf einzelne Verkehrsträger letztlich nicht fundiert.

Aus den vorliegenden Studien schließt die ECMT auf externe Kosten des Lärms in Höhe von 9 - 12 ECU pro $1000 \mathrm{tkm}$ im Straßengüterverkehr.

Als letzte bedeutende Externalität sollen die Unfallschäden quantifiziert werden. Die Bewertung menschlichen Lebens ist sicher ein sensibles Thema und eher dem Bereich der Ethik als der Ökonomie zuzuordnen. Da eine Transportentscheidung aber immer auch das statistische Risiko einer Gefährdung menschlichen Lebens oder menschlicher Gesundheit bedeutet - immerhin wurden allein in Deutschland 1998 fast 8.000 Personen im Straßenverkehr getötet und beinahe 500.000 verletzt $^{73}$ - enthält sie implizit eine Bewertung menschlichen Lebens.

Die externen Kosten der Unfälle können sowohl durch Schadensbewertungen als auch durch Ermittlung von Zahlungsbereitschaften quantifiziert werden. Schadensbewertungen umfassen in der Regel den Verwaltungsaufwand bei Unfällen, die medizinische Versorgung, Schmerzensgelder und den Produktionsausfall. In einigen Fällen wird der soziale Wert eines Menschenlebens ebenfalls als Kostengröße mit aufgenommen. Insbesondere diese nichtmateriellen Schäden haben einen wesentlichen Einfluß auf die Höhe der Ergebnisse. Werden die Werte anhand von Zahlungsbereitschaften geschätzt, ergeben sich deutlich höhere Werte, insbesondere gegenüber Schätzungen, die nur die rein materiellen Schäden erfassen. Insgesamt scheinen Werte von in etwa 1 Mio. ECU pro statistischem Leben realistisch zu sein. Die offiziellen Werte, die in Europa bei der Beurteilung von Infrastrukturprojekten angesetzt werden, betrugen 1990 demgegenüber 78.000 ECU (Portugal) bis 1,4 Mio. ECU (Finnland). Zur Beurteilung der nicht tödlich Verletzten werden diese Daten in der Regel mit einem Faktor kleiner 1 multipliziert.

Aus den vorliegenden Ergebnissen schließt die ECMT auf durchschnittliche externe Unfallkosten von $21 \mathrm{ECU}$ pro $1000 \mathrm{tkm}$.

Insgesamt ergeben sich damit folgende externe Kosten des Straßengüterverkehrs:

73 Vgl. DIW (1999). 
Abb. 19: Externe Effekte des StraBengüterverkehrs (ECU/ 1000 tkm)

\begin{tabular}{|l|c|c|c|}
\hline $\begin{array}{l}\text { Art der } \\
\text { Externalităt }\end{array}$ & Leichte LKW & Schwerverkehr & $\begin{array}{c}\text { Gewichteter } \\
\text { Durchschnitt }\end{array}$ \\
\hline Unfalle & 300 & 10 & 21 \\
\hline Klimawandel & 66 & 8 & 10 \\
\hline Luftverschmutzung & 106 & 20 & 23 \\
\hline Lårm & 25 & 8 & 8 \\
\hline Gesamt & 649 & 52 & 77 \\
\hline
\end{tabular}

Quelle: ECMT (1998).

Pro tkm fielen zu Beginn der 90er Jahre also nach Rechnung der ECMT durchschnittlich externe Kosten in Höhe von 0,077 ECU oder etwa 0,15 DM pro Tonnenkilometer an. Bei der angenommenen durchschnittlichen Beladung von 3 Tonnen sind dies 0,45 DM pro gefahrenem Kilometer. Beim für den internationalen Straßengüterverkehr relevanten Schwerverkehr betragen die externen Kosten pro Tonnenkilometer im Schnitt 0,052 ECU oder 0,1 DM pro Tonnenkilometer, bei einer durchschnittlichen Belastung von $6 \mathrm{t}$ also 0,6 DM pro gefahrenem Kilometer. 
Abb. 20: Die externen Effekte des StraBenverkehrs

\begin{tabular}{|c|c|c|c|}
\hline & Lokale Effekte & Regionale Effekte & Globale Effekte \\
\hline Physische Effekte & $\begin{array}{l}\text { Luftverschmutzung: } \\
\text { Stickoxide } \\
\text { fluchtige organische } \\
\text { Verbindungen } \\
\text { feste Partikel, vermut- } \\
\text { lich gesundheits- } \\
\text { schädlich, Gebăude- } \\
\text { schäden } \\
\text { sichtbarer Rauch } \\
\text { unangenehmer Ge- } \\
\text { ruch } \\
\text { Staub und Schmutz } \\
\text { Spritzwasser } \\
\text { Lärm, Vibrationen } \\
\text { Wasserver- } \\
\text { schmutzung } \\
\text { Abnutzung der Stra- } \\
\text { Beninfrastruktur } \\
\end{array}$ & $\begin{array}{l}\text { Luftverschmutzung: } \\
\mathrm{NO}_{\mathrm{x}} \text { and } \mathrm{HC} \text { als Ver- } \\
\text { ursacher von Smog } \\
\text { und bodennahem } \\
\text { Ozon } \\
\mathrm{NO}_{\mathrm{x}}, \mathrm{SO}_{\mathrm{x}} \text { als Verur- } \\
\text { sacher von saurem } \\
\text { Regen } \\
\text { Landverbrauch fur } \\
\text { Verkehrsinfrastruktur } \\
\text { Wasserverschmut- } \\
\text { zung (Salz, Öl) }\end{array}$ & $\begin{array}{l}\text { Luftverschmutzung: } \\
\text { Kohlendioxid als Mit- } \\
\text { verursacher der globa- } \\
\text { len Erwärmung } \\
\text { Verbrauch fossiler } \\
\text { Energiereserven }\end{array}$ \\
\hline Soziale Effekte & $\begin{array}{l}\text { Unfälle } \\
\text { Zeitverzögerungen } \\
\end{array}$ & $\begin{array}{l}\text { Veränderte Flächen- } \\
\text { nutzung }\end{array}$ & \\
\hline $\begin{array}{l}\text { Subjektive Wir- } \\
\text { kungen }\end{array}$ & $\begin{array}{l}\text { Angst } \\
\text { Trennwirkung } \\
\text { Beeinträchtigung des } \\
\text { Stadtbildes }\end{array}$ & $\begin{array}{l}\text { Mobilitätsverlust für } \\
\text { nichtmotorisierte Ver- } \\
\text { kehrsteilnehmer }\end{array}$ & \\
\hline
\end{tabular}

Quelle: Mitchell, C. G. B. (1991), S. 27 
Axel Hennighausen - 978-3-631-75701-7

Downloaded from PubFactory at 01/11/2019 02:45:58AM

via free access 


\section{Die Gestaltung der Verkehrspolitik in Deutschland und der EU}

\subsection{Die Regulierung des Straßengüterverkehrs in Deutschland vor 1998}

Die im 2. Kapitel diskutierten Besonderheiten des Verkehrswesens hatten zur Folge, daß in vielen, wenn nicht den meisten Ländern die Verkehrsmärkte staatlich reguliert, also dem marktlichen Alloktionsmechanismus weitgehend entzogen wurden. Worin diese Regulierung bestand und welche Folgen sie hatte, soll in diesem Abschnitt am Beispiel Deutschlands ausgeführt werden.

Der Begriff der staatlichen Regulierung läßt sich nicht einheitlich abgrenzen. In einer sehr weiten Fassung werden darunter alle staatlichen Eingriffe in die Vertragsfreiheit gefaßt. ${ }^{74}$ Ziel der Regulierung ist es, Marktmechanismen bewußt zu beschränken oder den Markt dort, wo er nicht existiert, zu ersetzen. Neben staatlicher Wettbewerbsbeschränkung ist auch private möglich. Diese privaten Absprachen uber Preise oder Marktzutritte werden in der Bundesrepublik mit dem Gesetz gegen Wettbewerbsbeschränkungen untersagt. Dieses kennt jedoch sogenannte Ausnahmebereiche, in denen einige oder alle Vorschriften des Gesetzes keine Geltung haben. Der Straßengüterverkehr gehörte bis zu diesen sogenannten partiellen Ausnahmebereichen ${ }^{75}$. Er unterlag damit der kontrollierten Wettbewerbsordnung, d.h. die Bestimmungen des GWB wurden durch andere gesetzliche Regelungen ersetzt, die in diesem Fall im Güterkraftverkehrsgesetz (GüKG) festgelegt waren. Die Einhaltung dieser Bestimmungen wurde für den Straßengüterfernverkehr vom Bundesamt für den Güterfernverkehr (BAG) in Köln kontrolliert, welches dem Bundesverkehrsministerium zugeordnet war (und ist). ${ }^{76}$

\subsubsection{Staatliche Interventionspolitik im Verkehrssektor}

Instrumente für Markteingriffe existieren in großer Zahl. ${ }^{77}$ Zum Schutz regulierter Monopole vor Konkurrenten und zur Verhinderung ruinöser Konkurrenz wird der Zutritt zu den entsprechenden Märkten an subjektive oder objektive Zugangsbedingungen geknüpft. Um zu verhindern, daß geschützte Monopolisten ihre Position zum Nachteil der Konsumenten ausnützen, werden Preise, Gewinne und Kosten reglementiert oder Qualitätsniveaus festgelegt. Als Gegenstück zum Privi-

74 Vgl. Lange, T. (1985), S. 163. Als Regulierung werden nur direkte Eingriffe bezeichnet, indirekte Maßnahmen, wie z. B. Geldpolitik, fallen nicht unter diesen Begriff.

Vgl. auch Krakowski, M. (1988), S. 10 f.

75 Vgl. Hoener, W. (1980), 23ff.

76 Trotz Liberalisierung der Verkehrsmärkte und dem damit verbundenen Wegfall seiner ursprlinglichen Aufgaben existiert das Amt mit anderer Schwerpunktsetzung weiter.

77 Vgl. dazu Lange, T. (1985), S. 175 f. 
leg der geschützten Unternehmen können diesen noch andere Verpflichtungen auferlegt werden, hier ist z. B. der sogenannte Kontrahierungszwang zu nennen.

Im Verkehrssektor ${ }^{78}$ existierten nach LAASER vier sogenannte Regulierungsparameter: ${ }^{79}$

$>$ Marktzutrittsbeschränkungen

$>$ Preiskontrollen

$>$ Qualităts-, Kapazităts- und Konditionenfestsetzungszwang

$>$ Kontrahierungszwang

Bei den Marktzutrittsbeschränkungen im innerstaatlichen Straßengüterverkehr unterschied das Güterkraftverkehrsgesetz zwischen dem gewerblichen Güterverkehr einerseits und dem Werkverkehr andererseits. Ersterer teilte sich nochmals in Güternah- und Güterfernverkehr auf. Der Werkverkehr unterlag keinen Marktzutrittsbeschränkungen, dort eingesetzte Fahrzeuge waren lediglich meldepflichtig. Um einen Mißbrauch dieser privilegierten Position zu verhindern, war der Werkverkehr inhaltlich genau gegenüber dem gewerblichen Güterverkehr abgegrenzt: Er mußte durch Angestellte des jeweiligen Unternehmens durchgefuhrt werden und durfte nur solche Güter befördern, die selbst erzeugt oder zur Verarbeitung erworben wurden. ${ }^{80}$ Insbesondere diejenigen Fälle, in denen Beförderer durch Anund Verkauf der Ware Handel vortăuschten und damit die Regulierungen zu umgehen versuchten, waren zu unterbinden. Trotz mehrerer solcher Versuche zur Eingrenzung des Werkfernverkehrs ${ }^{81}$ stieg sein Anteil am gesamten Binnengüterfernverkehr von $3,5 \%$ in 1955 auf $8,2 \%$ in $1991 .^{82} \mathrm{Da}$ er aufgrund des Verbotes, fremde Ladung aufzunehmen, einen wesentlich höheren Anteil an Leerfahrten ${ }^{83}$ hatte und damit eine geringe Wirtschaftlichkeit aufwies, ist dieses Wachstum nur mit uberhöhten Preisen und zu geringen Kapazitäten auf den regulierten Marktsegmenten zu erklären.

Der Güternahverkehr, d.h. Verkehr innerhalb der sogenannten Nahzone $50 \mathrm{~km}$ um den Standort des Transportunternehmens, unterlag einer subjektiven Marktzutrittsbeschränkung. Subjektive Beschränkungen waren - und sind - an persönliche Kriterien gebunden, so z. B. fachliche Eignung, Zuverlåssigkeit oder finanzielle Leistungsfahigkeit. Die Genehmigung wird nicht fur das Unternehmen erteilt,

78 Im folgenden werden nur die Instrumente zur Regulierung des Straßenguterverkehrs betrachtet.

79 Vgl. Soltwedel, R., C.-F. Laaser, et al. (1986), S. 192.

80 Vgl. Grabenhorst, K. (1994), S. 157 f.

81 Vgl. Basedow, J. (1989), S. 71 .

82 Vgl. Walther, M. (1996), S. 93.

83 Dazu gehörte auch das Verbot des Konzernverkehrs. Diese Vorschrift untersagte es mehreren Verladern, zum Zwecke des Transports Gemeinschaftsunternehmen zu grunden.

Vgl. Basedow, J. (1989), S. 121. 
sondern für jedes einzelne Fahrzeug ( $\S 3$, Abs. 2 und 3 GüKG). Waren diese subjektiven Kriterien erfullt, mußte die Genehmigung erteilt werden, es handelte sich demnach um eine sogenannte gebundene Erlaubnis.

Im Güterfernverkehr waren neben dieser subjektiven Marktzugangsbeschränkung noch objektive Kriterien zu erfüllen. ${ }^{84}$ Diese bestanden in den zahlenmäßigen Beschränkungen der Güterfernverkehrsgenehmigungen. Sie wurden vom Bundesverkehrsminister unter Berücksichtigung des öffentlichen Verkehrsbedürfnisses und der Verkehrssicherheit festgelegt und nach einem bestimmten Schlüssel auf die Länder verteilt. ${ }^{85}$

Der Zugang zum zwischenstaatlichen Güterverkehr war bis 1992 ebenfalls kontingentiert. Die Höhe der Kontingente wurde in bilateralen Vereinbarungen festgelegt, die entsprechenden Genehmigungen wurden fur einen bestimmten Zeitraum (i. d. R. ein Jahr) oder für eine einzelne Fahrt erteilt. Ab 1985 wurden die bilateralen Kontingente durch sogenannte EG-Lizenzen ergänzt, die zum Wechsel- und Transitverkehr innerhalb der Gemeinschaft berechtigten. Diese wurden im Laufe der Zeit aufgestockt, bis 1993 die mengenmäßigen Beschränkungen im grenzüberschreitenden Verkehr innerhalb der EG aufgehoben wurden. Im Verkehr mit Nicht-EU-Ländern gilt weiterhin das System der bilateralen Kontingente.

Der Verkehr innerhalb eines Landes durch Unternehmen, die in diesem Land nicht ansässig sind - die sogenannte Kabotage - war dagegen untersagt (Kabotagevorbehalt). Diese Beschränkung der allgemeinen Dienstleistungsfreiheit war allerdings mit der Einfuhrung des Binnenmarktes nicht mehr aufrecht zu halten. Ab 1994 wurden daher aufgrund der Kabotage-Verordnung (EWG) Nr. 3118(93) ${ }^{86}$ ein Kontingent an Kabotage-Lizenzen geschaffen. Diese berechtigten zu unbegrenzten Güterbeförderungen in Mitgliedsstaaten, in denen der Spediteur nicht ansăssig war. Im folgenden wurde ăhnlich verfahren wie beim grenzüberschreitenden Güterverkehr: Das Kontingent wurde kontinuierlich, ausgehend von 30.000 Genehmigungen, jährlich um $30 \%$ erhöht, bis am 30.06.1998 die mengenmäßige Zugangsbeschränkung als Ganzes wegfiel. Das Kontingent hat schon 1997 nicht mehr marktzugangsbeschränkend gewirkt. ${ }^{87}$

Um eine Diskriminierung des deutschen Transportgewerbes zu vermeiden, wurde in Deutschland parallel mit der formalen Abschaffung der Kabotagebegrenzung das Guterverkehrsrecht abgeändert. Um das Paradoxon zu vermeiden, daß deutsche Transporteure innerhalb des Binnenmarktes unbegrenzt, innerhalb Deutsch-

84 Vgl. Walther, M. (1996), S. 88 f.

85 Vgl. dazu Grabenhorst, K. (1994), S. $78 \mathrm{ff}$.

86 Verordnung (EG) Nr. 3315/94/ des Rates vom 22.12.1994, veroffentlicht im Amtsblatt L 350 vom 31.12.94 und 3118/93 vom 01.01.94, veroffentlicht im Amtsblatt L 279 vom 12.11.93.

87 
lands jedoch nur limitiert durch die Fernverkehrsgenehmigungen Güterkraftverkehr betreiben dürfen, wurde das GüKG zum 30.06.1998 angeglichen. Die Unterscheidung zwischen Fernverkehr, Nahverkehr und Umzugsverkehr fiel weg, auf eine Kontingentierung der Fernverkehrsgenehmigungen wird seitdem verzichtet. ${ }^{88}$

Eine weitere Form der Regulierung, die Preiskontrollen, waren für den Guternahund den Güterfernverkehr im großen und ganzen identisch. Thre Ausgestaltung hat sich im Laufe der Zeit gewandelt. Direkt nach dem zweiten Weltkrieg hatte das GüKG den in den dreißiger Jahren aufgestellten Reichskraftwagentarif (RKT) ubernommen und damit Festpreise für den Güterfernverkehr festgelegt. Im Rahmen der sogenannten „Kleinen Verkehrsreform" in 1961 wurden diese starren Tarife zugunsten von Margentarifen ersetzt. Das Tarifbildungsverfahren bestand aus drei Abschnitten: Zunächst wurden „marktgerechte Entgelte“ von der sogenannten Tarifkommission ermittelt. Diese setzte sich aus Vertretern des Güterkraftverkehrsgewerbes und der verladenden Wirtschaft zusammen. Die so festgesetzten Entgelte wurden dem Bundesverkehrsminister zur Prufung vorgelegt, der sie im Einvernehmen mit dem Bundeswirtschaftsminister genehmigen mußte. War diese Genehmigung erfolgt, wurden die Tarife durch Rechtsverordnung verkündet und für allgemeinverbindlich erklärt.

Das obligatorische Tarifwesen wurde mit Wirkung vom 01.01.1994 aufgehoben. Seitdem können die Preise im innerstaatlichen Güterkraftverkehr frei vereinbart werden.

Im internationalen Güterverkehr innerhalb der Gemeinschaft bestand bei grenzuberschreitenden Transporten ein Mischsystem aus Margentarifen und Referenztarifen. Obwohl letztere eigentlich dominierend sein sollten, hatten die EWGGründungsmitglieder Deutschland, Frankreich, Italien und Benelux untereinander obligatorische bilaterale Tarife vereinbart und damit ein tatsächliches Übergewicht der Margentarife geschaffen. ${ }^{89}$ Diese Regelung lief 1989 aus und wurde nicht verlăngert, so daß im grenzüberschreitenden Güterverkehr ab 1990 Beförderungsentgelte keiner staatlichen Regulierung mehr unterworfen sind.

\subsubsection{Die Folgen der Marktregulierung}

Die Regulierung des Straßenguterverkehrs hatte zwei verschiedene Ziele: Zum einen sollten die negativen Wirkungen, die aufgrund der „Besonderheiten des Verkehrssektors" befurrchtet wurden, verhindert werden. Zu Beginn der Regulierung dominierten insbesondere Bedenken gegenüber ruinöser Konkurrenz auf den Verkehrsmärkten. Nachdem diese These in den sechziger Jahren an theoretischer und empirischer Relevanz verlor, wurden die Externalităten des Straßengüterver-

8 Bolln, K. (1998), S. 9 f.

89 Vgl. Willeke, R. (1987), S. 83 ff. 
kehrs, also Umweltschutzaspekte, stärker in den Mittelpunkt der Argumentation gerückt. Zum anderen war aber der Schutz der nach gemeinwirtschaftlichen Prinzipien arbeitenden Bahn immer explizites Ziel der Verkehrsmarktregulierung. Obwohl letzteres in der öffentlich geführten Diskussion im Vergleich zu den allokativen Argumenten weniger stark betont wurde, war es wohl doch für das tatsächliche Handeln meist entscheidender. ${ }^{90}$

Im Rückblick läßt sich sagen, daß keines der anvisierten Ziele erreicht wurde. Der Anteil der Bahn an den Gütertransporten ist trotz aller Versuche, sie gegen die Konkurrenz der Straße zu schützen, kontinuierlich zurückgegangen. Der Straßengüterverkehr war seit den zwanziger Jahren in immer höherem Maße in der Lage, der Bahn die rentablen Transporte streitig zu machen, da er dem gebrochenen Schienentransport durch größere Schnelligkeit, Flexibilität und teilweise auch geringere Kosten (z. B. durch wegfallende Umladevorgänge) überlegen war. ${ }^{91}$ Die Versuche, diesen qualitativen Vorteil durch mengenmäßige Beschränkungen zu neutralisieren, müssen angesichts der quantitativen Entwicklung der Verkehrsträger als mißlungen gelten.

Viele andere Besonderheiten des Verkehrssektors, wie sie zu Beginn des 2. Kapitel dargelegt wurden, haben sich wie erwăhnt im Laufe der Zeit als okonomisch irrelevant herausgestellt und werden im allgemeinen nicht mehr als Rechtfertigung für Marktregulierungen herangezogen. ${ }^{92}$ Dies gilt insbesondere für die ruinöse Konkurrenz zwischen den Anbietern. Die Externalitäten des Straßengüterverkehrs müssen aber weiterhin und in immer zunehmendem Maße als ernstes Problem aufgefaßt werden. Die Beschränkung der Transportkapazitäten im regulierten Markt hat das Wachstum des Straßengüterverkehrs und damit einen Anstieg der Umweltschäden zwar gebremst, aber nicht verhindert.

Insbesondere der modal shift, der Wechsel von den umweltfreundlicheren Verkehrsmitteln Bahn und Binnenschiffahrt hin zur Straße, hat sich auch im regulierten Markt vollzogen - wenn auch nicht im selben Ausmaß wie in Verkehrsmärkten, die dem freien Wettbewerb ausgesetzt waren. Da die „Internalisierung“ der Umweltschäden aber ausschließlich in globalen Mengenbeschränkungen bestand und nicht am eigentlichen Umweltschaden ansetzte, hat sie sicher zu unnötigen Ineffizienzen gefürt.

Zusammenfassend muß konstatiert werden, daß die Marktregulierung in erster Linie den im Markt befindlichen Unternehmen geholfen hat, da sie Knappheits-

90 Ähnlich argumentieren Soltwedel, R., C.-F. Laaser, et al. (1986), S. 208. Das Bundesverfassungsgericht hat 1975 die Kontingentierung des Guterfernverkehrs explizit mit dem Hinweis auf den Schutz der Bahn als „überragend wichtigem Gemeinschaftsgut" gerechtfertig. Vgl. Grabenhorst, K. (1994), S. 179.

91 Vgl. Klenke, D. (1995), S. 7.

92 Vgl. Soltwedel, R., C.-F. Laaser, et al. (1986), S. 255 f. 
preise furr ihre Konzessionen erzielen konnten. Das Wachstum des Guterverkehrs insgesamt und die Verschiebung des modal split zuungunsten der Bahn konnten dagegen nicht - oder nicht in relevantem Maße - aufgehalten werden, d. h. weder das Umweltziel noch der Schutz der Bahn wurden realisiert. Die Monopolrenten der Transporteure waren vom Verbraucher zu tragen. ${ }^{93}$

\subsection{Harmonisierungsmaßnahmen der Europăischen Union}

Da Verkehr von der Natur der Sache her nicht auf das Gebiet eines Staates begrenzt ist, bestanden schon immer Bemühungen, neben den nationalen Verkehrsmarktordnungen eine internationale Koordination der das Verkehrswesen betreffenden Rechtsnormen zu erreichen. In der Binnen- und Seeschiffahrt sowie im Eisenbahnverkehr existieren gultige Abkommen, die teilweise bis ins letzte Jahrhundert datieren. ${ }^{94}$ Im Straßenverkehr dagegen waren multilaterale Bemühungen zur Harmonisierung der gesetzlichen Regelungen lange Zeit ohne Erfolg geblieben.

Bemühungen um die Harmonisierung der wesentlichen Wettbewerbsparameter, die zur Vorbereitung der Liberalisierung der Verkehrsmärkte notwendig waren, setzten erst mit dem Untătigkeitsurteil des Europäischen Gerichtshofs ${ }^{95}$ ein. Dieses kam durch eine bis dahin einmalige Klage des Europåischen Parlaments gegen den Ministerrat zustande. Das Parlament wollte nach Jahren des verkehrspolitischen Stillstandes erreichen, daß die Verzögerungspolitik des Ministerrates für rechtswidrig erklärt wurde. Obwohl den Anträgen nur teilweise stattgegeben wurde, wird das Urteil als Einstieg in die gemeinsame Verkehrspolitik gesehen. ${ }^{96}$

Die Ziele dieser Europăischen Verkehrspolitik lassen sich grob unter den Stichworten Liberalisierung und Harmonisierung zusammenfassen. So wurden, wie in Kapitel 3.1.1 dargelegt, die europäischen Verkehrsmärkte von abgeschotteten, wettbewerblichen Ausnahmeregelungen unterworfenen Märkten in den europäischen Wettbewerb uberfuhrt. Mit der Liberalisierung einher gingen Bemuhungen, die Wettbewerbsbedingungen furr das Transportgewerbe innerhalb der Europäischen Union zu harmonisieren. Damit sollte verhindert werden, daß ungleiche Standortbedingungen im Zusammenspiel mit den in Abschnitt 2.2 beschriebenen Marktmängeln die erwarteten Effizienzgewinne der Marktliberalisierung verwässern.

\footnotetext{
93 Vgl. Soltwedel, R., C.-F. Laaser, et al. (1986), S. $203 \mathrm{ff}$.

94 Vgl. Basedow, J. (1987) S. 1 f.

95 EuGH 22.05.1985 - Rs. 13/83 (Parlament vs. Rat), S. 159.

96 Vl. Koberlein (1997), S. 289 f.
} 


\subsubsection{Harmonisierung der technischen und sozialen Wettbewerbs- bedingungen}

Auf technischem Gebiet lag der Schwerpunkt der Harmonisierungsbemühungen im Bereich der Maße und Gewichte der LKW. Obwohl diese technischen Eigenschaften stark von nationalen Gegebenheiten, insbesondere der baulichen Ausgestaltung der Straßen und Brücken, determiniert waren, beeinflußten sie doch die Wettbewerbsposition der Transporteure so wesentlich, daß eine Vereinheitlichung unabdingbar erschien. Dennoch gelang eine Vereinheitlichung der Gewichte und Abmessungen der Fahrzeuge auf europăischer Ebene erst 1985, eine endgültige Regelung furr Fahrzeuge uber 3,5 $\mathrm{t}$ ist seit dem 17.09.1996 in Kraft. Der Einsatz von Fahrzeugen darf seitdem von einem Mitgliedsland nicht aus Gewichts- oder Abmessungsgründen untersagt werden, sofern das Fahrzeug den EU-Normen entspricht. $^{97}$

Eine weitere technische Vereinheitlichung betraf die Festlegung zulässiger Emissionen von Dieselmotoren. Die Richtlinie 88/77/EWG ${ }^{98}$ legte Emissionsgrenzwerte fest, die für die Erteilung der EG-Typgenehmigung eines Fahrzeugs zu beachten sind. Diese Grenzwerte wurden 1999 weiter verschärft.

Um die Teilnahme am Verkehr innerhalb der Gemeinschaft zu erleichtern, wurde ein einheitlicher Führerschein in der EU eingeführt und ab dem 12.06.1996 eine vereinheitlichte Regelung für den Zugang zum Beruf des Verkehrsunternehmers (Unternehmen und natüliche Personen, die Waren mit Fahrzeugen über 3,5 t Nutzlast oder $6 \mathrm{t}$ zul. Gesamtgewicht befördern) eingeführt. Die Richtlinie legt bestimmte qualitative Mindestanforderungen bezüglich Zuverlässigkeit, finanzieller Leistungsfähigkeit und fachlicher Eignung des Antragstellers fest ${ }^{99}$.

Eine Einigung konnte ebenfalls über die wichtigsten Sozialvorschriften erzielt werden. ${ }^{100}$ So wurden 1985 Mindestanforderungen an die Lenk- und Ruhezeiten und Mindestalter für Fahrzeugfahrer festgelegt.

Bezuglich der Sicherheit im Straßenverkehr konnten Mitte der neunziger Jahre wesentliche Vorschriften vereinheitlicht werden. 1992 wurde eine gemeinsame Vorschrift zur Geschwindigkeitsbegrenzung bei schweren LKW eingeführt, Vorschriften uber Verwendung von Sicherheitsgurten, Qualität der Reifen usw. wur-

97 Richtlinie Nr. 96/53/EG des Rates vom 25.07.1996, veroffentlicht im Amtsblatt L 235 vom 17.09.1996.

98 Richtlinie Nr. 88/77/EWG des Rates vom 03.12.1987, veroffentlicht im Amtsblatt L 36 vom 09.02.1988.

99 Richtlinie Nr. 96/26/EG des Rates vom 29.04.1996, verðffentlicht im Amtsblatt L 124 vom 23.05.1996.

100 Verordnung Nr. 3820/85 des Rates vom 20.12.1985, veroffentlicht im Amtsblatt L 370 vom 31.12.1985. 
den festgelegt. 1994 bis 1996 kamen Vorschriften über den Transport gefährlicher Guter auf der Straße hinzu (Sicherheitsberater in den Unternehmen, Vorschriften bzgl. Fahrzeugeigenschaften, Verpackung usw., Vorschriften über die Kontrolle der Fahrzeuge). ${ }^{101}$

Damit sind die technischen und sozialen Wettbewerbsbedingungen im wesentlichen vereinheitlicht. Wesentliche Unterschiede bestehen noch bei der Kontrolldichte, so daß die Angleichung zwar de jure, nicht jedoch de facto besteht. Zwar existieren auch hier Mindestanforderungen von Seiten der EU, diese reichen aber offensichtlich nicht aus, um eine Gleichbehandlung $\mathrm{zu}$ garantieren. ${ }^{102}$

\subsubsection{Harmonisierung der Verkehrsbesteuerung}

Im Gegensatz zu den weitgehenden Normierungen im technischen und sozialen Bereich sind bezuglich der steuerlichen Wettbewerbsbedingungen lange Zeit praktisch keine Einigungen erzielt worden.

1993 wurden Mindestsătze für die Besteuerung von Kraftfahrzeugen (damals je nach LKW-Typ 0 - 929 ECU jährlich, also bis zu etwa 1.400 DM $^{103}$ ) und Höchstsătze für Straßenbenutzungsgebühren (1.250 Euro pro Jahr) festgelegt. Eventuell erhobene Mautgebühren sollen an den tatsächlichen Kosten von Straßenbau und unterhaltung orientiert sein. Benutzungsgebuhren und Mauten ${ }^{104}$ dürfen nicht parallel erhoben werden, außer für besondere Einrichtungen wie Tunnel, Pässe oder Brücken. Die Regelungen beziehen sich nur auf Autobahnen oder autobahnähnliche Straßen. Die entsprechende Vorschrift ist allerdings aufgrund eines Urteils des Europäischen Gerichtshofes für unzulässig erklärt worden. Sie wurde daher 1999 durch eine neue Richtlinie abgeändert ${ }^{105}$, die im Grundsatz dieselben Regelungen enthält und Mindestsătze für die Kraftfahrzeugsteuern zwischen 0 und 929 Euro pro Jahr festlegt. Die Höhe der Sätze ist abhängig vom Gewicht der Fahrzeuge, der Achsanordnung und der Art der Federung. Die Benutzungsgebuhren sind seitdem auf ein Maximum zwischen 960 und 1.550 Euro festgelegt, abhängig von der Schadstoffklasse des LKW und der Anzahl der Achsen.

101 Die Angaben und Verweise auf die entsprechenden Rechtstitel sind entnommen aus DG07 (1999).

102 Grabenhorst, K. (1994), S. 54.

${ }^{103}$ Vgl. Richtlinie 93/89/EWG des Rates, veroffentlicht im Amtsblatt L 279 vom 12.11.1993 und Eickhof, N. und M. Franke (1994), S. 244.

104 Mauten sind fulr die konkrete Inanspruchnahme eines bestimmten Straßenabschnitts zu leistende Gebuhren, wăhrend Benutzungsgebuhren zur Nutzung eines Straßennetzes innerhalb eines bestimmten Zeitraums berechtigen.

${ }^{105}$ Richtlinie 99/62/EG des Rates vom 17.06.1999, veroffentlicht im Amtsblatt L 187 vom 20.07.1999. 
Für Mineralölsteuern wurde 1992 eine Richtlinie mit dem Ziel der Annäherung der Steuersätze vom Rat verabschiedet. ${ }^{106}$ Mit dieser Richtlinie wurde eine Mindesthöhe für die Besteuerung von Mineralölen festgelegt. Diese betrug für Diesel 245 ECU pro 1.000 1, eine Überprufung der Höhe war alle zwei Jahre vorgesehen. Die entsprechende Untergrenze liegt allerdings unter den tatsächlichen Steuersätzen aller Mitgliedsländer und wird somit nicht wirksam.

Zusammenfassend kann festgestellt werden, daß zur Zeit keine Maßnahmen existieren, die eine Angleichung der Steuern auf den Straßengüterverkehr in Europa bewirken. Damit ist die Frage der effizienten Finanzierung der Verkehrsinfrastruktur innerhalb Europas bisher ungeklärt.

Maßnahmen zum Schutz der Umwelt wurden von Seiten der Europäischen Union bisher nur in geringem Maße vorgenommen. Eine Ausnahme bildet die Festlegung von Schadstoffklassen und eventuell die Vereinheitlichung von Sicherheitsvorschriften. Die Union war jedoch insgesamt nicht in der Lage, die Folgen des Wegfall der nationalen Verkehrsmarktordnungen im Umweltbereich zu kompensieren.

${ }^{106}$ Richtlinie 92/82/EWG des Rates vom 19.10.1992, veroffentlicht im Amtsblatt L 316 vom 31.10.1992. 
Axel Hennighausen - 978-3-631-75701-7

Downloaded from PubFactory at 01/11/2019 02:45:58AM

via free access 


\section{Infrastrukturfinanzierung und Verkehrslenkung in einem ge- schlossenen Verkehrsmarkt}

\subsection{Vorbemerkungen}

Im 2. Kapitel wurde der Verkehrssektor auf mögliche Formen von Marktversagen untersucht. Aus diesen wurde in den meisten kontinentaleuropäischen Ländern der Schluß gezogen, daß der Gütertransport für die marktliche Allokation nicht geeignet und daher staatlich zu regulieren sei. Wie dargestellt konnte diese Regulierungspolitik der vergangenen Jahrzehnte die anvisierten Ziele nicht erreichen. Daher sollen in diesem Kapitel Möglichkeiten aufgezeigt werden, wie die skizzierten Ineffizienzen des Verkehrsmarktes reduziert werden können. Dabei wird wie in den folgenden Kapiteln auch - angenommen, daß die Infrastruktur durch den Staat bereitgestellt wird und in Art und Ausmaß unabhängig vom System der Finanzierung ist. Die Bereitstellung der Infrastruktur ist also aus der Betrachtung ausgenommen, es wird lediglich nach Möglichkeiten zur effizienten Deckung der Wegekosten und zur Verkehrslenkung gesucht.

Ergebnis dieses Abschnitts soll ein System von Abgaben und Auflagen sein, welches zu einem möglichst optimalen Ausmaß an Straßennutzung führt. Dazu wird in einem ersten Schritt dargelegt, welche Ziele mit den gegebenen Instrumenten verfolgt werden können. Darauf folgend wird ein System entworfen, welche die verschiedenen Zielsetzungen bestmöglich in Einklang bringt. In diesem Kapitel wird noch von einem abgeschotteten Güterverkehrsmarkt ausgegangen, eine Situation, die dem deutschen Markt bis vor kurzem noch weitgehend entsprach. Damit wird von vielen zusătzlichen Aspekten, die sich im Zusammenhang mit offenen Mărkten ergeben, zunăchst abstrahiert. Wir schaffen also mit der hier darzustellenden vereinfachten Ausgangslage ein Referenzmodell, welches als Grundlage zur Beurteilung der Art der Wegekostenfinanzierung und der effizienten Lenkung des Straßengüterverkehrs in der Europäischen Union dienen soll.

\subsection{Ziele und Instrumente nationaler Verkehrspolitik}

\subsubsection{Die Abgeltung der Wegekosten}

Die Frage nach der Finanzierung der Wegekosten durch die einzelnen Verkehrsträger ist in der verkehrswissenschaftlichen Diskussion seit langem Gegenstand kontroverser Debatten. Schon bei der Definition der Wegekosten kann - wie die unterschiedlichen Berechnungsansătze in Kapitel 2.3.1 zeigen - keine Einigkeit erzielt werden. Dennoch besteht eine grundsătzliche Übereinstimmung dahingehend, daß die Nutzer der Verkehrsinfrastruktur die furr deren Bereitstellung und 
Unterhalt anfallenden Kosten zu tragen haben. Ziel der Verkehrspolitik sollte also die Deckung der Wegekosten durch die Infrastrukturnutzer sein. Dies bedeutet, daß bei denjenigen Abgaben, die in einen Zusammenhang mit der Nutzung der Verkehrswege gesetzt werden können, eine Äquivalenz zwischen Abgabe und Leistung gefordert wird. Da in diesem Fall die gesamte Gruppe der Verkehrsteilnehmer fur die von ihnen in Anspruch genommenen Straßen zahlen soll und nicht jeder Einzelne entsprechend seiner persönlichen Inanspruchnahme, spricht man auch von gruppenmäßiger oder partieller Äquivalenz. ${ }^{107}$

Die Einnahmen zur Deckung der dem Verkehr zuzurechnenden Wegekosten kann der Staat mit Hilfe von Steuern oder sonstiger Einnahmeninstrumente, also Gebühren und Beiträge erzielen. ${ }^{108}$ Beispielhaft kann man zur Klassifikation dieser Einnahmeninstrumente den $\S 3$ I der deutschen Abgabenordnung (AO) heranziehen: „Steuern sind Geldleistungen, die nicht eine Gegenleistung für eine besondere Leistung darstellen und von einem öffentlich-rechtlichen Gemeinwesen zur Erzielung von Einnahmen allen auferlegt werden, bei denen der Tatbestand zutriff, an den das Gesetz die Leistungspflicht knüpft; die Erzielung von Einnahmen kann Nebenzweck sein. [...]".

Von Steuern spricht man also, wenn die Zahlung keinen Anspruch auf Gegenleistung begrundet. ${ }^{109}$ Damit ist allerdings nicht zwingend die sogenannte NonAffektation verbunden. Auch zweckgebundene Steuern, deren Aufkommen für bestimmte Ausgaben reserviert ist, fallen unter den Steuerbegriff. Beispielsweise war das Aufkommen der Mineralölsteuer zwischen 1955 und 1973 laut Gesetz großteils fur Straßenbauinvestitionen zu verwenden. ${ }^{110}$

Ist mit Abgaben ein Anspruch auf Gegenleistung von Seiten des Staates verbunden, werden sie als Gebühren oder Beiträge bezeichnet. Gebühren dienen zur Deckung der Kosten einer individuell zurechenbaren staatlichen Leistung. Sie ăhneln damit am ehesten den Marktpreisen. Beiträge sind dagegen Entgelte für Leistungen, die nicht individuell, sondern nur gruppenbezogen zugerechnet werden können. Damit ist nicht die konkrete Inanspruchnahme der Gegenleistung des Staates Anlaß der Beitragserhebung, sondern die Möglichkeit dazu. Ein Nutzungsausschluß findet also auf Ebene der Gruppe statt, nicht, wie bei Marktpreisen oder Gebuhren, beim einzelnen Wirtschaftssubjekt. Beispiele für Gebuhren sind Parkgebuhren, für Beiträge Autobahnvignetten oder Anliegerbeiträge. ${ }^{111}$

107 Vgl. Brummerhoff, D. (2001), S. 386f.

${ }^{108}$ Die Einteilung in Steuern, Gebuhren und Beiträgen entspricht dem klassischen dreigeteilten Abgabensystem. Vgl. dazu Selmer, P., C. Brodersen, et al. (1989), S. 50 und 64 ff.

109 Vgl. Selmer, P., C. Brodersen, et al. (1989), S. 52.

110 Die entsprechenden Regelungen wurden im Verkehrsfinanzgesetz (1955) und im Straßenbaufinanzierungsgesetz (1960) getroffen. Vgl. Koberlein, C. (1997), S. 174.

111 Vgl. Homburg, S. (1997), 174 ff. 
Wir werden im folgenden untersuchen, welche Finanzierungsinstrumente sinnvollerweise zur Wegekostendeckung genutzt werden sollten. Bei der tatsächlichen Anwendung eines Finanzierungsinstruments müssen die ökonomischen Besonderheiten der Verkehrsinfrastruktur beachtet werden. Wie im Kapitel 2.2.1 dargestellt sind dies Subadditivitäten in der Bereitstellung und die Tatsache, daß die Infrastruktur im Spektrum zwischen öffentlichen und privaten Gütern näher an den öffentlichen anzusiedeln sind.

Bei sinkenden Durchschnittskosten ergeben sich im allgemeinen zwei Probleme: Zum einen sind, wie in Abschnitt 2.2.1 dargestellt, Grenzkostenpreise nicht kostendeckend. Zum anderen resultieren die sinkenden Durchschnittskosten bei der Verkehrsinfrastruktur aus einem hohen Fixkostenblock, welcher in der Regel nicht beliebig verändert werden kann. Bei zeitlich schwankender Nachfrage müssen die Abgaben daher gleichzeitig die Problematik eines effizienten Auslastungsgrades der Infrastruktur berücksichtigen. ${ }^{112}$ Die Ausgestaltung von Instrumenten zur Wegekostenfinanzierung muß beide Aspekte mit einbeziehen. Im folgenden sollen Instrumente zur optimalen Preissetzung bei natürlichen Monopolen und Instrumente zur optimalen Kapazitätsauslastung kurz dargestellt werden, um sie im năchsten Schritt entsprechend der praktischen Erfordernisse der Infrastrukturfinanzierung zu gestalten.

Ein Zustand, der die Bedingungen der Pareto-Optimalität erfüllt und damit den sozialen Ertrag maximiert, wird erreicht, wenn alle Unternehmen ihre Preise entsprechend ihren Grenzkosten setzen. Wie oben erwähnt, hat diese Form der Tarifgestaltung Defizite des Anbieters zur Folge, da die Durchschnittskosten die Grenzkosten ubersteigen. ${ }^{113}$ Der Anbieter der Verkehrsinfrastruktur wuirde dagegen seinen privaten Gewinn maximieren, wenn er Grenzertrag = Grenzkosten setzt. Diese Monopolpreise fuhhren jedoch zu statischen Wohlfahrtsverlusten, wie sich leicht anhand des Konsumentenrentenkonzeptes zeigen läßt: Die Summe aus Konsumenten- und Produzentenrente ist bei Monopolpreisen geringer als bei wohlfahrtsmaximierenden Preisen. ${ }^{114}$

112 Das Instrument muß auch als Anreiz dienen, die Anlagen in ausreichendem Umfang bereitzustellen. Dieser Aspekt wird aber, wie schon dargelegt, in dieser Arbeit ausgeklammert.

113 Vgl. Boadway, R. W. and D. E. Wildasin (1984), S. 171.

114 Neben diesen Wohlfahrtsverlusten sind noch weitere denkbar. Wird die Infrastruktur von offentlichen Unternehmen angeboten, haben diese eventuell keinen Anreiz, die effiziente Technologie einzusetzen, so daß ihre Durchschnittskostenkurven von denen privater Unternehmen abweichen (X-Ineffizienz). Erfolgt das Angebot durch private Unternehmen, hăngt die Effizienz von der Art des Regulierungsmechanismus ab. Wenn z. B. aufgrund nichtbeobachtbarer Durchschnittskosten den Unternehmen eine feste Kapitalrendite zugesichert wird (rate-ofreturn Regulierung), kann es zu einem ineffizient hohen Kapitaleinsatz kommen, dem sog. Averch-Johnson Effekt.

Vgl. dazu Boadway, R. W. and D. E. Wildasin (1984), S. 173. 
Da die Wohlfahrtsverluste, die aus dem gewinnmaximierenden Verhalten des Monopolisten folgen, unerwünscht sind, sollte im entsprechenden Markt ein alternativer Preisbildungsmechanismus durchgesetzt werden. Er muß einerseits Vollkostendeckung für den Anbieter garantieren, unter dieser Prämisse aber ein mőglichst hohes Angebot sichern. Eine Mőglichkeit, dies zu erreichen, wäre vollkommene Preisdiskriminierung: Kann der Anbieter von jedem Nachfrager Preise entsprechend seiner Zahlungsbereitschaft verlangen, also die gesamte Konsumentenrente abschöpfen, kann er kostendeckend anbieten und die Gesamtwohlfahrt entspricht derjenigen bei Grenzkostenpreisen. Vollkommene Preisdiskriminierung kann aber aufgrund des Informationsproblems als undurchfuhrbar angesehen werden. Alternativ dazu könnten Grenzkostenpreise angesetzt und das Defizit mittels nichtverzerrender Steuern ausgeglichen werden. In der Realität sind Steuersysteme allerdings nicht neutral, d.h. die Steuererhebung ihrerseits mindert wieder die Wohlfahrt. ${ }^{115}$ Die Regulierungsliteratur fordert daher, daß der natürliche Monopolist kostendeckend arbeiten soll und sein Defizit mittels verzerrender Preise deckt.

Der einfachste Fall solcher second-best Preise sind Durchschnittskostenpreise. Sie decken die Gesamtkosten des Unternehmens, ohne die gleichen Wohlfahrtsverluste wie Monopolpreise zur Folge zu haben. Es ist allerdings möglich, Kostendekkung auch bei geringeren gesamtwirtschaftlichen Verlusten zu realisieren. In der Literatur werden im allgemeinen dazu zwei Ansătze unvollständiger Preisdiskriminierung vorgeschlagen: Ramsey-Preise und gespaltene Tarife.

Bei Ramsey-Preisen wird gefordert, daß die entstehenden Gesamtkosten so auf die Nachfrager aufzuteilen sind, daß die Aufschlăge auf die Grenzkosten umgekehrt proportional zu den Preiselastizităten der Nachfrager sind. Kunden mit geringen Preiselastizitäten werden auch bei hohen Preisaufschlägen nur geringfügig mit reduzierter Nachfrage reagieren, ihre Belastung führt daher zu geringeren Wohlfahrtsverlusten als die Belastung preiselastischer Nachfrager. Zur Verdeutlichung sei dies graphisch erläutert:

115 Vgl. Boadway, R. W. and D. E. Wildasin (1984), S. 174 f. 
Abb. 21: Ramsey-Preise
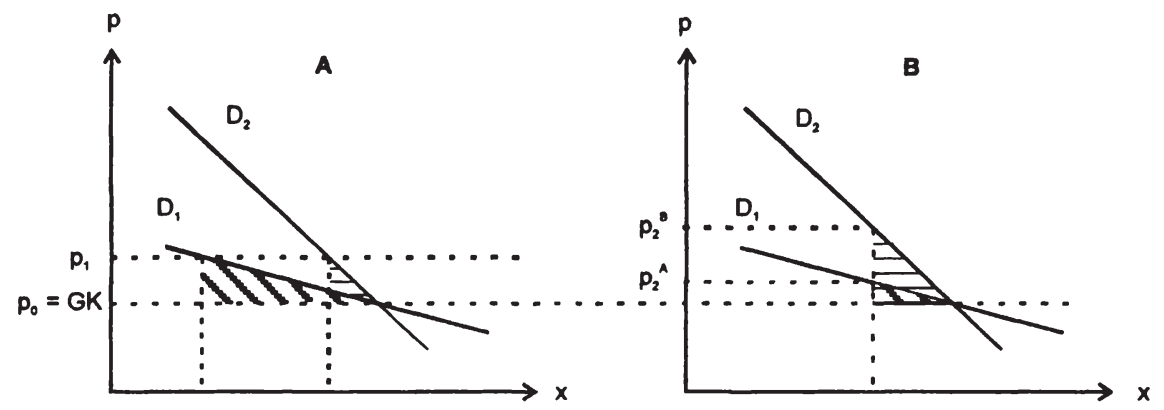

Quelle: Krakowski, M. (1988).

Es existieren zwei unterschiedlich preiselastische Nachfragefunktionen $D_{1}$ und $\mathrm{D}_{2}$, die sich im Anfangsgleichgewicht - aus Grunden der einfacheren Darstellung - schneiden. Gegenüber der Ausgangslage mit einem einheitlichen Preis po (Diagramm A), welcher kostendeckend sei, werden bei Ramsey-Preisen (Diagramm B) fur jeden Nachfrager Preise umgekehrt proportional zu seiner Nachfrageelastizität festgelegt. Die Preise sind so gesetzt, daß der Anbieter insgesamt kostendekkend arbeitet, d. h. die Deckungsbeiträge $\left(p_{2}{ }^{A}-G K\right) \circ x^{*}$ und $\left(p_{2}{ }^{B}-G K\right) \circ x^{*}$ ausreichen, um die Fixkosten abzudecken. Wahrend in $\mathrm{A}$ bei einheitlichem Preis unterschiedliche Nachfragemengen $x_{1}$ und $x_{2}$ existieren, sind in $B$ die Preise so gesetzt, daß der Nachfrageruckgang bei beiden Gruppen gleich ist und zur Menge $\mathrm{x}^{*}$ fuhrt. Der durch Kostendeckung entstehende Wohlfahrtsverlust (schrăg und waagerecht schraffierte Fläche in B) wird so gegenüber den einheitlichen Preisen in A minimiert. ${ }^{116}$ Dies setzt natürlich voraus, daß tatsăchlich verschiedene Mărkte mit unterschiedlichen Nachfrageelastizităten existieren und das anbietende Unternehmen in der Lage ist, die Preise zu differenzieren. Letzteres wiederum geht nur, wenn das Unternehmen entweder unterschiedliche Produkte anbietet oder Arbitragekăufe unterbinden kann.

Die Alternative zur Kostendeckung sind gespaltene Tarife. Ein typisches Beispiel dafür sind Preise, die sich aus einer Grundgebuhr und einem nutzungsabhängigen Preis zusammensetzen. Wenn die Grundgebuhr die Fixkosten abdeckt, können die nutzungsabhăngigen Preise den Grenzkosten entsprechen. Der Wohlfahrtsgewinn sei wiederum beispielhaft anhand einer Zeichnung verdeutlicht.

${ }^{116}$ Fur einen Nachweis siehe Baumol, W. J. and D. Bradford (1970), S. 272. 
Abb. 22: Gespaltene Tarife

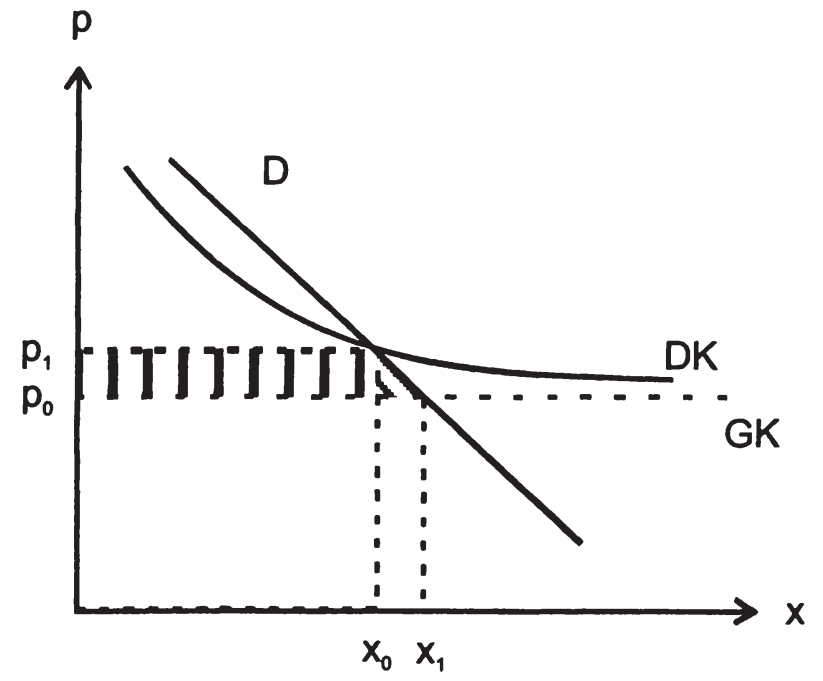

Quelle: Krakowski, M. (1988).

Nimmt man an, daß der Preis in der Ausgangslage $p_{0}$ die gesamten Kosten des Anbieters deckt, kann die Wohlfahrt erhöht werden, indem der Anbieter die dunkelgraue Flăche als Grundgebühr festsetzt und einen Nutzungspreis in Hơhe der Grenzkosten von $\mathrm{p}_{1}$ fordert. Die Konsumentenrente wurde in diesem Fall durch die Ausdehnung der Menge von $\mathrm{x}_{0}$ auf $\mathrm{x}_{1}$ um die senkrecht schraffierte Flăche ansteigen. Gespaltene Tarife erhöhen also verglichen mit ausschließlich nutzungsabhängigen Tarifen die Wohlfahrt. $\mathrm{Zu}$ berulcksichtigen ist, daß Grundgebuhren zwar keine marginalen excess burden hervorrufen, aber in der Lage sind, inframarginal zu verzerren. Sie können „Kleinverbraucher“ aus dem Markt drängen, bei denen die totalen Kosten der Grundgebühr höher sind als der totale Nutzen aus dem Konsum des jeweiligen Gutes. ${ }^{117}$ Dem kann die Wahlmöglichkeit zwischen proportionalen und gespaltenen Tarifen abhelfen. ${ }^{118}$

Nachdem die drei wesentlichen Ansătze zur Preissetzung bei natürlichen Monopolen - Durchschnittskostenpreise, Ramsey-Preise und gespaltene Tarife - dargestellt wurden, soll auf das zweite Argument im Zusammenhang mit hohen Fixkostenblöcken, dem Problem begrenzter Kapazităten bei schwankender Nachfrage, eingegangen werden.

117 Vgl. Boadway, R. W. and D. E. Wildasin (1984), S. 175.

118 Vgl. Krakowski (1988), S. 91. 
Im Straßenverkehr wird die Kapazität durch Breite und Ausbaugrad der Straße bestimmt, beides Größen, die kurzfristig nicht variiert werden können. Gleichzeitig schwankt, wie in Kapitel 2.1 dargestellt, die Nachfrage nach Infrastrukturkapazität zeitlich stark. Die optimale Tarifgestaltung bei der Bereitstellung solcher nichtlagerfahiger Güter und Dienste mit regelmäßigen Nachfrageschwankungen ${ }^{119}$ wird als Peak-load pricing bezeichnet.

Beim peak-load pricing müssen zwei Aspekte unterschieden werden: Die optimalen Preise jeder Periode, also die Preisgestaltung bei gegebener Kapazităt, und die optimale Kapazität der Anlage. Hier soll der Zielsetzung der Arbeit entsprechend allerdings nur das kurzfristige Problem der optimalen Preisgestaltung bei gegebenen Anlagen betrachten werden.

Die Fragestellung bei diesem Problem lautet, welcher Preisvektor die Konsumenten zum Kauf der gesellschaftlich optimalen Menge in jeder Teilperiode veranlaßt. Die Antwort darauf gibt die Grenzkostenpreisregel: Die Preise jeder Teilperiode sollen den jeweiligen Opportunitătskosten entsprechen, also den realen Ressourcenverzehr in der jeweiligen Verwendung zum Ausdruck bringen unabhängig davon, ob die vorhandene Kapazität für die gegebene Nachfragestruktur optimal ist oder nicht.

Dargestellt ist ein Angebot an Verkehrsinfrastruktur zu konstanten Grenzkosten bis zur Kapazitätsgrenze $x_{2}^{1}$. Ab diesem Punkt ist eine Ausweitung des Angebots nicht mehr möglich, die Grenzkosten sind inderminiert.

In der Spitzenperiode sorgt der Preis für einen Ausgleich von Nachfrage und vorhandener Infrastrukturkapazităt. Da die Grenzkosten an der Kapazitătsgrenze unbestimmt sind, ist der Preis $\mathbf{p}_{2}$ allein nachfragedeterminiert. Diejenige Periode, die die Kapazität voll in Anspruch nimmt, trägt - bei limitationalen Produktionsprozessen - als einzige zu den Kapazitätskosten bei. Da sie dennoch eine höhere Nachfrage aufweist, wird dieser Fall auch als firm-peak Fall bezeichnet.

Die Preise $p_{1}$ und $p_{2}$ erhöhen die Wohlfahrt gegenüber einem gemeinsamen Durchschnittskostenpreis $\mathrm{p}_{0}$. Dieser drängt die Nachfrage der Schwachlastperiode zurück und ruft somit einen excess burden hervor, während er in der Spitzenperiode die Zahlungsbereitschaft bei gegebener Kapazität nicht abschöpft und so zu Einnahmenverlusten führt, denen keine Konsumentenrente gegenübersteht.

119 Vgl. Schellhaaß, M. (1987). "Peak-load-Pricing: Allgemeine Grundsătze." Wirtschaftswissenschaftliches Studium 10: 463-469. 
Abb. 23: Optimale Preise bei gegebener Kapazităt
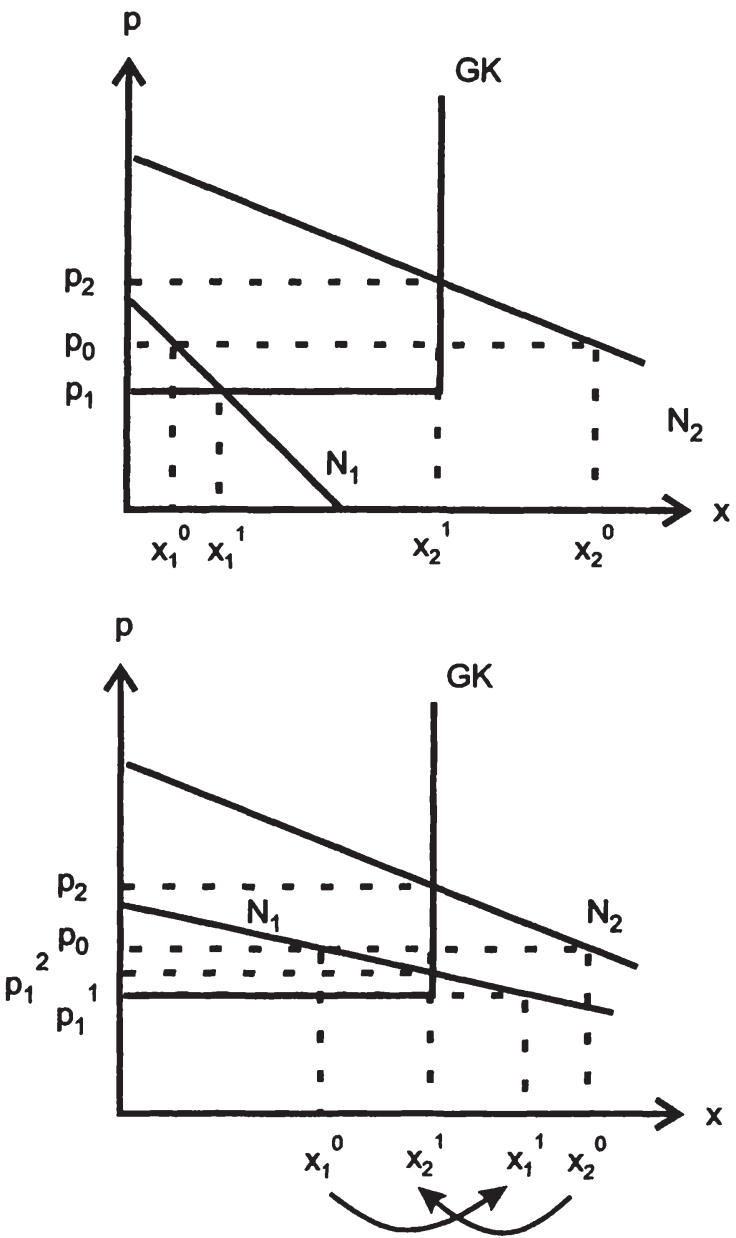

Quelle: Schellhaaß, M. (1987).

Diese Darstellung zeigt, daß Peak-load-pricing die optimale Nutzung einer Anlage mit unterschiedlichen Auslastungsgraden gewährleistet. Der für diesen Abschnitt der Arbeit relevante Nebenzweck der optimalen Nutzung ist, daß die Spitzenperiode - im shifting-peak Fall auch die Schwachlastperiode - einen Deckungsbeitrag 
zu den Kapazitätskosten, mithin den Kosten der Bereitstellung der Verkehrsinfrastruktur, liefert.

Dieser Beitrag reicht im Fall sinkender Durchschnittskosten allerdings nicht aus, um die gesamten Wegekosten $\mathrm{zu}$ decken. Wie MOHRING gezeigt hat, ${ }^{120}$ realisiert peak-load-pricing nur dann ein kostendeckendes Aufkommen, wenn konstante Skalenerträge vorliegen (wie in der obigen Zeichnungen mit den Kurvenverläufen implizit angenommen). Liegen steigende Skalenerträge vor, reicht die Überlastgebuhr alleine nicht aus, um das Defizit, d.h. die Differenz aus Grenzkostenpreisen und Durchschnittskosten, abzudecken.

Es hat sich im folgenden eine längere Diskussion um die tatsächliche Relevanz der steigenden Skalenerträge entwickelt, die an dieser Stelle nicht ensprechend gewuirdigt werden kann. Beide Seiten haben einiges an schlüssigen Argumenten zu bieten, so daß letztlich empirische Studien uber die Richtigkeit der jeweiligen Aussagen zu entscheiden hätten. Diese jedoch weisen in ihren Ergebnissen ebenfalls keine klare Tendenz auf. ${ }^{121}$ Die gleichzeitige Lossung sowohl der allokativen als auch der fiskalischen Aspekte, welche sich im Zusammenhang mit sinkenden Durchschnittskosten ergeben, also optimale Verteilung der Nutzer uber die Zeit und Finanzierung des Fixkostenblockes, mit Hilfe eines einzigen Instrumentes dürfte aber in den meisten Fällen nicht möglich sein. Peak-load pricing stellt also nur in Ausnahmen den Königsweg der Verkehrsinfrastrukturfinanzierung dar.

\subsubsection{Die Internalisierung der Externalităten des Straßengüterverkehrs}

Neben der Einnahmenerzielung zur Deckung der Wegekosten durch Steuern, Gebuhren und Beiträge kann ein weiteres staatliches Ziel die Lenkung unerwulinschten Verhaltens sein. Steuern sollen zwar laut $\$ 3$ AO primär der Erzielung von Einnahmen dienen, also einen fiskalischen Zweck verfolgen. Sie können allerdings auch gezielt eingesetzt werden, um das Verhalten des Besteuerten zu beeinflussen, d. h. zur Internalisierung externer Effekte.

Lenkungsziele werden allerdings bisher nur in seltenen Fällen mittels Abgaben verfolgt. Üblicherweise werden nichtfiskalische Instrumente wie Auflagen, planerische Instrumente, Kooperationslösungen, öffentliche Ausgaben, Haftungsregeln oder zwangsfreie Instrumente zur Verfolgung des Lenkungsziels eingesetzt.

Unter den genannten wiederum dominieren die Auflagen, also direkte Verhaltensvorschriften. Sie existieren in Form von Ge- und Verboten. Verbote untersagen

120 Vgl. Mohring, H. (1970).

121 Vgl. dazu Hau, T. D. (1998).

122 Fur eine genauere Einteilung siehe Wicke, L. (1993), S. 194f. Ausgenommen werden aus der spatteren Betrachtung offentliche Ausgaben als umweltpolitische Maßnahmen und freiwillige Instrumente, da beide in der Verkehrspolitk keine bedeutende Rolle spielen. 
besonders gefährliche Umwelteinwirkungen. Gebote schreiben den Umfang an erlaubten Emissionen vor, sollen also ein Verhalten durchsetzen, bei dem im Gegensatz zum Verbot eine gewisse Verunreinigung noch erlaubt ist. Gebote können in Form von Emissionsnormen umgesetzt werden. In diesem Fall wird die absolute Höhe der Schadstoffmenge festgelegt, die bei der Emission einer Anlage nicht uberschritten werden darf. ${ }^{123}$

Ein Beispiel für solche Emissionsnormen im Verkehrsbereich sind Grenzwerte für die Zulassung neuer Fahrzeuge, aber auch örtliche oder zeitliche Fahrbeschränkungen (Zonierungen) wie die Sperrung der Innenstădte für bestimmte Fahrzeuge.

Für LKW existieren $z$. Zt. folgende Werte:

Abb. 24: Abgasgrenzwerte fur LKW und Busse

\begin{tabular}{|c|c|c|c|c|}
\hline \multicolumn{5}{|c|}{ Abgasgrenzwerte fur LKW und Busse (Grenzwerte fur die Serienproduktion) } \\
\hline & seit 1988/90 & 1. Stufe ab 92/93 & 2. Stufe ab $95 / 96$ & 3. Stufe ab 99 \\
\hline CO & $13,3 \mathrm{~g} / \mathrm{kWh}$ & $4,9 \mathrm{~g} / \mathrm{kWh}$ & $4,0 \mathrm{~g} / \mathrm{kWh}$ & $2,0 \mathrm{~g} / \mathrm{kWh}$ \\
\hline HC & $2,6 \mathrm{~g} / \mathrm{kWh}$ & $1,23 \mathrm{~g} / \mathrm{kWh}$ & $1,1 \mathrm{~g} / \mathrm{kWh}$ & $0,6 \mathrm{~g} / \mathrm{kWh}$ \\
\hline Nox & $15,8 \mathrm{~g} / \mathrm{kWh}$ & $9,0 \mathrm{~g} / \mathrm{kWh}$ & $7,0 \mathrm{~g} / \mathrm{kWh}$ & unter $5,0 \mathrm{~g} / \mathrm{kWh}$ \\
\hline Partikel & - & $0,4 \mathrm{~g} / \mathrm{kWh} \mathrm{l})$ & $0,15 \mathrm{~g} / \mathrm{kWh}$ & unter $0,1 \mathrm{~g} / \mathrm{kWh}$ \\
\hline
\end{tabular}

Quelle: Umweltbundesamt.

Die Gebote können aber auch als Reduzierungsverpflichtungen um einen bestimmten absoluten oder relativen Betrag ausgestaltet sein. Die Vorteile von Auflagen sind ihre schnelle Wirksamkeit, verbunden mit größerer Reaktionssicherheit, was insbesondere bei der unmittelbaren Gefahrenabwehr von Bedeutung ist. $\mathrm{Da}$ die $\mathrm{Ge}$ - und Verbotsbestände klar vorgegeben sind, haben Auflagen gegenuber anderen Instrumenten den Vorteil größerer Praktikabilität.

Bei Umweltabgaben wird versucht, mittels der Erhebung von Abgaben okonomische Anreize zu schaffen und damit umweltpolitische Ziele zu verwirklichen. Sie lassen sich als Umweltabgaben im weiteren Sinne und im engeren Sinne einteilen. Bei letzterem dominiert die Anreizfunktion der Abgabe tatsăchlich oder zumindest der Absicht nach. Bei ersterer steht die Finanzierungsfunktion im Vordergrund, die Umweltwirkung ist ein untergeordnetes Ziel.

Umweltabgaben können als Pigou-Steuer oder mittels des Standard-PreisAnsatzes umgesetzt werden. Im ersten Fall wird eine Steuer so ausgestaltet, daß sie gerade dem marginalen externen Effekt im Optimum entspricht. Aufgrund des

${ }^{123}$ Emissionsnormen werden eigentlich nur festen Anlagen auferlegt. Bei Kraftfahrzeugen spricht man dagegen von Produktnormen. Da der Begriff Emissionsnorm jedoch allgemeinverstăndlicher und eine Verwechslung ausgeschlossen ist, soll er in dieser Arbeit auch furr Emissionsbegrenzungen von Kraftfahrzeugen gelten. 
hohen Informationsbedarfs sind Pigou-Steuern aber fur die praktische Anwendung in den allermeisten Fällen nicht geeignet. Der Gesetzgeber würde für ihre Umsetzung zum einen private Informationen bezuglich des subjektiven Schadens benötigen. Zum anderen müßte er diesen Schaden, der sich in der Regel aus dem Zusammenwirken mehrerer Quellen ergibt, dem einzelnen Verursacher, hier z.B. einem einzelnen LKW, zuordnen können. Er muß also eine Beziehung zwischen Emission und Immission herstellen, welche sowohl räumlich als auch zeitlich auseinander liegen können. ${ }^{124}$

Abb. 25: Pigou-Steuer und Standard-Preis-Ansatz

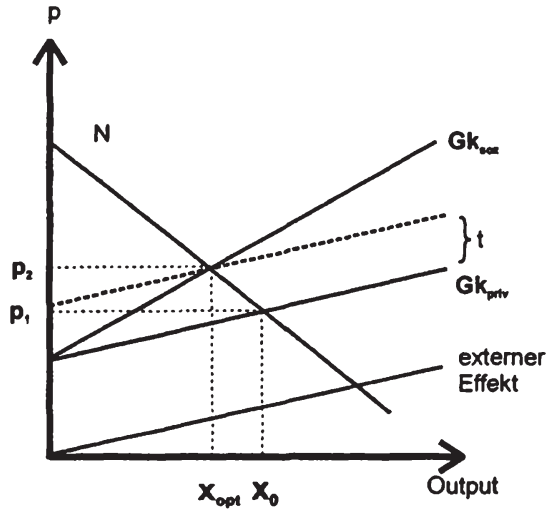

Pigou-Lösung

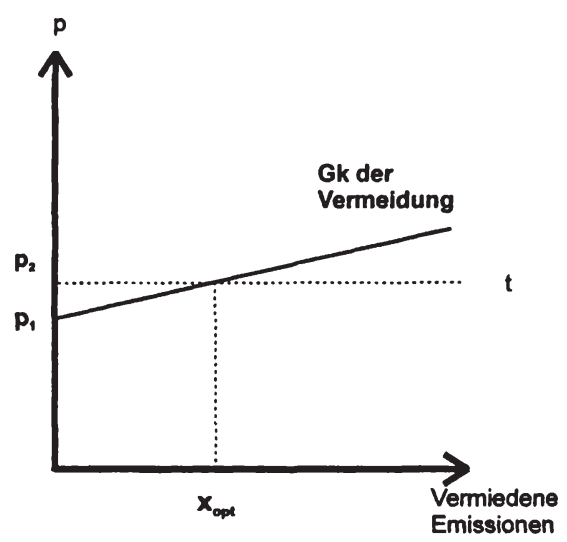

Standard-Preis-Ansatz

$\mathrm{Da}$ das Informationsproblem in der Praxis nicht gelöst werden kann, die in Abb. 25 abgetragenen privaten und externen Grenzkosten also nicht bekannt sind und der optimale Steuersatz somit nicht ermittelt werden kann, wird ersatzweise der sogenannte Preis-Standard-Ansatz angewandt. Bei diesem wird die praktisch nicht lösbare Frage nach dem optimalen Verschmutzungsgrad $x_{\text {opt }}$ nicht gestellt, sondern seine Festlegung einer exogenen Institution, z.B. der Politik, überlassen. Der Steuersatz, der zu dieser gewünschten Immissionsmenge führt, wird dann per trial-and-error festgelegt.

Ein Nachteil von Abgaben ${ }^{125}$ ist, daß sie das Abgabensystem verkomplizieren. Dazu gehört auch, daß insbesondere Steuern einem langwierigen Gesetzgebungsverfahren unterworfen sind und daher an Veränderungen in der Belastung nur schwer anzupassen sind. Abgaben rufen zudem im allgemeinen den Widerstand der Betroffenen und der umsetzenden Bürokratie hervor. Die gewünschten Anpas-

124 Vgl. Weimann, J. (1995), S. 205f.

125 Vgl. Wicke, L. (1993), S. 407 f. 
sungsreaktionen treten zudem nicht zwangsläufig auf. Bei nichtkompetitiven Marktstrukturen ist es möglich, daß Betroffene nicht in der erwarteten Weise auf die Lenkungssteuer reagieren. ${ }^{126}$ Abgaben lassen sich meist schwer an spezielle, z. B. regionale, Gegebenheiten anpassen und können daher in der Anwendung ineffizient sein.

Abgaben sind jedoch vorteilhaft, wenn es darum geht, die statische Effizienz der Umweltverbesserung sicherzustellen. Dies läßt sich am besten im Vergleich mit den oben dargestellten Auflagen darstellen.

Abb. 26: Ókonomische Efrizienz von Abgaben- und Auflagenlosungen

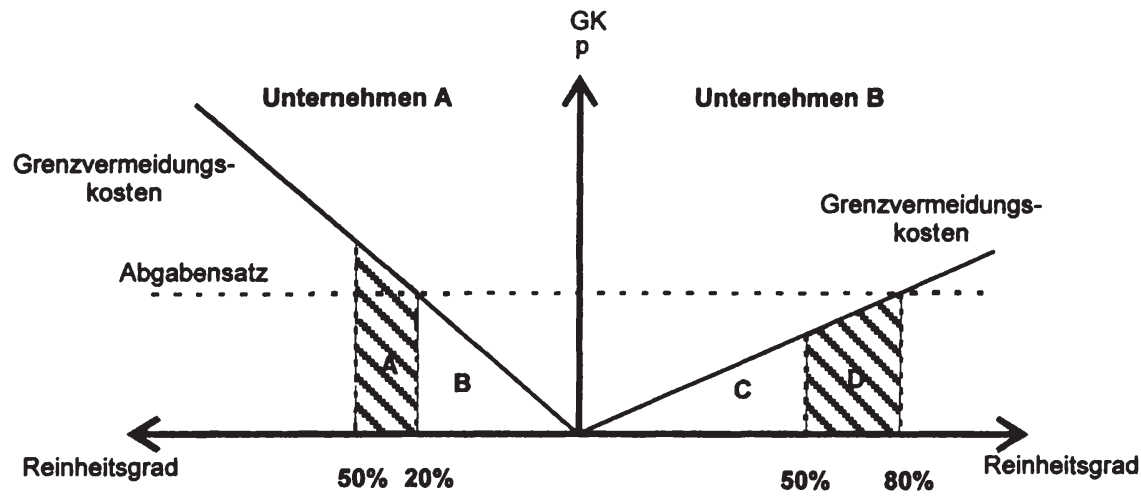

Quelle: Wicke, L. (1993).

In obiger Zeichnung seien zwei gleich große Unternehmen dargestellt. Die Grenzkosten geben die Kosten einer zusätzlichen Steigerung des Reinheitsgrades des verschmutzten Umweltmediums fur jedes Unternehmen an.

Zur Halbierung der Umweltbelastung kann eine Behörde entweder fur jedes Unternehmen eine Schadstoffreduktion um 50\% vorschreiben oder aber eine Abgabe so festlegen, daß beide Unternehmen zusammen die vorgeschriebene Schadstoffreduktion erfullen.

Im ersten Fall belaufen sich die Kosten auf die Flächen B, C und die schraffierte Fläche A. Im Fall der Umweltabgabe könnten die Unternehmen zwischen den Kosten der Reinigung und der Höhe der Abgabe abwägen. Unternehmen A würde in diesem Fall nur eine Schadstoffreduktion um $20 \%$ vornehmen, Unternehmen B dagegen um $80 \%$, so daß das Vermeidungsziel insgesamt erreicht wird. Durch die

${ }^{126}$ Wicke nennt folgendes Beispiel: Wenn Getrănkehersteller mit einer Einwegflaschengebuhr belastet werden, könnten sie diese gleichmäßig auf die Einweg- und Mehrwegflaschen verteilen (Schrägwålzung). Eine Stutzung des Mehrwegsystems wird damit nicht erreicht. 
Berücksichtigung der individuellen Situation der Unternehmen sind die Gesamtkosten jedoch um (A - D) geringer. Das Hauptargument für Abgaben ist also deren statische ökonomische Effizienz. Allerdings können noch andere Gründe dafur angefuhrt werden: Abgaben sind dynamisch effizient, sie bieten einen ständigen Anreiz zur Verbesserung der Vermeidungstechnik und damit zur Reduktion der Abgabenlast. Sie sind marktkonform, d. h. lassen den Verschmutzern die Freiheit, zwischen Umweltverschmutzung und Abgabe zu wählen. Dies hat inbesondere für solche, meist kleinere, Unternehmen Vorteile, die von der Einfuhrung effizienter Vermeidungstechniken finanziell uberfordert würden.

Eine weitere Möglichkeit zur Internalisierung externer Kosten ist eine Verschärfung des Haftungsrechts. Theoretisch bietet die juristische Lösung einiges an Vorteilen: ${ }^{127}$

Im allgemeinen begrundet das Haftungsrecht Anspruche auf Schadensersatz, Unterlassung oder Beseitigung. Gegenüber dem Emittenten können also nicht nur die Vermeidungskosten, sondern der tatsächlich angefallene Schaden eingeklagt werden. Solange der Verursacher also eine Vermeidungstechnologie implementieren kann, die kostengünstiger ist als der von ihm verursachte Schaden, wird er diese einsetzen. Damit verbunden ist gleichzeitig ein starker Anreiz für den Produzenten, technologische Fortschritte auszunutzen, um so die potentiellen Schäden und damit sein Haftungsrisiko $\mathrm{zu}$ reduzieren. ${ }^{128}$

Was auf theoretischer Ebene positiv klingt, zeigt bei der praktischen Tauglichkeit einige Schwăchen. Haftungsregeln können erst dann wirken, wenn individuelle Schäden entstanden sind, der Schädiger identifiziert werden kann und ein kausaler Zusammenhang zwischen beiden herstellbar ist. Langsam oder über große Distanzen wirkende Stoffe und solche, die erst in der Summe einen Schaden auslösen, sind demnach prinzipiell der Internalisierung durch Schadenshaftung nicht zugănglich.

Ein weiteres Problem ist der Haftungstatbestand. Liegt die Beweislast beim Geschädigten, dürfte es im konkreten Einzelfall nur selten möglich sein, den tatsächlichen Zusammenhang zwischen Schädiger und Schaden nachzuweisen. Um das Verursacherprinzip durchzusetzen, wäre also eine Umkehr der Beweislast auf den Schädiger nötig. Dies könnte nach folgenden Strategien erfolgen: ${ }^{129}$ Der Produzent muß immer dann haften, wenn die den Schaden auslösende Anlage nicht dem Stand der Technik entspricht. Damit ist ein hoher Anreiz zur Modernisierung gegeben.

127 Vgl. Eckhardt, K. (1993), S. 27 f.

128 Vgl. Cansier, D. (1981), S. $192 \mathrm{ff}$.

129 Wicke, L. (1993), S. 256 f. 
Bei der sogenannten Produzentenhaftung wird dagegen die Schuld des Emittenten grundsătzlich unterstellt. Er hat allerdings die Möglichkeit, den Schuldvorwurf zu widerlegen. In diesem Fall liegt also eine Beweislastumkehr vor. Noch weitergehend ist die sogenannte Gefährdungshaftung. In diesem Fall tritt die Schadensersatzpflicht auch dann ein, wenn kein Verschulden des Verursachers vorliegt. Wird im Interesse des Betreibers ein besonders gefährlicher Betrieb gestattet, soll er auch dann haften, wenn er die verkehrsübliche Sorgfalt eingehalten hat.

Als letztes Instrumentarium zur Internalisierung externer Effekte sollen Umweltzertifikate dargestellt werden. Der Grundgedanke ist - ähnlich dem Preis-Standard Ansatz, daß der Staat nicht versucht, eine pareto-effiziente Allokation zu erreichen, sondern eine politisch definierte Emissionsgesamtmenge festlegt. Diese wird in kleine Partien zerlegt und potentiellen Verschmutzern in Form von Zertifikaten zugewiesen. Damit werden Eigentumsrechte geschaffen, die einen Markt für Umweltschädigung etablieren können.

Abb. 27: Die Funktionsweise von Umweltlizenzen

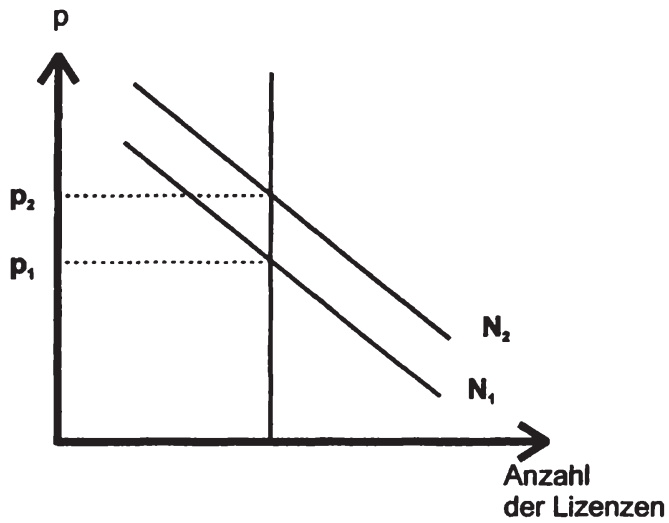

Quelle: Wicke, L. (1993).

Angewandt auf den Verkehrsmarkt hätten also Spediteure die Möglichkeit, in Vermeidungstechnologien zu investieren, mithin den Fuhrpark mit modernen Fahrzeugen auszustatten oder auf dem entsprechenden Markt Verschmutzungslizenzen zu erwerben. Erhöht sich - aus welchem Grund auch immer - das Interesse an den Lizenzen $\left(\mathrm{N}_{1}\right.$ verschiebt sich $\mathrm{zu} \mathrm{N}_{2}$ ) und damit deren Preis, wird es für einige Spediteure rentabel sein, alte Fahrzeuge zu ersetzen und dafur ihre Verschmutzungslizenzen $\mathrm{zu}$ verkaufen. Diese einzelwirtschaftliche Kostenminimierung stellt sicher, daß der Umweltschutz gesamtwirtschaftlich effizient gehandhabt wird. Der Unterschied zum Preis-Standard Ansatz besteht also darin, daß bei diesem der Preis durch den Planer vorgegeben ist und die Emittenten ihre 
Mengen anpassen, während bei Lizenzen die Menge exogen ist und der Preis für Umweltverschmutzung am Zertifikatemarkt gebildet wird.

Vorteil gegenüber den Abgabenlösungen ist, daß sich das Informationsproblem des Gesetzgebers verringert. Nach Festlegung der gewunschten Menge wird die Allokation durch den Markt geregelt. Dennoch ist die Zertifikatelösung mit einigen Problemen verbunden, die insbesondere im Zusammenhang mit nichtkompetitiven Märkten auftauchen. Sind relativ wenige Verschmutzer vorhanden, können diese durch strategisches Verhalten die Grenzkostenpreisbildung verhindern. Dieses Problem relativiert auch einen Vorteil von Lizenzen gegenüber Abgabenlösungen: Da Lizenzen, regional vergeben werden können, ist eine Feinsteuerung eigentlich leichter möglich ist als mit anderen Instrumenten. Die regionale Vergabe reduziert jedoch die Anzahl der Verschmutzer und damit die Effizienz der Lösung. Im Straßengüterverkehrsmarkt dürfte die Marktmacht jedoch (noch) keine wesentliche Rolle spielen. 1990 waren etwas 10.000 Unternehmen zum gewerblichen Güterkraftverkehr angemeldet, davon ein Drittel mit nur einem Lastkraftwagen und nur $7 \%$ mit mehr als $10 .^{130}$ Es kann also von kompetitiven Strukturen ausgegangen werden.

Als weiteres Problem der regionalen Vergabe wird genannt, daß die durch Lizenzen vorgegebenen Höchstgrenzen nur dann wirksam werden können, wenn sich die Gebiete wirksam voneinander abgrenzen lassen, d. h. dem Verbreitungsraum der Emission entsprechen. Lizenzen sind daher zwar für die lokalen und regionalen Effekte des Straßengüterverkehrs prinzipiell geeignet, für global wirkende Schadstoffe jedoch kaum.

\subsection{Die Ausgestaltung der Instrumente nationaler Güterverkehrspolitik}

Nach der Darstellung der Ziele der Verkehrspolitik und der Mittel zu deren Erreichung soll im nun folgenden Abschnitt eine praktikable und effiziente Ausgestaltung dieser Instrumente im Bereich des Straßengüterverkehrs ausgearbeitet werden. Die Ziele wurden im Abschnitt 4.2 definiert: Zum einen soll der Straßengüterverkehr die von ihm genutzte Infrastruktur selbst finanzieren, zum anderen soll er die von ihm verursachten externen Kosten in der Kalkulation mit berücksichtigen.

Der folgende Abschnitt wird die Ausarbeitung von Instrumenten zur Umsetzung beider Ziele getrennt behandeln und dann zu einer einheitlichen Verkehrspolitik zusammenfassen. Indem internationale Aspekte der Finanzierung und Steuerung des Straßengüterverkehrs, insbesondere Fragen der Kompetenzverteilung, außer Acht gelassen werden, wird die Analyse zunächst so einfach wie möglich gehal-

${ }^{130}$ DIW (1996). 
ten. Bei der Finanzierung der Infrastruktur wird zudem - wie schon zu Beginn erwăhnt - nicht untersucht, wieviel Straßeninfrastruktur tatsächlich zur Verfügung gestellt werden sollte. Diese Frage würde die Aufgabenstellung dieser Arbeit sprengen. Stattdessen wird von einer gegebenen Straßenkapazităt ausgegangen und nach Instrumenten gesucht, mit denen diese optimal finanziert werden kann.

\subsubsection{Abgaben zur Finanzierung der Straßenverkehrsinfrastruktur}

Infrastruktur weist, wie im Kapitel 2.2.1 abgeleitet, sinkende Durchschnittskosten bei der Bereitstellung auf. Grenzkostenpreise kőnnen demnach nicht die Bereitstellungskosten der Infrastruktur decken. ${ }^{131}$ Um diese Kostendeckung dennoch zu erreichen, wäre eine Differenzierung der Preise entweder uber gespaltene Tarife oder Ramsey-Preise nötig. Um Ramsey-Preise ermitteln zu können, benötigen wir die Nachfrageelastizităten der Transporteure. Wir müssen also wissen, um wieviel die Transportnachfrage innerhalb einer Gütergruppe abnehmen wird, wenn der Preis um einen bestimmten Prozentsatz steigt. Weiterhin benötigen wir eine Bemessungsgrundlage, die eng genug mit der jeweils transportierten Gütergruppe korreliert ist.

Die Preiselastizităten im Straßengüterverkehr sind mit $-0,5$ bis $-0,9$ insgesamt relativ gering. ${ }^{132}$ Dies hat folgende Grunde: Der Transportkostenanteil an den Gesamtkosten der meisten Güter ist eher niedrig. Ausnahmen bilden vor allem geringwertige Grund- und Rohstoffe, z. B. Sand, Schotter, Salz, Zement u. ä., bei denen die Transportkosten ein bis zwei Drittel der Gesamtkosten ausmachen. ${ }^{133}$ Zudem ist die Nachfrage vor allem nach Transportleistungen auf der Straße nur zu einem Teil vom Preis abhängig, eine größere Rolle spielen qualitative Eigenschaften des Straßengüterverkehrs. Insbesondere hochwertige Güter weisen besondere Anforderungen an den Transportvorgang auf: Schnellverderbliche Guter müssen in Fahrzeugen mit konservierenden Einrichtungen oder aber besonders schnell transportiert werden. Besonders empfindliche Güter sollten - wenn möglich - im ungebrochenen Verkehr, d. h. ohne Umladung befordert werden. Viele Guter fallen nur in geringen Mengen an und benötigen spezielle Gefåße usw. Diese speziellen Anforderungen erfullt praktisch nur der Straßengüterverkehr, so daß ein Preisanstieg besonders bei hochwertigen Gütern kaum zu Abwanderungen zu anderen Verkehrstrăgern fuhrt. ${ }^{134}$

131 Fur eine theoretische Herleitung siehe Winston, C. (1985), S. 78.

132 Baum, H. (1985), S. 212.

133 Mangels neuerer Daten muß auf eine entsprechende Untersuchung aus dem Jahr 1971 zurlackgegriffen werden, die naturlich die gesamten neueren Entwicklungen nicht einbezieht. Sie kann daher nur als grobe Richtschnur dienen. Vgl. dazu Voigt, F. (1973), S. 319.

134 Vgl. Koberlein, C. (1997), S. $68 \mathrm{ff}$. 
Wir stellen also fest, daß die direkte Preiselastizität insgesamt sehr gering ist und die Kreuzpreiselastizität bei hochwertigen Gütern aufgrund nichtpreislicher Faktoren ebenfalls kaum ins Gewicht fällt. Ramsey-Preise würden erfordern, daß Transporte hochwertiger Güter deutlich stärker besteuert werden als Transporte z. B. von Rohmaterialien. Dies setzt jedoch eine einigermaßen praktikable Trennbarkeit voraus. Ein Ansatzpunkt wăren die Transportgefaße. Demnach mußte z. B. ein Kuhlcontainer einer höheren Steuer unterliegen als ein normaler Container oder ein offener LKW. Hier wiederum wird es schwierig, den Zensiten eindeutig zu bestimmen. Die moderne Transporttechnologie ist vermehrt dadurch gekennzeichnet, daß die Fahrzeuge mit einer Vielzahl verschiedener Aufbauten bzw. Auflieger ausgestattet werden können, um die kapitalintensiven Zugmaschinen besser zu nutzen. Ähnliches gilt beim Transport von Containern, die ebenfalls völlig Unterschiedliches beinhalten können. Die Bemessungsgrundlage variiert also von Fahrt zu Fahrt und ist somit kaum zu bestimmen. Ramsey-Preise kommen daher trotz ihrer guten theoretischen Eigenschaften aus praktischen Erwägungen zur Infrastrukturfinanzierung nicht in Frage.

Bei gespaltenen Tarifen stellt sich das Problem etwas einfacher dar. Sie existieren - zumindest ansatzweise - schon in Form von (nutzungsunabhăngigen) $\mathrm{Kfz}$ Steuern und (nutzungsabhängigen) Mineralölsteuern und teilweise Straßenmauten. Das Problem besteht also nur darin, die Fixkosten zu bestimmen und sie auf die Nutzer aufzuteilen. Dies allerdings ist nicht ohne Schwierigkeiten möglich, da die Nutzer genaugenommen keine homogenen Güter nachfragen. LKW stellen je nach zulässigem Gesamtgewicht, Art und Anordnung der Achsen, Art und $\mathrm{Zu}$ stand der Federung etc. sehr unterschiedliche Anforderungen an die Qualität der Straßen. Ist diese furr den jeweiligen Fahrzeugtyp zu niedrig, kőnnen schon wenige Fahrten strukturelle Schäden an der Fahrbahn verursachen. So wächst nach dem klassischen AASHO-Road-Test der Schaden an einer Straße exponentiell um den Faktor vier mit dem Achsgewicht des Fahrzeuges. An diesem Test ist zwar in letzter Zeit einige Kritik geübt worden, die sich vor allem auf die ungenügende Berücksichtigung anderer Faktoren bezog. Der verursachte Schaden ist, wie neuere Tests erwiesen haben, außer von der Achslast noch von der Anordnung der Achsen (einzelne Achse, Tandem-, Tridemachse), der Art der Bereifung (einzelne Reifen, Doppelbereifung, Luftdruck), der Art der Federung (keine, Blattfederung, Luftfederung, ...), dem Zustand von Achsen und Federung und der Art der Achsen (angetrieben, tragend) abhängig. Insgesamt kann er aber trotzdem als ungefährer Anhaltspunkt dienen. Dies bedeutet, plastisch dargestellt, daß eine $10 \mathrm{t}$ Achse den zehntausendfachen Schaden einer $1 \mathrm{t}$ Achse an einer Straße verursacht. ${ }^{135}$

Es wäre nun allokativ schädlich, dem Kleinlaster Fixkostenanteile anzulasten, für deren Zustandekommen nicht er, sondern der Schwertransporter verantwortlich

135 Vgl. dazu und zur Kritik am Ansatz OECD (1988), S. 18 und 23 ff. 
ist. Dies wurde, wie unter 4.2.1 dargestellt, einer unangemessenen Markteintrittsbarriere entsprechen und damit vor allem kleinere Wettbewerber verdrängen. $\mathrm{Zu}$ dem würde ein excess burden entstehen, da die Steuer für die Beförderer einen Anreiz schaff, vorbei an ökonomischen Notwendigkeiten zu große Fahrzeuge einzusetzen, welche aufgrund der undifferenzierten Ausgestaltung nicht ihre gesamten Fixkosten tragen und somit subventioniert würden.

Für die Ausgestaltung einer Grundgebühr wird daher folgende Möglichkeit vorgeschlagen: Jeder Teilnehmer zahlt eine Grundgebuhr, die die ihm anzulastenden Fixkosten deckt. Das sind die Kosten fur den Ausbaugrad, der notwendig ist, damit ein Fahrzeug mit der jeweiligen Achslast die Straße ohne merkliche Verkürzung ihrer Lebensdauer befahren kann. Ein gewisser Ausbaugrad ist jedoch gewichtsunabhăngig notwendig, da neben der Belastung durch die Fahrzeuge noch andere Faktoren wie z. B. das Klima (Regen, Sonneneinstrahlung, Temperaturwechsel) für die Lebensdauer eine Straße verantwortlich sind und den Ausbaugrad beeinflussen. Daher muß diese Grundgebühr bis zu einem bestimmten höchstzulässigen Gewicht einheitlich sein. Ab diesem Höchstgewicht muß zusătzlich zu dieser allgemeinen Kfz-Steuer ein pauschaler Schwerverkehrsaufschlag entrichtet werden, der die zusătzlichen Kosten eines höheren Ausbaugrades entgilt. Dieser Schwerverkehrsaufschlag könnte z. B. an der zulässigen Achslast des Fahrzeugs ausgerichtet sein.

$\mathrm{Ab}$ einer gewissen Achslast müßte ein zusätzlicher Ausbaugrad allerdings von nur noch relativ wenigen Fahrzeugen finanziert werden. Für diese Schwertransporte wirde die Grundgebuhr daher prohibitiv hoch werden. Um die Grundgebühr nicht zur Markteintrittsschranke werden zu lassen, wird daher vorgeschlagen, den Schwerverkehr nicht in vollem Umfang mit den Fixkosten der Straßenerstellung zu belasten, d. $h$. die Höhe der Schwerverkehrsaufschläge nach oben zu begrenzen. Stattdessen muß eine entsprechend der Belastungswirkung einer zusätzlichen Tonne Achslast progressiv gestaffelte Kilometergebuhr entrichtet werden, um die dem Schwerverkehr zuzurechnenden Kosten der vorzeitigen Straßenerneuerung zu entgelten. ${ }^{136}$ Der „eigentliche“ Schwerverkehr hätte also außer der nach oben limitierten Grundgebühr noch eine zusătzliche Nutzungsgebühr zu entrichten. Diese kann z. B. kilometerabhängig ausgestaltet sein und bei der jährlichen Inspektion uber das einfache Ablesen der geeichten Tachometer ermittelt werden. Evtl. kann ein schlechter Zustand von Reifen und Federung in diesem Zusammenhang ebenfalls ermittelt und in Form eines Aufschlags aufgerechnet werden.

Diejenigen Transporter, die aufgrund ihrer technischen Beschaffenheit Straßenschäden verursachen, sind also gezwungen, diese in ihr Kalkul miteinzubeziehen. Sie müssen zwischen der kostensparenden Vergrößerung der Transportgefäße

${ }^{136}$ Vgl. Winston, C. (1991), S. 116. 
einerseits und den erhöhten Kilometerkosten andererseits abwägen. Somit wird sichergestellt, daß die Transportdurchfuhrung nicht ohne Berücksichtigung der Infrastrukturkosten disponiert wird. ${ }^{137}$

Die vorgeschlagene Kfz-Steuer wird also zweistufig konzipiert. Die erste Stufe wird von allen Fahrzeugen getragen und gilt als „Eintrittspreis“ furr das Straßennetz. Die zweite Stufe wird als Schwerverkehrsaufschlag konzipiert und entgilt den höheren Ausbaugrad, der durch die großen Achslasten nötig wird. Dieser Aufschlag kann achslastabhängig erhoben werden, so daß eine direkte Beziehung zwischen Gewicht und Ausbaugrad erkennbar wird.

Neben der Grundgebühr für die Bereitstellung der Infrastruktur sind noch die Grenzkosten, also Kosten der Instandhaltung und des Betriebs zu entrichten. Diese sind, wie aus Abb. 15 abzulesen ist, jedoch relativ gering. Der Anteil der laufenden Kosten an den Gesamtkosten schwankt im Zeitablauf zwischen 20 und 25 $\%$. Ein Teil davon dient zudem der Wiederherstellung der nicht für den Schwerstverkehr geeigneten Infrastruktur und wird demnach schon durch die oben geforderte zusätzliche Nutzungsgebühr abgedeckt. Die reinen Grenzkosten betragen also nur $5 \%$ (Betriebskosten) bis $25 \%$ (gesamte laufende Kosten) der Infrastruktur.

Da die fahrzeugspezifischen Unterschiede schon in der Grundgebühr (incl. Schwerverkehrsaufschlag) erfaßt sind, kann die Nutzungsgebühr für alle Fahrzeuge außer dem Schwerstverkehr gleich sein. Ideal wäre daher eine rein kilometerabhängige Abgabe. Ersatzweise kann die Mineralölsteuer die Grenzkosten der Straßennutzung erfassen, obwohl sie je nach Verbrauch unterschiedliche Kilometerkosten induziert und damit nicht kostenorientiert ausgestaltet werden kann.

\section{Exkurs: Die Interdependenz von zulässiger Achslast und Straßenausbaugrad}

Abweichend von der gewählten Vorgehensweise soll hier kurz auf ein Problem im Zusammenhang mit der Bereitstellung der Straßenverkehrsinfrastruktur eingegangen werden: Wie oben diskutiert, ist die Struktur der zweistufigen Kfz-Steuer wesentlich vom Ausbaugrad der Straßen abhängig. Dieses Verhältnis soll in diesem Exkurs dargestellt werden.

${ }^{137}$ Durch die zur Zeit in Deutschland geltende Regelung, bei der die KfZ-Gebulhren nach zulăssigem Gesamtgewicht erhoben werden, besteht die Neigung, die Anzahl der Achsen zu minimieren, um so den Treibstoffverbrauch zu senken. Schwere LKW haben zudem oftmals die Möglichkeit, Achsen anzuheben, um bei Unterauslastung nochmals eine Treibstoffkostenreduktion herbeizufuhren. 
Abb. 28: Optimale Achslast

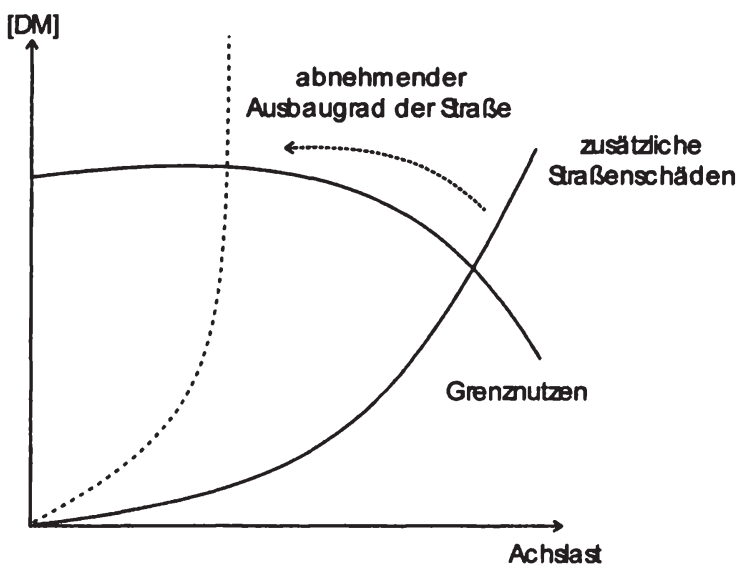

Quelle: OECD (1988), eigene Darstellung.

In Abb. 28 wird zunächst die Beziehung zwischen Straßenschäden und LKWGewicht abgetragen. Wie schon oben dargestellt wachsen die Schäden exponentiell mit dem Exponenten 2 - 4 in Abhängigkeit von der Achslast. Dabei hängt der tatsächliche Verlauf vom Ausbaugrad der jeweiligen Straße ab. Während z. B. eine Schotterpiste schon durch kleinere Fahrzeuge zerstört werden kann, verursachen Fahrzeuge unter $30 t$ auf europäischen Fernstraßen kaum strukturelle Schäden (besser bekannt als Spurrinnen).

Der zweite Faktor ist der zusătzliche Nutzen einer höheren Achslast. Er ist in Abb. 28 eher intuitiv abgetragen, sein genauer Verlauf spielt auch keine wesentliche Rolle für die Argumentation. Grundsătzlich besteht er zum einen in der Möglichkeit, größere Fahrzeuge zu bauen, vor allem aber in der Treibstoffersparnis, die aus einer geringeren Anzahl von Achsen folgt. Festzuhalten ist aus dieser Darstellung, daß es einen Optimalpunkt gibt, ab dem der zusätzliche Nutzen einer höheren Achslast von den ihr zuzurechnenden Straßenschäden überkompensiert wird. Es muß also ein optimaler Ausbaugrad der Straßen festgelegt werden, der dann seinerseits wieder die Struktur der oben dargestellten zweistufigen KfzSteuer bestimmt. Dazu kann auf einen Aspekt des peak-load pricing zurückgegriffen werden, die Bestimmung der langfristig optimalen Kapazităt einer Anlage. ${ }^{138}$

138 Vgl. zur folgenden Argumentation Wellisch, D. (1999), S. 221 ff. 
Abb. 29: Optimaler Straßenausbaugrad

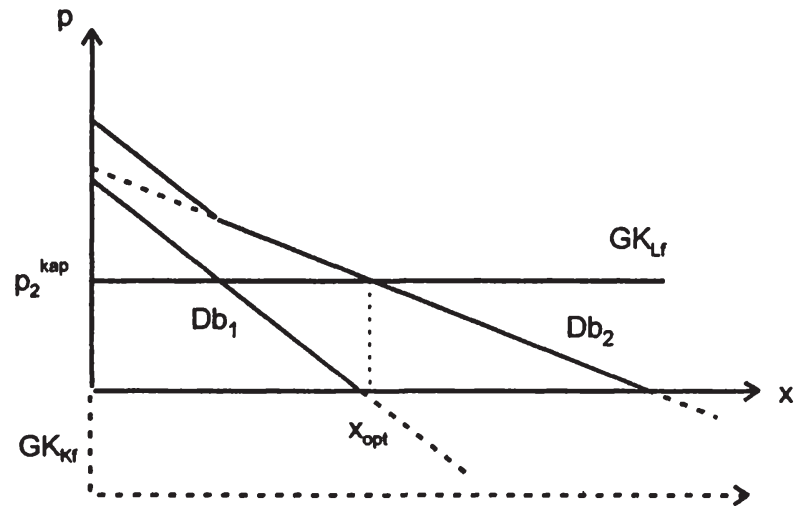

Quelle: SchellhaaB, M. (1987).

Jeder Erlös aus den Grundgebuhren der einzelnen Steuerklassen, der die laufenden Kosten, d. h. die kurzfristigen Grenzkosten $\mathrm{GK}_{\mathrm{Kf}}$, in $\mathrm{Abb}$. 29 ubersteigt, liefert einen Deckungsbeitrag zu den Kapazitätskosten. Nur dieser Deckungsbeitrag ist kapazitätswirksam. In der Zeichnung ist das Koordinatensystem so verschoben worden, daß die neue Abszisse auf der Höhe der kurzfristigen Grenzkosten liegt. Die Kurven stellen also die Gesamtnachfrage minus den $\mathrm{Gk}_{\mathrm{kf}}$, mithin die Kapazitătsnachfrage der einzelnen Periode, den Deckungsbeitrag, dar. Die effektive Kapazitătsnachfrage, also der maximale Ausbaugrad, wird ermittelt, indem die beiden Funktionen aggregiert werden. Die optimale Kapazităt $x_{\text {opt }}$ ist erreicht, wenn die marginalen Kosten eines Infrastrukturausbaus genauso hoch sind wie deren Erlöse. Im hier gewăhlten Beispiel ist dies die Grundgebühr der höchsten Steuerklasse (geometrisch: Schnittpunkt der effektiven Nachfragefunktion nach Kapazităt mit der langfristigen Grenzkostenkurve $\mathrm{GK}_{\mathrm{Lf}}$ ), die geringeren Steuerklassen tragen also nichts zur Finanzierung der zusätzlichen Kapazität bei. Übersteigen die Ausbaukosten der Verkehrsinfrastruktur die Zahlungsbereitschaft der Schwertransporter, sollte eine Verbesserung der Straßen hinsichtlich ihrer Tragfähigkeit ausbleiben. Der Schwerverkehr verursacht dann strukturelle Schäden an den Straßen, die durch die diskutierte nutzungsabhängige Schwerverkehrsabgabe entgolten werden müssen.

\subsubsection{Instrumente zur Internalisierung externer Effekte des Straßen- güterverkehrs}

Die externen Effekte des Verkehrs und die Methoden zu ihrer Internalisierung gehören $\mathrm{zu}$ den wohl bestuntersuchten Feldern in der angewandten Ökonomie. 
Das folgende Kapitel kann sich also darauf beschränken, die vorhandenen Ansătze aufzuarbeiten und zu systematisieren.

Die externen Kosten innerhalb des Verkehrssektors umfassen in erster Linie die externen Staukosten. ${ }^{139}$ Deren Internalisierung kann uber eine Pigou-Steuer erreicht werden, bei der einem zusătzlichen Straßennutzer neben seinen privaten Fahrtkosten noch die von ihm verursachten Zeitverzögerungen Dritter angelastet werden.

Dazu soll ein Modell modifiziert werden, welches schon in Abschnitt 2.2.1 im Zusammenhang mit der Infrastrukturfinanzierung diskutiert wurde. Die unten dargestellte Abbildung zeigt das grundsătzliche Problem der Internalisierung von Stauexternalitäten im Verkehr: Wie anfangs diskutiert, existiert beim Verkehr das Phänomen der periodisch schwankenden Nachfrage. Oben sind der Einfachheit halber zwei unterschiedliche Nachfragefunktionen eingezeichnet, was der ganzen Komplexităt von Berufsverkehr, Wochenendverkehr, Urlaubsverkehr etc. nicht gerecht wird, aber das grundlegende Problem umreißt.

Abb. 30: Relation zwischen Fahrtkosten und VerkehrsfluB

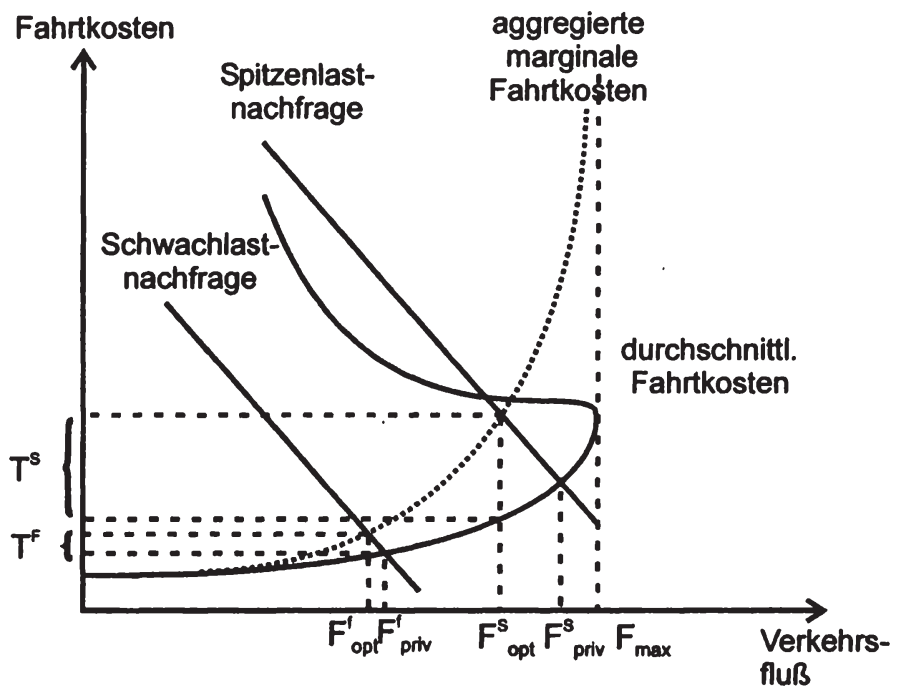

Quelle: Hau, T. D. (1998), eigene Darstellung.

Wie dargestellt berücksichtigt ein einzelner Verkehrsteilnehmer bei seiner Fahrentscheidung nur seine privaten Fahrtkosten, die hier der Einfachheit halber auf

139 Genaugenommen muß ein Teil der Unfallkosten dazugezahlt werden. Um eine doppelte Darstellung zu vermeiden, soll hier aber auf eine gesonderte Betrachtung verzichtet werden. 
die Zeitkosten reduziert seien. ${ }^{140}$ Diese entsprechen in der obigen Darstellung den durchschnittlichen Fahrtkosten, also den gesamten Zeitkosten aller Verkehrsteilnehmer geteilt durch die Anzahl der Verkehrsteilnehmer. Im Gleichgewicht der Schwachlastnachfrage wird daher ein Verkehrsfluß in der Höhe $F_{\text {priv }}^{f}$, im Gleich-

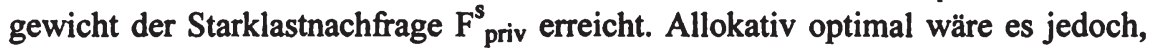
wenn jeder Verkehrsteilnehmer in seinem Kalkul zusätzlich diejenigen Kosten - in Form zusätzlichen Zeitbedarfs - berücksichtigen würde, die er durch seine Fahrentscheidung allen anderen Teilnehmern aufbürdet. Diese zusätzlichen Kosten werden durch die Kurve der aggregierten marginalen Fahrtkosten bestimmt, die die Summe der Zeitverzögerungen mißt, die ein zusätzlicher Fahrer verursacht.

Diese Mitberücksichtigung könnte durch eine Pigou-Steuer erreicht werden, d. h. jeder Verkehrsteilnehmer mußßte zusătzlich zu seinen privaten Kosten eine Steuer in Höhe der Differenz zwischen durchschnittlichen und aggregierten marginalen Kosten im Optimum zahlen. Diese Pigou-Steuer wäre je nach Lage der Nachfragefunktion unterschiedlich. In der Starklastperiode ist die optimale Steuer $T^{s}$ relativ hoch und führt in der gewählten Darstellung auch zu einem relevanten Rückgang des Verkehrsflusses auf $\mathrm{F}_{\text {opt }}^{\mathrm{s}}$. Damit verbunden ist ein Anstieg der Geschwindigkeit, abzulesen an den gesunkenen Fahrtkosten. In der Schwachlastperiode dagegen hat die optimale Steuer lediglich eine Höhe von $T^{f}$ und der Lenkungseffekt hin $\mathrm{zu} \mathrm{F}_{\text {opt }}^{\mathrm{s}}$ ist gering. Liegt die Nachfragekurve der Schwachlastperiode noch weiter Richtung Ursprung, geht der induzierte Zeitverlust durch eine zusătzliche Fahrt und damit die optimale Lenkungssteuer gegen Null.

Diese theoretisch einleuchtend und einfach klingende Staugebühr verliert einiges an Charme, wenn man die praktische Umsetzbarkeit der Maßnahme untersucht.

Eine theoretisch korrekte Pigou-Steuer würde z. B. erfordern, daß die Nachfragekurven der jeweiligen Zeiten bekannt sind. Diese zu ermitteln dürfte jedoch kaum möglich sein. Weiterhin wäre erforderlich, daß die Verkehrsdichte und damit die zusätzlich zu erwartenden Zeitverzögerungen zum jeweiligen Zeitpunkt ermittelt werden. Die technische Realisierung zumindest dieses Punktes ist relativ weit fortgeschritten. Schon jetzt existieren in der Bundesrepublik Verkehrsbeeinflussungsanlagen, die mit Hilfe von automatischer Verkehrsdatenerfassung funktionieren. Diese automatische Ermittlung der Verkehrsdichte erfolgt jedoch erst auf $2000 \mathrm{~km}$ Autobahn, eine flăchendeckende Installation würde also weitere erhebliche Kosten verursachen. Sie ist aber zumindest in denjenigen Gebieten, die bekanntermaßen staugefährdet sind, denkbar. ${ }^{141}$

140 Natürlich existieren noch andere Komponenten der Fahrtkosten, wie Treibstoffverbrauch usw. Diese können aber vernachlässigt werden wenn man annimmt, daß sie nicht wesentlich vom Verkehrsfluß abhăngen. Siehe dazu auch die Darstellung des Abschnitts 2.2.2.

${ }^{141} \mathrm{Vgl}$. Friedrich-Ebert-Stiftung (1995), S. 15. 
Bestehende Lösungen wurden allerdings weitestgehend ohne solche automatischen Verkehrsdatenerfassungen realisiert. Da Stau vor allem in Ballungsgebieten regelmäßig auftritt, beschränken sich die Erfahrungen im wesentlichen auf Maßnahmen in Innenstädten oder auf Verbindungen zwischen Ballungszentren. ${ }^{142}$ Das „klassische“" Beispiel ist Singapur, welches 1975 ein noch heute in dieser Form existierendes Verfahren einführte. Für dieses sogenannte Area License Scheme (ALS) wurden innerstädtische Zonen definiert, für deren Befahren innerhalb bestimmten Zeiten eine Gebühr entrichtet werden mußte. Die Gebühr galt zunächst nur fur PKW, da jedoch viele LKW die nunmehr staufreien Zeiten ausnutzten, mußte sie schon bald auch auf diese ausgedehnt werden. 1989 wurde das System umgestellt. Jetzt wurde die „Eintrittsgebühr" auch im nachmittäglichen Feierabendverkehr erhoben, um die Innenstadt während der Belastungszeit vom durchfahrenden Verkehr freizuhalten.

Andere Städte wie Hongkong oder Cambridge, UK, haben in ăhnlicher Weise versucht, den innerstädtischen Stau zu reduzieren, sind jedoch an politischen Widerständen gescheitert. Abweichend von diesen innerstädtischen Versuchen existieren in Frankreich und Kalifornien Staugebühren auf einzelnen, besonders belasteten Straßen. Ohne auf die einzelnen Projekte näher eingehen zu wollen, sollen doch die wesentlichen Erkenntnisse aus ihnen kurz dargelegt werden. Wie oben schon angedeutet, wurden bis auf eine Ausnahme alle Staugebühren nicht an der tatsăchlichen Auslastung ausgerichtet. Üblich war und ist vielmehr eine Koppelung der Gebuhren an bestimmte Tageszeiten in der Annahme, daß so eine hinreichend genaue Beziehung zur Verkehrsdichte hergestellt sei. Dies schuf natürlich Substitutionsmöglichkeiten - die durch die Beschränkung auf Innenstädte oder einzelne Straßen noch erweitert wurden. Die zeitliche und răumliche Substitution von Fahrten waren daher auch bei weitem die hăufigsten Reaktionen auf die Staugebühren, oftmals mit der Folge, daß sich der Stau einfach zeitlich verlagerte oder auf kostenlosen Straßen abspielte. Nachrangig waren das Bilden von Fahrgemeinschaften, das Zusammenlegen von Fahrten und die stärkere Nutzung des ÖPNV - also die ökologisch sinnvolleren Reaktionen. Um die einfacher Verlagerung des Staus zu vermeiden, mußten die Zeiträume, in denen Spitzenlastpreise gefordert wurden, ausgedehnt und zusätzliche Verkehrswege in die Gebührenzone aufgenommen werden, was wiederum zu Lasten der effizienten Aufteilung der Verkehrsmenge ging, da nun Ausweichreaktionen insgesamt erschwert bzw. fast unmöglich wurden.

Einen anderen Weg ging Cambridge. Ausgehend von der (allerdings stark vereinfachenden) Annahme, daß die externen Staukosten im wesentlichen mit den privaten Staukosten korreliert sind wurde den Fahrzeugen eine Uhr eingebaut, die mit dem Tachometer gekoppelt wurde und die tatsächlich benötigte Zeit für eine

${ }^{142} \mathrm{Vgl}$. zu den folgenden Beispielen Small, K. A. und J. A. Gomez-Ibanez (1998), S. 215 ff. 
Strecke maß. Wurden innerhalb dieser Zeit weniger als die festgelegten Kilometer zurückgelegt oder mußte der Wagen innerhalb einer bestimmten Strecke offter als festgelegt anhalten, wurden Staugebuhren berechnet. Dieses System scheiterte aus zweierlei Gründen. Der erste liegt mehr in der technischen Natur des Systems: Um nicht zur Kasse gebeten zu werden, versuchten viele Fahrer, durch riskante Fahrweise innerhalb der „kostenlosen“ Zeit zu bleiben, so daß diese Lösung schon aus sicherheitstechnischen Aspekten verworfen werden mußte.

Das zweite Problem ist eher grundlegender Natur und für die Beurteilung von Staugebühren stärker relevant als das Unfallrisiko, welches nur durch die konkrete Form der Messung zustande kam: Die Betroffenen wehrten sich gegen die Zahlung. Es war ihnen nicht zu vermitteln, warum sie, die sie ja schon durch den Stau selbst betroffen waren, noch zusătzliche Lasten in Form von Staugebuhren tragen sollten, also quasi doppelt bestraft wurden. Das Gebührensystem war daher politisch nicht tragbar, die Bemühungen zu seiner endgültigen Umsetzung wurden eingestellt. Es läßt sich also absehen, daß eine theoretisch exakte, an der tatsächlichen Verkehrsdichte ausgerichtete Staugebühr politisch nicht umsetzbar sein wird. Sie erweckt immer den Anschein einer Bestrafung der Verkehrsteilnehmer und wird daher von den Betroffenen abgelehnt.

Eine direkt mit dem Verkehrsfluß korrelierte Staugebuhr ist im Gegensatz zu den allokativ wenig sinnvollen tageszeitabhängigen Gebühren ex ante nicht planbar. Die Verkehrsteilnehmer können daher - abgesehen von Erfahrungswerten - nicht im voraus abschätzen, wieviel sie für die jeweilige Fahrt zu zahlen haben. Die Unterbrechung einer angefangenen Fahrt zumindest dürfte aber nur in den seltensten Fällen eine relevante Alternative sein. Eine entsprechende Anpassung des Verhaltens ist damit nahezu ausgeschlossen, das heißt natürlich auch, daß damit die Abgabe ihre lenkende Funktion verloren hătte. ${ }^{143}$

Betrachtet man alle diese Einschränkungen wird verständlich, warum in der Praxis direkt regulierende Maßnahmen im allgemeinen vorgezogen werden. ${ }^{144}$ Bezogen auf den LKW-Verkehr sind dies insbesondere zeitlich und räumlich definierte Zugangslimitierungen wie Sperrungen von Wohnstraßen oder besondere Zeiten fur Zulieferverkehr. Diese sind allerdings weniger staumotiviert, sondern sollen eher die sonstigen Belästigungen durch $\mathrm{LKW}$ verhindern.

${ }^{143}$ Eine ăhnliche Position vertritt KRUSE wenn er argumentiert, daß Preise ihre Lenkungswirkungen nur in dem Maße enfalten können, wie sie den Nachfragern zum relevanten Entscheidungszeitpunkt bekannt sind und diese die Möglichkeit haben, darauf gegebenenfalls durch die Wahl von Alternativen zu reagieren. Vgl. Kruse, J. (1996), S. 199.

144 Die starke Skepsis, die ordnungspolitischen Maßnahmen in der Lehrbuchliteratur zur Umweltठkonomik oftmals entgegengebracht wird, mußte in der neueren Literatur relativiert werden. Die fur die Ordnungspolitik ungunstigen Ergebnisse stammen nach Aussagen von CROPPER OATES oftmals aus von vornherein nicht neutral angelegten Vergleichen.

Vgl. Cropper, M. L. und W. E. Oates (1992), S. 699 f. 
Ähnliche Maßnahmen wie für den Innenstadtbereich sind grundsătzlich für alle Straßen denkbar. So ist es schon heute găngige Praxis, den LKW-Verkehr wăhrend besonders kritischer Zeiten, also z. B. in der Urlaubszeit, wăhrend des Berufsverkehrs oder vor und nach Wochenenden oder Feiertagen einzuschrănken, um die ublicherweise durch den Schwerlastverkehr belegte rechte Straßenhälfte freizugeben und damit Staus zu verhindern oder wenigstens zu reduzieren. Insgesamt dürften aufgrund der vielfältigen Umsetzungsprobleme bei pretialen Lenkungsinstrumenten diese direkten verkehrslenkenden Maßnahmen mehr Erfolg versprechen als die Implementierung von Staugebuhren.

Die weiteren externen Kosten des LKW-Verkehrs bestehen, wie in den theoretischen Grundlagen dargestellt, insbesondere aus Lärm, Luftverschmutzung und einer Gruppe anderer Folgen, wie Unfälle, Angst, Trennwirkung, Zeitverzögerungen und anderen, die hier zu psychosozialen Schăden zusammengefaßt werden sollen.

Die Internalisierung externer Effekte erfordert zunächst grundlegend, daß die Internalisierungssteuer möglichst direkt an der Externalităt ansetzt, um die gewuinschte Lenkungswirkung und nicht irgendeine unerwunschte Substitution anderer Art zu erzielen.

Wenden wir uns zunächst dem Lärm zu. Lärm als externer Effekt weist eine stark lokale Komponente auf. Das bedeutet, daß die Internalisierung des Lărms neben der „Lärmproduktion“ an sich Ort und Zeit dieser Störung mit in Betracht ziehen muß: Ein LKW, der tagsüber durch eine unbewohnte Gegend fahrt, verursacht nicht den gleichen externen Schaden wie derselbe LKW, wenn er nachts durch ein Wohnviertel fâhrt. Diese punktgenaue Steuerung ist natürlich mit einfachen Mitteln kaum möglich.

Generell sind drei Ansătze zur Lărmminderung denkbar: ${ }^{145}$

$>$ Verringerung von Gerăuschen an der Quelle

$>$ Verhinderung der Schallausbreitung

$>$ Verringerung des Lärmpegels am Einwirkungsort

Der Lărmpegel am Einwirkungsort kann verhindert werden, indem entsprechende bauliche Maßnahmen an Gebăuden, z. B. der Einbau von Lărmschutzfenstem, vorgenommen werden. Die Schallausbreitung läßt sich ublicherweise durch den Bau von Hindernissen zwischen Schallquelle und den Betroffenen vermindern, z. B. durch den Bau von Schallschutzmauern am Straßenrand. Beide Möglichkeiten zur Lärmminderung sind sicherlich weitverbreitet und spielen - sowohl jetzt als auch in Zukunft - eine quantitativ wichtige Rolle bei der Lărmbekămpfung. Sie

145 Kommission (1996). 
können jedoch keinen vollständigen Ersatz für die Reduktion des Lärms an der Quelle bieten. Zudem haben sie den Nachteil, daß sie im allgemeinen aus Steuermitteln oder privat finanziert werden, also dem Verursacher keinen Anreiz zur Minderung der Externalität bieten. Sie sollen daher bei der folgenden Diskussion außer Acht gelassen werden.

Die Verringerung von Gerăuschen an der Quelle kann auf mehreren Wegen erfolgen. Ein seit langem geläufiges Instrument sind Rechtsvorschriften bezüglich der zulässigen Geräuschemissionen bei Kraftfahrzeugen. Diese existieren seit 1992 in der Europäischen Union und wurden seitdem kontinuierlich nach unten angepaßt. Dabei wurde innerhalb von weniger als 25 Jahren eine Emissionsverminderung 11 $\mathrm{dB}$ (A) erreicht, was einer Lärmreduktion von $90 \%$ entspricht. Allerdings ist mit der neuesten Lärmobergrenze ein Punkt erreicht, ab dem eine weitere Emissionsreduktion nicht sinnvoll erscheint, da der größte Lärmanteil zumindest bei höheren Geschwindigkeiten von den Fahrbahngeräuschen herrührt. ${ }^{146}$ Eine Reduktion könnte also nicht mehr durch Verbesserungen am Fahrzeug selbst, sondern nur noch durch Modifikationen am System Reifen-Straße erreicht werden.

Abb. 31: EU-Grenzwerte für Geræ̆uschemissionen neuzugelassener LKW

\begin{tabular}{|l|l|c|c|c|}
\hline $\begin{array}{l}\text { Fahrzeug- } \\
\text { Kategorie }\end{array}$ & \multicolumn{1}{|c|}{1972} & 1982 & $1988 / 90$ & $1995 / 96$ \\
\hline LKW & $91 \mathrm{~dB}(\mathrm{~A})$ & $88 \mathrm{~dB}(\mathrm{~A})$ & $84 \mathrm{~dB}(\mathrm{~A})$ & $80 \mathrm{~dB}(\mathrm{~A})$ \\
\hline
\end{tabular}

Quelle: Kommission (1996).

Im Ergebnis haben diese beachtlichen Lärmreduktionen am einzelnen Fahrzeug allerdings nur zu geringen Änderungen des gesamten Straßenverkehrslärmpegels gefuhrt. Als Gründe werden unrealistische Prüfverfahren bei der Zulassung der Fahrzeugtypen, weiterhin eingesetzte Altfahrzeuge, die Wechselwirkung von Reifen und Fahrbahn und das deutlich gestiegene Fahrzeugaufkommen genannt. Zudem kann der Lärmpegel eines Fahrzeuges mit der Zeit deutlich ansteigen, wenn keine Wartung der Lärmminderungseinrichtungen erfolgt. ${ }^{147}$ Trotz scheinbarer Erfolge hat die Festlegung von fahrzeugspezifischen Standards also in diesem Punkt versagt. Europaweit üblich ist daher eine Ergänzung dieser Lärmschutznormen durch begrenzte LKW-Fahrverbote. Diese gelten vor allem nachts, teilweise sind besonders lårmarme Fahrzeuge davon ausgenommen. ${ }^{148}$ Diese können

146 Kommission (1996), S. 8 f.

147 Kommission (1996), S. 9.

148 Ein Beispiel dafür ist die Stadt Bad Reichenhall, die lärmarme Fahrzeuge von răumlich begrenzten LKW-Fahrverboten ausnimmt. In der Folge haben die LKW-Hersteller MercedesBenz und MAN Fahrzeuge entwickelt, die den Anforderungen dieser Kommune genugen.

Vgl. OECD (1991), S. 75. 
unter bestimmten Bedingungen, insbesondere einer genauen Abgrenzung der lärmberuhigten Gebiete, einer genauen Bestimmung des Begriffs „lärmarm“ und vor allem einer ausreichenden polizeilichen Überwachung durchaus den gewünschten Erfolg haben. Insbesondere können sie dazu fuhren, daß Spediteure schneller ihren Fuhrpark zugunsten leiserer Fahrzeuge erneuern, da sie sonst von bestimmten Routen ausgenommen bleiben. Eine weitere typische lärmmindernde Maßnahme ist die Festlegung von Höchstgeschwindigkeiten in bestimmten Gebieten. Diese Maßnahme wird in Zukunft an Bedeutung gewinnen müssen, da sie die Hauptursache des Verkehrlärms - Reifengerăusche bei hohen Geschwindigkeiten direkt bekämpft.

Insgesamt können die existierenden ordnungsrechtlichen Maßnahmen zur Lärmbekämpfung nur als unzureichend bezeichnet werden. Einen noch geringeren Stellenwert haben allerdings anreizorientierte Instrumente. Die einzigen Maßnahmen in der EU in diesem Bereich sind Subventionen, die LKW-Herstellern fur die Erforschung lärmmindernder Techniken gezahlt werden und Anschaffungsbeihilfen für besonders lärmarme LKW.

Beide Instrumente werden ausschließlich in Deutschland eingesetzt. Lenkungsabgaben zur Internalisierung des Verkehrslärms existieren trotz einiger Ansätze noch nicht. Theoretisch korrekt wäre - wie oben kurz angedeutet - eine Belastung jedes Fahrers mit den tatsächlich durch ihn verursachten externen Kosten.

Diese allerdings sind nicht nur von seinem Fahrzeug und seiner Fahrweise abhăngig, sondern auch von der Tageszeit, örtlichen Gegebenheiten (Besiedlungsdichte, Năhe zu Wohngebieten, Erholungsgebieten, Schulen, Krankenhäusern) und dem Gesamtverkehrsaufkommen. Die Miteinbeziehung all dieser Einflußfaktoren dürfte technisch unmöglich bzw. okonomisch nicht vertretbar sein. Läßt man dagegen alle nicht fahrzeug- bzw. fahrerspezifischen Elemente aus, ist die Abgabe nur noch gering mit der eigentlichen Externalităt korreliert. Sie würde damit Anreizwirkungen entfalten, die nicht auf die Beseitigung des Umweltschadens ausgerichtet wăren. Beispielsweise könnte es ökonomisch effizient sein, den bestehenden Fuhrpark so aufzuteilen, daß leisere Fahrzeuge in besonders sensiblen Gebieten eingesetzt werden und der Altbestand an Fahrzeugen auf weniger bedenklichen Routen verkehrt. Ohne die räumliche Differenzierung des eingesetzten Internalisierungsinstrumentes wäre dieser Anreiz nicht geschaffen. Genauso verhallt es sich mit der Verlagerung von Fahrten: Ohne zeitliche Differenzierung könnten LKW-Fahrer einen Anreiz haben, eine bestimmte Strecke nachts zu benutzen, bspw. um damit die Fahrzeit zu reduzieren. Sie wüden damit den möglichen externen Schaden maximieren, anstatt ihn zu verringern. Hier scheint die größere Zielgenauigkeit ordnungsrechtlicher Maßnahmen dem okonomischen Instrumentarium uberlegen. Einzig die Maximallautstärke von Neufahrzeugen 
könnte Bemessungsgrundlage einer Steuer sein, um damit den potentiellen Lärm des Einzelfahrzeugs zu mindern.

Da jedoch - wie oben erwăhnt - die okonomisch sinnvolle Untergrenze für die Lärmemission einzelner Fahrzeuge erreicht ist, bleibt das Potential für die Senkung der Lärmemissionen gering. Eine andere Meinung bezüglich in diesem Punkt vertritt Wicke, der eine herstellerseitige Lärmabgabe - allerdings für PKW fordert. Für die Ausgestaltung schlägt er vor, neben dem zulässigen Höchstwert einen wünschenswerten Lărmzielwert einzufuhren. Wird der Lärmzielwert unterschritten, ist keine Abgabe zu zahlen. Zwischen dem Zielwert und dem zulässigen Höchstwert verbleibt eine Bandbreite, innerhalb derer nach $\mathrm{dB}(\mathrm{A})$ gestaffelte $\mathrm{Ab}$ gaben einen Anreiz für Autoproduzenten bieten, die Lărmemission des Fahrzeugs zu reduzieren. Da eine entsprechende Nachrüstung kaum in Frage kommt, wird die Steuer nur beim Kauf eines Neufahrzeugs, also beim Hersteller oder beim Importeur fällig, was auch die Kosten der Steuererhebung gering hält. ${ }^{149}$

Nachdem festgestellt wurde, daß Lärm aufgrund vieler Faktoren nicht als Bemessungsgrundlage für eine Internalisierungssteuer geeignet ist, wollen wir uns im folgenden der Luftverschmutzung durch den Verkehr zuwenden. Obwohl sich die Ermittlung des externen Schadens wesentlich schwieriger gestaltet als beispielsweise beim Straßenlärm ${ }^{150}$, sind dort Abgaben zur Internalisierung der Luftverschmutzung in weitaus stärkerem Maße in der Diskussion. Dies mag an zweierlei liegen: Zum einen spielt sicherlich Lärm in der aktuellen Umweltdiskussion eine wesentlich geringere Rolle als die Luftverschmutzung. Zum anderen mag es Gründe geben, die trotz der empirischen Schwierigkeiten bei der Bewertung Schäden, die durch Verunreinigungen der Luft entstehen, Lenkungsabgaben in diesem Bereich sinnvoll erscheinen lassen.

Der externe Effekt der Luftverschmutzung besteht zum einen in der direkten Schadigung der menschlichen Gesundheit durch die Aufnahme der Schadstoffe in den Abgasen, zum anderen im globalen oder zumindest großflächigen Problem der Luftverschmutzung, verbunden mit Begriffen wie saurer Regen, Smog, Sommersmog und Treibhauseffekt. Für die Internalisierung des externen Effektes haben die unterschiedlichen Wirkungsweisen eine große Bedeutung. Für den lokalen Effekt, die direkte Schädigung durch Abgase, gelten im wesentlichen die für den Lärm getroffenen Aussagen: Eine sinnvolle Internalisierung müßte die vielen Besonderheiten der Wirkungskette mitberücksichtigen, die aus einer Emission eine Externalität werden lassen. Ein LKW in einer unbewohnten Gegend wird mit seinen Abgasen, wie mit seinem Lărm, nur zu einer geringen Belästigung führen. Es wäre daher falsch, ihn fur Krankheiten der Atemwege, Krebs u. a. zur Verantwortung zu ziehen. Ein LKW in einer dichtbesiedelten Region, womöglich mit Bau-

149 Vgl. Wicke, L. (1993), S. $418 \mathrm{ff}$.

150 Vgl. dazu Kapitel 2.3.2. 
denkmălem in Straßennähe, verursacht dagegen in hohem Maße soziale Kosten, die er im Sinne einer optimalen Ressourcenallokation tragen mußte. Hier gilt dieselbe Aussage wie beim Lărm: Eine Lenkungsabgabe kann die erforderliche Feinsteuerung nicht oder nur mit prohibitiv hohen Kosten leisten, so daß der Schutz von Gebăuden oder Menschen vor zu starken Abgasen uber ordnungsrechtliche Maßnahmen geregelt werden muß.

Die Internalisierung der großflăchigen Luftverschmutzung dagegen ist prädestiniert furr eine Steuerung durch Umweltabgaben. ${ }^{151}$ Das Gefährungspotential der einzelnen Abgasbestandteile ist weitgend untersucht und dürfte für eine hinreichend exakte Bestimmung der Bemessungsgrundlage ausreichen.

Um eine einheitliche Bemessungsgrundlage fur Luftverschmutzung zu erhalten, müssen in einem ersten Schritt die unterschiedlichen toxikologischen Wirkungen der einzelnen Schadstoffkomponenten auf einen einheitlichen Wert normiert werden. Nur so läßt sich die unterschiedliche Zusammensetzung der Abgase, z.B. von Otto- oder Dieselmotoren, in einer einzelnen Abgabe berücksichtigen. Hier werden die einzelnen Stoffe der Literatur folgend ${ }^{152}$ auf die Toxidität von CO normiert.

Abb. 32: Relative Toxiditătsfaktoren der Kfz-Emissionen

\begin{tabular}{|l|c|}
\hline Schadstoff & Toxiditătsfaktor \\
\hline CO & 1 \\
\hline HC & 3,33 \\
\hline Nox & 0,4 \\
\hline Partikel & 20 \\
\hline
\end{tabular}

Quelle: Neu, H. (1990), S. 165, eigene Berechnungen.

Da die genauen Wirkungszusammenhänge nicht ausreichend bekannt sind, sollen die in Abb. 24 dargestellten geplanten Grenzwerte der Abgasbestandteile, wie sie in dieser Form von der Europäischen Kommission vorgeschlagen wurden, als Hilfsgröße furr die Schädlichkeit der einzelnen Stoffe angesetzt werden. Demnach werden beispielsweise Kohlenwasserstoffe $(\mathrm{HC})$, deren Grenzwerte gut ein Drittel unter denen von Kohlenmonoxid (CO) liegen, als dreimal sçhădlicher angesehen.

151 Die Internalisierung der regionalen und globalen Externalitaten reduziert naturlich auch auf lokaler Ebene die Umweltschăden. Da es sich aber nicht um eine zielgenaue Internalisierung handelt, sondern eher um einen erwünschten Nebeneffekt, soll - wie oben schon diskutiert - fur diese Form der Reduktion nicht der Begriff „Internalisierung“" gebraucht werden. 
Der zweite Schritt ist dagegen etwas komplizierter. Hier ist festzustellen, wer der eigentliche Verursacher der Externalität ist: Luftverschmutzung hängt zum einen von der Bauweise des Fahrzeugs ab. Wird bei der Konstruktion des Fahrzeugs nicht auf eine entsprechend saubere Verbrennung bzw. Reinigungstechnik geachtet, steigen die Emissionen pro gefahrenem Kilometer. Diese potentielle Umweltbelastung müßte dem Hersteller des Fahrzeugs angelastet werden. Andererseits ist es die tatsächlich erbrachte Transportleistung, die erst den eigentlichen Schaden in Form von Emissionen verursacht. Dieser Argumentation folgend müßte der Fahrzeugnutzer zur Zahlung verpflichtet werden. ${ }^{153}$

Die Besteuerung des Emissionspotentials - etwa in Form einer Herstellerabgabe hätte insofern Vorteile, als sie eine Signalfunktion beim Kauf erfullt. Damit ist ausgeschlossen, daß Informationsdefizite bezüglich der uber die Lebensdauer eines Fahrzeugs zu leistenden Zahlungen dazu füren, daß eine suboptimale Entscheidung getroffen wird, z. B. indem das scheinbar billigere, aber letztendlich umweltschädlichere Fahrzeug erworben wird.

Die Ausgestaltung einer solchen Steuer ließe sich ähnlich der oben skizzierten herstellerseitigen Lärmabgabe regeln. Danach wird, wie heute schon üblich, vom Gesetzgeber ein Höchstwert für Abgasemissionen festgelegt, der von keinem Fahrzeug uberschritten werden darf. Zusätzlich zu dieser Obergrenze wird noch ein wünschenswerter Zielwert für die Schadstoffemissionen festgelegt, der beispielsweise durch den Stand der Technik in der Abgasvermeidung bestimmt wird. Überschreitet ein Fahrzeug diesen gewünschten Zielwert, bleibt aber unter der zulässigen Höchstgrenze, muß der Hersteller eine Abgassteuer je nach Höhe der Überschreitung zahlen.

Bei der Festlegung des zulässigen Höchstwertes wäre auch denkbar, ihn nicht für jeden einzelnen Schadstoff zu bestimmen, sondern die Toxidität der einzelnen Schadstoffe auf den Toxiditätsfaktor von Kohlenmonoxid zu normieren, die einzelnen Grenzen zu einem gemeinsamen Grenzwert zu aggregieren und dann bspw. eine zehnprozentige Unterschreitung dieser Größe als Zielwert anzupeilen. Damit wäre den Kraftfahrzeugherstellern eine größere Flexibilität hinsichtlich der Motorkonstruktion gegeben, d. h. sie könnten zunächst die Reduktion einzelner Schadstoffe in Angriff nehmen und mußten nicht alle Emissionen gleichzeitig senken, um ihre Steuerlast zu mindern.

Ein ähnlicher Vorschlag existiert für die Besteuerung der Fahrzeugnutzer. ${ }^{154} \mathrm{Da}-$ nach müßte die jetzige Kfz-Steuer umgewandelt werden. Die Bemessungs-

153 Neu, H. (1990), S. 162 f.

154 Der folgende Vorschlag wurde von Neu in die Diskussion eingebracht und in vereinfachter Form vom Wissenschaftlichen Beirat beim BmV ubernommen.

Vgl. Wissenschaftlicher Beirat beim BmV (1992), S. 123 f. und Neu, H. (1990). 
grundlage wäre in Zukunft ein Steuersatz, der sich aus der Differenz zwischen tatsächlichem und höchstzulässigem Schadstoffausstoß ergibt, multipliziert mit der tatsächlich erbrachten Kilometerleistung. Der Schadstoffausstoß eines Fahrzeugs wird bei der ASU schon jetzt in regelmäßigen Abständen gemessen und könnte ebenfalls problemlos mit obengenannten Gewichten zu einer Gesamtgröße aggregiert werden. Zusătzlich dazu müßten die Prüfer die in diesem Zeitraum zurückgelegten Kilometer am Tachometer des Fahrzeugs ermitteln und eine Kontrollmitteilung an die zuständige Finanzbehörde senden. ${ }^{155}$ Die Steuer kann entweder nachträglich abgezogen oder im voraus pauschal bezahlt und im nachhinein mit der tatsächlich zu zahlenden Summe verrechnet werden. Letzteres hat den Vorteil, daß eine höhere Steuerpauschale aufgrund schlechterer Abgaswerte schon vor der jeweiligen Fahrt fállig ist und damit eine Eintrittbarriere für weniger umweltbewußte Fahrer darstellen kann. Die Ermittlung der Pauschale kann aufgrund von Fahrzeugtypen (Schadstoffausstoß) und Nutzerklassen (Fahrkilometer) erfolgen. Insbesondere die Kategorisierung der Nutzer dürfe jedoch einige Schwierigkeiten bereiten. Daher wird vorgeschlagen, ähnlich wie bei Vorauszahlungen an Versorgungsunternehmen, sich bei der Festlegung der Pauschale an der letztjährigen Steuerschuld zu orientieren.

Die andere, wohl meistdiskutierte, weil am leichtesten umzusetzende Alternative zur Internalisierung der vom Straßenverkehr verursachten Luftverschmutzung wird in der Erhöhung der Mineralölsteuer gesehen. Da die Schadstoffemissionen großteils vom Treibstoffverbrauch abhängig sind, kann dieser im Großteil aller Fälle als hinreichend genauer Indikator für die erzeugte Luftverschmutzung dienen. Insbesondere beim Kohlendioxid ist die Verbindung zwischen Verbrauch und Emission eindeutig. Andere Abgasbestandteile, insbesondere solche, die Ergebnis unvollständiger Verbrennungsprozesse sind, also Kohlenwasserstoffe, Stickoxide und Kohlenmonoxid, sind dagegen wenig mit dem Treibstoffverbrauch korreliert. Bei hohen Drehzahlen verbessert sich der Verbrennungsprozeß, d.h. die Emissionen nehmen ab, wăhrend sich der Treibstoffverbrauch erhöht. ${ }^{156}$ Eine Orientierung am Treibstoffverbrauch kann daher falsche Anreize setzen, die die Entwicklung einer effizienteren Verbrennungs- oder Abgasreinigungstechnik verhindern. Der große Vorteil einer umweltgerechten Ausgestaltung der Mineralölsteuer ist ihre einfache Erhebung. Im Gegensatz zu allen anderen Abgabenlösungen sind keine komplizierten Verfahren oder technische Einrichtungen zur Bestimmung der Bemessungsgrundlage notwendig. Sie kann daher relativ schnell und furr alle Fahrzeuge gleichzeitig eingefuhrt werden.

155 Dies setzt allerdings manipulationssichere Fahrtenschreiber bei LKW voraus.

$156 \mathrm{Vgl}$. Wissenschaftlicher Beirat beim BmV (1992), S. 121. 


\subsection{Zusammenfassung}

Abschließend zu Kapitel 1 sollen die vorgenannten Instrumente nochmals zusammengefaßt und zu einem einheitlichen System integriert werden, welches dann als Referenzmodell fur das folgende System der internationalen Besteuerung dienen soll.

Faßt man alle obengenannten Maßnahmen zusammen, könnte eine allokativ sinnvolle Regelung des LKW-Verkehrs etwa wie folgt aussehen:

$>$ Verschärfung der ordnungspolitischen Maßnahmen im lokalen Bereich, insbesondere im Hinblick auf Staus, Lärm und Abgase

$>$ Einführung eines konsistenten Systems der Besteuerung.

Die Besteuerung des LKW-Verkehrs müßte im wesentlichen aus einer ausdifferenzierten $\mathrm{Kfz}$-Besteuerung bestehen.

$>$ Alle LKW würden die Grundgebühr für die Straßennutzung zahlen. Ab einem gewissen Belastungsfaktor - je nach Fahrzeugtyp - käme eine achslastabhängige Komponente hinzu.

$>$ Für LKW ab einer gewisse Achslast wäre zusätzlich eine kilometerabhängige Straßennutzungsgebühr zu zahlen

$>$ Beim Kauf eines LKW müßte der Hersteller eine Steuer je nach Höhe des Abgasausstoßes zahlen

$>$ Alle LKW haben zusätzlich eine Abgassteuer zu entrichten, deren Bemessungsgrundlage die Abgase 1t. ASU und die jährlich gefahrenen Kilometer sind.

Bei der hier genannten Lösung fâllt ins Auge, daß das von Seiten der Europäischen Kommission in ihrem Grünbuch präferierte road pricing in den Vorschläge zur Finanzierung der Infrastruktur und der Lenkung des Straßengüterverkehrs nur eine untergeordnete Rolle spielt.

Der Begriff des road pricing umfaßt im angloamerikanischen alle Formen von Straßenbenutzungsgebühren. Ursprunglich im Zusammenhang mit der Infrastrukturfinanzierung und der Internalisierung von Stauexternalităten entwickelt, wurde sein potentieller Anwendungsbereich auf die Internalisierung von Umweltexternalităten ausgedehnt. Der Grundgedanke in beiden Fällen ist, daß der Verkehrsteilnehmer die mit den Grenzkosten seiner Fahrtentscheidung belastet werden soll und er so eine optimale Entscheidung fällt.

Um im Bereich der Externalitäten jedoch erstbeste Lösungen erzielen zu können, muß die Gebuhr genau dem externen Schaden entsprechen. Dies jedoch ist - wie 
oben diskutiert - mit kaum lösbaren Informationsproblemen seitens des Planers und der Betroffenen verbunden ist. Die Kosten dieser Informationsbeschaffung müssen also beim auszuwăhlenden System in die Kalkulation einbezogen werden. In solchen zweitbesten Systemen können kostengünstigere Formen der Verkehrsfinanzierung und -lenkung insgesamt effizienter sein als Grenzkostenpreise. ${ }^{157}$

Bei der Infrastrukturfinanzierung hat sich gezeigt, daß ein Großteil der entstehenden Kosten Fixkosten der Straßenerstellung sind und nur ein kleiner Teil der Fahrzeuge zusătzliche variable Kosten verursacht. Dieser kleine Teil dürfte jedoch vom Volumen nicht ausreichen, um eine so technisch aufwendige Lösung wie elektronische Gebuhrenerhebung zu rechtfertigen. Bei der Optimierung der StraBennutzung, d.h. der Verwendung von Gebühren, um durch zeitliche und răumliche Verlagerung von Transportvorgängen periodische Überlastungen von Straßen zu vermeiden, wurde gezeigt, daß der "Straßenpreis“ eine wesentliche Funktion von Preisen - die Informationsfunktion - nicht erfullt. Er ist somit nicht geeignet, diesen Optimierungsvorgang zu unterstützen.

Die Eignung des road-pricing zur Internalisierung von Umweltschäden muß differenzierter gesehen werden. Wiederum spielt das das Informationsproblem, also die Kosten der Umsetzung eine wesentliche Rolle fur die Effizienz der Straßenbenutzungsgebühren. Bei globalen Umweltschäden z. B. ist der Verursacher - $\mathrm{CO}_{2}$ so hinreichend mit dem Mineralölverbrauch korreliert, daß die Mineralölbesteuerung als Instrumentarium völlig ausreicht. Im städtischen Bereich dagegen können sowohl die Kosten der Umweltverschmutzung - Lärm, Abgase, Unfallle - sehr hoch sein als auch die Implementierung eines Kontrollsystems aufgrund der kleinen Fläche relativ günstig. Gelingt es dann noch, das Informationsproblem der Betroffenen zu lossen, stellt road-pricing ein effzientes Instrumentarium zur Internalisierung der Umweltschäden dar. Beim hier diskutierten System zur Finanzierung und Lenkung des Straßengüterverkehrs müssen die Schäden allerdings über den gesamten betroffenen Raum erfaßt und kontrolliert werden. Da zudem keine Kumulation der Schäden wie in Ballungszentren vorliegt, werden in absehbarer Zeit die Kosten kaum von den zu erwartenden Effizienzsteigerungen überkompensiert werden.

Es sind daher die klassischen Instrumente der Kfz- und der Mineralölbesteuerung einerseits und der Umweltstandards in Form von Auflagen andererseits, die wenn auch in anderer Ausgestaltung als heute ublich - eine allokativ sinnvolle Finanzierung und Lenkung des Straßengüterverkehrs realisieren.

157 Die second-best Aspekte des road pricing diskutieren Johansson-Stenman, O. und T. Sterner (1998), S. 150ff. 


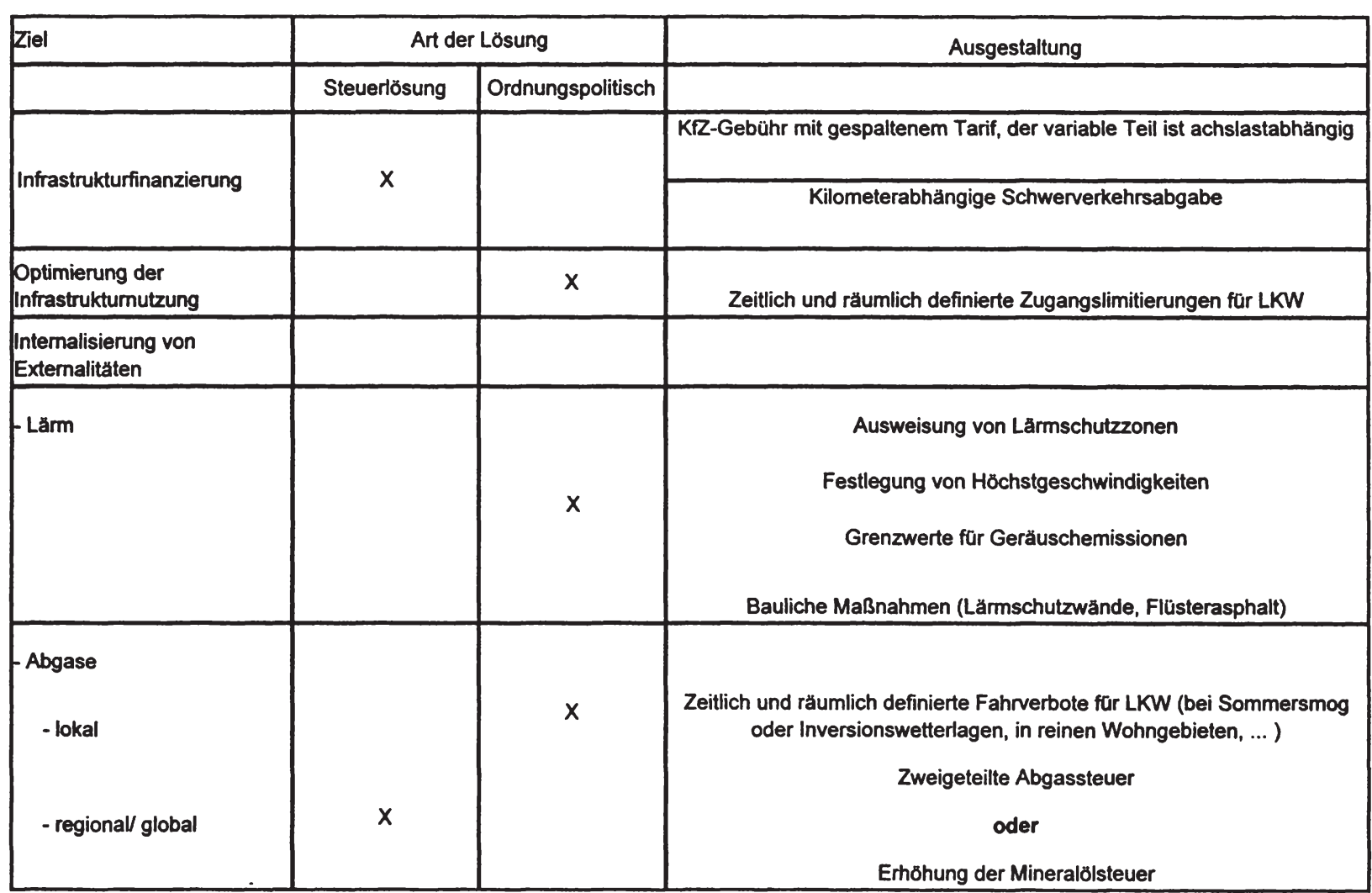


Axel Hennighausen - 978-3-631-75701-7

Downloaded from PubFactory at 01/11/2019 02:45:58AM

via free access 


\section{Die Folgen einzelstaatlicher Verkehrspolitik im Binnenmarkt}

\subsection{Vorbemerkungen}

Das vorangehende Kapitel hat gezeigt, mittels welcher Instrumente die Finanzierung der Verkehrsinfrastruktur und die Lenkung der Verkehrsteilnehmer hin zu effizientem Fahrverhalten innerhalb eines nach außen abgeschlossenen Gebietes vorgenommen werden kann. Die im Abschnitt 1 beschriebene Deregulierung der Verkehrsmärkte im Zusammenhang mit der Einführung des Binnenmarktes böte also die Gelegenheit, das „alte“ Instrumentarium der Verkehrsregulierung durch entsprechend angepaßte und marktnähere Lösungen zu ersetzen und damit die Allokation der für den Güterverkehr eingesetzten Ressourcen zu verbessern.

Allerdings stellt sich im Rahmen einer Föderation wie der Europäischen Union die Frage, wie und ob ein einzelner Staat, der nach wie vor innerhalb des Rahmens gemeinschaftlicher Vereinbarungen fur die Verkehrspolitik seines Landes zuständig ist, für eine effiziente Allokation der Ressourcen in diesem Sektor sorgen kann ${ }^{158}$. Dazu wäre notwendig, daß den Staaten auch im Binnenmarkt die gesamte, zur effizienten Lenkung und Finanzierung notwendige Palette ordnungsund fiskalpolitischer Instrumente zur Verfügung steht. Tatsächlich ist, wie in Abschnitt 3.2 beschrieben, ein Großteil des verkehrspolitischen Instrumentariums formal weiterhin den einzelnen Staaten innerhalb der EU unterstellt. Harmonisierungsmaßnahmen im Verkehrsbereich blieben bisher auf technische und soziale Fragen beschränkt. Fraglich ist aber, ob diese formale Kompetenz die tatsächlichen Möglichkeiten der einzelnen Staaten richtig beschreibt. Im folgende Kapitel soll daher untersucht werden, ob die relative Unabhängigkeit der Staaten beim Einsatz verkehrspolitischer Instrumente in Verbindung mit der hohen Interdependenz der Verkehrsmärkte zu Lösungen führt, die von den in Kapitel 1 skizzierten abweichen.

\subsection{Modelltheoretische Grundlagen}

Die Bereitstellung der Verkehrsinfrastruktur läßt sich modellmäßig als das Angebot eines öffentlichen Gutes beschreiben. Im Rahmen einer Föderation kann das Angebot dieses Gutes als wettbewerbsmäßiger Prozeß zwischen den einzelnen Gebietskörperschaften verstanden werden, in dem die einzelnen Länder um das Steueraufkommen innerhalb der Föderation konkurrieren.

158 Der Effizienzbegriff muß in diesem Kapitel neu definiert werden. Im Gegensatz zu vorigen Kapiteln muß durch die Internationalisierung des Problems zwischen nationaler und internationaler oder weltweiter Effizienz unterschieden werden. Wenn - wie in diesem Fall - nichts zusătzlich erwăhnt wird, ist die weltweite Effizienz gemeint. 
Die entsprechende Literatur zu dieser Thematik ist vielfältig und in ihren Ergebnissen nicht einheitlich. BRITO und OAKLAND beginnen einen Aufsatz mit dem Satz: „Different analysts have produced results which range over the entire spectrum of possibilities. ${ }^{\text {"159 }}$ Damit ist das Dilemma schon ausreichend beschrieben: Je nach Modellierung der jeweiligen Ausgangslage kőnnen sich andere Ergebnisse ergeben. Diese können nicht im Detail dargestellt werden. Ein Überblick uber die verschiedenen Grundprinzipien der Modellierung erscheint aber vonnöten, um die Auswirkungen unterschiedlicher Ansătze auf das Ergebnis aufzuzeigen.

\subsubsection{Das Verhalten der Staaten}

Wenn das staatliche Angebot an offentlichen Gutern untersucht werden soll, dann muß zunăchst eine Hypothese uber das Verhalten des betreffenden Staates aufgestellt werden. Die von BRENNAN/BUCHANAN als "traditionelle Finanzwissenschaft" bezeichnete Schule betrachtet den Staat nicht als eigenständigen Akteur. Implizit wird ein „wohlwollender Diktator“ angenommen, der unter den gegebenen Restriktionen die Wohlfahrt seiner Bürger maximiert. Diese Abstraktion von jeglicher Form der politischen Entscheidungsfindung ist in seiner Einfachheit nutzlich, wenn ein Ideal festgelegt werden soll, an dem sich ein reales System zu messen hat. Genau dies ist im 1. Kapitel geschehen, als ein optimales Steuersystem fur einen nach außen abgeschlossenen Staat hergeleitet wurde.

Desweiteren ist diese Vorgehensweise von Vorteil, um die Auswirkungen verschiedener Gegebenheiten der Realităt analytisch voneinander zu trennen. Im hier zu untersuchenden Fall geht es konkret darum, diejenigen Folgen zu untersuchen, die eine fóderale Organisation des Staates für die Finanzierung und Lenkung des Straßengüterverkehrs hat. Es bietet sich daher an, zunächst einmal vom Verhalten eines Staates, welches nicht durch die Organisation des Staatengebildes, sondern z. B. durch die Motivation seiner Akteure, bestimmt ist, zu abstrahieren, um nicht verschiedene Wirkungen miteinander zu vermischen.

Die „neue politische Ökonomie“ hingegen versucht, staatliches Verhalten zu endogenisieren und damit die ökonomischen Modelle um wesentliche Einflußgrößen zu ergănzen. Im Rahmen dieser Ansătze sind vor allem drei Ausprăgungen zu erwähnen: Im einfachsten Fall maximiert der Staat den Nutzen eines einzelnen reprăsentativen Individuums. Diese Interpretation ist allerdings wieder weitgehend mit der Nichtexistenz von Staaten identisch, da eine Beeinflussung des Ergebnisses durch staatliche Akteure mit eigenen Interessen nicht stattfindet. ${ }^{160}$ Der Ansatz ist allerdings in Modellen zur Untersuchung staatlicher Verhaltensweisen

159 Brito, D. L. and W. H. Oakland (1980), S. 691.

160 Vgl. Wildasin (1994), S. 37. 
im Staatenwettbewerb, die das Gegeneinander einzelner Staaten zum Gegenstand haben, eine zulässige Vereinfachung.

Die beiden „eigentlichen“ Ansătze der neuen politischen Ökonomie, die in diesem Zusammenhang von Interesse sind, sind das Medianwähler- und das Leviathanmodell. Ersteres untersucht die nichtmarktliche Koordination einzelwirtschaftlicher Interessen mit Hilfe von Abstimmungen. Wie sich zeigen läßt, wird unter bestimmten Voraussetzungen das Ergebnis eines Abstimmungsprozesses durch den Medianwähler determiniert. ${ }^{161}$ Diese eindeutige Lősung läßt sich zwar nur mit äußerst restriktiven Annahmen - insbesondere der Annahme eingipfliger Präferenzen - erzielen, ist aber eine einfache Möglichkeit, eine nichtmarktliche Koordination abzubilden ${ }^{162}$. Sie wird daher häufig für Modelle genutzt, die den Mechanismus zur Bereitstellung öffentlicher Güter in einem komplexeren Umfeld, z. B. in einem föderalistisch organisierten Staat, abzubilden versuchen. ${ }^{163}$

Im Gegensatz zum Medianwählermodell wird beim Leviathan-Ansatz angenommen, daß der Staat nicht die Interessen einer Wählermehrheit verfolgt, sondern ausschließlich in seinem Eigeninteresse handelt, d. h. sich aufkommensmaximierend verhält. Dieser von BRENNAN und BUCHANAN in die Diskussion gebrachte Ansatz ist weniger als ein positiver Erklärungsversuch $\mathrm{zu}$ verstehen, er dient vielmehr dazu, die Schwächen der traditionellen wohlfahrtsmaximierenden Modelle und der aus ihnen abgeleiteten Maßnahmen aufzuzeigen. ${ }^{164}$ Beispielsweise kann eine aus dem neoklassischen finanzwissenschaftlichen Instrumentarium stammende Maßnahme zu einem völlig konträren Ergebnis führen, wenn die staatliche Zielfunktion nicht Wohlfahrts- sondern Aufkommensmaximierung ist.

\subsubsection{Das Verhaltnis der Staaten zueinander}

Aus der Preistheorie sind verschiedene Formen des Preissetzungsverhaltens bekannt. Diese lassen sich analog auf den Wettbewerb zwischen Staaten übertragen. ${ }^{165}$ Für die Modellierung wesentlich ist die Frage der gegenseitigen Abhängigkeiten, die verkürzend dargestellt wird als Problem der jeweiligen GröBe. Sind die Staaten im Verhältnis zueinander klein, geht man bei der Modellierung davon aus, daß das Verhalten einer Gebietskörperschaft das Verhalten

161 Vgl. van den Doel, H. and B. van Velthove (1993), S. $105 \mathrm{ff}$.

162 Genaugenommen ist das Medianwăhlermodell eine einfache Möglichkeit, um bei Mehrheitswahlverfahren einen Gleichgewichtszustand abzubilden. Unter wenig restriktiven Annahmen werden allerdings Wahlverfahren - wie ARROW gezeigt hat - nicht zu einem eindeutigen Ergebnis fuhren, was eine genaue Analyse naturlich erheblich erschwert.

Vgl. Arrow, K. J. (1950).

163 Vgl. Wildasin, D. E. (1994), S. 43 ff.

164 Vgl. Brennan, G. and J. M. Buchanan (1988), S. 19 f.

${ }^{165}$ Die folgende Darstellung orientiert sich an Hohaus, B. (1996), S. $50 \mathrm{ff}$. 
anderer nicht beeinflußt. Diese Vorgehensweise bringt zwar einiges an Vorteilen, insbesondere ist sie formal leichter zu handhaben, muß sich jedoch den Vorwurf gefallen lassen, die Realităt in vielen Fällen nur unzureichend zu modellieren. Staaten werden im Verhältnis zueinander häufig groß sein, d. h., daß die Maßnahmen eines Staates furr andere in Preis- und Mengenänderungen resultieren. In solchen Fällen ist es nicht möglich, das Verhalten einer Gebietskörperschaft ohne gleichzeitige Beachtung der Reaktion auf dieses Verhalten zu analysieren. In diesen Füllen werden die Fragestellungen mit Hilfe spieltheoretischer Methoden analysiert.

\subsection{Die Folgen für die Besteuerungsinstrumente}

Nach Darstellung der möglichen Formen der Modellierung des Steuerwettbewerbs soll in diesem Kapitel die tatsăchliche Analyse erfolgen. Hierbei wird zunăchst auf den einfachsten Fall eines kleinen Landes abgestellt, welches seine eigene Wohlfahrt maximiert. Wir grenzen also sowohl mögliche eigene Zielvorstellungen staatlicher Akteure als auch Interaktionen mit dem Ausland aus. Der Ansatz mag damit die Realităt nicht vollständig abbilden, er ist jedoch einfacher zu handhaben und produziert eindeutige Ergebnisse. Zudem werden die Abweichungen, die sich durch realitätsnahere Modellierungen ergeben, keine grundsătzlich anderen Ergebnisse liefern. Da diese Arbeit nur grundlegend aufzeigen soll, welche Folgen der zwischenstaatliche Wettbewerb für die Besteuerung des Güterverkehrs hat, reicht die einfachere Darstellung aus.

Bei der Betrachtung des staatlichen Verhaltens kann die ursprünglich vorgenommene Einteilung in stationäre und mobile Anlagen insofern beibehalten werden, als sich für den Staat hieraus zwei unterschiedliche Optimierungsprobleme ergeben.

Die stationären Anlagen, d. h. die Straßen, sind als öffentliche Güter vorstellbar, welche Spillovers erzeugen, also einen Nutzen für Bürger anderer Gebietskörperschaften generieren. Diese von WILLIAMS (1966) und BRAINARD und DOLBEAR (1967) in die Diskussion gebrachte Fragestellung betont die mögliche Unterversorgung mit offentlichen Gutern bei dezentraler Bereitstellung. Ist es allerdings möglich, die nicht ansässigen Nutzer zur Finanzierung heranzuziehen, kann sich ein anderes Bild ergeben. Letzteres soll in dieser Arbeit untersucht werden.

Die mobilen Anlagen - also die Beforderer - sind Unternehmen, welche zwar de jure an einem bestimmten „Standort" produzieren, aber de facto ihre Leistung von jedem Ort aus erbringen kőnnen, da die eigentliche Produktion - der Gütertransport - unabhängig vom Sitz des Unternehmens überall in Europa stattfinden kann. Auf Veränderungen der standortabhängigen Variablen, insbesondere Steuern und technische Vorschriften, kann demnach ohne große Verzoggerung mit Standort- 
verlagerung reagiert werden. Die „standortabhängige“ Besteuerung des Güterverkehrs kann daher als Besteuerung einer mobilen Steuerquelle modelliert werden.

\subsubsection{Abgaben auf die Benutzung der Verkehrsinfrastruktur}

In diesem Kapitel soll die Entwicklung der Besteuerung für die Benutzung der Verkehrsinfrastruktur analysiert werden. ${ }^{166}$ Der inländische Staat möge sich dabei zum Ziel setzen, mittels des Instrumentes der Besteuerung die Wohlfahrt der Inländer - gegebenenfalls auf Kosten der Ausländer - zu maximieren.

Formal können wir dies darstellen, indem wir ein repräsentatives inländisches Individuum unterstellen, welches ein privates Gut $\mathrm{X}$ und ein öffentliches Konsumgut $R^{167}$ nachfragt.

Das private Gut wird mittels Transport W (also Transportleistung gemessen in tkm) als einzigem Input hergestellt. Diese „Produktion“, d. h. der Transport des Gutes X, verursacht negative Konsumexternalitäten, die ebenfalls in das Kalkül des Wirtschaftssubjektes eingehen. Um das öffentliche Konsumgut anbieten zu können, besteuert der Staat den Transportvorgang. Diese Besteuerung ist an die Benutzung der stationären Anlagen des jeweiligen Landes, also die Straßen, gebunden. Sie kann direkt in Form von Straßenbenutzungsgebühren, Mauten usw. vorgenommen werden oder aber durch die Besteuerung einer mit der Fahrt korrelierten Bemessungsgrundlage wie dem Mineralölverbrauch erfolgen.

Die Besteuerung verteuert die Transporte und führt so zu deren Rückgang. Dies ist auch intuitiv einleuchtend, da, wie in Abschnitt 2.1 dargestellt, der Transport von Gutern durch Preisdifferenzen zwischen dem Ort der Herstellung und dem des Verbrauchs ausgelöst wird. Sind die Frachttarife höher als die Preisdifferenzen, unterbleibt der Transportvorgang.

Formal ausgedrückt entspricht die Nutzenfunktion des Individuums

$$
\mathrm{U}=\mathrm{U}(\mathrm{X}, \mathrm{C}, \mathrm{R}) \text {, }
$$

wobei das private Gut $\mathrm{X}$ und das offentliche Gut $\mathrm{R}$ positiv, die Konsumexternalität $\mathrm{C}$ negativ in die Nutzenfunktion eingeht.

Die inlăndische und die auslăndische Produktionsfunktion lauten

$$
\mathrm{X}=\mathrm{X}(\mathrm{W}) \text { (Inland), bzw. } \mathrm{X}^{*}=\mathrm{X}^{*}\left(\mathrm{~W}^{*}\right) \text { (Ausland). }
$$

Die Güter im In- und Ausland werden also mittels inländischem Transport als einzigem Produktionsfaktor hergestellt. W ist demnach inländischer Verkehr, W*

${ }^{166}$ Die Argumentation folgt Amott, R. and R. E. Grieson (1981).

167 Beim offentlichen Gut handelt es sich hier um ein echtes Konsumgut, also nicht um einen offentlichen Input wie z. B: Verkehrsinfrastruktur. 
Transporte von Ausländern im Inland. Diese explizite Trennung von In- und Ausland bedeutet, daß „ausländische Transporte“ als Transporte vom Ausland ins Ausland, also Durchfahrten, zu interpretieren sind. Im Gegensatz zu den beweglichen Anlagen ist demnach nicht die Nationalităt des Beförderers, sondern Ladeund Entladeort für die Begriffsbestimmung ausschlaggebend.

Der Transportvorgang im Inland erhöht nicht nur die inländische Produktion, sondern verursacht zusătzlich externe Kosten:

$$
C=C\left(W ; W^{*}\right) \text {. }
$$

Wie aus der Gleichung 1.13 abzulesen ist, wird der externe Schaden außer vom Ausmaß der von Inländern erbrachten Transportleistung auch von ausländischen Beforderungsvorgången im Inland beeinflußt.

Das Ausmaß dieses Transportes ist per Definition abhăngig von den Frachttarifen und damit auch von der Höhe des Steuersatzes, d. $h$.

$$
W=W\left(t_{I}\right) \text { bzw. } W^{*}=W^{*}\left(t_{A}\right) \text {. }
$$

Der inländische Fiskus erhebt Steuern, die die Benutzung der Verkehrs als Bemessungsgrundlage haben. Er kann somit sowohl auf die inländischen, als auch auf die ausländischen Nutzer der Verkehrsinfrastruktur des Landes zugreifen. ${ }^{168}$

Mit Hilfe der Steuereinnahmen finanziert der Staat das öffentliche Konsumgut:

$$
R=t_{I} \circ W+t_{A} \circ W^{*} \text {. }
$$

Setzt man diese Gleichungen in die Nutzenfunktion ein, erhălt man die Gleichung:

$$
\mathrm{U}=\mathrm{U}\left[\mathrm{X}\left(\mathrm{W}\left(\mathrm{t}_{\mathrm{I}}\right)\right), \mathrm{C}\left(\mathrm{W}\left(\mathrm{t}_{\mathrm{I}}\right), \mathrm{W}^{*}\left(\mathrm{t}_{\mathrm{A}}\right)\right), \mathrm{R}\left(\mathrm{t}_{\mathrm{I}} \circ \mathrm{W}\left(\mathrm{t}_{\mathrm{I}}\right), \mathrm{t}_{\mathrm{A}} \circ \mathrm{W}^{*}\left(\mathrm{t}_{\mathrm{A}}\right)\right]\right.
$$

Betrachten wir zunăchst die Ergebnisse für einen geschlossenen Verkehrsmarkt, also die Ausgangslage aus Kapitel 1. In diesem Fall ist $\mathrm{W}^{*}=0$, einziges Instrument des Staates ist $t_{i}$. Die Optimierung der Funktion mit $t_{i}$ als Maximierer ergibt:

$$
\frac{\partial \mathrm{W}}{\partial \mathrm{t}_{\mathrm{i}}}\left[\frac{\partial \mathrm{U}}{\partial \mathrm{X}} \frac{\partial \mathrm{X}}{\partial \mathrm{W}}+\frac{\partial \mathrm{U}}{\partial \mathrm{C}} \frac{\partial \mathrm{C}}{\partial \mathrm{W}}\right]+\frac{\partial \mathrm{U}}{\partial \mathrm{R}}\left[\mathrm{W}+\mathrm{t}_{\mathrm{i}} \frac{\partial \mathrm{W}}{\partial \mathrm{t}_{\mathrm{i}}}\right]=0
$$

bzw.

$$
-\frac{\partial \mathrm{W}}{\partial \mathrm{t}_{\mathrm{i}}}\left[\frac{\partial \mathrm{U}}{\partial \mathrm{X}} \frac{\partial \mathrm{X}}{\partial \mathrm{W}}+\frac{\partial \mathrm{U}}{\partial \mathrm{C}} \frac{\partial \mathrm{C}}{\partial \mathrm{W}}\right]=\frac{\partial \mathrm{U}}{\partial \mathrm{R}}\left[\mathrm{W}+\mathrm{t}_{\mathrm{i}} \frac{\partial \mathrm{W}}{\partial \mathrm{t}_{\mathrm{i}}}\right]
$$

168 Von praktischen Problemen bei der Erfassung der Besteuerten wird hier abstrahiert. 
Der Klammerausdruck auf der rechten Seite in $1.22 \mathrm{~b}$ bezeichnet die Veränderung des Steueraufkommens durch die Veränderung des Steuersatzes. Multipliziert mit dem Grenznutzen aus der Bereitstellung des öffentlichen Gutes ergibt sich der Zusatznutzen aus der Verwendung der Einnahmen einer höheren Transportbesteuerung.

Der Klammerausdruck auf der linken Seite der Gleichung $1.22 \mathrm{~b}$ zeigt den Nettonutzen einer zusätzlichen Transporteinheit. Dieser setzt sich zusammen aus dem positiven Nutzen, den der Konsum privater Güter stiftet, die mittels zusätzlicher Transportleistung bereitgestellt werden können, und dem (negativ bewerteten) Umweltschaden, den die Inländer durch den zusătzlichen Verkehr erleiden. Dieser Nettonutzen einer zusätzlichen Transporteinheit wird multipliziert mit der (negativen) Veränderung des Transports durch die Veränderung der Besteuerung.

Als Optimalitătsregel erhalten wir also die Bedingung, daß der Nutzen einer zusätzlichen Einheit des öffentlichen Gutes dem (negativen) Nettonutzen aus dem Minderkonsum des privaten Gutes und des Umweltschadens entsprechen muß.

Öffnen wir den Verkehrsmarkt für Ausländer und erlauben Preisdiskriminierung, d. h. unterschiedliche Steuern für aus- und inländische Transporteure, erhalten wir durch Optimierung mit $\mathrm{t}_{\mathbf{A}}$ als Maximierer die Funktion

$$
-\frac{\partial \mathrm{U}}{\partial \mathrm{C}} \frac{\partial \mathrm{C}}{\partial \mathrm{W}^{*}} \frac{\partial \mathrm{W}^{*}}{\partial \mathrm{t}_{\mathrm{a}}}=\frac{\partial \mathrm{U}}{\partial \mathrm{R}}\left[\mathrm{W}^{*}+\mathrm{t}_{\mathrm{a}} \frac{\partial \mathrm{W}^{*}}{\partial \mathrm{t}_{\mathrm{a}}}\right]
$$

Der Zusatznutzen der Einnahmen aus der Besteuerung ausländischer Transporteure entspricht hier dem Umweltschaden, der durch zusätzliche Transportleistung im Transitverkehr ausgelöst wird. Diese Steuer ist höher als die entsprechende Steuer für Inländer, da das Transitland den Nutzen, der sich für das Ausland aus dessen Fahrten ergibt, in seiner Kalkulation nicht berücksichtigt.

In der Europäischen Union ist eine Preisdiskriminierung dieser Art jedoch nicht zulässig. ${ }^{169}$ Für die Abbildung der Realităt muß also $t_{A}=t_{i}$ angenommen werden, d. h. das Inland darf den ausländischen Nutzer der inländischen Verkehrsinfrastruktur nicht anders besteuern als den Inländer.

Optimierung ergibt

${ }^{169}$ Die Diskriminierung zwischen In- und Ausländern bei der Verkehrsbesteuerung stellt nach Ansicht des EuGH ein Verstoß gegen Art. 95 EGV dar und ist somit eine irrelevante Alternative. Ein entsprechendes Urteil wurde 1990 gefallt, als Deutschland eine Absenkung der KfzSteuer $\left(t_{t}\right)$ mit der Einfuhrung von Straßenbenutzungsgebuhren $\left(t_{I}\right.$ und $\left.t_{A}\right)$ verband.

Vgl. Weindl, J. (1996), S. 206f. 


$$
\begin{aligned}
& -\frac{\partial \mathrm{W}}{\partial \mathrm{t}_{\mathrm{i}}}\left[\frac{\partial \mathrm{U}}{\partial \mathrm{X}} \frac{\partial \mathrm{X}}{\partial \mathrm{W}}+\frac{\partial \mathrm{U}}{\partial \mathrm{C}}\left(\frac{\partial \mathrm{C}}{\partial \mathrm{W}}+\frac{\partial \mathrm{C}}{\partial \mathrm{W}^{*}}\right)\right] \\
& =\frac{\partial \mathrm{U}}{\partial \mathrm{R}}\left[\mathrm{W}+\mathrm{W}^{*}+\mathrm{t}_{\mathrm{i}}\left(\frac{\partial \mathrm{W}}{\partial \mathrm{t}_{\mathrm{i}}}+\frac{\partial \mathrm{W}^{*}}{\partial \mathrm{t}_{\mathrm{i}}}\right)\right]
\end{aligned}
$$

Auf der linken Seite in 1.24 erhalten wir als zusätzlichen Term im Vergleich zum abgeschotteten Verkehrsmarkt die Umweltschäden durch ausländische Fahrten $\frac{\partial \mathrm{C}}{\partial \mathrm{W}^{*}}$. Dies zeigt an, daß der Nettonutzen einer zusätzlichen Transporteinheit geringer ist, als in der Ausgangslage, da die ausländischen Transporteure zwar zum Umweltschaden beitragen, aber für Inländer keinen positiven Nutzen in Form von zusătzlichem privaten Konsum schaffen. Unter sonst gleichen Bedingungen wären also weniger gefahrene Tonnenkilometer, mithin eine höhere Besteuerung zu bevorzugen, da aufgrund der vermiedenen Umweltschăden der Nutzenentgang geringer ausfiele als in der gleichen Situation nur mit inländischen Transporteuren. Der linke Term der Gleichung wird gegenuber der urspringlichen Ausgangslage also kleiner.

Auf der rechten Seite wird der Term in Klammern um den Ausdruck W* ergänzt, da das offentliche Gut gegenuber dem geschlossenen Verkehrsmarkt zusătzlich durch die Besteuerung ausländischer Transporte finanziert wird. Der rechte Term in 1.24 wird also c. p. größer.

Im inländischen Optimum, d. h. bei Gültigkeit der Gleichheitsbedingung, muß der (negative) letzte Term der Gleichung 1.24 diesen „Finanzierungseffekt" kompensieren.

Befinden wir uns auf dem steigenden Ast der Laffer-Kurve, wird die Aufkommensminderung bedingt durch den Rückgang der Transporte $t_{i}\left(\frac{\partial W}{\partial t_{i}}+\frac{\partial W^{*}}{\partial t_{i}}\right)$ also durch das höhere Steueraufkommen $\left(W+W^{*}\right)$ überkompensiert, muß der Steuersatz $t_{i}$ steigen, um den rechten Term absolut zu verkleinern.

Dies ist ökonomisch plausibel: Durch die zusătzlichen ausländischen Transporte steigt die Umweltbelastung an, damit sinkt der Nettonutzen aus zusätzlicher Transportleistung. Anders gesagt, eine zusätzliche Besteuerung der Transporte fuhrt zu einem geringeren Nutzenrückgang als in einem geschlossenen Markt ohne Besteuerung der Ausländer. Daher ist es auch sinnvoll, die Besteuerung der Transportwege zu erhöhen, um zusätzliche Einnahmen für die Finanzierung des offentlichen Gutes zu erhalten. 
Wir erkennen also, daß bei einer Öffnung der Märkte, d. h. durch die Besteuerung auch ausländischer Transporte, ein Anreiz für die Staaten besteht, den Steuersatz für Mineralölprodukte oder ähnliche fahrwegsabhängige Steuern zu erhöhen. ${ }^{170}$

\subsubsection{Abgaben auf den Fahrzeugbesitz}

Die hier wesentliche Eigenschaft der sogenannten mobilen Anlagen, d. h. der Fahrzeuge, ist schon in ihrem Namen enthalten - sie sind mobil. Diese Mobilität war jedoch, wie schon dargelegt, vor der Liberalisierung der Transportmärkte in Europa institutionell eingeschrănkt.

Seit der Liberalisierung konkurrieren die Beförderer innerhalb der Europäischen Union um diesen größer gewordenen Markt. Da aufgrund der großen Konkurrenz angenommen werden kann, daß die Preise furr die Beforderer ein Datum darstellen, ist die angebotene Transportkapazităt im wesentlichen kostendeterminiert. Diese Kosten sind in einigen Punkten für alle europäischen Beförderer gleich, in anderen unterscheiden sie sich. Identisch sind bis auf geringe Unterschiede die Kosten für die Transportgefäße (die Fahrzeugvorhaltekosten), da allen Transporteuren prinzipiell die gleiche Technologie zur Verfugung steht und die technischen Richtlinien furr die Fahrzeuge europaweit weitestgehend harmonisiert sind. Zwar wird die Einhaltung dieser Vorschriften von Land zu Land noch in deutlich unterschiedlichem Maße kontrolliert, diese Unterschiede gelten jedoch furr alle Transporteure gleichermaßen. Die Fahrzeugeinsatzkosten sind ebenfalls unabhăngig vom Standort des Gewerbes, so daß im wesentlichen zwei standortabhängige Größen verbleiben: Die Personalkosten und die standortabhängige Besteuerung. Letztere soll Gegenstand der folgenden Analyse sein.

Die standortabhängige Besteuerung besteht im wesentlichen aus der Kraftfahrzeugsteuer, Gewerbesteuern oder ihr vergleichbaren Steuerarten und der Körperschaft- bzw. Einkommensteuer. ${ }^{171}$ Da alle Steuern außer der Kraftfahrzeugsteuer nicht sektorspezifisch sind, also keinen geeigneten verkehrspolitischen Aktionsparameter für den Staat darstellen, werden sie im folgenden aus der Betrachtung ausgeklammert.

Das optimale Verhalten eines Staates bei der Festlegung der Höhe der KfzSteuersătze wird im folgenden mittels eines einfachen Modells abgebildet ${ }^{172}$ :

$170 \mathrm{Vgl}$. für ein ahnliches Ergebnis auch Amott, R. und R. E. Grieson (1981).

171 Einige andere kleinere Steuern, z. B. Steuern auf Warentransportversicherungen, Vermőgenund Erbschaftsteuer und Registrierungssteuern seien hier ausgenommen. Für eine genaue Auflistung vgl. DG21 (1997).

172 Das Modell entspricht dem Kapitalsteuerwettbewerbsmodell von ZODROW und MIESZKOWSKI. Die Modellierung der Unternehmensansiedlung mit Hilfe eines Modells der Kapitalbesteuerung mag auf den ersten Blick ungewőhnlich anmuten. Da aber keine Überfullungskosten auf- 
Eine Föderation bestehe aus einer Anzahl von $\mathrm{N}$ identischen Gebietskörperschaften, im folgenden Länder genannt. Diese Lănder sind im Verhältnis zueinander klein, so daß Maßnahmen eines Landes nicht zu Reaktionen der anderen fuhren. ${ }^{173}$

In den Ländern werde der Einfachheit halber nur ein Konsumgut $\mathbf{X}_{\mathbf{i}}$ mit Hilfe des Faktors Kapital K (hier z. B. in Form von Fahrzeugen) hergestellt. Dieser „Fak-

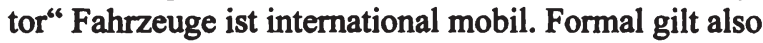

$$
\overline{\mathrm{K}}=\mathbf{n K _ { i }} \quad \mathrm{i}=1, \ldots, \mathrm{n} .
$$

In jeder Gebietskörperschaft werde das Gut unter Verwendung einer linearhomogenen Produktionsfunktion hergestellt.

$$
\mathbf{X}_{\mathbf{i}}=\mathbf{F}\left(\mathrm{K}_{\mathrm{i}}\right)
$$

Eine restriktive Annahme dieses Modells ist die unterstellte abnehmende Grenzproduktivităt der Fahrzeuge $\left(f_{k k}<0\right)$, welche jedoch für eine innere Lösung des Problems notwendig ist. Diese Annahme widerspricht zunächst der Intuition: Warum soll ein zusätzlicher LKW in einem Land eine geringere Produktivität haben als der vorangegangene, wenn das Gut Transport europaweit angeboten wird? Eine Erklårung könnte aber sein, daß bei zunehmender Anzahl von Transportkapazität an einem Standort die Leistungserbringung in immer größerer răumlicher Entfernung getätigt werden muß, welche dazu fuhrt, daß eine zusătzliche Transportleistung mit höheren Transaktionskosten als die vorherige verbunden ist.

Solche Kosten kőnnten beispielsweise Probleme mit Anschlußfahrten, regionalen Fahrverboten etc. sein.

Es sei nun wie im ersten Modell angenommen, daß neben einem repräsentativen Individuum ein Staat existiert, der in jedem Land das offentliche Gut $\mathbf{R}_{\mathbf{i}}$ anbietet. Um die Produktion des öffentlichen Gutes vernachlässigen zu können, wird es als Kauf des privaten Gutes durch den Staat modelliert. Die Grenzrate der Transformation zwischen offentlichem und privatem Gut wird dadurch zu 1.

Die Budgetbeschränkung des Staates lautet

$$
\mathbf{R}_{\mathbf{i}}=\mathbf{t}_{\mathbf{i}} \circ \mathbf{K}_{\mathbf{i}} \text {, }
$$

treten und Kapital der einzige Produktionsfaktor ist, entspricht die hier gewalhlte Modellierung der Problemstellung oder bedeutet zumindest keinen Verlust an Allgemeinheit.

Vgl. Zodrow, G. R. und P. Mieszkowski (1986).

${ }^{173}$ Diese Modellierung entspricht sicher nicht der Realităt in der Europåischen Union. HOYT hat gezeigt, daß der Steuerwettbewerb um so geringer ausfallt, je weniger Gebietskorperschaften miteinander im Wettbewerb stehen. Das hier dargestellte Modell ist also als Grenzfall anzusehen. Vgl. Hoyt, W. H. (1991), S. 127 ff. 
das heißt, das öffentliche Gut wird durch die Besteuerung der Fahrzeuge mit dem Steuersatz $t_{\mathrm{i}}$ finanziert. Aus dieser Form der Besteuerung und der Mobilităt der Fahrzeuge folgt aus dem Gewinnmaximierungsverhalten der Unternehmen die Arbitragebedingung:

$$
r+t_{i}=\frac{\partial F\left(K_{i}\right)}{\partial K_{i}}
$$

Die Transporteure müssen also im betreffenden Land i zusätzlich zur Rendite der Fahrzeuge r, die diese aufgrund der vollständigen Mobilität überall in der Föderation erzielen, die Steuer $t_{i}$ erwirtschaften.

Das repräsentative Individuum habe die Nutzenfunktion

$$
\mathrm{U}_{\mathrm{i}}=\mathrm{U}_{\mathrm{i}}\left(\mathrm{X}_{\mathrm{i}}, \mathrm{R}_{\mathrm{i}}\right) \text {. }
$$

Es unterliegt der Restriktion

$$
X_{i}=F\left(K_{i}\right)-\left(r+t_{i}\right) K_{i}+r(\bar{K} / n)
$$

d. h. sein maximal zur Verfügung stehendes Einkommen setzt sich aus inländischem Residualeinkommen ${ }^{174}$ und der Rendite der in inländischem Besitz befindlichen Fahrzeuge zusammen.

Der Staat als benevolenter Diktator maximiert den Nutzen des reprăsentativen Individuums, seine Maximierungsaufgabe läßt sich demnach formulieren als:

$$
\underset{t_{i}}{\operatorname{Max}} U_{i}\left[X_{i}, R_{i}\right]=U_{i}\left[F\left(K_{i}\left(t_{i}\right)\right)-(r+T) K+r(\bar{K} / n) ; T_{i} K_{i}\left(t_{i}\right)\right]
$$

Aus der Maximierung ergibt sich:

$$
\frac{\partial \mathrm{U} / \partial \mathrm{X}_{\mathrm{i}}}{\partial \mathrm{U} / \partial \mathrm{R}_{\mathrm{i}}}=\frac{1}{1+\frac{\mathrm{dK}_{\mathrm{i}}}{\mathrm{dt}_{\mathrm{i}}} \frac{\mathrm{t}_{\mathrm{i}}}{\mathrm{K}_{\mathrm{i}}}}>1\left(\text { wegen } \mathrm{dK}_{\mathrm{i}} / \mathrm{dt}_{\mathrm{i}}<0\right)
$$

Die Grenzrate der Substitution ist also größer als die Grenzrate der Transformation. Das öffentliche Gut wird bedingt durch die Mobilităt der besteuerten Fahrzeuge also in zu geringem Maße bereitgestellt. Das Ausmaß der Verzerrung hängt dabei von der Elastizităt ab, mit der die Transportunternehmen auf die Besteuerung reagieren.

${ }^{174}$ Das Residuum ist die Differenz aus dem Output und dem Ertrag das Faktors Kapital. 
Wie in Abb. 34 auf der folgenden Seite zu sehen ist, fuhrt die Einfuhrung einer Kfz-Steuer zur entsprechenden Reduktion des Fahrzeugeinsatzes im Inland. Die Fahrzeuge erwirtschaften also weiterhin die vom Markt vorgegebene Rendite r. Das Steueraufkommen wird vollständig vom immobilen Faktor Arbeit getragen, dessen Entlohnung von $\mathrm{ADF}$ auf $\mathrm{ABC}$ gesunken ist.

Selbst eine völlige Übertragung der Steuereinnahmen BCED auf den Faktor Arbeit kőnnte ihn nicht entschădigen, da die Steuereinnahmen um CEF geringer ausfallen als der Einkommensverlust. Ein Staat, der den Nutzen der Inländer maximiert, wird demnach auf die Besteuerung von Fahrzeugen, mithin auf die $\mathrm{Kfz}$-Steuer verzichten.

Diese Aussage ist, wie oben schon erwähnt, durch die restriktiven Annahmen eines kleinen Landes und vollstăndiger Mobilität des besteuerten Faktors zu erklären. Da beide in der Realität nur eingeschränkt zutreffen, wird der Satz der KfzSteuer bei optimierenden Staaten weiterhin positiv sein. Die hier ermittelte Aussage, daß eine Öffnung der Verkehrsmärkte in der Tendenz zur Absenkung der $\mathrm{Kfz}$-Steuer fuhrt, bleibt aber aufrechterhalten.

Abb. 34: Die Erosion mobiler Steuerbemessungsgrundlagen

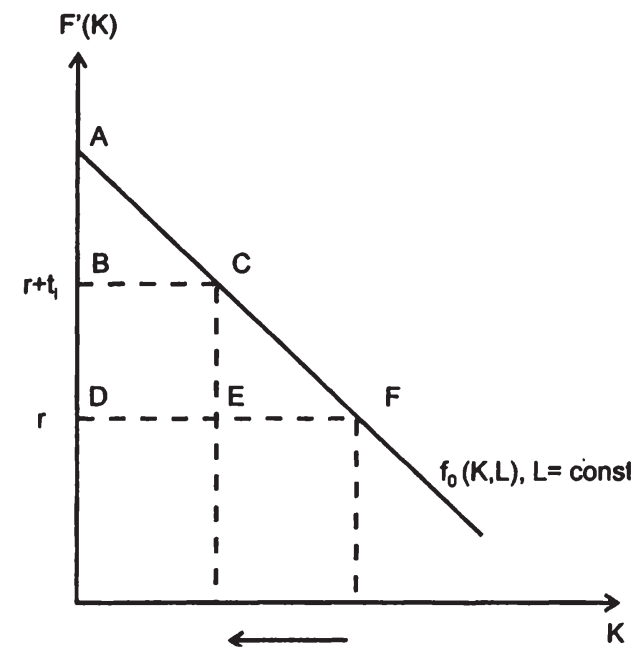

Quelle: Sinn, H.-W. (1997), S. 15.

\subsubsection{Zusammenfassung der Ergebnisse}

Im Zuge der Öffnung der europåischen Straßengüterverkehrsmårkte haben sich die Rahmenbedingungen für die betroffenen Staaten verändert. Im Kapitel 1 wur- 
de die $\mathrm{Kfz}$ - Besteuerung als ein geeignetes Instrument zur Finanzierung der Verkehrsinfrastruktur und zur Verhaltenslenkung in einem geschlossenen Verkehrsmarkt beschrieben. Kapitel 1 hat jedoch gezeigt, daß diese Form der Besteuerung in einem offenen Markt keinen geeigneten staatlichen Aktionsparameter darstellt, da die Zensiten der Besteuerung durch Ansiedlung in anderen Mitgliedsstaaten ausweichen können.

Die Mineralölsteuer als Instrument zur Internalisierung von Umweltschäden dagegen wird von Staaten, die im Interesse der Wohlfahrt ihrer Einwohner handeln, über ein gesamtwirtschaftlich optimales Maß hinaus erhoben. Da sie von allen Spediteuren gezahlt werden muß, die im Inland Transportleistung erbringen, werden solche Staaten sie außer zur Verhaltenslenkung zum Steuerexport nutzen.

Insgesamt verschiebt sich durch die Öffnung der Märkte also die Struktur der Verkehrsbesteuerung. Die empirische Überprüfung dieser Aussage soll Gegenstand des folgenden Abschnitts sein.

\subsection{Die quantitative Entwicklung der Verkehrsbesteuerung}

Der Güterverkehr unterliegt in der Europäischen Union einer Vielzahl von Steuern. Es bietet sich an, die oben angegebene Klassifikation beizubehalten und die Gesamtheit der relevanten Steuern in Steuern auf den Besitz der Fahrzeuge im weiteren Sinne, d. h. auf die mobilen Anlagen, und fahrwegsabhängige Steuern, d. h. Steuern auf stationäre Anlagen, einzuteilen. Nachdem dies geschehen ist, werden wir deren Entwicklung im Verlauf der letzten Jahre beobachten, um so unsere oben aufgestellten Hypothesen zu uberprufen.

\subsubsection{Steuern auf stationäre Anlagen}

Bei der Besteuerung der Benutzung stationärer Anlagen, also Straßen, Brücken und Tunnel zeigen die theoretischen Vorüberlegungen, daß die entsprechenden Steuersätze im Zuge der Verkehrsmarktliberalisierung steigen müßten.

Zur Untersuchung dieser Hypothese werden diejenigen Länder der EU herausgegriffen, die in relevantem Maße am Transitverkehr durch Deutschland beteiligt sind. Hierbei wurden 200.000 Ein- und Durchfahrten als Mindestgröße willkürlich zugrunde gelegt. Österreich wurde nicht berücksichtigt, da es erst seit 1995 Mitgliedsland ist und seine Verkehrsgesetzgebung vorher massiv von der der EULänder abwich, die Entwicklung also wenig Erklärungswert hat. Da die Entwicklung erst ab 1993 - dem Beginn der Verkehrsmarktliberalisierung - untersucht werden kann, ergibt sich das Problem einer unzureichenden Datenlage. Es ist daher durchaus möglich, daß Änderungen allein aufgrund der Datenlage als nicht signifikant erkannt werden. Daher muß auf eine ausfuhrliche statistische Analyse 
zugunsten einer deskriptiven Darstellung in Form eines einfachen Diagramms und des Vergleichs von Mittelwerten und Varianzen verzichtet werden.

Die Erhebung von Abgaben auf die Benutzung der Verkehrsinfrastruktur ist innerhalb der Europäischen Union, wie in Abschnitt 3.2.2 dargelegt wurde, nur innerhalb eines engen Spielraums möglich. Mauten sind nur für Sonderbauten zulässig und an die tatsächlichen Kosten der Infrastruktur gekoppelt. Straßenbenutzungsgebühren sind nach oben begrenzt. Als einzige nach oben offene Abgabe für die Benutzung der Infrastruktur verbleibt die Mineralőlsteuer, deren Entwicklung hier betrachtet werden soll. Da der Straßengüterverkehr analysiert wird, sind die Steuersătze auf Diesel die relevante Größe.

Abb. 35: Die Entwicklung der Mineralolbesteuerung in Europa

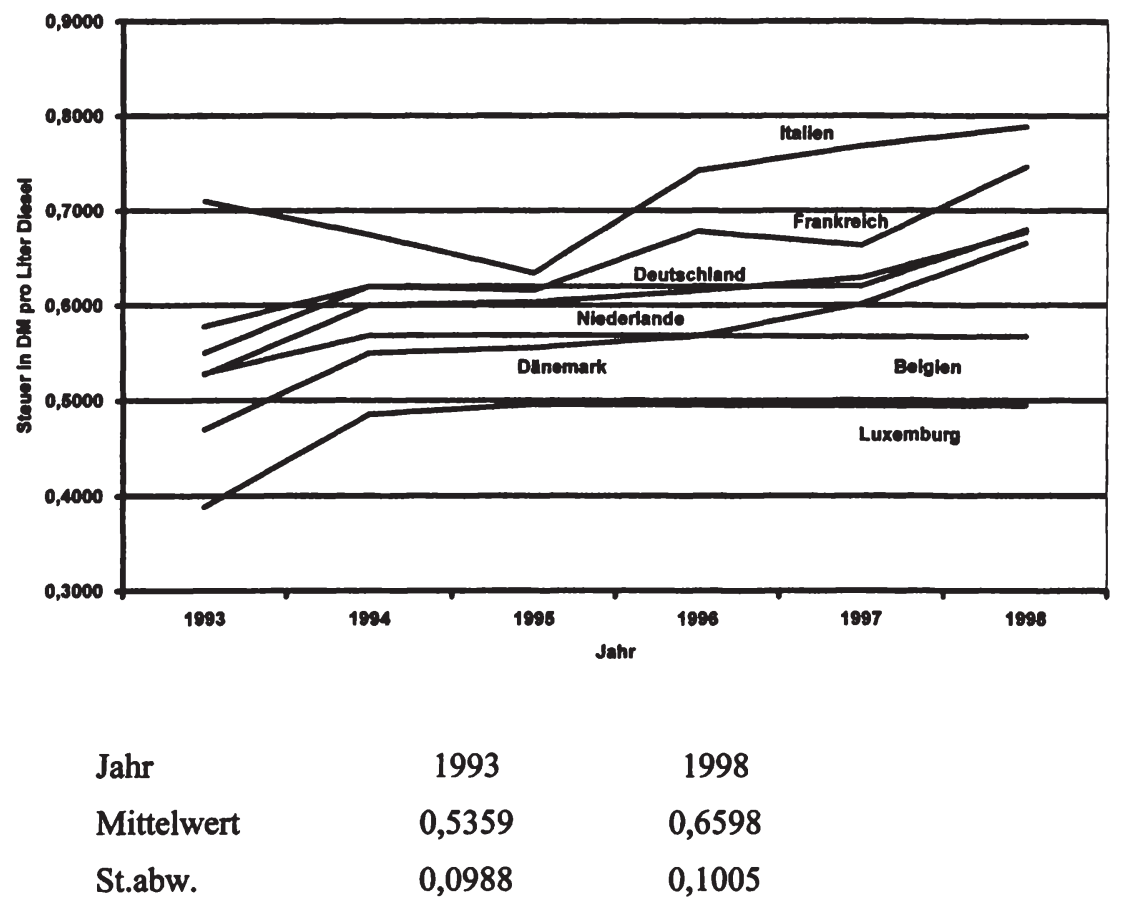

Quelle: BGL: Verkehrswissenschaftliche Zahlen (verschiedene Jahrgange), eigene Berechnungen.

Auch die Modellergebnisse bezüglich der Steuern auf die Benutzung der Verkehrsinfrastruktur werden weitgehend von den Daten bestătigt. Die Steuersătze 
auf Mineralöl sind in Europa seit 1993 kontinuierlich gestiegen, wie sich an der Veränderung der Mittelwerte ablesen läßt. Die Streuung der Sätze (= Veränderung der Standardabweichung) blieb dagegen weitgehend unverändert. Dies läßt sich mit den gleich gebliebenen Ausweichmöglichkeiten der Besteuerten erklären.

So wird auch die Ausnahme Luxemburg plausibel. Aufgrund seiner geringen răumlichen Ausdehnung hat dieses Land starke Anreize, mittels niedriger Gütersteuern Käufer zu attrahieren. Formal bedeutet dies, daß die Nachfrage nach Mineralöl in Luxemburg wesentlich empfindlicher auf Nachfrageänderungen reagiert als in den größeren Mitgliedsländern, daß Luxemburg sich also im elastischen Bereich der Nachfragekurve befindet. ${ }^{175}$ Eine Steuersenkung bringt Luxemburg also mehr Nachfrager und damit Steuern aus dem Ausland, als inländisches Steueraufkommen ausfällt. Der optimale Steuersatz fallt in Luxemburg somit niedriger aus als im Rest der Gemeinschaft.

Die hier dargestellte Interpretation genügt allerdings empirischen Ansprüchen nur unzureichend, da sie letztlich ohne eine genaue Analyse der - hierfur nicht ausreichenden - Daten erfolgt. Aufgrund der in den neunziger Jahren verstärkt geführten Debatte um die Umweltfolgen der Mobilität ist daher nicht auszuschließen, daß ein Teil der Mineralölsteuererhöhungen nicht auf den Wunsch nach Aufkommenserzielung zurückzufuhren ist, wie hier angenommen, sondern der Reduzierung des Verkehrs durch dessen gezielte Verteuerung dienen sollte. Da jedoch wie zu Beginn der Arbeit dargestellt, der Anstieg des Straßengüterverkehrs bisher unvermindert stattfindet und sich der modal split weiterhin zuungunsten von Bahn und Schiene entwickelt, ist zumindest nicht davon auszugehen, daß eine eventuell beabsichtigte Lenkung bisher stattgefunden hat. Insbesondere der in den dargestellten Modellen relevante grenzuberschreitende Verkehr und der Transitverkehr haben in den letzten Jahren hohe Wachstumsraten erfahren. Selbst wenn die Mineralölsteuererhöhungen also als Umweltsteuern intendiert waren, haben sie sich letztlich als Finanzierungsinstrumente furr den besteuernden Staat herausgestellt. Ohne den genauen statistischen Nachweis erbringen zu können, ist die Interpretation der Mineralölsteuererhöhung als Instrument für eine beggar-thy-neighbour Politik im Sinne der theoretischen Darlegungen zumindest als sehr wahrscheinlich anzunehmen.

${ }^{175}$ Ein typisches Gegenbeispiel hierfur ist die Schweiz, die quasi ein Monopol fulr einen Teil des Alpentransits besitzt und diese Sonderstellung mit Hilfe ihrer „Leistungsabhăngigen Schwerverkehrsabgabe" zur Generierung von Einnahmen ausnutzt bzw. ausnutzen wird.

Vgl. Hennighausen (1999). 


\subsubsection{Steuern auf mobile Anlagen}

Straßentransportunternehmen können in der Europäischen Union folgendenden Steuern unterliegen: ${ }^{176}$

$>$ Kraftfahrzeugsteuer

$>$ Mehrwertsteuer (auf den Kauf des Fahrzeuges)

$>$ Gewerbesteuer oder ähnliche Steuerarten

$>$ Körperschaftsteuer

$>$ Einkommensteuer

$>$ Vermögensteuer

$>$ Erbschaft-/Schenkungssteuer

Die Europăische Union zăhlt außerdem Steuern (bzw. Gebuhren), die bei der Anmeldung des Fahrzeuges zu zahlen sind, und Steuern, die die Fahrzeugversicherungen als Bemessungsgrundlage haben, dazu. ${ }^{177}$

In der ersten Gruppe ist lediglich die Kraftfahrzeugsteuer typisch fur Transportunternehmen, die anderen aufgelisteten Steuern werden von allen Unternehmen erhoben. Versicherungs- und Anmeldungssteuern sind zwar sektorspezifisch, vom Aufkommen her aber unbedeutend und sollen daher im folgenden nicht weiter betrachtet werden. Es bleibt also die $\mathrm{Kfz}$-Steuer als dasjenige Instrumentarium, mit dessen Hilfe der Staat die Ansiedlung von Straßentransportunternehmen beeinflussen kann. Die theoretischen Ausfuhrungen haben ein Verschwinden oder unter realistischeren Annahmen - eine Senkung dieser Steuer vorhergesagt. Diese Hypothese soll anhand der Entwicklung der Kfz-Steuer in der Europäischen Union uberprüft werden. Dazu werden auch hier wieder nur diejenigen Länder betrachtet, die in relevantem Maße am Transitverkehr durch Deutschland beteiligt sind.

Wir erkennen aus dem folgenden Diagramm und der Mittelwertberechnung, daß die Kfz-Steuer der betrachteten Länder am Ende des relevanten Zeitraumes durchschnittlich deutlich niedriger ausfällt als zu Beginn. Wie die Standardabweichung zeigt, haben sich zudem die Steuersätze der einzelnen Länder stark angenähert. An dieser Aussage ändert sich prinzipiell nichts, wenn das Haupttransitland Deutschland, welches aufgrund der zu Beginn sehr hohen Steuern das Ergebnis beeinflussen könnte, aus der Analyse herausgenommen wird.

${ }^{176}$ Mit der folgenden Einteilung orientiere ich mich an der Aufstellung des Bundesverbandes Guterkraftverkehr Logistik und Entsorgung (BGL) e. V.

177 Vgl. DG21 (1997), S. 6 f. 
Abb. 36: Die Entwicklung der Kfz-Besteuerung in Europa

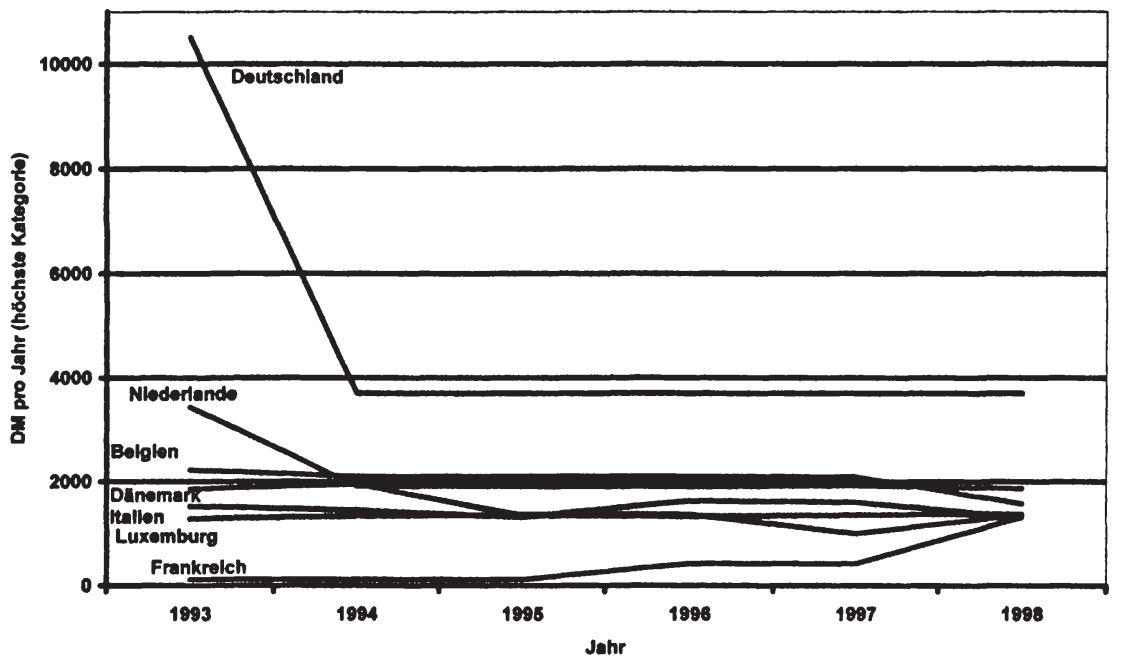

\begin{tabular}{llcc} 
& \multicolumn{1}{c}{ Jahr } & 1993 & 1998 \\
Incl. Deutschland & Mittelwert & $2.992,29$ & $1.786,86$ \\
& St.abw. & $3.460,51$ & 865,50 \\
& & & \\
Excl. Deutschland & Mittelwert & $1.740,17$ & $1.468,50$ \\
& St.abw. & $1.095,74$ & 218,09
\end{tabular}

Quelle: BGL: Verkehrswissenschaftliche Zahlen (verschiedene Jahrgănge), eigene Berechnungen.

Aus den Daten ist außerdem ersichtlich, daß Deutschland weiterhin die höchste $\mathrm{Kfz}-\mathrm{Steuer}$ der betrachteten Länder besitzt. Es wäre aufgrund der Modellergebnisse zu vermuten, daß Spediteure ins Ausland ausweichen, um der deutschen Besteuerung $\mathrm{zu}$ entgehen. Tatsăchlich hat das Bundesamt für Güterverkehr schon 1999, also ein Jahr nach der Freigabe der Kabotage, festgestellt, daß vermehrt deutsche Verkehrsunternehmen in anderen EU-Mitgliedsstaaten selbständige 
Tochterunternehmen grunden, welche dann innerhalb von Deutschland ihre Leistungen anbieten. ${ }^{178}$

Falls - entgegen den Annahmen des hier dargestellten Modells - Mobilitätskosten existieren, können diese höheren deutschen Steuersătze allerdings rational sein. Eine Steuersenkung hat nicht nur die Ausweitung der Bemessungsgrundlage durch zuwandernde ausländische Unternehmen zur Folge, sondern senkt c. p. gleichzeitig das von Inländern erzielte Steueraufkommen. Ohne vollständige Mobilität werden große Länder (mit großer heimischer Bemessungsgrundlage) daher tendenziell höhere Steuersătze erheben als kleine Länder. ${ }^{179}$

Wie können also feststellen, daß unsere Hypothese bezüglich der Entwicklung der $\mathrm{Kfz}$-Besteuerung für Europa einige Plausibilität besitzt. In einer Föderation ohne harmonisierte Fahrzeugbesteuerung würde dieses Besteuerungsinstrument über kurz oder lang verschwinden oder sich zumindest auf einem niedrigen Niveau einpendeln.

178 Vgl. BAG (1999), S. 7.

179 Vgl. dazu Kanbur, R. und M. Keen (1993), S. 880 ff. 


\section{Infrastrukturfinanzierung und Verkehrslenkung in einem Staaten- bund}

\subsection{Grundlagen für die Neugestaltung}

\subsubsection{Die bisherigen Ergebnisse}

Zu Beginn des 1. Kapitels dieser Arbeit wurde gezeigt, wie Deutschland - beispielhaft furr viele kontinentaleuropäische Länder - mit den Besonderheiten des Straßengüterverkehrs umgegangen ist. Diese Politik umfassender staatlicher Regulierung hat jedoch nie die gewünschten Ergebnisse erzielt. Wie dagegen eine optimale Verkehrsbesteuerung und -regulierung aussehen kann, wenn ein Land in seinem Handeln keinen Beschränkungen durch das Verhalten seiner Nachbarn unterworfen ist, wurde in Kapitel 1 diskutiert.

In Kapitel 1 wurde dargestellt, welche Änderungen in der Besteuerung des StraBengüterverkehrs zu erwarten sind, wenn die Abschottung eines Verkehrsmarktes gegenüber dem Ausland aufgeben wird und ein Land neben den Nutzen und Kosten der inländischen Verkehrsteilnehmer und Konsumenten auch die ausländischen Transporteure in sein Kalkül mit einbeziehen muß. Wir haben gesehen, daß die Kfz-Steuern, die vormals als sinnvolle Instrumente zur Infrastrukturfinanzierung und teilweise auch zur Internalisierung von Umweltexternalităten dargestellt wurden, in einem offenen Verkehrsmarkt verschwinden oder stark reduziert werden und sich der Schwerpunkt auf nutzungsabhängige Abgaben wie die Mineralolsteuer verlagert.

Die Regeln für eine effiziente Besteuerung, wie sie im 1. Kapitel abgeleitet wurden, können also in dieser Form nicht zur Anwendung gebracht werden, wenn der Rahmen der Analyse sich so grundlegend geändert hat wie die institutionellen Gegebenheiten der europäischen Verkehrspolitik. Nationale Verkehrspolitik kann nicht mehr isoliert betrachtet werden, sie muß im Kontext eines föderalistisch organisierten Staatenbundes gesehen und beurteilt werden, in dem einzelne Staaten die Wohlfahrt ihrer Bürger steigern können, indem sie die der Nachbarn verringern.

Um die Modifikationen zu erkennen, die aus diesen neuen Gegebenheiten entstehen können, sollen zunächst die normativen Aussagen über die optimale Verkehrsbesteuerung den positiven Aussagen uber die Entwicklung der Verkehrsbesteuerung in einer Föderation gegenübergestellt werden:

Die Ergebnisse der normativen Theorie der Regulierung, wie sie in Abschnitt 4.3 dargestellt wurden, sind relativ eindeutig: Aufgrund der hohen Fixkostenanteile sollten Mittel zur Infrastrukturfinanzierung vorwiegend mittels nutzungsunabhän- 
giger Gebuhren oder Beiträge aufgebracht werden. Ein Teil der Umweltverschmutzung könnte ebenfalls nutzungsunabhängig besteuert werden, indem nicht die tatsăchliche Verschmutzung, sondern das Emissionspotential als Bemessungsgrundlage genommen wird. Innerhalb dieses Rahmens spricht also vieles für die besprochene Modifikation und evtl. Erhőhung der Kfz-Steuer.

Die weitere Internalisierung von Externalitäten sollte im wesentlichen uber ordnungspolitische Maßnahmen erfolgen, da Preise ihre Signalfunktion bei den vorwiegend lokal wirkenden und zeitabhängigen Effekten nicht in ausreichendem Maße erfullen können. Lediglich die Infrastrukturabnutzung durch den Schwerstverkehr sowie die globalen Schäden (Treibhauseffekt etc.) sollten durch nutzungsabhängige Gebühren, etwa in Form von Abgassteuern oder einer Erhöhung der Mineralölbesteuerung entgolten werden.

Diesen normativen Aussagen, welche ein Übergewicht ordnungspolitischer Maßnahmen und nutzungsunabhăngiger Abgaben nahelegen, steht die Untersuchung des Kapitels 1 über die zu beobachtende Entwicklung der Verkehrbesteuerung gegenuber, die ein durch Steuerwettbewerb verursachtes Verschwinden nutzungsunabhängiger verbunden mit einem Anstieg nutzungsabhängiger Steuern prognostiziert. Die Öffnung der europäischen Verkehrsmärkte ohne weitere Koordination der Verkehrspolitiken wird also uber eine gewisse Frist zu einer allokativ wenig wünschenswerten Verschiebung innerhalb des Instrumentenmix, welcher zur Finanzierung und Lenkung des Güterverkehrs genutzt werden kann, führen.

Das folgende Kapitel soll nun klären, ob es Möglichkeiten gibt, diese unerwünschten Effekte der Verkehrsmarktliberalisierung abzumildern oder mittels geeigneter Instrumentarien in eine wlinschenswerte Richtung zu lenken.

\subsubsection{Møglichkeiten zur Begrenzung des Steuerwettbewerbs}

Wenn man prinzipiell anerkennt, daß der internationale Steuerwettbewerb, wie er in Kapitel 1 dargestellt wurde, zu einem insgesamt unerwulinschten Ergebnis fuhrt, bieten sich mehrere Möglichkeiten an, diesen Wettbewerb zu beschränken oder gar zu verhindern.

Zum einen existiert die „Brachiallösung“ einer vollständigen Steuerharmonisierung. Würden alle Länder innerhalb der Europäischen Union ein einheitliches System der Verkehrsbesteuerung mit gleichen Sătzen und Bemessungsgrundlagen anwenden, wăre die Möglichkeit zur Steuerausweichung durch Verlagerung der Bemessungsgrundlage in andere Länder nicht mehr gegeben. Gleichzeitig schwände aber auch jede effizienzsteigernde Eigenständigkeit der Länder, die Möglichkeit, auf spezielle Bedürfnisse ihrer Bürger einzugehen oder ohne langwierige Absprachen die Rahmenbedingungen für Transporte $\mathrm{zu}$ ăndern. Um dies $\mathrm{zu}$ vermeiden, kann eine teilweise Harmonisierung angestrebt werden, 
d. h. es werden nur einige als notwendig erachtete Aspekte vereinheitlicht. Beispielsweise kann die zu wăhlende Bemessungsgrundlage normiert werden, um für die Zensiten eine größere Transparenz zu schaffen. Dies stellt furr sich genommen natürlich keine Vermeidung des Steuerwettbewerbs dar, es vergrößert sogar durch die verbesserten Informationen die Anreize zur Steuerausweichung. Die einheitliche Bemessungsgrundlage kann aber immerhin die Länder zwingen, mit offenen Karten zu spielen, d. h. Steuerwettbewerb mittels der Sätze zu betreiben und damit als solchen auszuweisen und anderen Ländern die Möglichkeit zu geben, adäquat darauf $\mathrm{zu}$ reagieren. Sie sind zudem Voraussetzung für weitere Harmonisierungsmaßnahmen. Im Zusammenhang mit der Vereinheitlichung der Bemessungsgrundlage steht das Verbot gewisser Besteuerungspraktiken. Darunter fallt insbesondere die Gewăhrung von Vergunstigungen gegenuber Gebietsfremden bzw. der Ausschluß ansăssiger Unternehmen von Vergünstigungen. Ein weiterer wichtiger Punkt ist die Handhabung von Verwaltungsvorschriften. Geringe Kontrolldichte bspw. kann eine Möglichkeit sein, trotz vorhandener Gesetze eine einseitige Bevorzugung bestimmter Unternehmen zu erreichen. Dieses aus der Diskussion um die Kapitalbesteuerung bekannte Vorgehen ${ }^{180}$ wird angewandt, um $\mathrm{zu}$ verhindern, daß durch selektive Regelungen ausländische Steuerbasen angezogen werden, ohne gleichzeitig die eigenen zu reduzieren. Ist dies möglich, erhöht sich natürlich der Anreiz zur Schädigung des Nachbarn. So wäre vorstellbar, daß ein Land ausländischen Transporteuren bei der Verlagerung ihrer Aktivitäten eine zeitlich befristete Steuerbefreiung oder ähnliches anbietet.

Bei den Steuersätzen ist die Festlegung von Ober- und Untergrenzen zur Begrenzung des Steuerwettbewerbs möglich. Damit soll einerseits die Ausnutzung von Marktmacht in Form uberhöhter „Preise“ zuungunsten anderer Länder (z. B. uberhöhte Mautgebühren an Paßstraßen), andererseits die Festlegung von „Dumpingpreisen“ zur Attrahierung ausländischer Bemessungsgrundlagen ausgeschlossen werden.

Alle bisher genannten Maßnahmen führen zu einer mehr oder weniger weitgehenden Einengung des Gestaltungsspielraums und damit tendenziell zu einer ähnlichen Struktur und Höhe der Güterverkehrsbesteuerung. Dieses Vorgehen kann aber nur als Notlösung angesehen werden, da es den Ländern den Spielraum zur Verfolgung eigener Interessen - hier im Sinne der Steigerung der Wohlfahrt ihrer Bürger - nimmt.

Unterscheiden sich nämlich die Präferenzen der betroffenen Gebietskörperschaften, fuhrt eine einheitliche Lösung über alle Länder hinweg zu einem Ergebnis, welches mindestens eine betroffene Gruppe schlechter stellt als eine dezentrale Entscheidung.

${ }^{180} \mathrm{Vgl.} \mathrm{OECD} \mathrm{(1998).}$ 
In Abb. 31 ist das Problem zentrale vs. dezentrale Bereitstellung als Entscheidung zwischen zwei beliebigen Gütern X und Y skizziert. Während Land A eine höhere Menge X zuungunsten von Y bevorzugt, präferiert B das genaue Gegenteil. Eine zentrale Entscheidung durch eine ubergeordnete Instanz wird sich zwischen den Vorstellungen der beiden Länder bewegen. Dies bedeutet jedoch, daß jedes oder mindestens ein Land durch die Zentralisierung auf ein niedrigeres Nutzenniveau gesetzt wird. Diese sogenannten Fremdbestimmungskosten fehlen bei dezentraler Bereitstellung. Sie sind den negativen Folgen des Steuerwettbewerbs, der sich aus unkoordinierten Entscheidungen ergeben kann, immer gegenüberzustellen.

Abb. 37: Wohlfahrtsgewinne durch Dezentralisierung

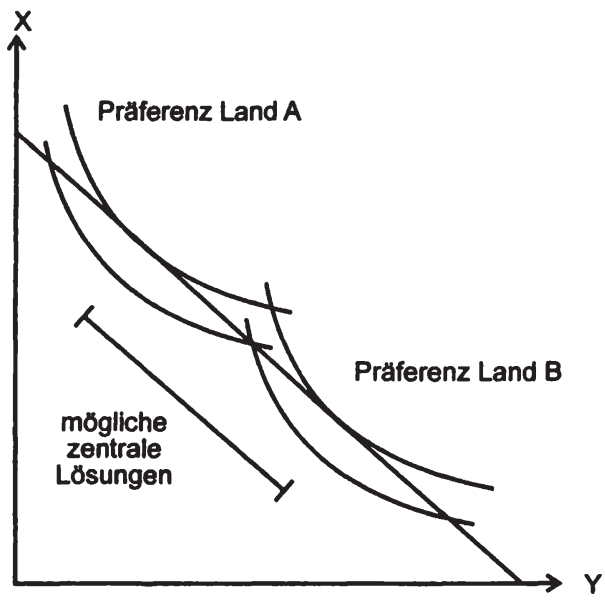

Quelle: Wust, H. F. (1981), S. 23.

Natürlich wăre denkbar, daß auch eine übergeordnete Instanz die Steuern regional differenziert und damit ein effizientes Ergebnis erreicht. Dies wird jedoch eher als unwahrscheinlich erachtet, da sowohl bei der praktischen Durchfuihrung als auch bei der Informationsbeschaffung so große Probleme entstehen werden, daß faktisch immer eine Orientierung an Durchschnittswerten, wie in der obigen Zeichnung dargestellt, stattfindet. ${ }^{18}$

Als letzte Möglichkeit zur Bereinigung des Dilemmas zwischen den Vor- und Nachteilen der Eigenstăndigkeit besteht die Möglichkeit, die Zuständigkeiten zwischen den einzelnen staatlichen Ebenen möglichst so aufzuteilen, daß ein Steuerwettbewerb trotz weitgehend dezentraler Strukturen unmöglich oder unattraktiv wird.

181 Vgl. Wink, R. (1995), S. 194. 
Die Zuordnung von Kompetenzen zu den geeigneten staatlichen Ebenen kann sich grundsätzlich an zwei Prinzipien orientieren: Dem Subsidiaritätsprinzip und dem Prinzip der fiskalischen Äquivalenz. ${ }^{182}$

Das Subsidiaritätsprinzip wird im allgemeinen der katholischen Soziallehre zugerechnet, wenngleich es schon wesentlich fruher in ähnlicher Weise formuliert wurde. ${ }^{183}$ Der entsprechende Absatz in der päpstlichen Sozialenzyklika Quadragesimo Anno aus dem Jahre 1931 sei hier kurz zitiert: „,... (es) ist an jenem hochbedeutenden Grundsatz nichts zu rütteln, der keine Verschiebung und Abänderung duldet: Was von den einzelnen Menschen mit eigener Kraft und durch eigene Tätigkeit geleistet werden kann, darf ihnen nicht entrissen und der Gemeinschaft übertragen werden. Ebenso ist es eine Ungerechtigkeit und zugleich eine schwere Verletzung und Störung der rechten Ordnung, wenn Aufgaben, die von kleineren und untergeordneten Gemeinschaften bewältigt werden können, der höheren und übergeordneten Gesellschaft zugeschoben werden. Denn jede soziale Leistung soll ihrem Sinn und Wesen nach ein Dienst an den Gliedern des sozialen Körpers sein, darf sie aber niemals vernichten oder ganz aufsaugen. “184

Kurz gefaßt besagt also das Subsidiaritätsprinzip, daß übergeordnete Gemeinschaften keine Kompetenzen an sich ziehen sollten, wenn die Möglichkeiten einzelner Personen oder kleinerer Gemeinschaften ausreichen, um eine Aufgabe auszuführen. ${ }^{185}$ Diese Interpretation in Form einer einfachen Kompetenzzuweisungsregel, wie sie auch - mit Einschränkungen - im Vertrag von Maastricht verankert ist, schränkt die ursprüngliche Bedeutung des Subsidiaritätsprinzips jedoch unzulässig ein. Die oben dargestellte negative Bedeutung muß vielmehr um einen positiven Bestandteil ergänzt werden: Statt der unteren Ebene diejenigen Aufgaben zu entziehen, zu deren Wahrnehmung sie nicht mehr in der Lage ist, müssen übergeordnete Institution zunächst versuchen, die Kompetenz der unteren Ebene zu erhalten. Sie müssen also schon vor dem eigentlichen Scheitern Vorleistungen erbringen, um eben dieses zu verhindern. „Das Prinzip fordert [demnach] vorleistende Hilfe zur Entfaltung der Selbstverantwortlichkeit und nachrangige Hilfe bei ausgeschöpfter Selbstverantwortlichkeit. “" ${ }^{186}$

Außer ökonomischen Vorteilen kann man in der Eigenständigkeit auch einen Wert an sich sehen, sie also nicht als Mittel zur Realisierung unterschiedlicher Präferenzen, sondern als Ziel staatlichen Handelns zu begreifen: Selbst wenn keine starken regionalen Divergenzen vorherrschen, sollte das jeweilige politischen

\footnotetext{
182 Vgl. z. B. Olson Jr., M. (1969), S. 497.

183 Vgl. Kirsch, G. (1977), S. 6.

184 Zitat entnommen aus: Kirsch, G. (1977), S. 6.

185 Vgl. Sutter, M. (1998), S. 204 und Möschel, W. (1995), S. 232 ff.

${ }^{186}$ Sutter, M. (1998), S. 204.
} 
System die Möglichkeit offenlassen, eigene Vorstellungen auszubilden und umzusetzen.

Fiskalische Äquivalenz als zweites Prinzip der Kompetenzverteilung fordert, daß jedes $8 f f e n t l i c h e$ Gut von einer Gebietskörperschaft angeboten wird, deren räumliche Ausdehnung mit dem Kreis der Nutzer dieses Gutes übereinstimmt. ${ }^{187}$ Damit wird gewăhrleistet, daß diejenigen, die Vorteile aus dem Angebot offentlicher Güter ziehen, auch für dessen Bereitstellung zahlen müssen. Eine Umsetzung des fiskalischen Äquivalenzprinzips in Reinkultur würde jedoch auf eine Vielzahl sich uberlappender Gebietskörperschaften hinauslaufen, in denen jeder Bürger entsprechend seiner Präferenzen bezüglich des jeweiligen öffentlichen Gutes zum Mitglied wird. ${ }^{188}$ Allerdings vernachlässigt dieser Ansatz die Koordinations- und Verwaltungskosten, die eine solche Vielzahl von Gebietskörperschaften mit sich bringt. Zudem dürften die meisten Bürger nur begrenzt făhig oder willens sein, die Vielzahl von Ländern mitzugestalten oder effizient zu kontrollieren, so daß letztlich eine Aufteilung der Aufgaben auf lokale regionale, nationale oder supranationale Gebietskörperschaften die einzig pragmatische Lösung sein dürfte. Das Postulat der fiskalischen Äquivalenz reduziert sich somit auf zwei Forderungen: Wahl des optimalen Grades an Zentralität und Dezentralität bei der Kompetenzverteilung einerseits, d. h. der Zuordnung von Aufgaben, Einnahmen und Ausgaben, und Korrektur der dabei notwendigerweise entstehenden räumlichen Externalitäten andererseits.

Bei der Zuweisung der Einnahmenkompetenzen läßt sich eine Unterteilung in die Verteilung von Gestaltungs- und Ertragshoheit vornehmen. ${ }^{189}$ Die Gestaltungshoheit meint hierbei das Recht, einen Vorgang oder Gegenstand mit einer Steuer zu belegen und diese auszugestalten. Unter Ertragshoheit wird das Recht verstanden, die Einnahmen der Steuer dem eigenen Haushalt zuzurechnen. ${ }^{190}$ Je nach Verteilung der Kompetenzen auf die einzelnen föderalen Ebenen unterscheidet man freie oder gebundene Trennsysteme, Zuweisungs-, Zuschlags- oder Verbundsysteme. In der Praxis existieren diese meist parallel nebeneinander, man spricht in diesem Fall von sogenannten Mischsystemen. Diese stellen meist einen Kompromiß zwischen den Anforderungen eines ökonomisch rationalen Steuersystems auf der einen Seite und den Erfordernissen eines foderativen Staatsaufbaus mit weitgehend autonomen Gebietsk8rperschaften auf der anderen Seite dar.

Diese Zuweisung von Finanzquellen an die verschiedenen Ebenen von Gebietskörperschaften wird im allgemeinen durch ein System von Zuweisungen ergänzt.

187 Vgl. dazu Olson Jr., M. (1969).

${ }^{188}$ Einen solchen Ansatz schlägt Frey fur die Europaische Union vor. Vgl. Frey, B. S. (1997).

189 Die sogenannte Verwaltungshoheit ist von untergeordneter 8konomischer Bedeutung und soll hier nicht năher betrachtet werden.

190 Vgl. Peffekoven, R. (1980), S. 619. 
Diese können entweder horizontal, d. h. zwischen Gebietskörperschaften der gleichen Ebene, oder vertikal, von übergeordneten zu untergeordneten föderalen Ebenen, durchgefuhrt werden. Allokativ werden diese Zuweisungen damit gerechtfertigt, daß sich, wie oben kurz angedeutet, fiskalische Äquivalenz, die răumliche Übereinstimmung von Nutzern und Zahlern, durch die Zuweisung von Aufgaben und Einahmen nie vollständig realisieren läß $\mathrm{t}^{191}$.

Die Begrenzung eines als unerwünscht empfundenen Steuerwettbewerbs kann, wie in diesem Kapitel gezeigt, nicht einfach in der Harmonisierung bestimmter Steuern, die als Instrumente in diesem Wettbewerb eingesetzt werden, bestehen. Den Vorteilen aus der Limitierung schädlichen Wettbewerbs müssen vielmehr die damit verbundenen Nachteile aus der Einengung dezentraler Handlungsspielräume gegenubergestellt werden. Zur Beurteilung eines optimalen Grades an Dezentralität wurden das Prinzip der Subsidiarităt und das Prinzip der fiskalischen Äquivalenz sowie Möglichkeiten zu deren Umsetzung dargestellt. Beide mulssen bei der Ableitung eines konkreten Steuersystems, wie es im nächsten Kapitel erfolgen soll, berucksichtigt werden.

\subsection{Die Finanzierung der Infrastruktur in der EU}

Wenn ein System zur Finanzierung der Verkehrsinfrastruktur und zur Steuerung des Verkehrs in einer Föderation entwickelt werden soll, ist es von geringem Nutzen, dieselben Maßstăbe anlegen zu wollen, wie im Kapitel 1 fur einen einzelnen Staat. ${ }^{192}$ Wir müssen vielmehr mit berucksichtigen, daß neben die Zielsetzung einer (gesamtwirtschaftlich) optimalen Allokation der eigenen Ressourcen jedes Land auch noch ein Interesse an einer Verbesserung der eigenen Wohlfahrt zuungunsten der Nachbarstaaten haben kann, z. B. indem es versucht, Einnahmen aus ausländischen Quellen zu erzielen. Einige in Kapitel 1 als effizient angesehene Regelungen können damit in dieser Form nicht innerhalb einer Főderation, in der keine wirksamen Mechanismen zur Koordination der Steuersysteme existieren, angewandt werden und müssen somit modifiziert oder ersetzt werden.

Eine Weiterentwicklung der Kfz-Besteuerung z. B. ist, wie schon oben erwăhnt und im Kapitel 5.3.2 gezeigt, fur ein einzelnes Land innerhalb der gegebenen institutionellen Regelungen als Instrumentarium zur effizienteren Steuerung des Verkehrs unattraktiv. Damit fehlt eine wichtige Steuer zur Deckung der Fixkosten der stationären Anlagen. Daher soll zunächst untersucht werden, wie in Zukunft

191 Bei der Zuweisung von Einnahmen und Aufgaben werden noch andere Ziele, wie fiskalische Gleichheit, verfolgt, so daß fehlende fiskalische Äquivalenz nicht nur ein technisches Problem, sondern Ausdruck von Zielkonflikten sein kann.

192 Gerade dieser Fehler wird aber hăufig begangen, wenn es um Vorschlăge zur effizienteren Gestaltung des Verkehrswesens in Europa geht.

Vgl. dazu z. B. ECMT (1991) und ECMT (1998). 
eine Finanzierung der Verkehrsinfrastruktur innerhalb Europas geregelt werden kann.

In Abschnitt 4.3.1 wurde vorgeschlagen, eine zweigeteilte Steuer einzufuhren, deren erster - fixer - Teil, die Kosten der Straßenerstellung entgilt und deren zweiter - variabler - Teil als achslastabhängige Schwerverkehrsabgabe konzipiert ist und als Entgelt für die höhere Abnutzung der Straßen fungiert. Nun haben wir festgestellt, daß eine $\mathrm{Kfz}$-Steuer, die in nationaler Verantwortung abhăngig vom Standort des Fuhrunternehmers erhoben wird, in einem unkoordinierten Nebeneinander der Steuersysteme reduziert wird.

Es wird also eine andere Regelung fur die Finanzierung der Infrastruktur notwendig sein. Grundsătzlich bieten sich hierfür drei Möglichkeiten: Abschaffung der Kfz-Steuer und Ersetzen durch eine an die Infrastrukturnutzung gekoppelte Gebühr, Einrichtung eines (horizontalen) Finanzausgleichsverfahren für die Straßennutzung oder Übertragung der Gesetzgebungskompetenz auf die europäische Ebene mit vertikaler Verteilung der Steuereinnahmen. ${ }^{193}$

Der erste Vorschlag, die Abschaffung der Kfz-Steuer zugunsten einer Nutzungsgebuhhr, ist unter dem Schlagwort „Territorialitătsprinzip“ die zur Zeit wohl am stärksten propagierte Politikempfehlung. Der Vorschlag basiert auf der Forderung, denjenigen Staaten das Recht zur Besteuerung zu überlassen, auf deren Staatsgebieten Transporte durchgefuhrt werden. Damit verbunden sind einige kaum zu übersehende Vorteile: Zum einen ist eine Nutzungsgebühr, wie in Kapitel 5.3.1 gezeigt, relativ unempfindlich gegenuber internationalem Steuerwettbewerb. Im Gegenteil bietet sie sogar die Möglichkeit zum Steuerexport, d. h. zur Ausbeutung ausländischer Transporteure und ist damit ein für die einzelnen Mitgliedslănder ăußerst attraktives Finanzierungsinstrument.

Zum anderen sind als Grenzkostenpreise ausgestaltete Straßennutzungsgebühren dem Ökonomen als Finanzierungsinstrument gedanklich nahe: So schreibt die Kommission der EU in ihrem Weißbuch zur Infrastrukturfinanzierung: „Bei einer bestimmten Infrastrukturausstattung wird eine effiziente Verkehrsnutzung dadurch gefördert, daß die variablen Kosten sich in den Endpreisen für Betreiber und Nutzer niederschlagen. ${ }^{\text {"194 }}$ Die Kommission vermischt in dieser Argumentation allerdings in m. E. unzulässiger Weise die Aspekte der Infrastrukturfinanzierung und der Internalisierung von Externalităten. Sie geht dabei von der

193 Grundsătzlich wăre natlirlich auch denkbar, vielleicht sogar naheliegend, der Europäischen Union neben der Gesetzgebungskompetenz auch die Ertragskompetenz zu erteilen und sie die im europåischen Rahmen relevanten Teile des Fernstraßennetzes in eigener Regie betreiben zu lassen. Dies sprengt jedoch den Rahmen der Arbeit, die sich nur mit Finanzierungs-, nicht mit Bereitstellungsfragen befaßt und wird zudem in naher Zukunft angesichts der - sicher oftmals berechtigten - Subsidiaritătsbestrebungen der einzelnen Lander Utopie bleiben.

Kommission (1998), S. 3. 
strittigen Annahme aus, daß die Internalisierungssteuern aufkommensmäßig ausreichen, um den notwendigen Fixkostenblock zu decken. Ist dies der Fall, wäre man natürlich einer first-best-Lősung sehr nahe, da das Aufkommen aus einer allokationsverbessernden Steuer stammt und daher keine Verzerrung induziert. Das Aufkommen einer Internalisierungssteuer ${ }^{195}$ reicht allerdings, wie schon in Kapitel 4.2.1 gezeigt, nur bei konstanten oder fallenden Skalenerträgen aus, um ein ausreichendes Aufkommen zu erzielen. Ist dies nicht der Fall, mögen an den Grenzkosten ausgerichtete Entgelte zwar eine effiziente Nutzung der Infrastruktur fördern ${ }^{196}$, können diese aber nicht finanzieren. ${ }^{197}$ Wird eine variable Gebühr verlangt, die die Durchschnittskosten abdeckt, ist zwar die Finanzierung gewährleistet, die Infrastruktur wird aber ineffzient genutzt.

Da nutzungsabhängige Gebühren also vermutlich im Straßengüterverkehr entweder ineffizient oder aber nicht kostendeckend sind, soll im folgenden nach einer Möglichkeit gesucht werden, im europäischen Rahmen eine Grundgebühr für die Infrastrukturnutzung zu installieren. Diese muß einerseits gewissen Anforderungen an eine Grundgebühr genügen, wie sie im Kapitel 4.3.1 dargelegt wurden, muß aber andererseits auch so ausgestaltet sein, daß der Anreiz zur Abschaffung dieser Steuer, der in Kapitel 5.3.2 diskutiert wurde, genommen wird.

Die Verbindung aus beidem muß innerhalb eines föderativ aufgebauten Staatengebildes durch einen Verzicht auf nationalstaatliche Kompetenz erreicht werden. In diesem Fall kann dies über eine Einigung bezüglich der Aufteilung der Steuerquellen erfolgen. Dies kann, wie oben grundsätzlich dargelegt, auf mehreren Wegen geschehen: $\mathrm{Zu}$ einen kann die höchstrangige Gebietskörperschaft eine Infrastrukturabgabe erheben und entsprechend dem Verkehrsaufkommen den Mitgliedsländern zuweisen. Alternativ kann eine zentral ausgestaltete Abgabe von allen Mitgliedsstaaten dezentral erhoben werden. In den Termini des Finanzausgleichs würde letzteres die Einführung eines gebundenen Trennsystems bedeuten, eventuell ergänzt um eine horizontale Komponente, die die Spillover-Effekte internalisiert. Um dem Subsidiaritätsgedanken gerecht zu werden, soll letzteres zuerst analysiert werden.

Eine vergleichbares System im Rahmen der Verkehrsbesteuerung ist bereits mit der Straßenbenutzungsgebühr für schwere Nutzfahrzeuge installiert. ${ }^{198}$ Diese

195 Mit der Internalisierungssteuer sind in der Literatur konkret meist Staugebuhren gemeint, die als Hauptziel die effiziente zeitliche Allokation des Verkehrs zum Ziel haben und deren Nebenzweck die Finanzierung der Infrastruktur sein kann. Weitergehende Internalisierungssteuern, also Umweltsteuern i. e. S. sind in diesem Zusammenhang meist nicht gemeint.

Vgl. fur einen solchen Ansatz z. B. Hau, T. D. (1998).

196 Siehe dazu aber Pfahler, W. (1984).

$197 \mathrm{Zu}$ einer ahhnlichen Einschătzung dieser Aussagen kommt Holzhey, M. (2000), S. $46 \mathrm{ff}$.

198 Vgl. hierzu und den folgenden Ausfuhrungen Dickertmann, D. (1998). 
wurde - mehr oder minder explizit - zur gerechteren Anlastung der Infrastrukturkosten innerhalb eines Teils der EU eingerichtet ${ }^{199}$ und entspricht damit schon weitgehend einer supranationalen Grundgebühr für die Infrastrukturnutzung. Da es sich um eine gemeinsame Abgabe der Vertragslănder Deutschland, Dänemark und Benelux - inzwischen auch Schweden - handelte, mußte sichergestellt werden, daß alle Mitgliedsstaaten ,einen gerechten Anteil an den Einahmen aus den Benutzungsgebuhren ${ }^{\prime 200}$ erhalten (der Ausdruck ,gerecht" ist in der Richtlinie zur Erhebung von Maut- und Benutzungsgebühren allerdings selbst nicht năher erläutert). In der Praxis wird das Gebuhrenaufkommen in zwei Teile zerlegt und separat aufgeteilt. ${ }^{201}$ Das Gebührenaufkommen aus den Vertragsländern steht grundsätzlich denjenigen Ländern zu, in deren Gebuhrenstellen es entrichtet wurde. Allerdings wird es in einem bilateralen Ausgleich um die Differenz der im jeweils anderen Land gefahrenen Kilometer korrigiert. Dabei wird so vorgegangen, daß jedes Land die von inländischen Spediteuren in anderen Ländern gefahrenen Kilometer ermittelt. Die Kilometer werden saldiert und diese Größe mit einem durchschnittlichen Kilometerpreis

$\left(\frac{\text { Jahresgebür (1.250 EURO) }}{\text { durchschnittliche Jahresfahrleistung eines LKW }(130.000 \mathrm{~km})}\right)$,

multipliziert. Daraus ergibt sich ein an die „Nettotransitländer" zu zahlender Ausgleichsbetrag. ${ }^{202}$ Er entspricht allerdings nicht den tatsăchlichen Werten, da einerseits der durchschnittliche Kilometerpreis, wie der Name schon sagt, nicht die tatsăchlich gefahrenen Kilometer wiederspiegelt, sondern nur einen Durchschnittswert darstellt. Desweiteren stammten die entsprechenden Fahrdaten für diese Korrektur aus dem Jahr 1992 (also vor der Verkehrsmarktliberalisierung), da danach die Grenzkontrollen abgeschafft wurden und somit eine lückenlose Erfassung grenzüberschreitender Transporte nicht mehr möglich war. Das Zer-

199 Ein weiteres wichtiges Argument fur die Einfuhrung der Autobahngebuhr, wahrscheinlich das wichtigere, war seinerzeit die Notwendigkeit, die Wettbewerbsposition der deutschen Spediteure im Hinblick auf die Verkehrsmarktliberalisierung zu verbessern. Das Ziel einer gerechteren Kostenverteilung war demnach wohl eher vorgeschoben.

Vgl. Eickhof, N. und M. Franke (1994).

200 Eine entsprechende Passage findet sich in Art. 8, Abs. $2 \mathrm{~d}$ der Richtlinie.

201 Vgl. Dickertmann, D. (1998). S. $452 \mathrm{ff}$.

${ }^{202}$ Um die Anzahl der Zahlungsvorgănge innerhalb des bilateralen Ausgleichs zu minimieren, nimmt Deutschland eine Art Clearingfunktion wahr, indem es alle Forderungen und Verbindlichkeiten der Lander gegeneinander in einem Kontensystem erfaßt und die entsprechenden Salden uberweist bzw. einzieht. Zahlungen finden also nur zwischen Deutschland und den anderen Landern statt. Dies bietet sich an, da drei Viertel bis vier Funftel des Gesamtaufkommens aus der Straßenbenutzungsgebuhr Deutschland zustehen, die anderen Vertragsländer gegeneinander also nur geringe Forderungen haben.

Vgl. Dickertmann, D. (1998). S. 458 ff. 
legungsverfahren dürfte daher die tatsächliche Inanspruchnahme der Verkehrsinfrastruktur nur noch sehr grob wiederspiegeln.

Das Gebührenaufkommen aus Drittländern wird nach der Länge des zur Verfúgung gestellten Autobahnnetzes verteilt, wobei ein Korrekturfaktor das relative Transitaufkommen in den einzelnen Ländern berücksichtigt. Länder mit hohem Anteil an Transitverkehr erhalten also mehr, als sich aus ihrem Anteil an Autobahnkilometern ergeben würde. Konkret sind von den Vertragsländern Deutschland und Belgien durch diese Regelung begünstigt. ${ }^{203}$

Abb. 38: Verteilungsschlüssel für das gemeinsame Gebuhrenaufkommen aus Drittlăndern

\begin{tabular}{|l|l|}
\hline Vertragsland & Anteil am Aufkommen (v. H.) \\
\hline Belgien & 13,0 \\
\hline Dånemark & 4,0 \\
\hline Deutschland & 73,0 \\
\hline Luxemburg & 1,0 \\
\hline Niederlande & 9,0 \\
\hline
\end{tabular}

Quelle: Art. 13, Abs. 3 des Übereinkommens uber die Erhebung von Gebühren für die Benutzung bestimmter Straßen mit schweren Nutzfahrzeugen.

BGBI. II 1994, S. 1768-1781.

Es soll nun untersucht werden, ob die Straßenbenutzungsgebuhr und das Verfahren zu ihrer Aufteilung ein geeignetes Instrument wäre, um die Fixkosten der Verkehrsinfrastruktur in Europa zu finanzieren und so die Kfz-Steuer zu ersetzen oder mindestens zu ergänzen.

Die Anforderungen an eine Grundgebuhr innerhalb eines nach außen abgeschotteten Verkehrsmarktes wurde in Kapitel 4.3.1 detailliert dargelegt. Im Ergebnis wurde eine zweistufige $\mathrm{Kfz}$-Steuer, d. h. eine allgemeine $\mathrm{Kfz}$-Steuer plus teils pauschal, teils kilometerabhängig erhobener Schwerverkehrszulage für sinnvoll erachtet. Letztere soll dazu dienen, die gewichtsbedingten Straßenschäden, die durch die größere Belastung durch schwere Fahrzeuge entsteht, diesen auch anzulasten. Auf den ersten Blick scheint die Straßenbenutzungsgebühr für schwere LKW in Verbindung mit den schon existierenden nationalen Kfz-Steuern einer solchen Schwerverkehrszulage zu entsprechen. Dennoch existieren einige wesentliche Unterschiede, deren Relevanz im folgenden diskutiert werden soll.

${ }^{203}$ Vgl. Dickertmann, D. (1998), S. 455. 
Zunächst einmal wird die LKW-Autobahngebühr schon ab einem zulässigen Gesamtgewicht von $12 \mathrm{t}$ erhoben. Wir hatten im entsprechenden Kapitel verlangt, $\mathrm{da} B$ die Schwerverkehrszulage ab demjenigen Gewicht verlangt werden sollte, $a b$ dem bauliche Veränderungen notwendig werden, um strukturelle Schäden durch die höhere Gewichtsbelastung zu vermeiden. Da es sich hierbei um ein eher technisches denn ökonomisches Problem handelt, soll die Frage nach dem Eingangsgewicht hier nicht diskutiert werden, es dürfte allerdings deutlich höher liegen.

Die Tatsache, daß die Hőhe der Schwerverkehrszulage vom Ausbaugrad der StraBe abhăngen muß, wirft allerdings noch ein weiteres Problem auf: In einem abgeschlossenen Staatswesen wurde ein besser ausgebautes Straßennetz erfordern, daß der fixe Teil der Schwerverkehrsabgabe höher anzusetzen ist und im Gegenzug das zulăssige Gesamtgewicht, bei dem die kilometerabhängige Abgabe einsetzen sollte, steigt. Ausbaugrad, Grundgebuhhr und Schwerverkehrszulage sind also simultan zu bestimmende Größen ${ }^{204}$. Diese einfache Rechnung, die allein durch den technisch optimalen Ausbaugrad bestimmt wird, gilt allerdings nicht mehr in einer offenen Ökonomie.

Soll dem Subsidiaritătsgedanken folgend der Ausbaugrad in nationaler Verantwortung verbleiben, kann die einheitliche Schwerverkehrsabgabe dazu fuhren, daß bei geringem Ausbaugrad der Straßen eines Landes die Straßenschäden durch eine am Durchschnitt aller Länder orientierte Schwerverkehrsabgabe nicht mehr gedeckt werden. Es wäre daher zu überlegen, ob der Schlüssel zur Verteilung der Einnahmen nicht zugunsten dieser Staaten zu ändern wäre, so daß sie für die zusătzlichen Schäden kompensiert würden. Eine solche Modifikation der Einnahmenverteilung könnte allerdings zur Folge haben, daß sich ein Land für einen suboptimal niedrigen Ausbaugrad entscheidet, um so die Fixkosten der Infrastruktur zugunsten der Inländer stärker durch die Schwerverkehrszulage zu finanzieren. Eine am Durchschnitt aller Länder orientierte Zulage bietet in einem foderativ organisierten Staat demnach eine - zumindest in dynamischer Hinsicht - bessere Lősung als z. B. ein Verteilungsschlüssel, der einmalig aufgrund des status quo der Infrastrukturausstattung festgelegt wird. Diejenigen Länder, die durch ihren geringen Ausbaugrad mehr Schåden haben, als durch die Abgabe finanziert wird, haben einen Anreiz, ihre Straßen in Zukunft an den tatsächlichen Belastungen auszurichten. Bestenfalls könnte darluber nachgedacht werden, diese Länder für eine Übergangsphase zu kompensieren.

Eine weitere Einschrănkung der LKW-Autobahngebühr ist, wie der Name sagt, daß sie nur für die Nutzung der jeweils höchsten Straßenkategorie des jeweiligen Landes zu zahlen ist. Ersteres ist vor dem Hintergrund des Wunsches einer größe-

204 Eigentlich zahlt auch das zulässige Gesamtgewicht der LKW zu diesen Parametern dazu, da diesbezliglich aber eine EU-weite Einigung erzielt werden konnte, soll dieser Punkt nicht weiter betrachtet werden. 
ren Beteiligung des Transitverkehrs an den Infrastrukturkosten zu verstehen. Eine zusätzliche Schwerverkehrsabgabe im Sinne dieser Arbeit kann diese Einschränkung allerdings nicht mehr zulassen. Da sie generell die zusätzlichen Straßenschäden entgelten soll, die ein schwerer LKW induziert, muß sie für alle Straßentypen gleichermaßen erhoben werden.

Der in der Literatur strittigste Punkt ist die Erhebungsform der Autobahngebühr als Pauschale. Eine Pauschale ist allerdings gerechtfertigt, wenn sie als Grundgebühr furr die Finanzierung der Infrastruktur dient, was bis zu einer gewissen Achslast auch für sinnvoll erachtet wurde. Darüber hinaus sollten, wie schon diskutiert, die gefahrenen Kilometer als Basis dienen. Werden diese einfach am Tachometer ermittelt, ist die oben kritisierte Unterscheidung nach Straßenkategorien nicht mehr möglich, so daß auch dieses Problem wegfällt.

Die Tatsache, daß die LKW-Autobahngebühr zur Zeit noch von einem geringen Teil der EU-Mitgliedsländer erhoben wird, stellt das wohl größte Ausgestaltungsproblem bei der Transformation in eine Schwerverkehrsabgabe dar. Einige Länder, insbesondere Frankreich, Italien und Spanien, haben ein etabliertes System mautfinanzierter Autobahnen. Eine zusätzliche Belastung der Nutzer wäre in diesem kostendeckend angelegten System nicht zu rechtfertigen. Andererseits ist eine Erfassung der in den Vertragsländern gefahrenen Kilometer wegen fehlender Grenzkontrollen ohne elektronische Erfassungsgeräte nicht zu leisten. Hier müßte entweder eine EU-weite Vereinheitlichung der Verkehrsfinanzierung installiert werden, d. h. wahrscheinlich eine Abschaffung der Mautgebühren zugunsten von Steuern oder allgemeinen Straßennutzungsgebuhren, oder die NichtVertragsländer müßten für eine Übergangszeit weiter die Vignettenlösung praktizieren.

Das Grundproblem der Schwerverkehrsabgabe liegt jedoch abseits dieser Ausgestaltungsfragen in der Verteilung der Einnahmen auf die Vertragsländer. Wie schon ausgefuhrt muß dieser Schlüssel die zusätzliche Abnutzung, die der gesamte Schwerverkehr der EU an den Verkehrsanlagen des jeweiligen Landes verursacht, entgelten. Fraglich ist, ob das Verfahren zur Aufteilung der LKWAutobahngebühr, also die Aufteilung nach der Lănge der Straßen höchster Kategorie des jeweiligen Landes, korrigiert um das anteilige Transitvolumen, als hierfür ausreichend gewertet werden kann. Oben wurde schon diskutiert, daß der Ausbaugrad des Straßennetzes als weiterer Korrekturfaktor in die Bewertung eingehen sollte, um damit eine gewisse Vielfalt auch in der Ausgestaltung der Verkehrsinfrastruktur zu ermöglichen. Ein weiteres Problem ist, daß in den seltensten Fällen das gesamte Autobahnnetz für den Transitverkehr in Frage kommt. Es dürften vielmehr nur einige ausgewählte Strecken sein, die für den durchfahrenden Verkehr tatsăchlich in Frage kommen. Je kleiner der Anteil dieser Strecken am gesamten Autobahnnetz ist, desto stärker werden Ausländer relativ zu ihrer 
tatsăchlichen Nutzung von der Schwerverkehrsabgabe betroffen. Da es jedoch kaum möglich scheint, die tatsächlich vom Transitverkehr genutzten Strecken vernünftig abzugrenzen, kann das Autobahnnetz zumindest als Năherungsgroßße gut genutzt werden.

Zusammenfassend sollte die Schwerverkehrsabgabe von jedem einzelnen Mitgliedsland der EU in Form eines festen Betrages als Aufschlag zur Kfz-Steuer erhoben werden. $\mathrm{Ab}$ einer gewissen Achslast ist zusătzlich eine von den gefahrenen Jahreskilometern abhängige Abgabe zu zahlen. Dieser Aufschlag wird dann auf die EU-Mitgliedsländer je nach Länge des Autobahnnetzes verteilt, wobei Korrekturfaktoren eingebaut werden, die das Transitaufkommen mitberücksichtigen. Damit ist ein Minimum an Zentralisierung erreicht: Jedes Land kann weiterhin frei über Ausbaugrad und Höhe der Kfz-Besteuerung bestimmen, lediglich Schwerverkehrszuschläge sind europaweit einheitlich geregelt. Damit ist derjenige Teil der Steuer, der besonders anfällig für Steuerwettbewerb ist, europaweit einheitlich geregelt.

Eine einheitliche Regelung der gesamten $\mathrm{Kfz}$-Besteuerung hătte demgegenüber den Vorteil, daß ein Anreiz der untergeordneten Gebietskörperschaften zur Absenkung der allgemeinen $\mathrm{Kfz}$-Steuer zum Zwecke der Subventionierung der heimischen Transportindustrie außer Kraft gesetzt wäre. Einen dementsprechenden Versuch hatte es mit Mindestsätzen für die Kfz - Steuern innerhalb Europas auch gegeben. ${ }^{205}$ Allerdings hätte diese Maßnahme gegenuber der dezentraleren vorangegangenen Lösung nur geringe Vorteile: Existiert eine allgemeine $\mathrm{Kfz}$-Steuer in Form einer Clubgebuhr für die Infrastrukturnutzung und setzt die vereinheitlichte Schwerverkehrsabgabe auf dieser auf, muß es in der Verantwortung des einzelnen Staates verbleiben, die Höhe der Steuer und damit den Kostendeckungsgrad der Verkehrsinfrastruktur zu bestimmen. Die Europäische Union sollte wenn möglich diesen Aspekt, bei dem es sich letztlich um ein innerstaatliches Verteilungsproblem handelt, nicht leichtfertig dem Verantwortungsbereich der Einzelstaaten entziehen. Da die allgemeine Kfz-Steuer auch den Pkw Fahrern auferlegt wird, ist sie als Instrumentarium im Steuerwettbewerb relativ ungeeignet. Ein Großteil der Zensiten - mindestens die privaten Fahrzeugbesitzer - ist international nicht mobil und weicht der Steuer daher nicht aus. Eine Kfz-Steuer mit einer so breiten Bemessungsgrundlage, die auch immobile Zensiten umfaßt, ist dann kein geeignetes Instrumentarium im Steuerwettbewerb mehr: Den Vorteilen aus der Attrahierung ausländischer Bemessungsgrundlagen durch die Senkung der Steuer steht dann ein Verlust an inländischen Steuern gegenüber, der anders ausgeglichen werden muß. Je geringer die Mobilität der Bemessungsgrundlage ist, desto höher werden diese Verluste ausfallen und desto geringer ist der Anreiz, die Steuer zu senken. ${ }^{206}$

${ }^{205} \mathrm{Vgl.} \mathrm{dazu} \mathrm{S.} 68$.

${ }^{206} \mathrm{Vgl}$. zu diesen Ausfuhrungen Hohaus, B. (1996), S. $70 \mathrm{ff}$. 
Es kann allerdings sinnvoll sein, eine Wettbewerbsregel einzufuhren, um die Entscheidung der Einzelstaaten tatsăchlich auf die innerstaatlichen Aspekte zu beschränken. Hier bietet sich eine Regelung an, die die OECD auch im Rahmen ihres Programmes gegen schädlichen Steuerwettbewerb vorschlug: Ein Land soll solche steuerliche Maßnahmen unterlassen, die gezielt eine bestimmte Gruppe besser stellen als andere Zensiten in gleicher steuerlicher Lage. Damit soll vermieden werden, daß ein Staat die Bemessungsgrundlagen aufteilt, um den mobilen Teil ohne große Einnahmenverluste geringer besteuern zu können als den immobilen. Übertragen auf den Verkehr kann dies bedeuten, daß LKW einer Steuer unterliegen, die nicht niedriger als eine entsprechende Kfz-Steuer fur PKW sein darf. Idealerweise sollten sogar beide Fahrzeuggruppen mit derselben Steuer belegt werden, um von Beginn an steuerwettbewerbliche Elemente bei dieser Steuer zu minimieren. Damit wăre die Bemessungsgrundlage auch entsprechend breit genug, um die „Kosten“ des Steuerwettbewerbs in Form von Steuerausfallen so hoch zu setzen, daß dieser ausbleibt.

\subsection{Die Reduktion der Umweltschåden durch den Straßengüterverkehr innerhalb der $\mathbf{E U}$}

\subsubsection{Probleme innerhalb der Europäischen Union}

Die Finanzierung der Verkehrsinfrastruktur innerhalb der Europäischen Union kann auf einem zumindest in den Grundsătzen existierenden System der Verkehrsbesteuerung aufbauen. Bei der Bekămpfung der schädlichen Umweltwirkungen des Verkehrs - einschließlich der Stauproblematik - gibt es dagegen kaum unionsweite Maßnahmen. Es wurden lediglich - wie oben dargelegt - Mindestsătze für Kraftfahrzeug- und Mineralölsteuern festgelegt. Die Kraftfahrzeugsteuersătze wurden 1999 zusătzlich nach Schadstoffklassen (Euro 0 bis III) differenziert. Eine Differenzierung furr die Schadstoffklassen Euro 0 bis II und besser gilt seit dem 01.04.2001 auch für die oben diskutierte Autobahngebühr. ${ }^{207}$ Ein schon 1996 von der Kommission verfaßtes Grünbuch zu „fairen und effizienten Preisen im Verkehr" und das im Anschluß verfaßte Weißbuch „Faire Preise für die Infrastrukturbenutzung", welches ebenfalls die Umweltproblematik thematisiert, haben dagegen bisher $\mathrm{zu}$ keinen weiteren Handlungen angeregt. ${ }^{208}$

Der Europäische Rat begrenzte im Gegenteil die Straßenbenutzungsgebühren in der Höhe nach oben. Die Obergrenze soll offensichtlich die einzelnen Staaten daran hindern, durch "uberhöhte“ Abgaben den Transitverkehr auszubeuten, wie es sich im entsprechenden Modell als wahrscheinlich herausgestellt hat. Die

207 Bundesministerium fur Verkehr (2001).

208 Vgl. Kommission (1996) und Kommission (1998). 
Richtlinie 1999/62/EG weist damit auf eine Tendenz des Rates zur Limitierung streckenabhăngiger Abgaben hin. Damit entsteht zunăchst ein Gegensatz zur erklärten Absicht der Kommission, die effiziente Steuerung des Verkehrs in stärkerem Maße an der tatsăchlichen Nutzung auszurichten. Offensichtlich kann sich im Rat also derjenige Teil der Länder durchsetzen, der weniger stark vom Transitverkehr betroffen ist und daher von niedrigeren streckenbezogenen Gebuhren profitiert. Ein vermehrter Einsatz von Straßenbenutzungsgebühren scheint auf absehbare Zeit im Rat nicht durchsetzbar zu sein.

Die Europäische Kommission ist damit zum gegebenen Zeitpunkt weit entfernt von ihren ehrgeizigen Plänen, ab 2001 Nutzergebühren in Höhe der sozialen Grenzkosten des Verkehrs einzufuhren, wie sie es im entsprechenden Weißbuch ankündigt. ${ }^{209}$ Auch hier scheint also die Notwendigkeit zu bestehen, statt der vorgesehenen Harmonisierungsmaßnahmen dezentrale Lösungen anzustreben, um den unterschiedlichen einzelstaatlichen Interessen gerecht $\mathrm{zu}$ werden und die Handlungsblockade zu umgehen. Kritisch hieran ist allerdings, daß solche Maßnahmen immer auf die gegensătzlichen Interessen von Transitstaaten und Staaten in Randlage treffen müssen. Letztere haben keine Vorteile aus der Internalisierung der sozialen Kosten in den Transitländern und werden daher versuchen, die Implementierung verkehrssteuernder Instrumente zu unterbinden. Eine Diskussion uber Verkehrslenkung in einer Föderation wird daher weniger von allokativen Argumenten als vielmehr von Verteilungsaspekten geprägt sein. Jede Politikempfehlung muß dieses in der Natur der Sache liegende Dilemma anerkennen und mit berucksichtigen. Eine einfache Dezentralisierung der Maßnahmen zur Bekămpfung umweltpolitischer Folgen des Verkehrs, wie sie ökonomisch naheliegen mag, ist somit nicht ohne weiteres möglich ${ }^{210}$ : Peripher gelegene Staaten könnten einseitig getroffene Regelungen der Transitländer jederzeit mit dem „Binnenmarktargument" kippen, Transitländer dagegen haben ublicherweise nur wenig Verständnis für den Transportbedarf der „Randstaaten“ und werden diesen für sie nachteiligen Transit zu verhindern suchen.

Typisch für diese stăndig wechselnden Versuche einzelner Lănder inmitten der EU, den Transitverkehr zu begrenzen und ihrer Nachbarn, diese Reduktion wieder aufzuheben sind die bilateralen Vertrăge zwischen der Schweiz und der Europăischen Union und der Dauerstreit der EU mit Österreich um den Brennertransit.

Der Schweizer Fall begann Dezember 1992 mit der Ablehnung eines EU-Beitritts seitens der Eidgenossen. ${ }^{211}$ Um die mit der Nichtteilnahme am Binnenmarkt ver-

209 Vgl. Kommission (1998).

210 Diese Maßnahmen würden vermutlich in vielen Fallen dem Grundsatz der Nichtdiskriminierung widersprechen, da es sich faktisch kaum vermeiden laßt, z. B. bei Fahrverboten Ausländer schlechter zu stellen als Inländer.

211 Vgl. zu den folgenden Ausfuhrungen EDA/EVD (2000). 
bundenen negativen Folgen abzumildern, nahm die Schweizer Regierung Verhandlungen mit der Europåischen Union auf, um dennoch einige Erleichterungen im wirtschaftlichen Verkehr mit den EU-Staaten zu erhalten. Die Union ihrerseits hatte geringes Interesse an Verträgen, die der Schweiz einseitig Vorteile verschafften und war daher von Beginn an auf die Wahrung ihrer Interessen bedacht. Eine dieser „Kröten“, die die Schweiz in diesem Zusammenhang entsprechend den Vorstellungen der Europäischen Union zu schlucken hatte, war die Öffnung des Alpentransits für schwere LKW nach EU-Norm. Dieser Teil der bilateralen Verträge, das Landverkehrsabkommen, war wohl maßgeblich daran beteiligt, daß der gesamte Verhandlungsprozeß bis 1998, also in etwa sechs Jahre, dauerte. Der gesamte Prozeß war von ständigem Widerstand der Schweizer Bevölkerung begleitet, die mit mehreren Initiativen die befurchtete Zunahme des Verkehrs zu unterbinden versuchten. Ein Kompromiß wurde schließlich mit der begleitenden Einführung einer sogenannten „Leistungsabhängigen Schwerverkehrsabgabe“ und dem massiven Ausbau der Eisenbahnstrecken zur sogenannten „Neuen Eisenbahn-Alpentransversale (NEAT)" gefunden.

Der Abschluß der Verträge stellt allerdings noch nicht das Ende des Streites um den Alpentransit dar. Die Schweiz hat zur Umsetzung der Verträge ein „Verkehrsverlagerungsgesetz" beschlossen, welches zusätzlich die Einfuhrung sogenannter "flankierender Maßnahmen" enthielt, mit denen das schnelle Wachstum des Straßengüterverkehrs abgefedert werden sollte. Diese bestehen straßenseitig in der Intensivierung der Schwerverkehrskontrollen, der Kontrolle der Arbeitsbedingungen des fahrenden Personals sowie der Einfuhrung von Mindestgeschwindigkeiten auf Gebirgsstrecken. ${ }^{212}$ Das verladende Gewerbe in der Europäischen Union befüchtet nun, daß dieses Maßnahmenpaket genutzt werden soll, um durch die höhere Kontrollintensität einen Abschreckungseffekt zu erzeugen und damit - entgegen den Vereinbarungen des Landverkehrsabkommens - den Transitverkehr weiterhin zum Umweg über Österreich und Frankreich zu zwingen. ${ }^{213}$ Daß diese Befürchtungen nicht völlig aus der Luft gegriffen sind, zeigt das Beispiel Österreichs, welches im folgenden kurz erläutert werden soll.

Österreich hatte im Jahre 1989 einen Antrag auf Beitritt zur Europäischen Union gestellt. Dieser Beitritt erfolgte am 01.01.1995. Der Zeitraum dazwischen war mit langen Verhandlungen ausgefullt, die zum nicht geringen Teil durch die unterschiedlichen Auffassungen bezüglich der Verkehrsentwicklung geprägt waren. Österreich hatte zum Zeitpunkt des Beitrittsantrages sowohl den Transit-, als auch den bilateralen Verkehr mengenmäßig limitiert, was insbesondere auf die Kritik

${ }^{212} \mathrm{Vgl}$. Art. 6 des Bundesgesetzes zur Verlagerung von alpenquerendem Güterverkehr auf die Schiene (Verkehrsverlagerungsgesetz) vom 08.10.1999. Abgedruckt im Bundesblatt Nr. 42 vom 26. Oktober 1999, S. $8728 \mathrm{ff}$. [http://www.admin.ch/ch/d/ff/1999/index0_42.html].

$213 \mathrm{Vgl}$. BGL (2000c). 
der suldlichen Mitgliedsländer Italien und Griechenland stieß. ${ }^{214}$ Die Europăische Union strebte daher ein Transitabkommen mit Österreich an, um die entstandenen Behinderungen abzumildern.

Wesentlicher Bestandteil des Vertrages war das sogenannte „Ökomodell“, mit welchem die Union eine generelle Deckelung des Transitvolumens zu verhindern suchte. Das Modell orientiert sich dabei am Ausstoß an Stickoxiden, die nach allgemeiner Überzeugung wesentlich für das befürchtete - Waldsterben sind. Aufgrund der verfugbaren Statistiken wurde der Ausstoß für das Jahr 1991 errechnet. Laut Vereinbarung ${ }^{215}$ sollen die so ermittelten Stickoxidemissionen bis 2003 auf $40 \%$ des Ausgangswertes reduziert werden. Wird in einem Jahr der Ausgangswert von 1991 um mehr als $8 \%$ überschritten, reduzieren sich die zulässigen Emissionen für die Folgejahre entsprechend. Die Verwaltung der zulăssigen Transitfahrten erfolgt über das sogenannte „Ökopunktesystem“, nach dem jeder LKW entsprechend seiner Umweltklassifizierung für Transitfahrten Ökopunkte erwerben muß. Nach anfanglichen Unstimmigkeiten bezliglich der Interpretation der Verträge, die allerdings im Zuge der Beitrittsverhandlungen beseitigt wurden, funktionierte das Ökopunktesystem sehr gut. Dies hing allerdings auch damit zusammen, daß rezessionsbedingt 1993 und 1994 weniger Fahrten durchgefuhrt wurden, als ursprünglich angenommen.

Dieses Transitabkommen stellte bei den Beitrittsverhandlungen ein Problem dar: Während die Kommission der Auffassung war, daß es in wesentlichen Punkten gegen Gemeinschaftsrecht verstieß, insbesondere bezüglich des österreichischen zulăssigen Gesamtgewichts (38 t), des Systems der Straßenverkehrsabgaben und der Kontrolle der Ökopunkte an der Grenze, bestand Österreich auf die Übernahme des Transitvertrages in den Beitrittsvertrag. Dies jedoch hätte ein Abgehen von der ublichen Verfahrensweise bedeutet, nach der jedes Beitrittsland sich zur Übernahme des aquis communautaire, des Rechtsbestandes der Gemeinschaft verpflichtet. Diesen Präzedensfall wollte die Union auf alle Fălle vermeiden. Während ihr dies bei den meisten strittigen Aspekten, insbesondere der Höhe der Straßenbenutzungsgebühren und dem zulässigen Höchstgewicht gelang, konnte Österreich eine Fortfuhrung des Ökopunktesystems im Alpentransit durchsetzen.

Mit dem Anziehen der Konjunktur in 1995, verbunden mit der vertragsgemäßen Absenkung der österreichischen Straßenbenutzungsgebuhr, stieg die Anzahl der Transitfahrten merklich an. Die Regierung versuchte dann, der wachsenden Unzufriedenheit der Anrainer mit deutlichen Anhebungen der Brennermaut Mitte 1995 und Anfang 1996 zu begegnen. Dies wiederum wurde von der Europåischen

214 Vgl. hierzu und zu den folgenden Ausfuhrungen Brandt, E. und P. Schăfer (1996).

$215 \mathrm{Vgl}$. Abkommen zwischen der Europalischen Wirtschaftsgemeinschaft und der Republik Österreich uber den Guterverkehr im Transit auf der Schiene und der Strasse. Amtsblatt L 373 vom 21.12.1992 S. 6 - 24 [http://europa.eu.int/eur-lex/de/lif/dat/1992/de_292A1221_01.html]. 
Kommission als Vertragsverletzung interpretiert und vor den Europäischen Gerichtshof gebracht. Auch hier sah es zunächst nach einem Teilerfolg für Österreich aus, da die Kommission in einem Kompromiß die Brennermaut sowie deren Höhe bestätigte und nur bemängelte, daß sie nicht für die gesamte Autobahn, sondern nur für einen kleinen Teilabschnitt verlangt wurde. ${ }^{216}$ Würde Österreich dies ändern, könnte die Klage zurückgezogen werden. Dies ist allerdings bis jetzt noch nicht in ausreichender Weise geschehen, so daß eine Entscheidung des EuGH in dieser Frage aussteht.

Die steigende Konjunktur hat auch die Ökopunkte merklich verknappt. Schon 1999 haben sie am Jahresende zu Engpässen gefuhrt. Durch Anwendung der 108 \% Regel erhält die Bundesrepublik im Jahr 2000 3.650.484 statt 3.804.420 Punkte, also $4 \%$ weniger als die ohnehin knappen Punkte in 1999. Dies fuhrt wohl im Jahr 2000 noch nicht zu einer Reduktion der Fahrten uber die Alpen, hat aber zumindest einen Streit über die Verteilung der Ökopunkte an die einzelnen europäischen Staaten gefuhrt. ${ }^{217}$ Wird die von Österreich geforderte Reduktion voll durchschlagen, können allerdings schon nächstes Jahr ernsthafte Engpässe auftreten.

Neben diesen Argumenten versucht Österreich, ähnlich den „flankierenden Maßnahmen" in der Schweiz, den Alpentransit zusätzlich durch Erhöhung der Kontrolldichte zu erschweren. So beklagen sich Transportverbände uber Fahrzeugkontrollen an den Grenzen, die zu erheblichen Verzögerungen im Transit fuihren. ${ }^{218}$

Deutschland als weiteres Transitland hat sich bisher solcher Maßnahmen weitestgehend enthalten. Lediglich die hohe Kontrolldichte könnte in eine ähnliche Richtung gedeutet werden. Es ist allerdings zu vermuten, daß ein weiteres Ansteigen des Transitverkehrs z. B. durch den Beitritt der mittel- und osteuropäischen Staaten, den Druck auf die Politik ebenfalls erhöht und nationale Alleingänge provoziert.

Alles in allem kann die Situation bezüglich der umweltpolitischen - also fahrwegsabhängigen - Maßnahmen nur als unbefriedigend bezeichnet werden. Die naturgegeben gegensätzlichen Interessen der einzelnen Staaten sind durch die Re-

${ }^{216}$ Vgl. Kraus, D. (1998). [http://www.zis.at/zis/eu511.html].

Die Gebuhr wurde deshalb fur einen Teilabschnitt verlangt, weil sie die im Inntal gelegenen Unternehmen nicht uber Gebuhr belasten sollte. Dies jedoch wurde von der Kommission als mittelbare Diskriminierung angesehen, da die Beschränkung auf einen kleinen Teilabschnitt zwar nicht juristisch, aber faktisch zu einer Benachteiligung ausländischer Transporteure fuhrt.

217 Vgl. BGL (2000a). Schon 2000 können vereinzelt deutsche Spediteure nicht mit Ökopunkten ausgestattet werden, wăhrend andere Lănder uber ausreichend Reserven verfügen.

218 Vgl. BGL (1999). 
gelungen der Europäischen Union - insbesondere die Wegekostenrichtlinie ${ }^{219}$ - in nur unzureichender Weise in Übereinstimmung gebracht worden. Vor allem die Transitländer sehen sich durch die restriktive Handhabung der Obergrenzen gegenuber der Peripherie benachteiligt und suchen nach Moglichkeiten, die Richtlinien zu umgehen. Die Kommission ihrerseits legt den Schwerpunkt weiterhin auf den ungestörten Binnenverkehr und versucht, nationale Alleingänge zu unterbinden. Sie geht dabei zunehmend auch zur Harmonisierung ordnungspolitischer Maßnahmen uber, mit denen die Transitstaaten zuletzt versucht hatten, die Folgen des Verkehrswachstums abzumildern. 1998 wurde ein Vorschlag zur Harmonisierung der Bestimmungen über Fahrverbote für Nutzfahrzeuge im grenzüberschreitenden Verkehr ${ }^{220}$ sowie Vorschläge zur Harmonisierung der technischen Überwachung von schweren Nutzfahrzeugen ${ }^{221}$, die z. Zt. in Europa beide deutlich unterschiedlich gehandhabt werden, eingebracht. Damit werden jedoch nahezu alle Möglichkeiten der einzelnen Staaten, eigene verkehrspolitische Vorstellungen zu entwickeln, verbaut.

\subsubsection{Eine alternative Losung}

Wir haben im vorigen Abschnitt gesehen, daß die umweltpolitischen Aspekte des Straßengütertransits innerhalb der Europäischen Union bisher großteils unter Hinnahme eines gewissen Dissenses geregelt wurden. Die ausgehandelten Kompromisse sind daher recht labil und bedürfen ständig neuer Korrekturen und Klärungen. Sie leiden unter den Versuchen der Betroffenen, die Regelungen zu ihren Gunsten auszulegen und damit zu unterminieren. Das Dilemma sei kurz anhand einer Grafik erläutert:

In der unten folgenden Darstellung sind die Nutzen und die Kosten einer Fernstraße dargestellt. Der Nutzen einer (neuen) Straße besteht in der Möglichkeit, einige Orte schneller erreichen zu können als es ohne diese möglich gewesen wäre. Dieser Nutzen nimmt mit zunehmender Entfernung von der Fernstraße ab, da ein gewisser Aufwand betrieben werden muß, um zu dieser Verbindung zu gelangen. Bei den Kosten der Fernverbindung handelt es sich um die Umweltschäden, die durch Nutzung dieser Straße entstehen. Typischerweise steigen diese Kosten mit abnehmender Entfernung uberproportional an. Der Grund hierfü ist in der Dominanz lokaler Externalităten, insbesondere Lärm und Abgase zu suchen.

In der Darstellung laßßt sich erkennen, daß der Nettonutzen einer Fernanbindung, d. h. die Differenz zwischen Nutzen und Kosten, der in obiger Darstellung gestri-

219 Richtlinie 99/62/EG des Rates vom 17.06.1999, veroffentlicht im Amtsblatt L 187 vom 20.07.1999.

220 Vgl. Vorschlag der Kommission KOM(98) 115 endg., Amtsblatt C 198 vom 24.06.1998.

221 Vgl. Vorschlag der Kommission KOM(98) 117 endg., Amtsblatt C 190 vom 18.06.1998 sowie Geänderter Vorschlag KOM(99) 458 endg., Amtsblatt C 116E vom 26.04.2000. 
chelt eingezeichnet wurde, mit abnehmender Entfernung zur Straße zunächst zunimmt. $\mathrm{Ab}$ einem bestimmten Punkt kehrt sich diese Entwicklung jedoch um und mündet letztlich in einem negativen Nettonutzen entlang des Fahrweges. Das entstehende Dilemma ist, daß zwar der Gesamtnutzen (die Flăche unter der Nutzenkurve) größer ist als die entsprechenden Gesamtkosten über den gesamten Raum, daß lokal, also nahe der Fernverkehrsverbindung, aber das Gegenteil der Fall ist.

Abb. 39: Rüumliche Verteilung von Kosten und Nutzen einer Fernstraße

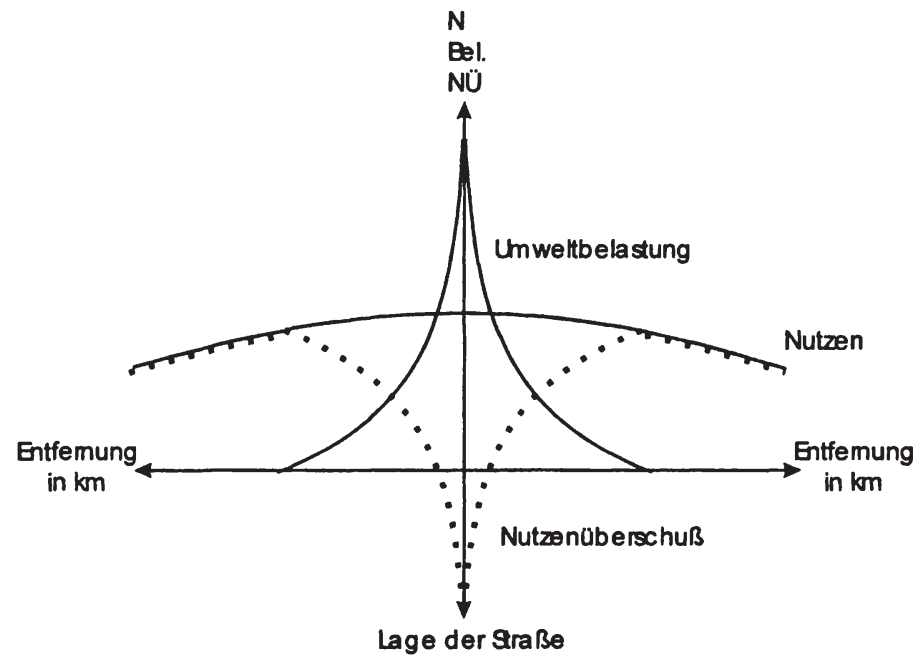

Quelle: Eigene Darstellung, angelehnt an Wink, R. (1995), S. 39.

Aus ökonomischer Sicht, d. h. bei Maximierung der Gesamtwohlfahrt des jeweiligen Landes wăre nun naheliegend, eine derartige verkehrspolitische Maßnahme dennoch durchzufuhren. Die lokal Betroffenen sehen das anders. Was von theoretischer Seite - und auch von der jeweiligen Entscheidungsinstanz - oftmals übersehen wird: Sie tun dies zu Recht, da für sie die Kosten der Maßnahme überwiegen. ${ }^{222}$ Solche Güter, von deren Bereitstellung eine Mehrheit profitiert, die jedoch von den Betroffenen vor Ort vehement abgelehnt werden, werden in der Literatur auch als locally unwanted land uses (LULU's) oder not-in-mybackyard - Güter (NIMBY's) bezeichnet.

Das hier dargestellte Dilemma kann einen wesentlichen Teil der Verhandlungen zwischen der Europäischen Union und den Alpentransitstaaten erklăren. Keine der beiden Seiten konnte - oder wollte - die Position des Gegenübers anerkennen. Die Kommission auf der einen Seite pochte auf die Notwendigkeit eines funktionie-

222 Vgl. z. B. Inhaber, H. (1992), S. 56. 
renden Alpentransit, womit sie offensichtlich Gesamtnutzen und -kosten der Anbindung Sudeuropas im Blickfeld hatte. Österreich und die Schweiz dagegen beharrten auf der Notwendigkeit zur Reduktion eben dieses Transitverkehrs, was aus der Betrachtung der für sie relevanten Kosten und Nutzen auch sinnvoll erschien. $\mathrm{Da}$ die Stabilităt der erzielten Einigungen immer auch von der Akzeptanz durch die Verhandlungspartner abhăngt, spielt dieses gegenseitige Unverstăndnis eine wesentliche Rolle bei der Beurteilung der Transitvertrăge.

Ein effizientes System zur Internalisierung der entstehenden Umweltschäden kann also nicht einfach an einem bestimmten Punkt im Kontinuum zwischen Zentralismus und Föderalismus angesiedelt werden. Zentral für den Erfolg umweltpolitischer Ansätze ist vielmehr, daß alle politischen Ebenen ihre Interessen in ausreichendem Maße berücksichtigt finden. Anders gesagt: In diesem Fall kann der politische Kompromiß gleichzeitig die ökonomisch sinnvolle Lösung sein.

HART und POMMEREHNE haben versucht, die Bedingungen für eine erfolgreiche Implementierung solcher locally unwanted land uses aufzuzeigen. ${ }^{223}$ Ein Kennzeichen des Transit oder auch des Verkehrs generell ist, wie bei anderen LULU's auch, daß grundsătzlich zwei Entscheidungen zu treffen sind. Die erste betrifft die Art und Weise, wie sich die Wirtschaft innerhalb eines Landes, einer Föderation oder sogar weltweit răumlich organisiert, mit anderen Worten wie transportintensiv bestimmte Güter hergestellt werden und welche Güter an einem bestimmten Ort überhaupt zur Verfügung gestellt werden können. Die zweite Frage handelt davon, wer die Belastungen, die aus diesem Verkehr resultieren, tragen muß.

Das Dilemma hierbei ist die unterschiedliche Natur der Entscheidungen. Die erste stellt die Lősung eines Effizienzproblems dar: Bis zu welcher Verkehrsmenge kann der Wohlfahrtsgewinn zusätzlicher Transporte - in Form kostengünstig hergestellter oder neu verfugbarer Güter - die dadurch entstehenden internen und externen Kosten des Güterverkehrs überkompensieren? Die zweite Entscheidung ist dagegen distributiv: Welcher Verkehrsträger soll zum Transport der Güter herangezogen werden? ${ }^{224}$ Wo soll der eventuell entstehende zusätzliche Straßenverkehr fahren?

In der zweiten Stufe wird also entschieden, welche Region die notwendigerweise anfallenden (externen) Kosten zusätzlicher Transporte zu tragen hat.

CALABRESI und BOBBIT haben diese Form der Entscheidung mit dem Begriff ,tragisch" belegt. ${ }^{225}$ Tragisch deswegen, weil nach Entscheidung der allokativen Fragestellung ein reines Verteilungsproblem zu lösen ist. Die Art und Weise, wie sich

223 Vgl. Hart, A. und W. W. Pommerehne (1994).

${ }^{224}$ Diese Frage ist nicht rein distributiver Natur, da sie - wie oben dargelegt - auch einen wesentlichen Einfluß auf die Kosten hat.

225 Vgl. Hart, A. und W. W. Pommerehne (1994), S. 194. 
Betroffene bei diesem Zuteilungsverfahren behandelt fuhlen, also die Fairness des Verfahrens, ist dabei entscheidend für deren Zustimmung oder Ablehnung und damit letztlich für das erfolgreiche Funktionieren des Verkehrssystems.

Fairness selbst ist jedoch ein wenig brauchbarer, weil unbestimmter Begriff. Das Kriterium „Fairness“" muß nach POMMEREHNE und HART daher in weitere Kategorien zerlegt werden. ${ }^{226}$ Als erste ist Kriterienfaimess zu nennen, also die Überzeugung der Betroffenen, bei der Festlegung von Gewichten für die einzelnen Auswahlkriterien fair behandelt worden zu sein. Es handelt sich also mit anderen Worten um Chancengleichheit z. B. bei der Art der Trassenwahl. Eine weitere Unterkategorie ist Ergebnisfairness. Diese beurteilt die relative Position der Betroffenen vor und nach der Entscheidung. Wird zum Beispiel eine Verkehrsverbindung durch eine relativ arme Region gelegt, kann das Ergebnis selbst dann als unakzeptabel gelten, wenn diese Region die ihr entstandenen Schäden, z. B. durch Mautgebühren, entgolten bekommt. Sie wird dann zwar nicht absolut schlechter gestellt als ohne diese Maßnahme, verschlechtert jedoch ihre relative Position zu anderen, reicheren Regionen, die einen Nutzen aus dieser Verkehrsverbindung ziehen. Die Trasse könnte also als ungerecht empfunden werden, obwohl die Betroffenen absolut gesehen keine Verschlechterung erfahren. Als letztes Kriterium wird Verfahrensfairness genannt. Unabhängig vom Ergebnis einer Entscheidung kann diese auch abgelehnt werden, wenn die Betroffenen die Art und Weise, wie diese zustandegekommen ist, nicht akzeptieren. Letztere wird von HART und POMMEREHNE auch als Fairness im engeren Sinne bezeichnet, da sie sich nicht mehr rational begrindet, sondern nur noch in einer unbestimmten Abneigung gegenuber bestimmten Vorgehensweisen besteht.

Um eine befriedigende und stabile Lősung umweltpolitischer Probleme im europäischen Verkehrssektor zu erzielen, ist eine Beachtung dieser Fairneßkriterien bei Entscheidungen unerläßlich. Dies ist beim grenzüberschreitenden Straßengüterverkehr allerdings keineswegs unkompliziert. Dies zeigt sich schon bei Betrachtung der Kriterienfaimeß. Der Verlauf der Transitstrecken ist faktisch auf wenige Routen limitiert. Die Benachteiligung bestimmter Regionen ist damit praktisch vorgegeben und kann kaum Gegenstand politischer Diskussion werden.

Die Ergebnisfairneß dagegen kann als entscheidender Punkt beim Transitverkehr gelten. $\mathrm{Da}$, wie in obiger Zeichnung dargestellt, Nutzen und Kosten des Güterverkehrs răumlich unterschiedlich streuen, ist eine Schlechterstellung der Transitregionen ohne weiteres möglich, wenn nicht wahrscheinlich. Hier liegt ein wesentliches Problem der traditionellen Nutzen-Kosten-Analyse: Die tatsächlichen Nutzen und Kosten des Straßenguterverkehrs sind - wie ausführlich im 2. Kapitel dargestellt - ökonomisch nur schwer zu ermitteln und in ihrer Höhe stark

${ }^{226}$ Vgl. Hart, A. und W. W. Pommerehne (1994), S. 195 ff. 
von der angewandten Meßmethode determiniert. Damit ergibt sich das Problem, $\mathrm{da} \beta$ aufgrund von Expertendiagnosen ein Ausmaß an Verkehrsaufkommen erzeugt werden kann, welches volkswirtschaftlich unsinnig ist. Dieses „zu hohe“ Verkehrsaufkommen wuirde sich vermutlich auch in einem politischen Abstimmungsprozeß durchsetzen, da die wichtigen Transitländer - im wesentlichen Deutschland und Österreich - in der Europăischen Union in der Minderheit sind. Wird dagegen eine tatsächliche Entschädigung angestrebt, kann dieser Fall nicht eintreten. Voraussetzung dafur ist jedoch, daß die Höhe der Kompensationszahlungen nicht zentralistisch festgelegt wird. Vielmehr mulssen die Geschădigten selbst entscheiden können, welche Höhe ihre Entschädigungsforderungen haben sollen, damit die gefundene Lösung stabil ist. Dies kann natürlich in hohen Zahlungen münden, wenn die entsprechenden Länder eine eventuell vorhandene Monopolstellung ausnützen. Allerdings dürfen nicht alle Preise, die die tatsächlichen gesellschaftlichen Kosten ubersteigen, mit Monopolpreisen gleichgesetzt werden. Werden reine Entschädigungszahlungen vorgenommen, verbleibt der Netto-Wohlfahrtsgewinn des Transports ausschließlich beim Produzenten, respektive Konsumenten der transportierten Waren. Dies muß allerdings nicht als fair empfunden werden. Oben wurde schon kurz angerissen, daß damit eine relative Verschlechterung des Transitlandes verbunden sein kann, die zu einer Ablehnung des Verhandlungsergebnisses führt. Preise, die über diesen Entschădigungszahlungen liegen, können damit einfach auch Ausdruck einer anderen Verteilung des Wohlfahrtsgewinnes aus dem zusätzlichen Güteraustausch sein. Das Transitland hat dann z. B. die Möglichkeit, die empfangenen Mittel in Verkehrsinfrastruktur zu investieren, um über andere Verkehrsträger, z. B. Eisenbahnen, oder aufwendigere Transitbauten, z. B. Tunnel, eine Entlastung der betroffenen Anwohner herbeizufuhren, ohne den Verkehr grundsătzlich zu unterbinden. Bekommt das Land lediglich die anfallenden Schäden ersetzt, können diese in der Regel ăußerst kostspieligen Investitionen eventuell nicht finanziert werden und der Transitstaat wird sich gegenüber dem Verkehr insgesamt ablehnend verhalten.

Die bisher in diesem Kapitel ausgefuhrten Sachverhalte lassen sich wie folgt zusammenfassen: Kosten und Nutzen des Straßenguterverkehrs fallen zum großen Teil nicht in denselben Regionen an. Zusätzliche Transporte erzeugen also Nettogewinner und -verlierer innerhalb der Europäischen Union. Die Quantifizierung dieser Salden ist allerdings durch die Probleme bei der Messung von externen Kosten des Verkehrs und der Wohlfahrtseffekte abnehmender Transportkosten mit großen Unsicherheiten behaftet. Allgemein akzeptierte Werte existieren nicht. Es ist demnach zum einen schwierig, von außen kommend eine geeignete Entscheidungsebene festzulegen, die von allen Parteien akzeptiert werden kann, zum anderen läßt sich weder Instrument noch Ausmaß der Verkehrssteuerung eindeutig bestimmen. Es muß also ein Instrumentarium gefunden werden, welches die Unbestimmtheit der genannten Situation handhabbar macht. Zu klären ist dem- 
nach nicht das genaue Steuerungsverfahren, sondern die Art und Weise, wie die Eigentumsrechte zwischen den einzelnen Gebietskörperschaften verteilt werden.

Als Methoden zur Lősung dieses Zuweisungsproblems werden in der neueren Literatur zu NIMBY-Gütern meist Aushandlungsverfahren ${ }^{227}$ vorgeschlagen. Diese zeichnen sich im Vergleich zu den sogenannten Schiedsspruchverfahren, zu denen beispielsweise die Nutzen-Kosten-Analyse zählt, dadurch aus, daß grundsätzlich von Seiten der Gemeinschaft kein Anspruch auf Durchsetzung des Transits besteht. Das Recht der einzelnen Staaten geht hier also über Gemeinschaftsrecht. Damit kann natürlich im Gegensatz zum Schiedsspruch auch die Nichtübereinkunt Ergebnis des Abstimmungsprozesses sein.

Zwei Arten von Aushandlungsverfahren sind üblich: Bilaterale Verhandlungen und Auktionen. Bei ersteren wird dem in Frage kommenden Transitstaat sein Recht auf Ablehnung des Durchgangsverkehrs quasi abgekauft. Dies entspricht in gewisser Weise den Verhandlungen mit der Schweiz, bei der die Schweiz als Gegenleistung für den Alpentransit sowohl direkte finanzielle Zugeständnisse in Form von Kilometerabgaben also auch Erleichterungen in anderen Politikfeldern erhielt. Auch Österreich hatte mit der Europäischen Union diesbezüglich verhandelt, konnte aber aufgrund seiner schwächeren Ausgangsposition - der Beitritt war oberstes Ziel - kein entsprechendes Ergebnis erzielen. Dies auch deswegen, weil Verhandlungslösungen im Konzept der Europäischen Union, die grundsätzlich die Übernahme des aquis communautaire für Beitrittskandidaten vorsieht, keine Rolle spielen.

Bilaterale Verhandlungen unterliegen stets dem Risiko strategischen Verhaltens einer Vertragspartei. So kann ein Transitland seine eventuell vorhandene Monopolmacht ausnutzen, um uberhöhte Forderungen $z \mathrm{zu}$ stellen und damit eventuell den gesamten Prozeß blockieren. Diese Lősung ist ökonomisch nicht zu rechtfertigen. Verhandlungen können tatsächlich also nur in Ausnahmefällen als Möglichkeit zur Lösung des Transitproblems führen. Als alternatives Instrument bei LULU-Anlagen werden daher in der Literatur Auktionen vorgeschlagen. Diese können natürlich die Ausgangslage - also einen oder wenige Anbieter und/oder Nachfrager - nicht ändern. Auktionen haben jedoch den Vorteil, daß sie durch Selbstbindung des Auktionators eine Indeterminiertheit des Verhandlungsergebnisses, welches auch ein Scheitern als Möglichkeit enthält, vermeiden. 228

Genauer gesagt ist der wesentliche Unterschied zwischen Verhandlungen und Auktionen, daß sich der Veranstalter der Auktion vor Beginn auf einen bestimmten Satz von Regeln festlegt, welcher den Bietern bekannt ist und der nach Abga-

227 Vgl. Hart, A. und W. W. Pommerehne (1994), S. 199.

228 Vgl. McAfee, R. P. und J. McMillan (1987), S. 703. 
be der Gebote nicht geändert werden kann. Die Regeln können allerdings vom Verkăufer so festgelegt werden, daß er die gesamte Zahlungsbereitschaft der Nachfrager abschöpft. Dies ist jedoch kein allokatives Problem, sondern distributiver Natur. Wie zu zeigen sein wird, läßt es sich zudem durch die Wahl bestimmter Auktionsformen abmildern. Das eigentliche Problem bei der Auktion von Transitgenehmigungen ist jedoch nicht der Preis der Einheiten, sondern die gehandelte Menge. Im Vorfeld der Auktion muß sichergestellt werden, daß eine bestimmte Anzahl von Fahrten garantiert ist, d. h. der ,monopolistische Transitanbieter" seine Angebotsmenge nicht unter ein Mindestma $\beta$ absenken kann. Eine Lösung dieses Problems soll nach der Einfuhrung in die Auktionstypen diskutiert werden.

Als Auktions-Grundmodelle lassen sich vier Typen unterscheiden, von denen zwei offen und zwei verdeckt stattfinden. Bei den offenen Varianten handelt es sich um die englische und die hollăndische Auktion. Bei der englischen Auktion, der wohl bekanntesten Variante, erhöht der Auktionator ausgehend von einem niedrigen Reservationspreis solange den Preis, bis er kein weiteres Gebot erhält. Der Zuschlagspreis entspricht demnach dem Gebot des letzten Bieters. Da dieser jederzeit uber die Gebote der Konkurrenten informiert ist, liegt der Preis marginal über der Zahlungsbereitschaft des năchstniedrigen Bieters.

Die holländische Variante verläuft im Prinzip ähnlich, allerdings umgekehrt: Der Auktionator geht von einem bestimmten Preis aus und senkt ihn so lange ab, bis sich ein Abnehmer findet. Im Unterschied zur englischen Variante wird also beim ersten Gebot die Auktion beendet. Die holländische Auktion verlăuft, da nur einmal geboten wird, deutlich schneller ab als die englische. ${ }^{229}$ Ein weiterer Unterschied ist, daß der erste Bieter in Unkenntnis uber die Zahlungsbereitschaft der Mitbieter bleibt. Er muß diese schătzen und dabei einen trade-off zwischen hoher Gewinnwahrscheinlichkeit und hoher Rente in Kauf nehmen.

Die andere Klasse von Auktionen sind sogenannte verdeckte (,sealed“) Auktionen, in denen jeder Bieter ein einziges Gebot abgibt, ohne dabei die Gebote der anderen zu kennen. Sie werden nochmals in sogenannte Auktionen zum höchsten Gebotspreis („first-price Auktionen") und Auktionen zum zweithöchsten Gebotspreis (,second-price Auktionen") unterschieden. In ersten gewinnt der Bieter mit dem höchsten Gebot, welches gleichzeitig als Preis zu zahlen ist. Wie bei der holländischen Auktion auch kennt der Bieter die Angebote der anderen nicht und muß den genannten trade-off beachten.

Im zweiten Fall, auch Vickrey-Auktion genannt, gewinnt der gleiche Bieter wie bei first-price Auktionen, er muß jedoch einen Preis nur in Höhe des zweithöch-

229 Vgl. Inhaber, H. (1998), S. 46 f. 
sten Gebotes zahlen. ${ }^{230}$ Damit entfällt der trade-off zwischen Gewinnwahrscheinlichkeit und Rente, ein Angebot unterhalb der eigenen Zahlungsbereitschaft ist bei diesem Typ also nicht sinnvoll, da es die Gewinnchance, nicht aber den Preis mindert. Angebote oberhalb der eigenen Zahlungsbereitschaft können zu einem Rentenverlust fuhren, so daß ein rationaler Bieter immer seine Zahlungsbereitschaft angeben wird.

Eine Grundaussage der Auktionstheorie ist, daß sich unter bestimmten Annahmen (die versteigerten Güter sind sogenannte Private-Value-Güter, die Bieterstruktur ist symmetrisch, die Bieter sind risikoneutral und es gibt keine kollusiven Verhandlungsweisen $)^{231}$ diese Standardtypen in ihren Ergebnissen nicht unterscheiden. Dieses sogenannte „Revenue Equivalence Theorem“232 besagt, daß unabhăngig vom Auktionstyp im Durchschnitt immer der Bieter mit der höchsten Zahlungsbereitschaft gewinnt und zwar zu einem Preis, der der Zahlungsbereitschaft des ersten „Verlierers“ entspricht. Der Käufer hat also die Opportunitătskosten seiner Entscheidung zu tragen. Treffen obengenannte Annahmen nicht zu, ist diese Äquivalenz der Auktionstypen nicht mehr gegeben. ${ }^{233}$

Beim Transitverkehr ist nun das Dilemma zu lösen, daß einerseits die Gemeinschaft ein berechtigtes Interesse am Durchgangsverkehr hat, daß andererseits die einzelne Region ein ebensolches Interesse hat, diesen Verkehr durchs eigene Land möglichst gering zu halten. Dieser Konflikt könnte mit Hilfe der Auktionsverfahren wie folgt gelöst werden: Zunăchst muß das Gut „Transitverkehr“ in eine handelbare Einheit transformiert werden. Dies könnte relativ einfach geschehen, indem man sich an die Praxis im österreichischen Transit anlehnt und die unterschiedlichen Fahrzeuge und Streckenlängen am Stickoxidausstoß normiert (Ökopunktesystem).

Der zweite Schritt ist komplexer, vermutlich existiert sogar eine eindeutige Lösung fur dieses Problem nicht und wir müssen uns mit einer Annäherung zufriedengeben: Bei einer Transitfahrt werden im allgemeinen mehrere Länder durchquert. Weigert sich ein Land, an der Auktion teilzunehmen, d. h. Transitfahrten anzubieten, sinkt der Wert der anderen Transitstrecken automatisch. Es ist für den einzelnen Transporteur daher nicht sinnvoll, beispielsweise für einen Transport von den Niederlanden nach Italien nur Ökopunkte für den Deutschlandtransit zu besitzen. Hat er diese erworben, konnte aber keine Rechte fur die Wei-

${ }^{230} \mathrm{Vgl.} \mathrm{Kemperer,} \mathrm{P.} \mathrm{(1999),} \mathrm{S.} 230$ f.

231 Vgl. McAfee, R. P. und J. McMillan (1987), S. 707 ff.

232 Vgl. Kemperer, P. (1999), S. 239 f.

${ }^{233}$ Einen guten Uberblick uber die Eigenschaften der verschiedenen Auktionsmodelle bietet Wolf. Vgl. Wolf, H. (1995). Für einen formalen Nachweis des Revenue Equivalence Theorems vgl. Kemperer, P. (1999). 
terfahrt durch Frankreich, Österreich oder die Schweiz kaufen, entwertet sich automatisch das Recht auf die Durchfahrung Deutschlands.

Formal läßt sich dieses sogenannte „Komplementaritătsproblem ${ }^{\star 234}$ wie folgt darstellen: ${ }^{235}$

$$
\begin{aligned}
& \text { - } W(A, B)>W(A)+W(B) \\
& \text { - } W(A, B, C, D)>W(A, B)+W(C, D)
\end{aligned}
$$

Der Wert W einer kompletten Transitroute (A, B) ist also höher als die Summe der Werte der Teilstrecken. Das Dilemma besteht also darin, daß die Transporteure eine Zahlungsbereitschaft für die Gesamtroute besitzen, die Lănder aber nur einzelne Streckenabschnitte anbieten können. Dies kann einerseits zu Fehlinvestitionen fuhren, indem für Abschnitte ein Preis geboten wird, der sich am Wert der Gesamtroute W(A, B) orientiert und furr den sich im Nachhinein herausstellen kann, daß er uber dem tatsächlichen Wert W(A) für den Käufer liegt, wenn ihm nicht gleichzeitig der Kauf der Anschlußfahrt durch das Nachbarland gelungen ist.

Nun sind Fehlinvestitionen in marktwirtschaftlich organisierten Systemen zunächst nichts grundsätzlich ungewöhnliches und rechtfertigen nicht zwangsläufig besondere staatliche Beachtung. Im Gegenteil dienen sie meist als Selektionskriterium, indem sie ineffizient arbeitende Unternehmen aus dem Markt ausscheiden lassen. In diesem Fall wird das Problem jedoch erst uber die Auktion dieser Rechte generiert und muß deswegen genauer betrachtet werden.

Das Problem wird dann besonders virulent, wenn ein Land seine „Flaschenhalsposition" tatsächlich ausnutzt und wenige oder keine Transitfahrten anbietet. Damit entwertet es gleichzeitig das Angebot aller anderen Staaten. Es ist allerdings fraglich, ob ein Land eine solche Position einnehmen wird. Die Ergebnisse des Abschnittes 0 lassen zumindest anderes vermuten: Da Staaten durch Abgaben auf stationäre Anlagen Einnahmen erzielen, haben sie keinen Anreiz, den Transitverkehr gegen Null konvergieren zu lassen. Zwar wird eine Diskriminierung zwischen in- und ausländischen Transporteuren, wie sie die vorzuschlagende Auktionslð̋sung zwangsläufig darstellt, zu einer Verteuerung des Transits führen. Sie wird aber aller Voraussicht nach nicht, wie bèfürchtet werden könnte, zu einer Blockadehaltung der Transitländer führen. ${ }^{236}$

234 Vgl. Wolf, H. (1995), S. 3.

$235 \mathrm{Vgl}$. Berger, U. E. (2000), S. $235 \mathrm{ff}$.

${ }^{236}$ Das Problem des ठ̈sterreichischen Ökopunktesystems ist gerade, daß Österreich als Transitland uber diesen Mechanismus zwar den Schaden begrenzen kann, aber durch ihn keinerlei Kompensation erhalt. Wäre dies der Fall, könnte der Transit vermutlich auch innenpolitisch deutlich besser ,verkauft" werden. 
Diskussionswürdig ist, ob diese Verteuerung ein Zeichen fur Ineffizienz, darstellt oder nur eine Folge der stärkeren Anerkennung regionaler Belange ist. Die Verteuerung der Transporte kann die Kosten des betroffenen Landes widerspiegeln und damit eine effiziente Lösung darstellen. Diese Lösung realisiert zwar nicht das in 5.3 beschriebene Gesamtoptimum, verhindert aber eine Ausbeutung der Transitländer, welche letztlich ebenfalls wohlfahrtsmindernd wirkt.

Abb 40: Die wichtigsten Straßenverbindungen in Europa

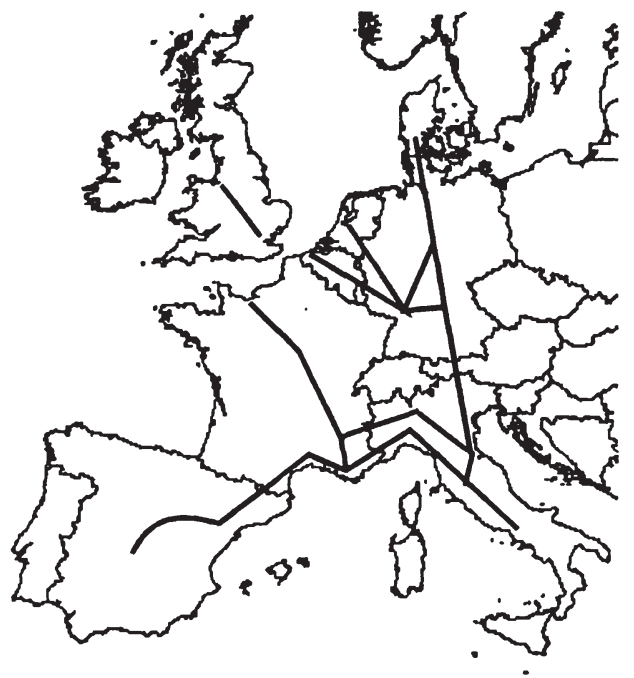

Quelle: Economic Commission for Europe (1992), eigene Darstellung.

Einen anderen Standpunkt hierzu vertritt LEVINSON, der in seinem Modell von einem globalen Ansatz ausgeht und in der Verteuerung, die durch eine dezentralen Bereitstellung von NIMBY-Gütern ausgelöst wird, eine Ursache ineffizienter Allokation sieht. ${ }^{237}$ Die Höhe dieser Ineffizienz wird dort von der Steuersatzelastizität der Nachfrage bestimmt, von der es abhängt, wie weit die optimale Steuer für Transitverkehr (im LEVINSON-Modell importierter Abfall) die externen Grenzkosten übersteigt. Reagiert die Nachfrage elastisch, d.h. können die Transporteure hohen Straßenbenutzungsgebühren ausweichen, haben die Transitländer nur geringe Möglichkeiten, uber ihre Kosten hinaus Renten abzuschöpfen. Auch in diesem Modell ist die Höhe der Ineffizienz also eine Frage der Marktkonstellation. Je höher die Preiselastizităt der Nachfrage, desto eher entspricht der dezentral erhobene Steuersatz dem Optimum. ${ }^{238}$ Es muß daher versucht werden, die Auktionsre-

237 Vgl. Levinson, A. (1998).

${ }^{238}$ Siehe Gleichung $7+8$ in Levinson, A. (1998), S. 35 . 
geln so festzulegen, daß der Gestaltungsspielraum des Monopolisten möglichst gering ist bzw. der Spielraum für die Transporteure möglichst hoch.

Um der Gefahr überhöhter Preise oder im Extremfall der „Angebotsverweigerung" von vornherein zu begegnen, könnte eine Art Untergrenze für den Transit eingefuhrt werden. Diese könnte man sich beispielsweise so vorstellen, $\mathrm{da} ß$ jedes Land in der Europäischen Union einen gleichen Anteil an Transitverkehr am gesamten eigenen Verkehrsaufkommen akzeptieren muß. So wurde beispielsweise in Deutschland 1998 auf den Straßen eine Verkehrsleistung von ca. 315,9 Mrd. tkm erbracht. Davon waren 30,3 Mrd. tkm, also knapp 10 Prozent, Durchgangsverkehr, 75,5 Mrd. tkm grenzüberschreitender Verkehr. Insgesamt waren also uber $100 \mathrm{Mrd}$. tkm, fast ein Drittel der gesamten Verkehrsleistung, kein reiner Binnenverkehr. Etwas über ein Viertel der Verkehrsleistung, 85,3 Mrd. tkm, wurden von ausländischen Fahrzeugen erbracht. ${ }^{239}$ Fraglich ist, welche Zahl in diesem Fall die relevante ist. Da die Ein- und Ausfuhren entweder durch inländischen Konsum oder aber inländische Produktion mitbestimmt sind, wăre es unangemessen, diese dem vom Ausland verursachten Verkehrsaufkommen zuzurechnen. Die Begrenzung ausländischer Beförderer wäre ebenfalls unzulässig, wenn diese innerhalb der Bundesrepublik transportieren, da sie dann lediglich Umweltschäden verursachen, die durch die inländische Produktions- und Konsumweise bestimmt sind. Es bleiben also die Durchfahrten in Höhe von 10 Prozent der gesamten Verkehrsleistung.

Nimmt man diese als Referenz, müßte jedes Land in der EU $10 \%$ seiner Verkehrsleistung dem Ausland kostenlos in Form von Ökopunkten zur Verfügung stellen. Besteht uber diese Verkehrsmenge hinaus Bedarf an Transitverkehr, muß dieser im Auktionsverfahren erworben werden. Damit ist zumindest sichergestellt, daß ein gewisser Grundstock an Durchgangsverkehr immer besteht und damit Komplementarităts- und Monopolproblem zumindest abgeschwächt sind. Gleichzeitig haben die „kleinen“ Transitländer keinen Anlaß zur Beschwerde, da ihre relative Position nicht schlechter ist als die anderer Mitgliedsländer.

Die beiden Mechanismen sollten zusammengenommen sicherstellen, daß der Transit durch den neuen Allokationsmechanismus nicht zusammenbricht. Es bleibt also noch festzulegen, wie das Angebot weiterer Ökopunkte und die Vergabe dieser Transitgenehmigungen geregelt werden sollte. Das besondere bei dieser Auktion ist, daß es sich um eine Auktion mit endogenen Mengen handelt, d. h. das Angebot an Transitgenehmigungen ist nicht ex ante gegeben, sondern eine Funktion des Auktionspreises.

Da die Externalităten des Verkehrs mit dessen Zunahme überproportional wachsen dürften, ist anzunehmen, daß die betroffenen Länder für die ersten Tranchen

239 Vgl. DIW (1999), elektronische Ausgabe. 
geringere Preise fordern werden als für spätere. Wenn sie dann für diese Tranchen höhere Preise erzielen, als sie erwarten, ist anzunehmen, daß sie weitere Transitfahrten anbieten. Umgekehrt werden die Spediteure fur einige Fahrten höhere Erlöse erzielen können als für andere und dementsprechend für die ersten Transittranchen eine höhere Zahlungsbereitschaft besitzen als für spätere. Generell dürfte die Nachfrage nach Transitgenehmigungen durch kleine Länder größer sein, da dort aufgrund des geringeren inländischen Verkehrs weniger Ökopunkte kostenlos ausgegeben werden. Kleinere Länder haben so die Möglichkeit, entsprechend ihrer Belastung höhere Knappheitsrenten durch die Auktion zu erzielen, was ihre Partizipation wahrscheinlicher macht.

Jedes Land bietet Transittranchen an, wobei für jede weitere Tranche ein höherer Preis gefordert wird als fur die vorangegangene. Die Bieter besitzen eine Zahlungsbereitschaft fur diese Tranchen, die sich in Form einer „normalen“, d. h. fallenden Nachfrage äußert. Aufgrund der Vielzahl der Nachfrager und der Heterogenität der Transportanlässe dürfte der stetige Verlauf gerechtfertigt sein. Im oben angenommenen Beispiel könnte das jeweilige Land die ersten drei Tranchen absetzen, für die letzten beiden bestünde zum gegebenen Preis keine Nachfrage.

Graphisch stellt sich das Problem wie folgt dar:

Abb. 41: Versteigerung mehrerer Objekte

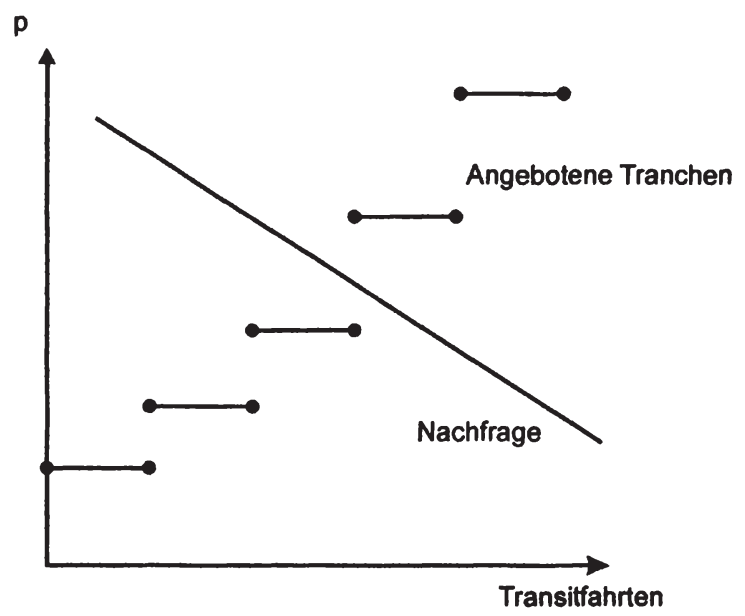

Quelle: Eigene Darstellung in Anlehnung an Berger, U. E. (2000).

Ein Problem besteht bezuglich des konkreten Verfahrens. Dieses muß den Informationsbedarf von Anbietern und Nachfragern gerecht werden, gleichzeitig Ab- 
sprachen, sogenanntem kollusiven Verhalten vorbeugen und wenn möglich sicherstellen, daß das Komplementaritătsproblem keine zu große Bedeutung gewinnt. Das Versteigern mehrerer Güter kann grundsătzlich in sequentiellen oder simultanen Verfahren oder in zweiseitigen Auktionen (double auctions) erfolgen. Beim sequentiellen Verfahren werden einfach eine bestimmte Zahl von Auktionen - je nach Anzahl der Transitpakete - hintereinander abgehalten. Dies erhöht zwar den Informationsstand der Bieter, da sie sich mit ihren Preisen an den Ergebnissen der vorangegangenen Auktion orientieren können. Bei simultanen Auktionen sind je nach Auktion zusătzliche Regeln zu beachten. ${ }^{240}$ Es mögen $n$ Tranchen zur Versteigerung anstehen. Bei der Englischen Auktion wird solange geboten, bis die n höchsten Gebote nicht mehr überboten werden. Bei der Holländischen Auktion darf der erste Bieter zum aufgerufenen Preis so viele Transitfahrten in Anspruch nehmen, wie er möchte. Bei der verdeckten Auktion zum höchsten Gebotspreis erhalten die $\mathrm{n}$ höchsten Bieter die Tranchen zu den gebotenen Preisen, wăhrend sie bei der verdeckten Auktion zum zweithöchsten Gebotspreis furr alle Güter nur den Preis des ersten Gebotes, welches nicht zum Zuge kommt, entrichten müssen.

Zweiseitige Auktionen können grundsătzlich verdeckt oder offen ablaufen. Der offene Fall ist allgemein bekannt, da er im wesentlichen dem Parketthandel auf Aktienmårkten entspricht, bei dem Bieter und Nachfrager der jeweiligen Gegenseite ihre Preisvorstellungen nennen und gegebenenfalls den Kauf abschließen. Bei der verdeckten Variante geben die Bieter und Nachfrager Umschläge mit ihren Preisvorstellungen anonym ab. Eine zentrale Agentur aggregiert diese zu Angebots- und Nachfragefunktionen und ermittelt so die zu tauschende Menge und den dazugehörigen Preis. ${ }^{241}$

Letzteres Verfahren erscheint am besten geeignet, um möglichst einfach die Interessen der Beteiligten in Übereinstimmung zu bringen und gleichzeitig das Problem endogener Mengen zu lösen. Jedes Land müßte demnach Transittranchen zu verschiedenen Preisen anbieten, die zu den genannten $10 \%$ freiem Transit dazukämen (die Angebotskurve würde also dementsprechend parallel nach außen verschoben).

Die Spediteure geben an, zu welchem Preis sie welche Mengen an Ökopunkten bereit sind zu kaufen. Die Nachfragen werden aggregiert und mit dem Angebot in Übereinstimmung gebracht. Der Gleichgewichtspreis ist dann von allen Nachfragern zu zahlen.

Falls einzelne' Spediteure zu klein sind, um sich an den Auktionen zu beteiligen, können die entsprechenden Interessenverbände oder zu diesem Zweck gegründete

240 Vgl. Berger, U. E. (2000), S. 224 ff.

241 Vgl. McAfee, R. P. and J. McMillan (1987), S. 725 f. Bei diskreten Mengen ergibt sich kein eindeutiger Preis, sondern ein Preisintervall. 
Organisationen das Bietverfahren übernehmen und die einzelnen Fahrten dann an ihre Mitglieder weitergeben.

Dieses Verfahren kann allerdings das Komplementaritătsproblem nicht lösen. Teilweise wird daher vorgeschlagen, eine Rücknahme des Angebotes zu ermöglichen. Dies kann allerdings nur gegen eine Gebühr erfolgen, um strategisches Bieten auszuschließen. ${ }^{242}$ Besteht dennoch Nachverhandlungsbedarf, d. h. haben einzelne Spediteure im Auktionsverfahren nicht den kompletten Transit erwerben können, kann der Ausgleich in einem zweiten Schritt auf sogenannten Sekundärmärkten erfolgen. Auf diesen können Spediteure, die für bestimmte Fahrten keine Genehmigungen ersteigern konnten, die fehlenden Lizenzen anderen Unternehmen abkaufen.

Zusammengefaßt sieht das Verfahren wie folgt aus:

1. Jedes Land stellt Transitlizenzen in der Höhe von $10 \%$ seiner nationalen Verkehrsleistung kostenlos zur Verfügung.

2. Zusätzlich bietet es Transitlizenzen in Tranchen zu unterschiedlichen Preisen an.

3. Jeder Spediteur (oder ein entsprechender Zusammenschluß) bietet für einzelne Lizenzen.

4. Eine zentrale Agentur ermittelt den Gleichgewichtspreis, verteilt die Lizenzen an alle Bieter, die mindestens diesen Preis geboten haben und die Gebuhren an die versteigernden Länder.

5. In einem Sekundärmarkt können die Bieter ihre Lizenzen untereinander tauschen, um Fahrten zu komplettieren.

\subsection{Zusammenfassung der Vorschläge}

Im vorigen Abschnitt wurden Möglichkeiten aufgezeigt, wie eine effiziente Finanzierung der Verkehrsinfrastruktur und eine Internalisierung der Umweltfolgen des Güterverkehrs bei weitgehender Aufrechterhaltung dezentraler Kompetenzen in der Europäischen Union erfolgen kann. In diesem Abschnitt sollen diese Vorschläge zusammengefaßt werden.

${ }^{242}$ Vgl. Wolf, H. (1995), S. 42 f. 
Abb. 42: Finanzierung und Lenkung des Straßengüterverkehrs

Internalisierung der Externalităten:

\section{National:}

- Ordnungspolitische Maßnahmen zur Internalisierung der extemen Effekte (4.3.2)

- Emissionsbezogene Steuer beim LKW-Kauf (4.3.2)

- Abgassteuer oder Mineralölsteuererhöhung (4.3.2)

In der EU:

- Versteigerung von Durchfahrtsrechten als Form des Handels mit Verschmutzungslizenzen (6.3)

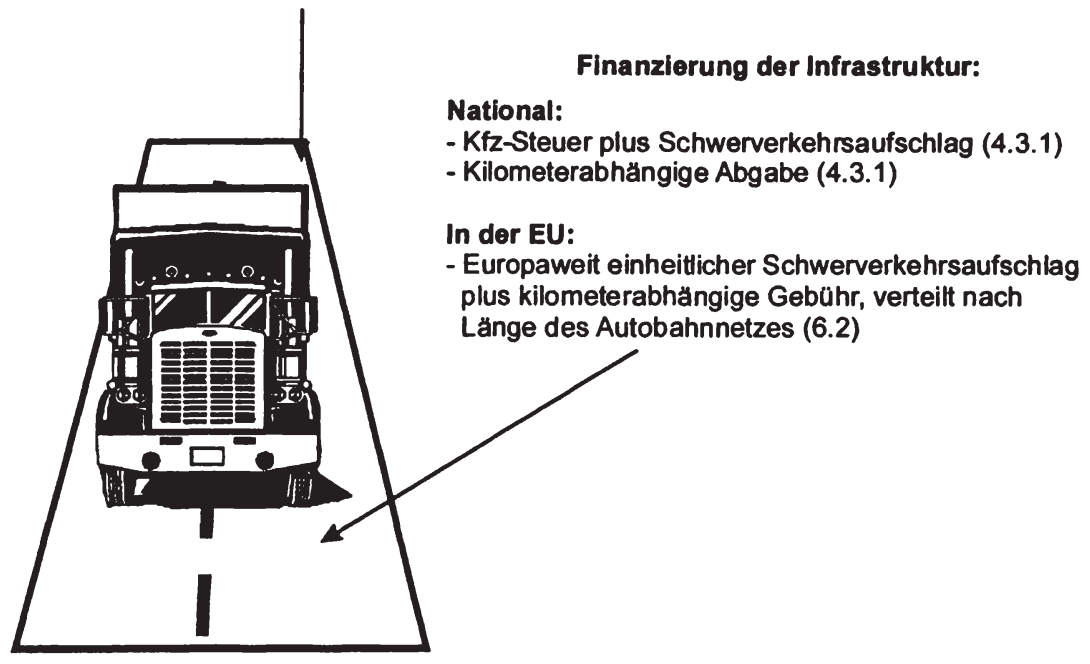

Wie der Darstellung in Abb. 42 zu entnehmen ist, stellen die Vorschläge zur Finanzierung der Verkehrsinfrastruktur in Abschnitt 6.2 und zur Internalisierung von Umweltschäden in Abschnitt 6.3 keinen Bruch mit dem System der Verkehrsbesteuerung, welches im 1. Kapitel vorgeschlagen wurde, dar. Sie sind eine Ergănzung und ermöglichen, sinnvolle Instrumente der Verkehrspolitik im Binnenmarkt mit seinen veränderten Gegebenheiten weiterhin einzusetzen.

Bei der Finanzierung der Verkehrsinfrastruktur muß lediglich der Schwerverkehrsaufschlag, nicht die gesamte $\mathrm{Kfz}-\mathrm{Steuer}$, europaweit harmonisiert und nach einem bestimmten Schlüssel auf die einzelnen Länder aufgeteilt werden. Durch die Vereinheitlichung wird es furr die Spediteure weniger interessant, ihre Fahrzeuge aus steuerlichen Grunden ins Ausland zu verlegen. Die jeweiligen 
Länder müßten Steuerwettbewerb mittels der für alle Fahrzeuge gultigen KfzSteuer betreiben, was aufgrund der großen inländischen Bemessungsgrundlage jedoch eher unattraktiv ist.

Bei der Internalisierung der Externalităten sollte sichergestellt werden, daß jedes Land weiterhin seine eigenen Vorstellungen bezüglich des Straßengüterverkehrs umsetzen kann, ohne gleichzeitig die Interessen der anderen Länder am Transitverkehr zu negieren. Vorgeschlagen wurde eine weitgehend dezentrale Lösung, bei der die einzige zentrale Regelung in einer Versteigerung von Transitlizenzen besteht. Um die Rechte der Transporteure nicht über Gebühr zu beeinträchtigen, wird eine Mindestanzahl an kostenlos anzubietenden Transitfahrten festgelegt. Das Modell ist also eine Weiterentwicklung des österreichischen Ökopunktemodells mit dem Unterschied, daß sich ein Land zusătzlich zur kostenlosen Vergabe zu einem Verkauf von weiteren Fahrten entscheiden und damit - bei vorhandener Zahlungsbereitschaft der Transporteure - eine Wohlfahrtssteigerung erreichen kann. 
Axel Hennighausen - 978-3-631-75701-7

Downloaded from PubFactory at 01/11/2019 02:45:58AM

via free access 


\section{Erweiterung und Schlußbetrachtung}

\subsection{Eine Erweiterung: Die Verteilung der Aufgabenkompetenz}

In der vorliegenden Arbeit haben wir uns ausschließlich mit Fragen der Finanzierung gegebener Infrastruktur und der Internalisierung der Umweltbelastung befaßt. Ein weiterer wesentlicher Aspekt, die Frage der Bereitstellung der Infrastruktur, wurde dagegen bisher ausgeklammert. Er soll im folgenden aber, da er eng mit obengenannten Problemen verbunden ist, zumindest als Ergänzung der vorliegenden Fragestellung angefugt werden.

Fassen wir nochmals kurz die Ergebnisse des Abschnitts 6.1 zusammen, in dem die Prinzipien optimaler Kompetenzverteilung diskutiert wurden: Eine Aufgabe soll derjenigen staatlichen Ebene zugewiesen werden, bei der Nutzen und Kosten räumlich zusammenfallen. Dabei ist zusätzlich darauf zu achten, daß die Entscheidungsebene möglichst weit unten in der Hierarchie angesiedelt ist. Notfalls haben ubergeordnete Körperschaften die untergeordneten bei der Aufgabenerfullung zu unterstützen.

Bei der Bereitstellung der Straßeninfrastruktur allerdings ist diese Abgrenzung mit größeren Schwierigkeiten verbunden. Jedes Straßenstück hat nicht nur für seine beiden Endpunkte einen Wert, sondern auch als Teil des gesamten Straßennetzes. Dies soll anhand der folgenden Illustration năher erläutert werden.

Grundlegend für Netzwerkexternalitäten ist die Komplementarität der einzelnen Netzwerkkomponenten. ${ }^{243}$ Diese können einfach an der in der folgenden Zeichnung links dargestellten Sterntopologie gezeigt werden. Die einzelnen Nutzer A bis $\mathrm{F}$ seien über einen zentralen Knoten miteinander verbunden. Bei $\mathrm{n}$ Nutzern ergeben sich $n(n-1)$ potentielle Verbindungen. Ein weiterer Nutzer verursacht positive Externalitäten in dem Sinne, als er $2 \mathrm{n}$ potentielle neue Verbindungen zum Netzwerk hinzufügt. Läßt sich also bspw. A neu an das Straßennetz anbinden, schafft er gleichzeitig für die anderen Nutzern B bis F eine höhere Anzahl fahrbarer Strecken und wertet damit das Gesamtnetz auf. Es wäre daher ökonomisch ineffizient, dem zusätzlichen Nutzer die gesamten Kosten des Anschlusses anzulasten. Erfolgt die Bereitstellung der Infrastruktur dezentral, d. h. hat jeder Nutzer selbst für seinen Anschluß zu sorgen, wird das Netz insofern einen zu geringen Ausbaugrad haben, als einzelne Anschlußwillige keine Zahlungsbereitschaft in Höhe der gesamten Kosten aufweisen und damit auf die Inanspruchnahme verzichten, obwohl der Gesamtnutzen der zusätzlichen Verbindung höher ist als seine gesamten Kosten.

${ }^{243}$ Vgl. dazu und zu den folgenden Ausfuhrungen Economides, N. (1996). 
Abb. 43: Netztopologien

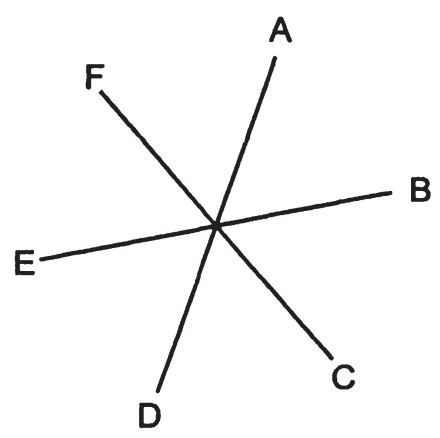

Sterntopologie

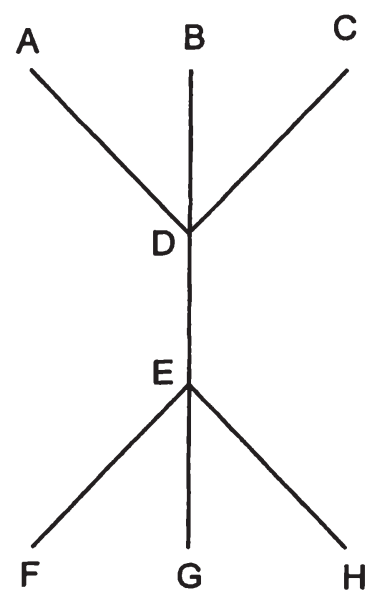

Baumstruktur

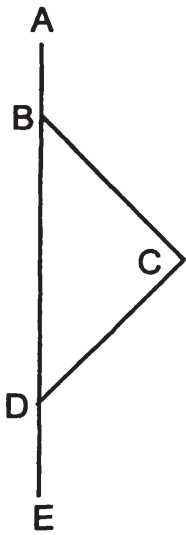

Umwegnetz

Quelle: Economides, N. (1996), Rothengatter, W. (1994), Røver, A. (1996), eigene Darstellung.

Diese Art der Netzexternalität ist allerdings nur als Beispiel hilfreich, sie zeigt noch nicht das eigentliche Problem der dezentralen Infrastrukturbereitstellung bei komplementären Netzkomponenten. Dieses wird durch die Baumstruktur in der Mitte der Abb. 43 abgebildet. Das Teilstück $\overline{\mathrm{DE}}$ dient hier einerseits als direkte Verbindung der Knoten D und E, andererseits auch als Verbindung zweier Subnetze $\overline{\mathrm{ABC}}$ und $\overline{\mathrm{FGH}}$. Die Orte D und $\mathrm{E}$ werden aber bei der Entscheidungsfindung bezüglich der Trassenfuhrung und des Ausbaugrades der Strecke das Mobilitätsbedürfnis der überregionalen Nutzer nicht berücksichtigen, sondern nur die Bedürfnisse ihres Teilsegmentes befriedigen. ${ }^{244}$ Dadurch ergibt sich bei dezentraler Bereitstellung ein insgesamt suboptimal koordiniertes Netz. Falls sich die Orte D und E ihrer besonderen Lagen bewußt sind und das Mobilitătsbedürnis der Subnetze in ihr Angebot mit einbeziehen, werden sie ihre monopolistische Anbietersituation ausnutzen und die Teilstrecke nur zu gesamtwirtschaftlich uberhöhten Preisen zur Verfügung stellen. Daraus ergibt sich eine Netzverantwortung für die jeweils höhere staatliche Ebene, um die Ineffizienzen zu vermeiden.

${ }^{244}$ Ein typisches Beispiel für eine solche Vorgehensweise stellt die Eisenbahninfrastruktur dar, deren Streckenfuhrung neben politischen Erwägungen vor allem von regionalen Nutzenvorstellungen geprägt war. Ergebnis dieser Infrastrukturpolitik sind Kopfbahnhöfe, Umfahrungen von regionalen Zentren usw. 
Anders stellt sich die Situation in der rechten Skizze der Abb. 43 dar. Hier ist die Verbindung $\overline{\mathrm{BCD}}$ nicht komplementär, sondern substitutiv zur direkten Strecke $\overline{\mathrm{BD}} .{ }^{245}$ Grundsätzlich besteht damit kein Koordinationsbedarf zwischen den beiden Teilstrecken. Dennoch ist zu berücksichtigen, daß Angebotsänderungen auf einem Teilstück, z. B. ein Ausbau der Infrastruktur, auch die Attraktivităt des anderen Teils beeinflussen. Dies ist bei konkurrierendem Angebot allerdings völlig normal und daher eigentlich kein Grund für Interventionen. Es läßt sich aber zeigen, daß die Konkurrenz zwar optimal in bezug auf das Preissetzungsverhalten der Konkurrenten ist, fur eine optimale Ausnutzung der Netzkapazität beim Vorliegen negativer Netzwerkexternalităten aber ein kooperatives Verhalten zu bevorzugen ist. Da ein einzelner Netzbenutzer bei seinen Wahlentscheidungen nur die eigenen Kosten berlicksichtigt, nicht jedoch die negativen Externalităten, die er durch sein Hinzutreten allen anderen Nutzern aufbürdet, wird er ein tendenziell überfulltes Teilnetz nicht verlassen, obwohl sein zusätzlicher Zeitaufwand durch die Zeitgewinne der verbleibenden Nutzer uberkompensiert würde. ${ }^{246}$ Dadurch sind die attraktiveren Straßen tendenziell übernutzt. Dies könnte dadurch beseitigt werden, daß sich beide Anbieter darauf einigen, im attraktiveren (weil kürzeren) Netz $\overline{\mathrm{BD}}$ höhere Preise zu verlangen, um damit die optimale Verteilung auf die Teilnetze zu erreichen. Kosteneffizienz ist also nur durch eine Koalition der Netzanbieter $\mathrm{zu}$ erreichen. ${ }^{247}$

Alles in allem zeigt die Diskussion der Netzwerkexternalităten, daß unkoordiniertes Verhalten auf unteren Ebenen nicht geeignet ist, ein gesamtwirtschaftlich optimales Angebot bereitzustellen. Fiskalische Äquivalenz im Verkehrsbereich erfordert daher, daß die Entscheidung uber Infrastrukturangebote innerhalb eines Netzes von einer Körperschaft vorgenommen wird, deren Größe mit der des Gesamtnetzes übereinstimmt. Dabei kann es durchaus sein, daß verschiedene Subnetze existieren, die untereinander keine wesentlichen Wechselwirkungen ausüben und daher unabhängig voneinander bereitgestellt werden können. Beispielsweise wird ein europäisches Hochgeschwindigkeitsnetz kaum relevante Interaktionen mit regionalen Straßennetzen haben, obwohl natürlich prinzipiell Verbindungen bestehen. Daher können die Verantwortungsbereiche für das Netz „Regionalstraßen“ ohne Effizienzverluste auf unterer Ebene angesiedelt sein, wăhrend für europäische Netze die EU als Ganzes zumindest eine koordinierende Funktion haben muß, um allokative Verzerrungen zu vermeiden.

${ }^{245}$ Vgl. dazu Rothengatter, W. (1994).

246 Vgl. Rover, A. (1996), S. 24 f.

247 Vgl. Rothengatter, W. (1994), S. 126. 


\subsection{SchluBbetrachtung}

Die Verkehrspolitik der Länder der Europäischen Union ist seit einem Jahrzehnt massiven Veränderungen unterworfen. Beginnend mit Harmonisierungsmaßnahmen der Union in verschiedenen Teilbereichen uber eine fast vollständige Deregulierung der Verkehrsmärkte stehen nun verstärkt Regelungen im Bereich der Besteuerung und Lenkung des Güterverkehrs auf europăischer Ebene an. Erste Versuche bei der Harmonisierung der Kfz- und Mineralölbesteuerung und bei Autobahngebuhren reichen bei weitem nicht aus, um die wachsenden Anforderungen an den Ausbaugrad der Infrastruktur zu finanzieren oder die deregulierungsbedingt wachsenden Verkehrsströme in eine allokativ effiziente Richtung zu lenken. Oftmals haben einzelne Länder keinerlei Interesse, die von der Europäischen Union vorgeschlagenen Maßnahmen zu unterstutzen oder in nationales Recht umzusetzen. Die Kommission ihrerseits hat bei ihren Maßnahmen oftmals zu stark die Belange des Binnenmarktes, nicht aber die Interessen der vom Verkehr betroffenen Staaten im Blick. Thre Vorschläge, wie das Grunbuch uber „Faire und effiziente Preise im Verkehr" oder ihr Weißbuch uber „Faire Preise fur die Infrastrukturbenutzung " legen ihren Fokus daher stark auf einen funktionierenden Verkehrssektor, weniger auf die unterschiedlichen Belange der einzelnen Mitgliedsländer.

Die vorliegende Arbeit hat die Gründe für das Scheitern der bisherigen Verkehrspolitik analysiert. Aufbauend auf der Erkenntnis, daß zum einen die Eigeninteressen der betroffenen Länder, zum anderen aber auch die grundsătzlichen Probleme bei der Bereitstellung von Gütern mit stark regional konzentrierten Kosten die ublichen Finanzierungs- und Lenkungsinstrumente unbrauchbar machen, wurde der Versuch unternommen, unter den gegebenen Umständen eine sinnvolle institutionelle Regelung für den Verkehrssektor zu finden.

Für die Finanzierung der Infrastruktur wird vorgeschlagen, diejenigen Teile der $\mathrm{Kfz}$-Besteuerung, die für zwischenstaatlichen Steuerwettbewerb anfällig sind, also die Schwerverkehrsabgabe, vom Rest der Steuer abzuspalten. Die zusätzlich erhobene Abgabe soll nach einem vorher festgelegten Verfahren auf die Mitgliedsländer aufgeteilt werden. Mit dieser Mindestharmonisierung soll einem Verschwinden dieser fur die Finanzierung der Fixkosten notwendigen Steuer vorgebeugt werden.

Für die Internalisierung der Umweltschäden wird die Chance für eine Einigung im Vorfeld skeptischer beurteilt, weswegen die üblichen Instrumente zur Internalisierung der negativen Externalităten nicht in Betracht gezogen werden. Statt dessen wird vorgeschlagen, im Rahmen eines Auktionsverfahrens die Transitrechte - also die zwischenstaatlichen Umwelteffekte - zwischen den einzelnen Gebietskörperschaften zu verteilen und die innerstaatliche Allokation in der Hand des jeweili- 
gen Landes zu belassen. Damit werden die Erkenntnisse, die sich aus dem Scheitern der bisherigen Verhandlungen ziehen ließen, berücksichtigt, indem die Harmonisierung innerhalb der Union auf ein notwendiges Minimum reduziert wird. Viele technische Probleme, die mit der Umsetzung dieses Vorschlags verbunden sein werden, konnten in dieser Arbeit nur angerissen oder gar nicht behandelt werden. Sie müssen Gegenstand späterer Untersuchungen sein. In diesem Sinne können die Ergebnisse dieser Arbeit nur als vorläufig gelten. Sie stellen aber dennoch einen ersten Versuch dar, das Problem des wachsenden Güterverkehrs in Europa unter Anerkennung der unterschiedlichen Interessen einzelner Länder zu lösen und damit ein stabileres Ergebnis zu erzielen, als es europaweit einheitliche Maßnahmen könnten. 
Axel Hennighausen - 978-3-631-75701-7

Downloaded from PubFactory at 01/11/2019 02:45:58AM

via free access 


\section{Literaturverzeichnis}

Aberle, Gerd (1984): Verkehrswegerechnungen und Wegeentgelte - Theoriedefizite und Datenlucken in der Verkehrspolitik. In: Probleme der Ordnungs- und Strukturpolitik: Festschrift fur Hellmuth Stefan Seidenfus. Hrsg.: Ewers, Hans-Jürgen und Schuster, Helmut. Göttingen: Vandenhoeck und Ruprecht.

Ahrens, Gerd-Axel (1991): Verkehrsbedingte Luft- und Lärmbelastungen - Emissionen, Immissionen, Wirkungen. Umweltbundesamt, Berlin.

Arnott, Richard; Grieson, Ronald E. (1981): Optimal Fiscal Policy for a State or Local Government. Journal of Urban Economics 9, S. 23-48.

Arrow, Kenneth J. (1950): A difficulty in the concept of social welfare. Journal of Political Economy 58, S. 328-346.

BAG (1999): Marktbeobachtung Güterverkehr. Bundesamt für Güterverkehr, Köln.

Basedow, Jürgen (1987): Einleitung: Verkehrsrecht und Verkehrspolitik als europäische Aufgabe. In: Europäische Verkehrspolitik, Nach dem Untätigkeitsurteil des Europäischen Gerichtshofes gegen den Rat vom 22. Mai 1985. Hrsg.: Basedow, Jürgen. Tübingen: J. C. B. Mohr (Paul Siebeck). (Studien zum ausländischen und internationalen Privatrecht).

Basedow, Jürgen (1989): Wettbewerb auf den Verkehrsmärkten: Eine rechtsvergleichende Untersuchung. Heidelberg: Müller (Augsburger Rechtsstudien Bd. 5).

Baum, Herbert (1985): Nachfrageelastizitäten im Güterverkehr - Ergebnisse einer empirischen Untersuchung. Zeitschrift für Verkehrswissenschaft 56 (4), S. 203-215.

Baumol, William J.; Bradford, David (1970): Optimal Departures From Marginal Cost Pricing. American Economic Review 60, S. 265-283.

Bell, Michael G. H.; Iida, Yashunori (1997): Transportation Network Analysis. Chister New York Weinheim Brisbane: John Wiley \& Sons.

Berger, Ulrike E. (2000): Engpässe bei Verkehrsinfrastrukturen. Berlin: Duncker \& Humblot (Volkswirtschaftliche Schriften; H. 503).

BGL (1997): Jahresbericht des BGL, Bundesverband Güterkraftverkehr und Logistik e.V., München.

BGL (2000a): Österreich verstößt erneut gegen EU-Recht. Pressemitteilung des Bundesverbandes furr Güterkraftverkehr und Logistik e.V. vom 20.01.2000. 
BGL (2000b): Russisches Roulette im alpenquerenden Verkehr geht weiter. Pressemitteilung des Bundesverbandes für Guterkraftverkehr und Logistik e.V. vom 27.06.2000.

BGL (2000c): BGL bittet Verkehrsminister Klimmt um Unterstützung im Alpentransit durch die Schweiz. Pressemitteilung des Bundesverbandes für Güterkraftverkehr und Logistik e. V. vom 20.01.2000.

BGL (o.J.): Verkehrswissenschaftliche Zahlen. Arbeitsgemeinschaft Güterfernverkehr im Bundesgebiet. Frankfurt, $M$.

Birnstiel, Ekkehard (1982): Theorie und Politik des Außenhandels. Stuttgart, Berlin, Köln, Mainz: Kohlhammer (Kohlhammer-Studienbücher: Wirtschaftswissenschaften).

Bleijenberg, A.N.; Dings, J.M.W.; Janse, P. (1997): European transport: emssion trends and policy responses. Centre for Energy Conservation and Environmental Technology Delft.

Boadway, Robin W.; Wildasin, David E. (1984): Public Sector Economics. 2. Aufl. Boston: Little, Brown and Company.

Bolln, Klaus (1998): Das neue deutsche Güterkraftverkehrsrecht, die neuen Inhalte des Güterkraftverkehrsgesetzes. In: Neuer Ordnungsrahmen im Strassengulterverkehr. Hrsg.: Knieps, Günter. Bergisch-Gladbach: (Schriftenreihe der Deutschen Verkehrswissenschaftlichen Gesellschaft e. V. Reihe B).

Bössmann, Eva (1979): Externe Effekte (I) und (II). Das Wirtschaftsstudium, (8) S. 95-98, 147-151.

Brandt, Eberhardt; Schäfer, Peter (1996): Der alpenquerende Transitverkehr - auf der Suche nach ,sustainable mobility“. Zeitschrift für Verkehrswissenschaft 67 (3), S.204-238.

Brennan, Geofffrey; Buchanan, James M. (1988): Besteuerung und Staatsgewalt: analytische Grundlagen einer Finanzverfassung. Hamburg: S + W Steuer- und Wirtschaftsverlag.

Brito, Dabobert L.; Oakland, William H. (1980): On Monopolistic Competition of Excludable Public Goods. American Economic Review 70, S. 691-704.

Brummerhoff, Dieter (2001): Finanzwissenschaft. 8. Aufl. München: R. Oldenbourg Verlag.

Brutscher, Sebastian (1993): Ökonomische Analyse der erwarteten Umweltwirkungen des Europäischen Binnenmarktes in den Bereichen Verkehrs-, Abfallund Energiewirtschaft, Universităt Hohenheim, Fakultăt Wirtschafts- und Sozialwissenschaft, Diss. 
Bundesministerium für Verkehr, Bau- und Wohnungswesen (2001): Informationen zur zeitbezogenen Autobahngebühr für schwere Nutzfahrzeuge unter besonderer Berücksichtigung der ab 1. April 2001 geltenden, neuen emissionsbezogenen Gebührenstruktur. Bundesministerium für Verkehr, Bauund Wohnungswesen, März 2001.

Cansier, Dieter (1981): Umweltschutz und Eigentumsrechte. In: Marktwirtschaft und Umwelt: Symposion vom 26.-28. März 1980 / veranst. vom WalterEucken-Inst. in Freiburg i. Br.- Hrsg: Wegehenkel, Lothar. J.C.B. Mohr (Paul Siebeck), Tübingen (Wirtschaftswissenschaftliche und wirtschaftsrechtliche Untersuchungen 17)

Cansier, Dieter (1993): Umweltökonomie. Stuttgart, Jena: G. Fischer.

Cecchini, Paolo (1988): Europa ,92: Der Vorteil des Binnenmarktes. BadenBaden: Nomos-Verlags-Gesellschaft.

Cropper, Maureen L.; Oates, Wallaces E. (1992): Environmental Economics: A Survey. Journal of Economic Literature 30, S. 675-740.

DG07 (1999): Der gemeinschaftliche Besitzstand im Verkehr. Leitfaden der Europäischen Kommission, Brüssel.

DG21 (08.09.1997): Vehicle Taxation in The European Union 1997. Background Paper. Europäische Kommission: Brüssel.

Dickertmann, Dietrich (1998): Die Erhebung und Zerlegung einer gemeinsamen Straßenbenutzungsgebühr für schwere Nutzfahrzeuge. Einstieg in einen europäischen Finanzausgleich. In: Politik und Verwaltung nach der Jahrtausendwende - Plädoyer für eine rationale Politik. Hrsg.: Konegen, Norbert; Kevenhörster, Paul; Woyke, Wichard. Opladen: Leske + Budrich.

DIW (1996): Verkehr in Zahlen 1996. Hamburg: Deutscher Verkehrs-Verlag.

DIW (1999): Verkehr in Zahlen 1999. Hamburg: Deutscher Verkehrs-Verlag.

Dogs, Ernst; Platz, Holger (1991): Externe Kosten des Verkehrs. Essen: PLANCO Consulting $\mathrm{GmbH}$.

Eckhardt, Klaus (1993): Probleme einer Umweltpolitik mit Abgaben. Frankfurt, Berlin, Bern: Peter Lang (Finanzwissenschaftliche Schriften 52).

ECMT (1991): Freight Transport and the Environment. European Conference of Ministers of Transport (CEMT/CM(96)6/final)

ECMT (1998): Efficient Transport for Europe, Policies for Internalisation of External Costs, European Conference of Ministers of Transport: Paris. 
Economides, Nicholas (1996): The Economics of Networks. International Journal of Industrial Organization 14 (2), S. 673-700.

EDA/EVD, Integrationsbüro (März 2000): Bilaterale sektorielle Abkommen Schweiz-EU, Integrationsbüro EDA/EVD,

Eggenschwiler, Kurt (1994): Dezibel \& Co. - Zu den Grundlągen der Akustik. Tagung der Vereinigung für Umweltrecht (VUR), Universităt Zürich, Zürich.

Eickhof, Norbert (1986): Theorien des Markt- und Wettbewerbsversagens. Wirtschaftsdienst 66 (9), S. 468-476.

Eickhof, Norbert; Franke, Martin (1994): Die Autobahngebühr für Lastkraftwagen - Ein zweckmäßiges Instrument der Verkehrspolitik? Wirtschaftsdienst V, S. 244-247.

Enderlein, Heinz; Kunert, Uwe (1990): Berechnung der Kosten und der Ausgaben für die Wege des Eisenbahn-, Straßen-, Binnenschiffs- und Luftverkehrs in der.Bundesrepublik Deutschland furr das Jahr 1987. Berlin: Duncker \& Humblot (Deutsches Institut für Wirtschaftsforschung: Beiträge zur Strukturforschung 119).

Enderlein, Heinz; Kunert, Uwe (1992): Ermittlung des Ersatzinvestitions-bedarfs für die Bundesverkehrswege. Berlin: Duncker \& Humblot (Deutsches Institut für Wirtschaftsforschung: Beiträge zur Strukturforschung 134).

Economic Commission for Europe (1992): International Transport in Europe. An Analysis of Major Traffic Flows in Corridors. New York: United Nations.

Ewers, Hans-Jürgen; Fonger, Matthias (1993): Gesamtwirtschaftliche Effizienz multimodaler Transportketten. Münster.

Freeman III, A. Myrick (1993): The Measurement of Environmental and Resource Values: Theory and Methods. Washington, D.C.: Resources for the Future.

Frey, Bruno S. (1997): Ein neuer Föderalismus für Europa: Die Idee der FOCJ. Tubingen: Mohr Siebeck (Beitrăge zur Ordnungstheorie und Ordnungspolitik).

Friedrich-Ebert-Stiftung (1995): Telematik im Verkehr. Probleme und Perspektiven. Mannheim: Druck Center Meckenheim (Wirtschaftspolitische Diskurse).

Fritsch, Michael; Wein, Thomas; Ewers, Hans-Jürgen (1996): Marktversagen und Wirtschaftspolitik: mikroőkonomische Grundlagen staatlichen Handelns. München: Vahlen.

Glück, Karl (1986): Zur monetären Bewertung der volkswirtschaftlichen Kosten durch Lärm. Berlin: Erich Schmidt Verlag (Berichte des Umweltbundesamtes). 
Grabenhorst, Kristina (1994): Der Ordnungsrahmen furr den Güterkraftverkehr in der Reform. 88 Köln, Berlin Bonn München: Carl Heymanns Verlag KG (Studien zum internationalen Wirtschaftsrecht und Atomenergierecht).

Grossekettler, Heinz (1985): Options- und Grenzkostenpreise für Kollektivgüter unterschiedlicher Art und Ordnung. Finanzarchiv 43 (2), S. 211-252.

Hart, Albert; Pommerehne, Werner W. (1994): Zur Standortwahl von NimbyGütern. Hamburger Jahrbuch für Wirtschafts- und Gesellschaftspolitik 39 (4), S. 189-211.

Hau, Timothy D. (1998): Congestion pricing and road investment. In: Road pricing, traffic congestion, and the environment: issues of efficiency and social feasibility. Hrsg.: Button, Kenneth J.; Verhoef, Erik T. Cheltenham: Edward Elgar Publishing Limited.

Hennighausen, Axel (1999): Die Leistungsabhängige Schwerverkehrsabgabe Verkehrsverlagerung oder Steuerexport? Zeitschrift fur Verkehrswissenschaft 70 (4), S. 257-273.

Hoener, Walter (1980): Der Güterverkehr als wettbewerbspolitischer Ausnahmebereich: zur Effizienz und Neuorientierung staatlicher Lenkungsmaßnahmen auf den Güterverkehrsmärkten der Bundesrepublik Deutschland. Opladen: Westdeutscher Verlag (Forschungsberichte des Landes Nordrhein-Westfalen Nr. 2942).

Hohaus, Bolko (1996): Steuerwettbewerb in Europa: eine Analyse der Folgen unbeschränkter Güter- und Faktormobilität im Europäischen Binnenmarkt. Frankfurt am Main, Berlin, Bern, New York, Paris, Wien: Lang (Europäische Hochschulschriften: Reihe 5, Volks und Betriebswirtschaft).

Holzapfel, Helmut; Traube, Klaus; Ulrich, Otto (1992): Autoverkehr 2000: Wege zu einem ökologisch und sozial vertrăglichen Straßenverkehr. Karlsruhe: C. F. Müller GmbH (Alternative Konzepte).

Holzhey, Michael (2000): Die geplante (Be-)Steuerung des Verkehrs durch die EU: Fiskalischer Dirigismus oder ordnungspolitische Notwendigkeit? In: Die Zukunft der Mobilităt. Hrsg.: Stackelberg, Friedrich von. Göttingen: Vandenhoeck \& Ruprecht. (Beitrăge aus dem Institut für Verkehrswissenschaft an der Universităt Münster).

Homburg, Stefan (1997): Allgemeine Steuerlehre. München: Vahlen (WiSo Kurzlehrbücher).

Hoyt, William H. (1991): Property Taxation, Nash Equilibrium, and Market Power. Journal of Urban Economics 30, S. 123-131. 
Inhaber, Herbert (1992): Of LULU's, NIMBY's, and NIMTOO's. The Public Interest 107, S. 52-64.

Inhaber, Herbert (1998): Slaying the NIMBY dragon. New Brunswick, New Jersey: Transaction Publishers.

Jochimsen, R. (1966): Theorie der Infrastruktur - Grundlagen der marktwirtschaftlichen Entwicklung. Tubingen: Mohr.

Johansson-Stenman, Olof; Sterner, Thomas (1998): What is the scope for environmental road pricing. In: Road pricing, traffic congestion, and the environment: issues of efficiency and social feasibility. Hrsg: Button, Kenneth J.; Verhoef, Erik T. Cheltenham: Edward Elgar Publishing Limited.

Kanbur, Ravi; Keen, Michael (1993): Jeux Sans Frontieres: Tax Competition and Tax Coordination When Countries Differ in Size. American Economic Review 83 (4), S. 877-892.

Kemperer, Paul: Auction Theory (1999): A Guide to the Literature. Journal of Economic Surveys 13 (3), S. 227-268.

Kirsch, Guy (1977): Einleitung. In: Föderalismus. Hrsg.: Kirsch, Guy. Stuttgart, New York: Gustav Fischer.

Klenke, Dietmar (1995): „Freier Stau für freie Bürger“ Die Geschichte der bundesdeutschen Verkehrspolitik 1949-1994. Darmstadt: Wissenschaftliche Buchgesellschaft.

Köberlein, Christian (1997): Kompendium der Verkehrspolitik. München, Wien: R. Oldenbourg Verlag.

Kommission, Europåische (1996): Grünbuch der Europåischen Kommission über die künftige Lärmschutzpolitik. Brussel,: Europäische Kommission (Bulletin der Europäischen Union zugl. KOM (96), 540 endg. ).

Kommission, Europåische (1996): Faire und effiziente Preise im Verkehr Politische Konzepte zur Internalisierung der externen Kosten des Verkehrs in der Europäischen Union. Brüssel,: Europäische Kommission (Bulletin der Europäischen Union zugl. KOM (95) 691 endg.).

Kommission, Europăische (1998): Faire Preise für die Infrastrukturbenutzung: Ein abgestuftes Konzept für einen Gemeinschaftsrahmen für Verkehrsinfrastrukturgebuhren in der EU. Brussel,: Europäische Kommission (Bulletin der Europäischen Union zugl. KOM (98) 446 endg.). 
Krakowski, Michael (1988): Theoretische Grundlagen der Regulierung. In: Regulierung in der Bundesrepublik Deutschland: die Ausnahmebereiche des Gesetzes gegen Wettbewerbsbeschränkungen. Hrsg.: Krakowski, Michael. Hamburg: Verlag Weltarchiv. (Veröffentlichungen des HWWA-Instituts fur Wirtschaftsforschung).

Kraus, Doris: Marathon - Verhandlung führt zu Einigung über Alpentransit. Die Presse, 02.12.1998.

Kruse, Jörg (1996): Liberalisierung der Telekommunikation in Deutschland. Wirtschaftsdienst 76 (2), S. 73-80.

Lange, Thomas (1985): Staatliche Regulierung. In: Der Staat in der Wirtschaft der Bundesrepublik Deutschland. Hrsg.: Grosser, Dieter. Opladen: Leske und Budrich. (UTB für Wissenschaft).

Levinson, Arik (1999): NIMBY taxes matter: the case of state hazardous waste disposal taxes. Journal of Public Economics 74, S. 31-51.

Linster, Myriam (1990): Background Facts and Figures. In: Transport Policy and the Environment. Hrsg.: The European Conference of Ministers of Transport. Paris: OECD Publications Service.

Loehr, William; Sandler, Todd (1978): Public goods and public policy. 3 Beverly Hills: SAGE Publications, Inc. (Comparative Political Economy and Public Policy Series).

McAfee, R. Preston; McMillan, John (1987): Auctions and Bidding. Journal of Economic Literature XXV, S. 699-738.

Mitchell, C.G.B.(1991): The Importance and Adverse Effects of Freight Transport. In: Freight Transport and the Environment. Hrsg.: The European Conference of Ministers of Transport. Paris: OECD Publications Service.

Mohring, Herbert (1970): The Peak Load Problem with Increasing Returns and Pricing Constraints. American Economic Review 60, S. 693-705.

Möschel, Wernhard (1995): Das Subsidiaritătsprinzip im Zwielicht. Wirtschaftswissenschaftliches Studium 24 (5), S. 232-236.

Musgrave, Richard A.; Musgrave, Peggy B. (1984): Public Finance in Theory and Practice. New York: McGraw - Hill Inc.

Myles, Gareth D. (1995): Public economics. Cambridge: Cambridge University Press.

Neu, Helmut (1990): Eine zweigeteilte Abgabensteuer zur Lösung des Autoabgasproblems. Zeitschrift fur Verkehrswissenschaft 61 (3), S. 161-177. 
Neuenschwander, Rene; Sommer, Heini; Suter, Stefan; Walter, Felix (1992): Externe Kosten des Agglomerationsverkehrs und Internalisierung. Schweizerische Zeitschrift für Volkswirtschaft und Statistik 128 (3), S. 437-451.

OECD (1988): Transport and the Environment. OECD: Paris (OECD Publications).

OECD (1991): Fighting Noise in the 1990s. OECD: Paris (OECD Publications).

OECD (09.04.1998): Harmful Tax Competition - An emerging global issue. OECD, Paris (OECD Publications).

OECD (1998): Harmful Tax Competition - An emerging global issue. OECD, Paris (OECD Publications).

Olson Jr., M. (1969): The Principle of "Fiscal Equivalence": The Divison of Responibilities among different Levels of Government. American Economic Review 59, S. 479-487.

o.V. (1995): Ziel der $\mathrm{CO}_{2}$-Minderung durch weltweit steigenden Energieverbrauch im Verkehrsbereich gefährdet. DIW-Wochenbericht 62(10), S. 228235.

Peffekoven, Rolf (1980): Finanzausgleich I: Wirtschaftstheoretische Grundlagen. In: Handwörterbuch der Wirtschaftswissenschaften. Hrsg.: Albers, Willi. Stuttgart: Gustav Fischer.

Pfähler, Wilhelm (1984): Sinkende Durchschnittskosten und Allokationspolitik. Das Wirtschaftsstudium (10), S. 470-475.

Quinet, Émile: The Social Costs of Transport (1994): Evaluation and Links with Internalisation Policies. In: Internalising the Social Costs of Transport. Hrsg.: Paris Cedex: OECD.

Rommerskirchen, Stefan (1991): Mehr Mobilität - mehr Wohlstand? Zeitschrift für Verkehrswissenschaft 43, S. 158-170.

Rothengatter, Werner (1994): Obstacles to the Use of Economic Instruments in Transport Policy. In: Internalising the Social Costs of Transport. Hrsg.: The European Conference of Ministers of Transport. Paris: OECD Publications Service.

Rőver, Andreas (1996): Marktversagen aufgrund von Netzwerkexternalităten. Wirtschaftswissenschaftliches Studium (8), S. 427-429.

Röver, Andreas (1996): Negative Netzwerkexternalitäten als Ursache ineffizienter Produktwahl. Jahrbuch für Nationalökonomie und Statistik 215 (1), S. 14-32.

Rutkowsky, Sven (1997): Belastung des Strassenverkehrs mit seinen Infrastruktur- und Opportunitätskosten. In: Ökologisch orientierte Verkehrspolitik in 
Polen und Deutschland. Hrsg.: Ewers, Hans-Jürgen. Göttingen: Vandenhoeck \& Ruprecht.

Schellhaaß, Manfred (1987): Die Grenzkostenpreisregel: Allgemeine Grundsătze. Wirtschaftswissenschaftliches Studium (5), S. 212-218.

Schellhaaß, Manfred (1987): Peak-load-Pricing: Allgemeine Grundsătze. Wirtschaftswissenschaftliches Studium (10), S. 463-469.

Selmer, Peter; Brodersen, Carsten; Nicolaysen, Gert (1989): Straßenbenutzungsabgaben fur den Schwerverkehr: verfassungs- und europarechtliche Probleme. Baden-Baden: Nomos Verlagsgesellschaft.

Sickinger, Hubert; Hussl, Richard (1993): Transit-Saga Bürgerwiderstand am Auspuff Europas. Thaur: Kultuverlag.

Sinn, Hans-Werner (1997): Das Selektionsprinzip und der Systemwettbewerb. In: Fiskalföderalismus in Europa. Hrsg.: Oberhauser, Alois. Berlin: Duncker \& Humblot. (Schriften des Vereins für Socialpolitik).

Small, Kenneth A.; Gomez-Ibanez, José A. (1998): Road Pricing for congestion management: the transition from theory to policy. In: Road pricing, traffic congestion, and the environment: issues of efficiency and social feasibility. Hrsg.: Button, Kenneth J.; Verhoef, Erik T. Cheltenham: Edward Elgar Publishing Limited.

Sohmen, Egon (1976): Allokationstheorie und Wirtschaftspolitik. Tübingen: J. B. C. Mohr.

Soltwedel, Rüdiger; Laaser, Claus-Friedrich; Groß, Alexander; Busch, Alexander (1986): Deregulierungspotentiale in der Bundesrepublik. Tübingen: J. C. B. Mohr (Paul Siebeck) (Kieler Studien 202).

Suntum, Ulrich van (1986): Verkehrspolitik. München: Vahlen.

Sutter, Matthias (1998): Subsidiaritätsprinzip im Zwielicht - eine notwendige Ergänzung. Wirtschaftswissenschaftliches Studium (4), S. 204-205.

Tegner, Henning (1997): Ökologische externe Effekte von Verkehrswegen Ziele, Instrumente und Grenzen der Internalisierung. In: Ökologisch orientierte Verkehrspolitik in Polen und Deutschland. Hrsg.: Ewers, Hans-Jürgen. Münster: Institut für Verkehrswissenschaft an der Universität Münster. (Beiträge aus dem Institut für Verkehrswissenschaft an der Universität Münster 144).

Teufel, Dieter; Bauer, Petra; Beker, Gabriele; Gauch, Erika; Schmitt, Kurt; Wagner, Thomas (1994): Umweltwirkungen von Finanzierungsinstrumenten im Verkehrsbereich (UPI - Bericht 21). 
Thomson, J. Michael (1978): Grundlagen der Verkehrspolitik. Bern, Stuttgart: Haupt.

Tiebout, Charles M. (1956): A Pure Theory of Local Expenditures. Journal of Political Economy 64, S. 416-424.

UIC, Internationaler Eisenbahnverband (1995): Externe Effekte des Verkehrs. Paris: Internationaler Eisenbahnverband (UIC).

Van den Doel, Hans; van Velthove, Ben (1993): Democracy and welfare economics. Cambridge u. a.: Cambridge Univ. Press.

Varian, Hal R. (1989): Grundzlige der Mikroökonomie. München, Wien: R. Oldenbourg Verlag (Internationale Standardlehrbücher der Wirtschafts- und Sozialwissenschaften).

Verhoef, Erik T.; Nijkamp, Peter; Rietveld, Piet (1997): The Social Feasibility of Road Pricing A Case Study for the Randstad Area. Journal of Transport Economics and Policy 31 (3), S. 255-276.

Voigt, Fritz (1973): Verkehr - Die Theorie der Verkehrswirtschaft. Erster Band Erste Hälfte. Berlin: Duncker \& Humblot.

Walther, Michael (1996): Verkehrspolitik in der Bundesrepublik Deutschland Verselbständigung und politische Steuerung. Balingen: Föll + Radtke.

Weimann, Joachim (1995): Umweltökonomie. Eine theorieorientierte Einfuhrung. 3. Aufl. Berlin, Heidelberg, New York, Tokyo: Springer-Verlag.

Weindl, Josef (1996): Europăische Gemeinschaft: Institutionelles System, Binnenmarkt sowie Wirtschafts- und Währungsunion auf der Grundlage des Maastrichter Vertrages. München, Wien: Oldenbourg

Wellisch, Dietmar (1999): Finanzwissenschaft. 1. Rechtfertigung der Staatstătigkeit. München: Vahlen. (Vahlens Handbücher der Wirtschafts- und Sozialwissenschaften).

Wicke, Lutz (1993): Umweltőkonomie Eine praxisorientierte Einfuhrung. 4. Aufl. München: Vahlen.

Wildasin, David E. (1994): Urban Public Finance. 2. Aufl. Langhorne: Harwood Academic Publishers (Fundamentals of pure and applied economics).

Willeke, Rainer (1987): Liberalisierung und Harmonisierung als Aufgabe und Chance einer gemeinsamen Verkehrspolitik im EG-Raum. Zeitschrift fur Verkehrswissenschaft 58 (2), S. 71-99. 
Willeke, Reiner (1996): Mobilität, Verkehrsmarktordnung, externe Kosten und Nutzen des Verkehrs. Frankfurt am Main: Verband der Automobilindustrie e.V. (Schriftenreihe des VDA 81).

Wink, Rüdiger (1995): Verkehrsinfrastrukturpolitik in der Marktwirtschaft: Eine institutionenökonomische Analyse. Berlin: Duncker \& Humblot (Schriftenreihe des Rheinisch-Westfälischen Instituts für Wirtschaftsforschung 59).

Winston, Clifford (1985): Conceptual Developments in the Economics of Transportation: An Interpretive Survey. Journal of Economic Literature 58 (3), S. 57-94.

Winston, Clifford (1991): Efficient Transportation Infrastructure Policy. Journal of Economic Perspectives 5 (1), S. 113-127.

Wissenschaftlicher Beirat beim Bundesminister für Verkehr (1992): Marktwirtschaftliche Instrumente zur Reduktion von Luftschadstoffemissionen des Verkehrs. Zeitschrift fur Verkehrswissenschaft 63(2), S. 114-133.

Wolf, Hartmut (1995): Möglichkeiten und Grenzen marktwirtschaftlicher Verfahren zur Vergabe von Start-/Landerechten auf Flughäfen - Vorschlag fur ein „Zweitbestes Auktionsverfahren“, Institut für Weltwirtschaft: Kiel (Kieler Arbeitspapiere 671).

Wust, Herbert Fritz (1981): Föderalismus: Grundlage für Effizienz in der Staatswirtschaft. Göttingen: Vandenhoeck und Ruprecht (Abhandlungen zu den Wirtschaftlichen Staatswissenschaften 20).

Zodrow, George R.; Mieszkowski, Peter (1986): Pigou, Tiebout, Property Taxation, and the Underprovision of Local Public Goods. Journal of Urban Economics 19, S: 356-370. 
Axel Hennighausen - 978-3-631-75701-7

Downloaded from PubFactory at 01/11/2019 02:45:58AM

via free access 


\section{Gesetzestexte und ăhnliches}

Abkommen zwischen der Europäischen Wirtschaftsgemeinschaft und der Republik Österreich über den Güterverkehr im Transit auf der Schiene und der Strasse. Amtsblatt L 373 vom 21.12.1992 S. 6-24.

Bundesgesetzes zur Verlagerung von alpenquerendem Güterverkehr auf die Schiene (Verkehrsverlagerungsgesetz) vom 08.10.1999. Abgedruckt im Bundesblatt Nr. 42 vom 26. Oktober 1999, S. 8728ff.

EuGH - Urteil vom 22.5.1985 - Rs. 13/83 (Parlament vs. Rat).

Geänderter Vorschlag KOM(99) 458 endg., Amtsblatt C 116E vom 26.04.2000.

Richtlinie 92/82/EWG des Rates vom 19.10.1992, veröffentlicht im Amtsblatt L 316 vom 31/10/1992.

Richtlinie 93/89/EWG des Rates, veröffentlicht im Amtsblatt L 279 vom 12.11.1993.

Richtlinie 96/26/EG des Rates vom 29.4.1996, veröffentlicht im Amtsblatt L 124 vom 23.5.1996.

Richtlinie 96/53/EG der Rates vom 25.7.1996, veröffentlicht im Amtsblatt L 235 vom 17.9.1996.

Richtlinie 99/62/EG des Rates vom 17.06.1999, veröffentlicht im Amtsblatt L 187 vom 20.7.1999.

Richtlinie 99/62/EG des Rates vom 17.06.1999, veröffentlicht im Amtsblatt L 187 vom 20.7.1999.

Übereinkommens über die Erhebung von Gebühren für die Benutzung bestimmter Straßen mit schweren Nutzfahrzeugen. BGBI. II 1994 S. 1768-1781.

Verordnung 3820/85 des Rates vom 20.12.1985, veröffentlicht im Amtsblatt L 370 vom 31.12.1985.

Vorschlag der Kommission KOM(98) 115 endg., Amtsblatt C 198 vom 24.06.1998.

Vorschlag der Kommission KOM(98) 117 endg., Amtsblatt C 190 vom 18.06.1998. 


\section{CeGE-Schriften}

Das CeGE - Center for Globalization and Europeanization of the Economy - wurde 1999 von der Wirtschaftswissenschaftlichen Fakultăt der Georg-August-Universităt Göttingen gegrũndet. Das Zentrum dient als Forum zur internationalen und interdisziplinăren Zusammenarbeit bei der Analyse ökonomischer Fragestellungen von europäischer oder globaler Bedeutung. In den CeGE-Schriften werden Forschungsergebnisse aus Dissertationen, Habilitationen und anderen Forschungsprojekten des Zentrums veröffentlicht.

Band 1 Axel Gerloff: Wechselkurspolitik in Mittel- und Osteuropa. Eine theoretische Analyse unter besonderer Berücksichtigung der Erfahrungen der zehn Kandidaten für eine EU-Osterweiterung. 2001.

Band 2 Ingo Konrad: Zur Integration ausgewählter mittel- und osteuropäischer Länder in die währungspolitische Ordnung Europas.

Band 3 Axel Hennighausen: Wegekostenfinanzierung und Lenkung im deregulierten europäischen Verkehrsmarkt. 2002. 